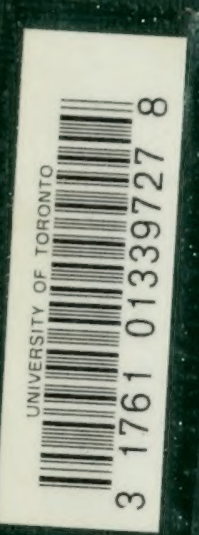









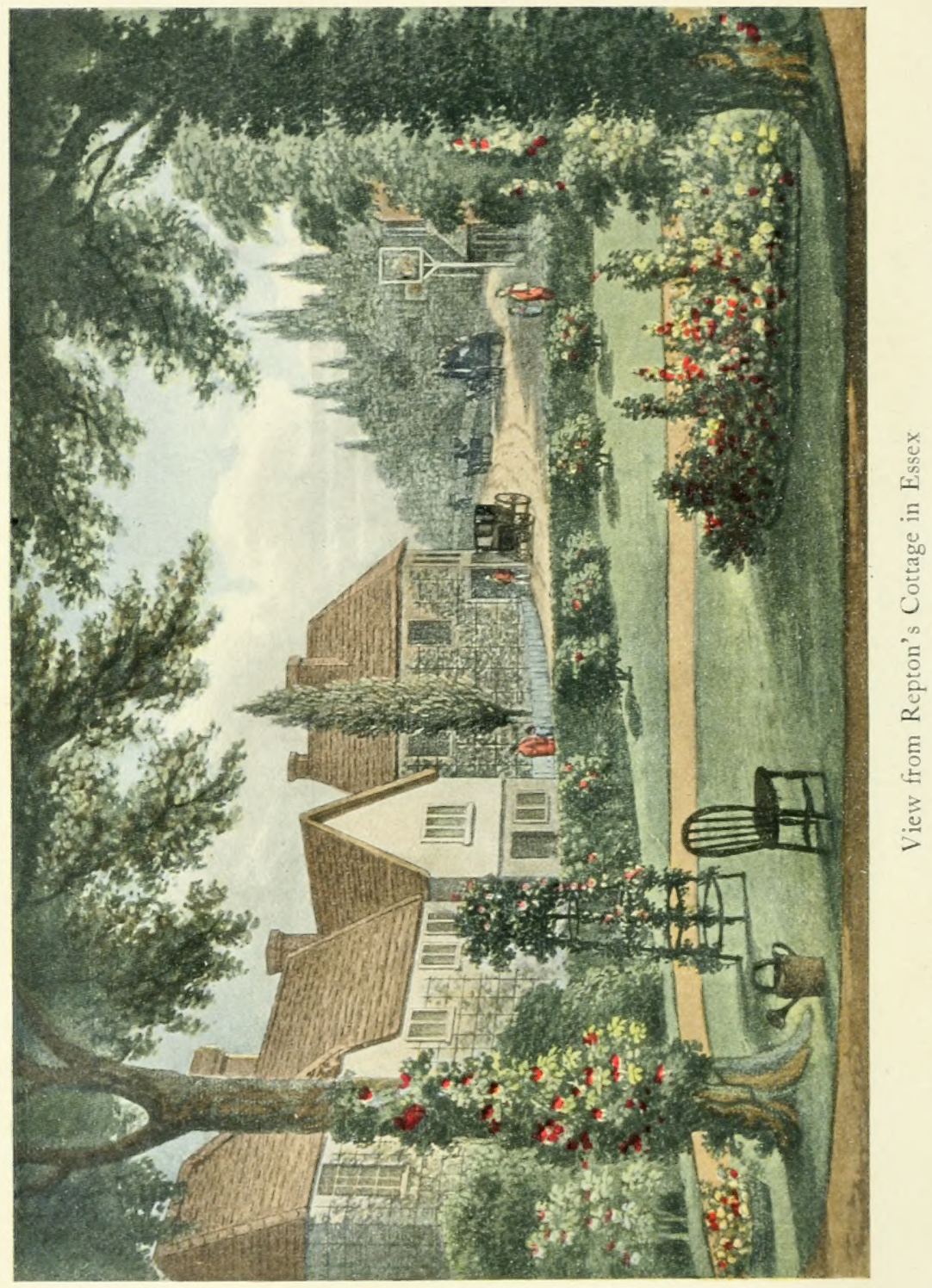




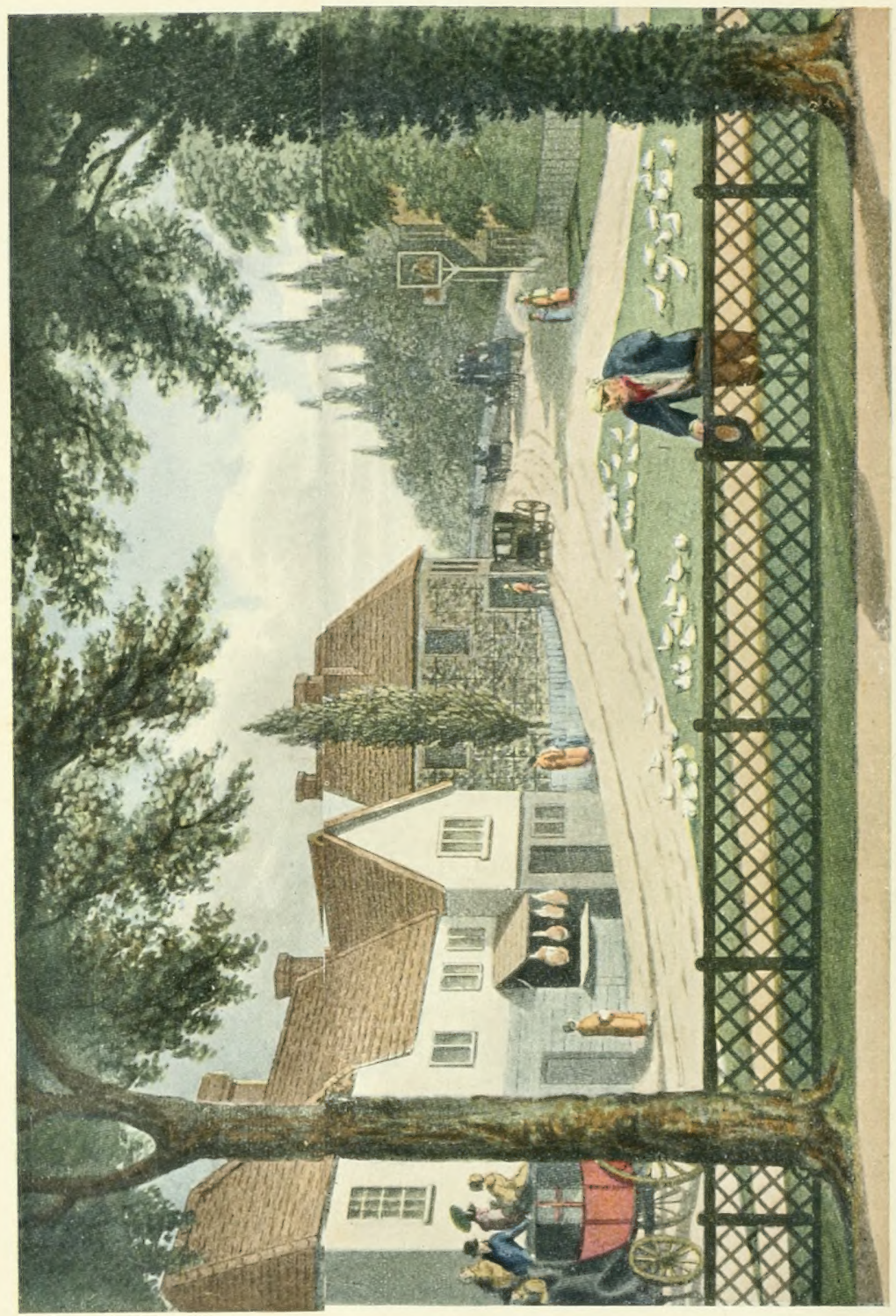





\section{The Art of \\ LANDSCAPE GARDENING}

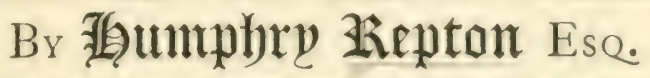

Including his SKETCHES AND HINTS ON LANDSCAPE GARDENING and THEORY AND PRACTICE OF LANDSCAPE GARDENING

Edited by JOHN NOLEN, A.M.

Member of the American Society of Landscape Architects

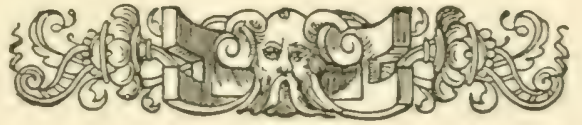

BOSTON AND NEW YORK HOUGHTON, MIFFLIN AND COMPANY

The Biberside press, Cambriage MDCCCCVII MDCDUU 
COPYRIGHT 1907 BY HOUGHTON, MIFFLIN AND COMYANY

ALL RIGHTS RESERVID

Published November roon

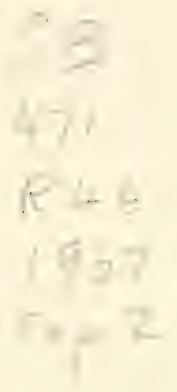


This is the first volume of a series of classics in Landscape Architecture which bas been undertaken at the suggestion and with the coopperation of the American Society of Landscape Arcbitects 



\section{Table of Contents}

INTRODUCTION

XV

SKETCHES AND HINTS ON LANDSCAPE GARDENING

Preface. Some General Remarks about Landscape Gardening

CinAp. I. Different Characters and Situations

Chap. II. Buildings

Chap. III. Proper Situations for a House 23

Chap. IV. Water

Chap. V. Large Private Places

39

Снар. VI. Formal Gardening

Chap. VII. Approaches

Снap. VIII. Affinity betwixt Painting and Gardening

Снap. IX. Sources of Pleasure in Landscape Gardening 


\section{THE THEORY AND PRACTICE OF LANDSCAPE GARDENING}

Preface. Some General Observations on Taste

Cнар. I. Introduction-General Principles - Utility - Scale - Examples of Comparative Proportion-Use of Perspective

Cнар. II. Ground apparently altered by the Situation of the Spectator-Reflections from the Surface of $W$ ater explained and applied - Different Effects of Light on Different Objects

Chap. III. Water-Its General Treatment - Art must deceive to imitate Nature - Water at Wentworth described-A River easier to imitate than a Lake

Chap. IV. Planting - Immediate and Future Effect - Clumps - Groups Masses - The Browsing-Line described - Combination of Masses to produce Great Woods - Character and Shape of Ground to be studied - Outline of New Plantations IO3 
Chap. V. Woods - Intricacy - Variety

- A Belt - On thinning Woods - Leaving Groups Opening a Lawn in Great Woods

Chap. VI. Fences - The Boundary-The Separation

Cнар. VII. Farm and Park Distinct Objects - Beauty and Profit seldom compatible

Chap. VIII. Pleasure-Grounds - FlowerGardens-Greenbouses and Conservatories - Various Modes of attacbing them to a House

Chap. IX. Landscape Gardening and Painting - Pictures may imitate $\mathrm{Na}$ ture, but Nature is not to copy Pictures

Chap. X. Ancient and Modern Gardening - Change of Style - Art and Nature considered

Chap. XI. Endless Variety of Situation and Character - First Impressions - Roads - Entrances - Adaptation of Ornamental Buildings 17I 
Chap. XII. Arcbitecture and Gardening inseparable - Forms and Arrangements of Different Eras Change in Customs alters Uses of Rooms

Chap. XIII. Formation of a new Place Application of Gardening and Architecture - Characteristic Arcbitecture-How far it should prevail internally

Chap. XIV. Conclusion-Concerning Colour - Difficulty of Comparisons betwixt Art and Nature 


\section{List of Plates}

Frontispiece. Tiew from Repton's Cotlage in Essex (before and after improvements)

Plate I. Illustrating Classic and Gotbic Arcbitecture in contrast with roundbeaded and pointed trees

Prate II. Thoresby (from a photograph by T.W. Sears)

PLATE III. The effect of removing trees in the oblique view of an avenue at Langley Park

Plate IV. Thoresby-The Deer Park (from a photograph by $\mathcal{T}$. W. Sears)

Plate V. Castle Hill, shewing the effect of cattle to mark the extent of a lawn which slopes from the eye

Plate VI. Latbom-View from the bouse, shewing the effect of removing the pond, wbich is so near the eye that its glare prevents the lawn from being seen beyond it

Plate VII. The Thames, from Purley: Morning The Thames, from Purley: Evening 88 
Plate VIII. Clumber House (from a pbotograpb by $\mathcal{T}$. W. Sears)

Plate IX. Water at Wentworth, Yorksbire 100 Plate X. Sberwood Forest (from a pbotograph by $\mathcal{T}$. W. Sears)

Plate XI. The Browsing-Line 108

Plate XII. View from the bouse at Shardeloes in 8 Plate XIII. Map of Bulstrode 120 Plate XIV. Farm and Park Plate XV. Flower-Garden, Valley Field $\quad 144$ Plate XVI. Blaize Castle, enlivened by a cottage in the distance

Plate XVII. Plans of bouses of various dates 192 Plate XVIII. Michel Grove, Sussex 196 Plate XIX. Asbton Court 208 Plate XX. Map of Baybam 210 Plate XXI. General View of Baybam 212 Plate XXIJ. Plan of Baybam 214 


\section{List of FIGURES}

FIG. I. Illustrating the sbape of the ground at Stanmore

Fig. 2. Illustrating the sbape of the ground at Brandsbury

FIG. 3. Sections to sbere the manner of adapting bouses to different natural sbapes of ground 29

Fig. 4. Diagram to shere the use of the buman figure as a scale for measuring objects

FIG. 5. Diagram 76

FIG. 6. Diagram 78

Fic. 7. View from Wentworth House, before it was improved, and while the improvements were going forward

80

FIG. 8. View from Wentworth House, sbewing the effect intended to be produced by the proposed alterations

Fig. 9. Diagram

Fig. Iо. Diagram

FIg. I1. Diagram

FIG. I2. Diagram 
FIG. I3. Artificial Scenery

FIG. 14. Natural Scenery

FIG. I 5. Diagram

FIG. I6. Diagram

FIG. I7. Diagram

FIG. I8. Diagram

FIG. 19. Diagram

FIG. 20. Diagram

FIG. 2I. Scene in the grounds at Attingham

Fig. 22. Stoke Park, Herefordsbire

FIG. 24. Examples of a plan for an extended front on the steep side of a bill

FIG. 25. Villa at Brentry Hill, sbewing specimens of economy with compactness adapted to its situation, character, and uses

FIG. 26. Ground-plan of Villa at Brentry Hill

FIG. 27. Diagram

Fig. 28. Diagram 


\section{Introduction}

H UMPHRY REPTON was born at Bury 1 Saint Edmunds, England, May 2, 1752, and died at Harestreet, Essex, March 24, 18 18. The period covered by his life is in many respects the most important in the history of landscape gardening. It is true that the reaction from the absurdities and excesses of formal gardening and the awakening to the beauty and value of a natural rural landscape came before his time. Addison and Pope were the most influential of the literary advocates of this great change, and William Kent and his successor "Capability" Brown were the practical men who applied the new ideas to the country-places of England, often indeed ruthlessly destroying formal grounds of great beauty in the zeal of a somewhat unbalanced reaction. But it is to the period of Repton and the work of Repton himself that we must look for the sound and rational development of the so-called landscape school of England, a school whose influence spread rapidly to the Continent of Europe and whose principles still control the treatment of large areas in the informal or naturalistic style.

This change in taste was not confined to gardening. It manifested itself in all the artistic 
expressions of the period. It was due to the movement called "romanticism," the renaissance of wonder. In almost innumerable ways the world acquired a new power of appeal and response to man. The glory of lake and mountain and meadow, the exquisite grace of childhood, the dignity and worth of manhood, the intrinsic interest of the commonplace, - to these and to other influences of a similar character mankind became sensitive. Romanticism was in truth an extraordinary development of imaginative sensibility, and the centre of the movement in England lay in its various, intimate, and subtle interpretations of the world of nature. Through it nature became to man an inexhaustible resource. Therefore the conditions were ready and the time was ripe for such ideals of landscape gardening as those held and advocated by Repton.

The work of Repton as landscape gardener is one of the most notable achievements in that profession. He has to his credit the creation, transformation, or improvement of over two hundred important places. His clients were in all parts of England and included men of nearly every degree and station. And to appreciate the scope of Repton's practice we must call to mind the extent and character and marvellous beauty of the typical English country-place of the eighteenth century. It included not only all that is best in the private places of our own time, but also the adequate setting 
for buildings of great size, corresponding to public buildings in the present day, and the creation of the type of scenery that is characteristic of modern "rural" or "country" parks. Without doubt the most suggestive ideals for the public parks of our own great cities, ideals that have impressed themselves upon the most distinguished landscape architects since Repton's day, are to be found in the "park" or informal pleasure-grounds of a wellto-do Englishman's estate. These "parks" were extensive in area, usually including from one to a thousand acres, and possessed all the interest and charm of beautiful natural scenery enhanced and perfected by discriminating art.

Repton's knowledge of nature and command of the processes of art were not superficial. Nature he knew at first hand. He was himself a naturelover. Before becoming a landscape gardener he was a "country gentleman." But he was also an artist, gifted with what he repeatedly refers to as "good taste" ; and by study and experience he added to his natural gifts. His profession to him was primarily an opportunity for design, design based alike upon an accurate knowledge of the peculiar local situation and conditions and upon the fundamental principles of art and the laws of nature. He knew well the meaning and value of such art principles as are suggested by the words proportion, variety, intricacy, harmony, and unity. One quotation will illustrate his point 
of view. Speaking of intricacy he says : "The eye, or rather the mind, is never long delighted with that which it surveys without effort, at a single glance, and therefore sees without exciting curiosity or interest. It is not the vast extent of lawn, the great expanse of water, or the long range of wood, that yields satisfaction; for these, if shapeless, or, which is the same thing, if their exact shape, however large, be too apparent, only attract our notice by the space they occupy; to fill that space with objects of beauty, to delight the eye after it has been struck, to fix the attention where it has been caught, to prolong astonishment into admiration, are purposes not unworthy of the greatest designs." He could not be accused of mere imitation, for, instead of attempting to reproduce the effects of nature in a mechanical or artificial way, he aimed rather to put in action the causes by which those effects are produced. Then, as he said, the effects would be natural. But Repton was also a practical man. He appreciated the principle of utility. He, like his American successor, Olmsted, had no sympathy with a design that did not provide adequately and frankly for the plain necessities of human living. Half-hearted compromises did not meet his favour; nevertheless he took pains to reconcile these necessary and artificial features with the artistic aims of the design as a whole.

Repton's most permanent contribution to his art, however, is to be found not in his works of 
landscape gardening, but in his writings on that subject. Neither among his predecessors nor successors has there been a man of equal genius and experience who has left such a substantial body of opinion behind him. This is the result partly of his desire permanently to lift his chosen profession to a higher plane, and partly of his systematic methods of work, which made it possible for him, even in the midst of a very active practice, to prepare material for publication. He speaks of his writings as "observations tending to establish fixed principles in the art of landscape gardening." His profession, he contended, should not be founded upon caprice and fashion. This view is well expressed in his dedication to King George III of his first book, "Sketches and Hints on Landscape Gardening," in which he says: "If it should appear that, instead of displaying new doctrines or furnishing novel ideas, this volume serves rather by a new method to elucidate old established principles, and to confirm long received opinions, I can only plead in my excuse that true taste, in every art, consists more in adapting tried expedients to peculiar circumstances than in that inordinate thirst after novelty, the characteristic of uncultivated minds, which from the facility of inventing wild theories, without experience, are apt to suppose that taste is displayed by novelty, genius by innovation, and that every change must necessarily tend to improvement." 
Repton's important writings are based upon his unique "Red Books." When asked for his opinion concerning the improvement of a place he was in the habit of delivering it in writing, bound in a small book, which contained maps, plans, and sketches to explain and illustrate the work or alterations proposed. This he called the "Red Book" of the place. More than two hundred such books were prepared by him in the course of his extensive practice. Therefore his published works, comprising as they do the most valuable material of the "Red Books," are not mere theories of landscape gardening; they represent the permanent results of his experience. Not only from their substance are they of value, but from their form also. They were written and illustrated not for his professional colleagues, but for his clients. Thus they have a wider appeal. They are free from technical terms and from small and relatively unimportant details. The only limitation upon the value of these writings is an inevitable scrappiness and repetition due to their origin and the conditions under which they were prepared for publication. As he quaintly observes in the preface to his most valuable book, "The Theory and Practice of Landscape Gardening," "the whole of this work has been written in a carriage during professional journeys from one place to another, and being seldom more than three days together in one place, the diffi- 
culty of producing this volume, such as it is, can hardly be conceived by those who enjoy the blessings of stationary retirement or a permanent home." To an unusual degree Repton's books state his own theory, relate his own practice, record his own ideals. They are the basis upon which he wished posterity to judge him, for he says: "It is rather upon my opinions in writing than on the partial and imperfect manner in which my plans have sometimes been executed, that I wish my fame to be established." The present volume is published to supply the demand for Repton's counsel. It is issued under the title of "The Art of Landscape Gardening," and contains his two best works: "Sketches and Hints on Landscape Gardening," published in 1795, and "The Theory and Practice of Landscape Gardening," published in 1803 . These two books, reprinted and illustrated in modern form and edited the better to serve modern conditions, constitute, it is believed, one of the most valuable works in English upon the principles of layingout ground.

To make his designs intelligible Repton found that a mere map or plan was insufficient; it could no more convey an idea of the landscape than the ground-plan of a house could of its elevation. To remedy this deficiency he invented a method of showing the proposed improvements by means of two illustrations or slides, as he called them, 
one imposed upon the other. These were usually in colour, the upper one representing the scene as it existed and the under one the scene as proposed. His object, he said, was " not to produce a book of pictures, but to furnish some hints for establishing the fact that true taste in landscape gardening, as well as in all the other polite arts, is not an accidental effect, operating on the outward senses, but an appeal to the understanding, which is able to compare, to separate, and to combine the various sources of pleasure derived from external objects, and to trace them to some preexisting cause in the structure of the human mind." It did not seem feasible nor indeed necessary to include in this volume all the illustrations in Repton's works, but those shown have been selected with discrimination to enforce the main points in his philosophy of landscape art. These are supplemented by a few recently taken photographs of English country-places, the improvement of which was outlined over a century ago by Repton himself.

Repton and his work occupy a unique and permanently important place in the history of landscape gardening. He came at a time of significant development in his profession, and by his native genius and attainments he secured the patronage of all England. He had opportunity to work out his ideas and ideals under unusually congenial conditions. Le Notre himself, with the support 
and favour of Louis XIV, scarcely surpassed him in opportunity. He became the medium for the practical expression of all that was best in the "new" gardening, and he showed himself capable at the same time of respecting and preserving what was most worthy in the old or formal style. He was not an iconoclast. His taste was catholic. In discussing the two schools he says: "I do not profess to follow either Le Nôtre or Brown, but, selecting beauties from the style of each, to adopt so much of the grandeur of the former as may accord with a palace, and so much of the grace of the latter as may call forth the charms of natural landscape. Each has its proper situation, and good taste will make fashion subservient to good sense." Repton possessed exquisite refinement of taste, without reaching the point of fastidiousness. He displayed considerable ingenuity in meeting peculiar problems, and a sympathetic knowledge of the necessities of a convenient and comfortable home. His pleasant personality, goodness of heart, and amiability undoubtedly helped his professional success. But the most significant contribution that remains for this and subsequent generations is his careful and complete statement in writing of the principles that he found fundamental in his long and instructive practice as a landscape gardener.

Cambridge, Mass., June, 1907.

John Nolen. 



\section{I}

SKETCHES AND HINTS ON LANDSCAPE-GARDENING 



\section{Preface}

TO

SKETCHES AND HINTS

70 improve the scenery of a country, and to dis1 play its native beauties with advantage, is an art which originated in England, and has therefore been called English gardening; yet as this expression is not sufficiently appropriate, especially since gardening, in its more confined sense of horticulture, has been likewise brought to the greatest perfection in this country, I have adopted the term landscape gardening, as most proper, because the art can only be advanced and perfected by the united powers of the landscape painter and the practical gardener. The former must conceive a plan, which the latter may be able to execute; for though a painter may represent a beautiful landscape on his canvas, and even surpass nature by the combination of her choicest materials, yet the luxuriant imagination of the painter must be subjected to the gardener's practical knowledge in planting, digging, and moving earth; that the simplest and readiest means of accomplishing each design may be suggested; since it is not by vast labour, or great expense, that nature is generally to be improved; on the contrary,

“ Insult not Nature with absurd expense,

Nor spoil her simple charms by vain pretence;

Weigh well the subject, be with caution bold,

Profuse of genius, not profuse of gold." 
If the knowledge of painting be insufficient without that of gardening, on the other hand, the mere gardener, without some skill in painting, will seldom be able to form a just idea of effects before they are carried into execution. This faculty of foreknowing effects constitutes the master in every branch of the polite arts; and can only be the result of a correct eye, a ready conception, and a fertility of invention, to which the professor adds practical experience.

But of this art, painting and gardening are not the only foundations: the artist must possess a competent knowledge of surveying, mechanics, hydraulics, agriculture, botany, and the general principles of architecture. It can hardly be expected that a man bred and constantly living in the kitchen-garden should possess all these requisites; yet because the immortal Brown" was originally a kitchen-gardener, it is too common to find every man who can handle a rake or spade pretending to give his opinion on the most difficult points of improvement. It may perhaps be asked from whence $\mathrm{Mr}$. Brown derived his knowledge? - the answer is obvious: that, being at first patronised by a few persons of rank and acknowledged good taste, he acquired, by degrees, the faculty of prejudging effects; partly from repeated trials, and partly from the experience of those to whose conversation and intimacy his genius had introduced him: and although he could not design, himself, there exist many pictures of scenery, made under his instruction, which his imagination alone had painted.

Since the art of landscape gardening requires the combination of certain portions of knowledge in so many different arts, it is no wonder that the professors 
of each should respectively suggest what is most obvious to their own experience; and thus the painter, the kitchen-gardener, the engineer, the land-agent, and the architect will frequently propose expedients different from those which the landscape gardener may think proper to adopt. The difficulties which I have occasionally experienced from these contending interests induced me to make a complete digest of each subject proposed to my consideration, affixing the reasons on which my opinion was founded, and stating the comparative advantages to the whole of adopting or rejecting certain parts of any plan. To make my designs intelligible, I found that a mere map was insufficient; as being no more capable of conveying an idea of the landscape than the ground-plan of a house does of its elevation. To remedy this deficiency, I delivered my opinions in writing, that they might not be misconceived or misrepresented; and I invented the peculiar kind of slides to my sketches, some of which are here reproduced.

Such drawings, to shew the proposed effects, can be useful but in a very few instances; yet I have often remarked, with some mortification, that it is the only part of my labours which the common observer has time or leisure to examine; although it is the least part of that perfection in the art, to which these hints and sketches will, I hope, contribute.

I confess that the great object of $m y$ ambition is not merely to produce a book of pictures, but to furnish some hints for establishing the fact that true taste in landscape gardening, as well as in all the other polite arts, is not an accidental effect, operating on the outward senses, but an appeal to the understanding, which 
is able to compare, to separate, and to combine, the various sources of pleasure derived from external objects, and to trace them to some pre-existing causes in the structure of the human mind. 


\section{Chapter I}

\section{Different Characters and Situations}

A LL rational improvement of grounds is, necessar1 ily, founded on a due attention to the character and situation of the place to be improved: the former teaches what is advisable, the latter what is possible, to be done; while the extent of the premises has less influence than is generally imagined; as, however large or small it may be, one of the fundamental principles of landscape gardening is to disguise the real boundary.

In deciding on the character of any place, some attention must be given to its situation with respect to other places; to the natural shape of the ground on which the house is or may be built; to the size and style of the house, and even to the rank of its possessor; together with the use which he intends to make of it, whether as a mansion or constant residence, a sportingseat, or a villa; which particular objects require distinct and opposite treatment. To give some idea of the variety that abounds in the characters and situations of different places, it will be proper to insert a few specimens from different subjects: I shall begin this work, therefore, by a remarkable instance of situation, only two miles distant from the capital.

Brandsbury ${ }^{2}$ is situated on a broad swelling hill, the ground gently falling from the house (which looks on rich distances) in almost every direction. Except a very narrow slip of plantation to the north, two large elms near the house, and a few in hedge-rows at a distance, 
the spot is destitute of trees: the first object, therefore, must be to shelter the house by home shrubberies; as on land of such value extensive plantations would be an unpardonable want of economy.

No general plan of embellishment can, perhaps, be devised which is more eligible than that so often adopted by Mr. Brown, viz. to surround a paddock with a fence, enclosing a shrubbery and gravel walk round the premises: this idea was happily executed by him at Mr. Drummond's delightful place near Stanmore; but as an attempt has been made to follow the same plan at Brandsbury, without considering the difference of the two situations, I shall beg leave to explain myself by the following sections and remarks.

Where the natural shape of the ground is concave, as that at Stanmore [Fig. I], nothing can be more desir-

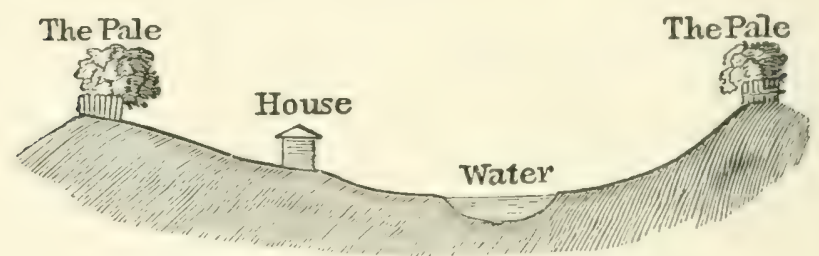

Fig. I. Illustrating the shape of the ground at Stanmore.

able than to enrich the horizon by plantations on the highest ground, and to flood the lowest by a lake or river: in such a situation the most pleasing scenes will be within the pale, looking on the opposite rising bank fringed with trees, or occasionally catching distant views over or beyond the fence.

On the contrary, if the natural shape be convex, any fence crossing the declivity must intercept those distant views which an eminence should command, and which 
at Brandsbury are so rich and varied that nothing can justify their total exclusion. A walk round a paddock in such a situation, enclosed by a lofty fence, would be a continual source of mortification; as every step would excite a wish either to peep through, or look over, the pale of confinement.

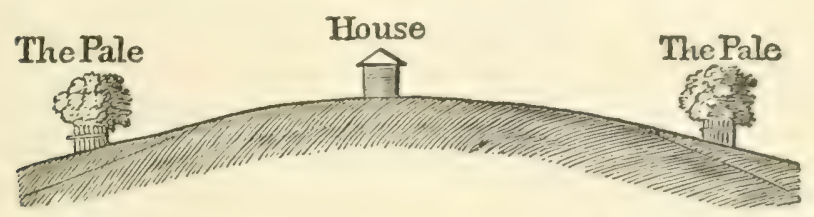

Fig. 2. Illustrating the shape of the ground at Brandsbury.

Where all the surrounding country presents the most beautiful pasture-ground, instead of excluding the vast herds of cattle which enliven the scene, I recommend that only a sufficient quantity of land round the house be enclosed to shelter and screen the barns, stables, kitchen-garden, offices, and other useful but unpleasing objects; and within this enclosure, though not containing more than ten or twelve acres, I propose to conduct walks through shrubberies, plantations, and small sequestered lawns, sometimes winding into rich internal scenery, and sometimes breaking out upon the most pleasing points for commanding distant prospects: at such places the pale may be sunk and concealed, while in others it will be so hid by plantation that the twelve acres thus enclosed will appear considerably larger than the sixty acres originally intended to be surrounded by a park pale.

The present character of Rivenhall Place is evidently gloomy and sequestered, with the appearance of being low and damp. The interference of art in former days has indeed rendered the improvement and restoration 
of its natural beauties a work of some labour; yet, by availing ourselves of those natural beauties, and displacing some of the encumbrances of art, the character of the place may be made picturesque and cheerful, and the situation, which is not really damp, may be so managed as to lose that appearance. The first object is to remove the stables, and all the trees and bushes in the low meadow, which may then with ease be converted into a pleasing piece of water, in the front of the house. In its present state, two tall elms are the first objects that attract our notice; from the tops of these trees the eye measures downwards to the house, that is very indistinctly seen amidst the confusion of bushes and buildings with which it is encumbered; and the present water appearing above the house, we necessarily conclude that the house stands low: but instead of this confusion, let water be the leading object, and the eye will naturally measure upwards to the house, and we shall then pronounce that it no longer appears in a low situation.

However delightful a romantic or mountainous country may appear to a traveller, the more solid advantages of a flat one to live in are universally allowed; and in such a country, if the gentle swell of the ground occasionally presents the eye with hanging woods, dipping their foliage in an expanse of silvery lake, or softly gliding river, we no longer ask for the abrupt precipice or foaming cataract. Livermere Park possesses ample lawns, rich woods, and an excellent supply of good-coloured water : its greatest defect is a want of clothing near the house, and round that part of the water where the banks are flat; yet, in other parts, the wood and water are most beautifully connected with each other.

Milton PARK. Where the ground naturally presents very little inequality of surface, a great appearance 
of extent is rather disgusting than pleasing, and little advantage is gained by attempts to let in distant objects; yet there is such infinite beauty to be produced by judicious management of the home scenery, as may well compensate the want of prospect. There is always great cheerfulness in a view on a flat lawn, well stocked with cattle, if it be properly bounded by a wood at a distance, neither too far off to lessen its importance nor too near to act as a confinement to the scene ; and which contributes also to break those straight lines that are the only causes of disgust in a flat situation. Uneven ground may be more striking as a picture and more interesting to the stranger's ere, it may be more bold or magnificent or romantic, but the character of cheerfulness is peculiar to the plain. Whether this effect be produced by the apparent ease of communication, or by the larger proportion of sky which enters into the landscape, or by the different manner in which cattle form themselves into groups on a plain, or on a sloping bank, I confess I am at a loss to decide: all three causes may, perhaps, contribute to produce that degree of cheerfulness which every one must have observed in the scenery of Milton.

Hasells Hall. There has hardly been proposed to my consideration a spot in which both situation and character have undergone a greater change than at Hasells Hall. From the former mode of approaching the house, especially from the Cambridge side, a stranger could hardly suppose there was any unequal ground in the park: even to the south, where the ground naturally falls towards a deep valley, the mistaken interference of art, in former days, had bolstered it up by flat bowling-greens, and formal terraces; while the declivity was so thickly planted as entirely to choke up the lowest ground, and shut out all idea of inequality. The first 
object of improvement is to point out those beautiful shapes in the ground which so copiously prevail in several parts of this park; the second, is to change its character of gloom and sombre dampness to a more cheerful shade; and the third, is to mark the whole with that degree of importance and extent which the size of the house and the surrounding territory demand.

CUlford. The house stands on the side of a hill, gently sloping towards the south; but nearly one half of the natural depth of the valley has been destroyed to obtain an expanse of water, which, in so flat a situation, I think ought not to have been attempted; and I am certain, by proper management of the water, the house would appear to stand on a sufficient eminence above it, and not so low as the present surface of the water seems to indicate; since the eye is always disposed to measure from the surface of neighbouring water, in forming a judgement of the height of any situation.

Crewe Hall. In judging the character of any place to which I am a stranger, I very minutely observe the first impression it makes upon my mind, and, comparing it with subsequent impressions, I inquire into the causes which may have rendered my first judgement erroneous. I confess there has hardly occurred to me an instance where I have experienced so great a fluctuation of opinion as in this place. I was led, from a consideration of the antiquity of the Crewe family in Cheshire, to expect a certain degree of magnificence; but my first view of the house being from an unfavourable point, and at too great a distance to judge of its real magnitude, I conceived it to be very small; and, measuring the surrounding objects by this false standard, the whole place lost that importance which I after- 
wards found it assume on a closer examination. In former days the dignity of a house was supposed to increase in proportion to the quantity of walls and buildings with which it was surrounded: to these were sometimes added tall ranks of trees, whose shade contributed to the gloom at that time held essential to magnificence.

Modern taste has discovered that greatness and cheerfulness are not incompatible; it has thrown down the ancient palisade and lofty walls because it is aware that liberty is the true portal of happiness; yet, while it encourages more cheerful freedom, it must not lay aside becoming dignity. When we formerly approached the mansion through a village of its poor dependants, we were not offended at their proximity, because the massy gates and numerous courts sufficiently marked the distance betwixt the palace and the cottage: these being removed, other expedients must be adopted to restore the native character of Crewe Hall.

TatTon PARK. The situation of Tatton may be justiy described as too splendid to be called interesting, and too vast to be deemed picturesque; yet it is altogether beautiful, in spite of that greatness which is rather the attribute of sublimity than of beauty. The mind is astonished and pleased at a very extensive prospect, but it cannot be interested, except by those objects which strike the eye distinctly; and the scenery of Tatton is at present of a kind much beyond the pencil's power to imitate with effect: it is like the attempt to paint a giant by himself in a miniature picture.

Perfection in landscape may be derived from various sources: if it is sublime, it may be wild, romantic, or greatly extensive: if beautiful, it may be comfortable, interesting, and graceful in all its parts; but there is no 


\section{I4 The Art of Landscape Gardening}

incongruity in blending these attributes, provided the natural situation continues to prevail; for this reason, no violation will be offered to the genius of Tatton Park, if we add to its splendour the amenity of interesting objects, and give to its vastness the elegance of comfort.

It is not from the situation only that the character of Tatton derives its greatness. The command of adjoining property, the style and magnitude of the mansion and all its appendages contribute to confer that degree of importance which ought here to be the leading object in every plan of improvement. Vastness of extent will no more constitute greatness of character in a park than a vast pile of differently coloured building will constitute greatness of character in a house. A park, from its vast extent, may perhaps surprise, but it will not impress us with the character of greatness and importance unless we are led to those parts where beauty is shewn to exist, with all its interest, amidst the boundless range of undivided property.

WeMBLy. In the vicinity of the metropolis there are few places so free from interruption as the grounds at Wembly ; and, indeed, in the course of my experience, I have seen no spot within so short a distance of London more perfectly secluded from those interferences which are the common effects of divided property and a populous neighbourhood. Wembly is as quiet and retired at seven miles' distance as it could have been at seventy.

The fatal experience of some, who begin improvements by building a house too sumptuous for the grounds, has occasionally induced others to consider the grounds independent of the house; but this, I conceive, will unavoidably lead to error. It is not necessary that the 
house and grounds should correspond with each other in point of size, but the characters of each should be in strict harmony, since it is hardly less incongruous to see a palace by the side of a neglected common than an ugly ill-designed mansion, whether large or small, in the midst of highly-improved scenery, to every part of which it must be considered as a disgrace.

Wenibeck. The house appears to stand much lower than it really does on account of the entrance in the basement storey; which, if carried up to the principal floor, will not only be of great advantage to the inside, by removing all necessity for ascending the present staircase, but the effect on the outside will be much greater than may at first be imagined; since, by giving an opportunity of altering the shape of the ground, it will take the house out of an hollow, and set it on a pleasing eminence. The ground, at present, slopes gradually towards the house, with a flat hanging level, which is evidently artificial; and from the northwest corner of the projecting wing there is a ridge of earth which divides this platform from the adjoining valley: the superfluous earth from this ridge will be sufficient to answer every purpose of raising the lawn to the house; and I propose to slope the ground with a gradual fall from the riding-house to the valley, and to cross this fall by an additional steep from the west front, making both to wind naturally towards the low ground of the valley. The earth may be raised just above the tops of the windows in the basement storey, which may still be sufficiently lighted by an area; but when the lower row of windows is totally hid, the house will appear too long for its height, and the depth of roof will be still more conspicuous. After various attempts to counteract this awkward effect, without any great oper- 
ation, the following appeared the most simple: viz. that the present pediment (which is incongruous to the battlements) should be raised as a square tower, and that the parapets, also, at the ends of the building, should be raised to unite with the chimneys in the gables. This will serve not only to hide more of the roof, but will give that importance to the whole fabric, which, in a large mass of Gothic building, is always increased by the irregularity of its outline.

I have also changed the colour of the roof and chimneys: for, though such minutix are apt to pass unnoticed in the great outline of improvement, I consider the mention of them as a duty of my profession; as the motley appearance of red brick with white stone, by breaking the unity of effect, will often destroy the magnificence of the most splendid composition. 


\section{Chapter II}

\section{Buildings}

$7 \mathrm{HE}$ perfection of landscape gardening depends on I a concealment of those operations of art by which nature is embellished; but where buildings are introduced, art declares herself openly, and should, therefore, be very careful, lest she have cause to blush at her interference. It is this circumstance that renders it absolutely necessary for the landscape gardener to have a competent knowledge of architecture: I am, however, well aware that no art is more difficult to be acquired; and although every inferior workman pretends to give plans for building, yet perfection in that art is confined to a very few gentlemen, who, with native genius and a liberal education, have acquired good taste by travel and observation.

This remark proceeds from the frequent instances I continually see of good houses built without any taste, and attempts to embellish scenery by ornamental buildings that are totally incongruous to their respective situations. The country carpenter or bricklayer is only accustomed to consider detached parts; the architect, on the contrary, finds it his office to consider the whole. There is some degree of merit in building good rooms, but there is more in connecting these rooms together; however, it is the regular bred architect alone who can add to these an outside according to the established rules of art: and where these rules are grossly violated, the eye of genuine taste will in- 
stantly be offended, although it may not always be able to explain the cause of its disgust.

To my profession belongs chiefly the external part of architecture or a knowledge of the effect of buildings on the surrounding scenery.

WELBECK. As every conspicuous building in a park should derive its character from that of the house, it is very essential to fix, with some precision, what that character ought to be; yet the various tastes of successive ages have so blended opposite styles of architecture that it is often difficult, in an old house, to determine the date to which its true character helongs. I venture to deliver it as my opinion that there are only two characters of buildings: the one may be called perpendicular, and the other horizontal. Under the first, I class all buildings erected in England before and during the early part of Queen Elizabeth's reign, whether deemed Saracenic, Saxon, Norman, or the Gothic of the thirteenth and fourteenth centuries; and even that peculiar kind called Queen Eilizaheth's Gothic, in which turrets prevailed, though battlements were discarded and Grecian columns occasionally introduced. Under the horizontal character I include all edifices built since the introduction of a more regular architecture, whether it copies the remains of Grecian or Roman models.

The character of the house should, of course, prevail in all such buildings as are very conspicuous, or in any degree intended as ornaments to the general scenery; such as lodges, pavilions, temples, helvederes, and the like. Yet, in adapting the Gothic style to buildings of small extent, there may be some reasonable objection: the fastidiousness even of good taste will, perhaps, observe that we always see vast piles of buildings in ancient Gothic remains, and that it is 
a modern or false Gothic only which can be adapted to so small a building as a keeper's lodge, a reposoir, or a pavilion. There may be some force in this objection, but there is always so much picturesque effect in the small fragments of those great piles that, without representing them as ruins, it is surely allowable to copy them for the purposes of ornament: and with respect to the mixture of different styles in Gothic edifices, I think there is no incongruity, provided the same character of perpendicular architecture be studiously retained; because there is hardly a cathedral in England in which such mixture may not be observed: and while the antiquary only can discover the Saxon and Norman styles from the Gothic of later date, the eye of taste will never be offended, except by the occasional introduction of some Grecian or Roman ornaments.

Wembly. The characters of Grecian and Gothic architecture are better distinguished by an attention to their general effects than to the minute parts peculiar to each. It is in architecture as in painting, beauty depends on light and shade, and these are caused by the openings or projections in the surface: if these tend to produce horizontal lines, the building must be deemed Grecian, however whimsically the doors or windows may be constructed; if, on the contrary, the shadows give a prevalence of perpendicular lines, the general character of the building will be Gothic; and this is evident from the large houses built in Queen Elizabeth's reign, where Grecian columns are introduced; nevertheless, we always consider them as Gothic buildings.

In Grecian architecture, we expect large cornices, windows ranged perfectly on the same line, and that line often more strongly marked by a horizontal fascia; 
but there are few breaks of any great depth; and if there be a portico, the shadow made by the columns is very trifling, compared with that broad horizontal shadow proceeding from the soffit; and the only ornament its roof will admit is either a flat pediment, departing very little from the horizontal tendency, or a dome, still rising from a horizontal base. With such buildings it may often be observed that trees of a pointed or conic shape have a beautiful effect, I believe chiefly from the circumstances of contrast; though an association with the ideas of I talian paintings, where we often see Grecian edifices blended with firs and cypresses, may also have some influence on the mind.

Trees of a conic shape mixed with Gothic buildings displease, from their affinity with the prevalent lines of the architecture; since the play of light and shadow in Gothic structures must proceed from those bold projections, either of towers or buttresses, which cause strong shadows in a perpendicular direction : at the same time the horizontal line of roof is broken into an irregular surface by the pinnacles, turrets, and battlements that form the principal enrichment of Gothic architecture; which becomes, therefore, peculiarly adapted to those situations where the shape of the ground occasionally hides the lower part of the building, while its roof is relieved by trees, whose forms contrast with those of the Gothic outline.

As this observation is new, and may, perhaps, be thought too fanciful, I must appeal to the eye, by the help of the illustration [Plate I], which I hope will find that my observation is not wholly chimerical ; and will, consequently, lay the foundation for this general principle; viz. that the lines of Gothic buildings are contrasted with round-headed trees; or, as Milton observes, - 


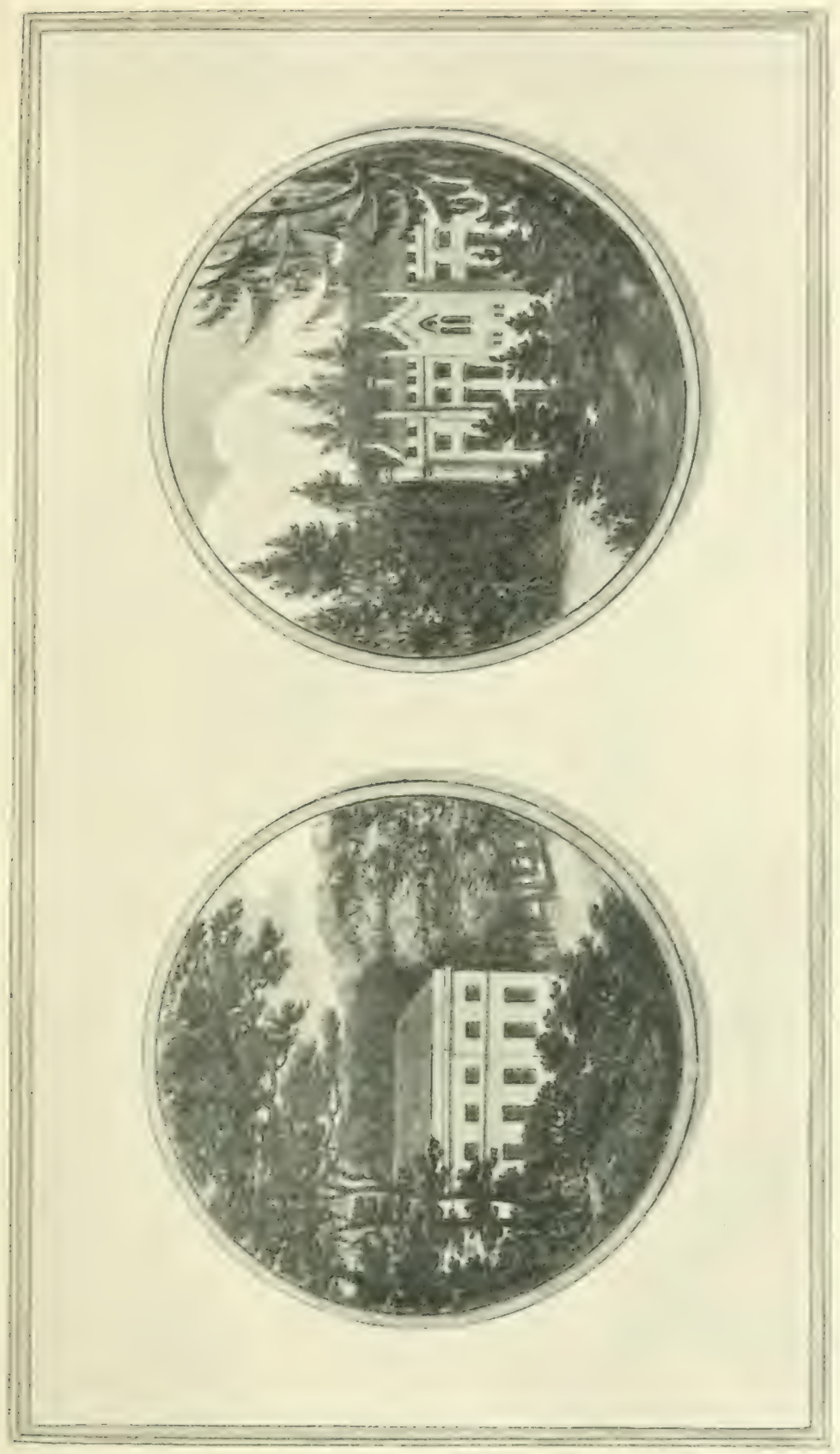





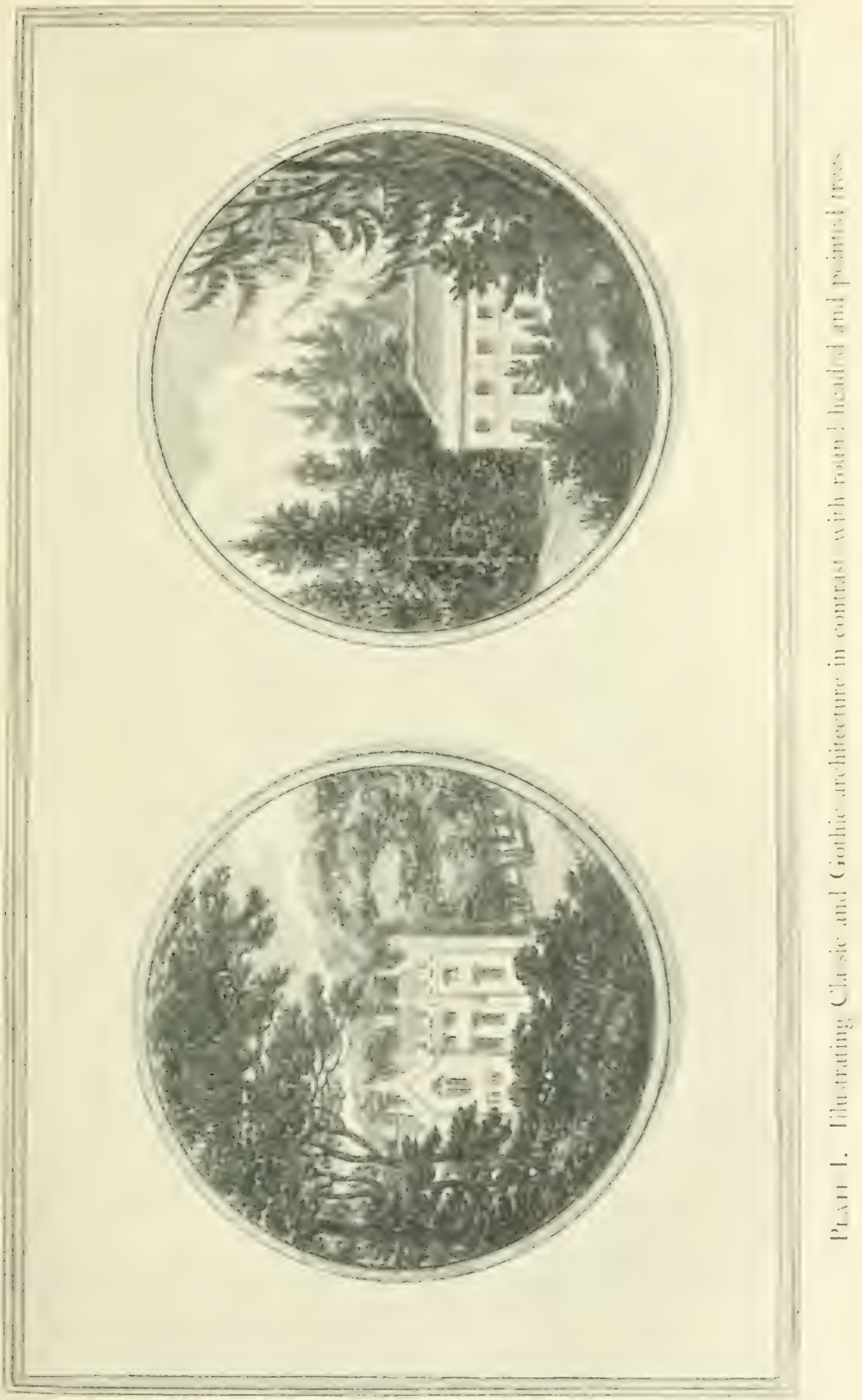



"Towers and battlements he sees,

Embosom'd high in tufted trees" ;

and that those of the Grecian will accord either with round or conic trees; but if the base be hid the contrast of the latter will be most pleasing.

The Gothic style of architecture being the most calculated for additions or repairs to an old house, I might here venture to recommend it on the score of mere utility; but when we take into the account that picturesque effect which is always produced by the mixture of Gothic buildings with round-headed trees, I confess myself to be rather sanguine in my hopes of producing such beauty at Wembly as will render that house, which has hitherto been a reproach to the place, the leading feature of the scenery. Instead of clogging all the improvements with the dread of shewing the house, I conceive it possible, without any very great expense, to convert the house itself into the most pleasing object throughout every part of the grounds from whence it may be visible.

Having stated some arguments for adopting the Gothic style, I shall now proceed to consider the objections that may be urged against it.

The first objection will arise from the expense of altering the outside, without any addition to the internal comfort of the mansion. The same objection may, indeed, be made to every species of external ornament in dress, furniture, equipage, or any other object of taste or elegance: the outside case of a harpsichord does not improve the tone of the instrument, but it decorates the room in which it is placed: thus it is as an ornament to the beautiful grounds at Wembly that I contend for the external improvement of the house. But in altering the house, we may add a room to any 
part of the building without injuring the picturesque outside, because an exact symmetry, so far from being necessary, is rather to be avoided in a Gothic building. Another objection may arise from the smallness of the house, as Gothic structures are in general of considerable magnitude; but the character of great or small is not governed by measurement: a great building may be made to appear small; and it is from the quantity of windows, and not their size, that we should pronounce the house at Wembly to be a very considerable edifice. 


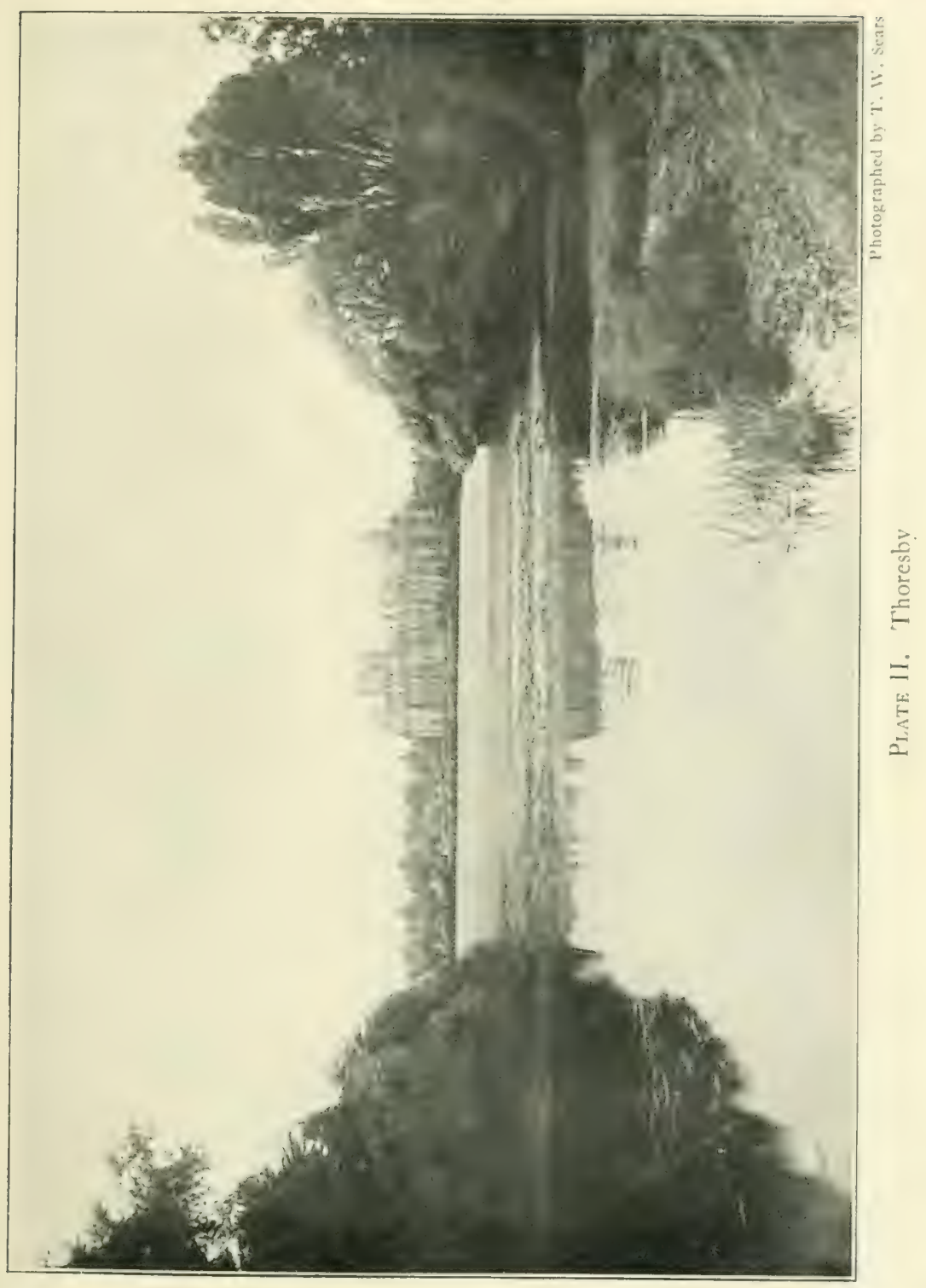





\section{Chapter III}

\section{Proper Situations for a House}

WELBECK. However various opinions may be on the choice of a situation for a house, yet there appear to be certain principles on which such choice ought to be founded; and these may be deduced from the following considerations :

First. The natural character of the surrounding country.

Secondly. The style, character, and size of the house.

Thirdly. The aspects of exposure, both with regard to the sun and the prevalent winds of the country.

Fourthly. The shape of the ground near the house.

Fifthly. The views from the several apartments; and,

Sixthly The numerous objects of comfort:- such as a dry soil, a supply of good water, proper space for offices, with various other conveniences essential to a mansion in the country; and which in a town may sometimes be dispensed with, or at least very differently disposed.

It is hardly possible to arrange these six considerations according to their respective weight or influence, which must depend on a comparison of one with the other, under a variety of circumstances; and even on the partiality of individuals in affixing different degrees of importance to each consideration. Hence it is obvious that there can be no danger of sameness in any two designs conducted on principles thus established, 
since in every different situation some one or more of these considerations must preponderate; and the most rational decision will result from a combined view of all the separate advantages or disadvantages to be foreseen from each. ${ }^{3}$

It was the custom of former times, in the choice of domestic situations, to let comfort and convenience prevail over every other consideration : thus the ancient baronial castles were built on the summit of hills, it: times when defence and security suggested the necessity of placing them there, and difficulty of access was a recommendation which, in our happier days, exists no more. But when this necessity no longer operated (as mankind are always apt to $\mathrm{fly}$ from one extreme to the other), houses were universally erected in the lowest situations, with a probable design to aroid those inconveniences to which the lofty positions had been subject; hence the frequent sites of many large mansions, and particularly abbeys and monasteries, the residence of persons who were willing to sacrifice the beauty of prospect for the more solid and permanent advantages of habitable convenience: amongst which shelter from wind and a supply of water were predominant considerations. Nor shall I withhold the following conjecture, which I hope will not be considered as a mere suggestion of fancy. When such buildings were surrounded by trees for the comfort of shade, might not the occasional want of circulation in the air have given the first idea of cutting long narrow glades through the woods to admit a current of wind? and is it not possible that this was the origin of those avenues which we frequently see pointing, from every direction, towards the most respectable habitations of the two last centuries? 
LANGLEY. It seems to have been as much the fashion of the present century to condemn avenues as it was in the last to plant them; and yet the subject is so little understood that most people think they sufficiently justify their opinion, in either case, by merely saying, "I like an avenue," or, "I hate an avenue" : it is my business to analyse this approbation or disgust.

The several degrees of pleasure which the mind derives from the love of order, of unity, antiquity, greatness of parts, and continuity are all in some measure gratified by the long perspective view of a stately avenue: for the truth of this assertion I appeal to the sensations that every one must have felt who has visited the lofty avenues of Windsor, Hatfield, Burleigh, etc., before experience had pointed out that tedious sameness and the many inconveniences which have deservedly brought avenues into disrepute. This sameness is so obvious that, by the effect of avenues, all novelty or diversity of situation is done away; and the views from every house in the kingdom may be reduced to the same landscape, if looking up or down a straight line, betwixt two green walls, deserves the name of landscape.

Among the inconveniences of long straight avenues may very properly be reckoned that of their acting as wind-spouts to direct cold blasts with more violence upon the dwelling, as driven through a long tube. But I propose rather to consider the objections in point of beauty. If at the end of a long avenue be placed an obelisk, or temple, or any other eye-trap, ignorance or childhood alone will be caught or pleased by it: the eye of taste or experience hates compulsion, and turns away with disgust from every artificial means of attracting its notice. For this reason an avenue is 
most pleasing, which, like that at Langley Park, climbs up a hill, and, passing over its summit, leaves the fancy to conceive its termination. ${ }^{4}$

One great mischief of an avenue is that it divides a park and cuts it into separate parts, destroying that unity of lawn or wood which is necessary to please in every composition: this is so obvious that, where a long avenue runs through a park from east to west, it would be hardly possible to avoid distinguishing it into the north and south lawn, or north and south division of the park.

But the greatest objection to an avenue is that (especially in uneven ground) it will often act as a curtain drawn across to exclude what is infinitely more interesting than any row of trees, however venerable or beautiful in themselves; and it is in undrawing this curtain at proper places that the utility of what is called breaking an avenue consists: for it is in vain we shall endeavour, by removing nine tenths of the trees in rows, to prevent its having the effect of an avenue when seen from either end. The illustration [Plate III] may serve to shew the effect of cutting down some chestnut-trees in the avenue at Langley, to let in the hill, richiy covered with oaks, and that majestic tree which steps out before its brethren like the leader of a host. Such openings may be made in several parts of this avenue with wonderful effect; and yet its venerable appearance from the windows of the saloon will not be injured, because the trees removed from the rows will hardly be missed in the general perspective view from the house. And though I should not advise the planting such an avenue, yet there will always be so much of ancient grandeur in the front trees, and in looking up this long vista at Langley, that I do not wish it should be further 


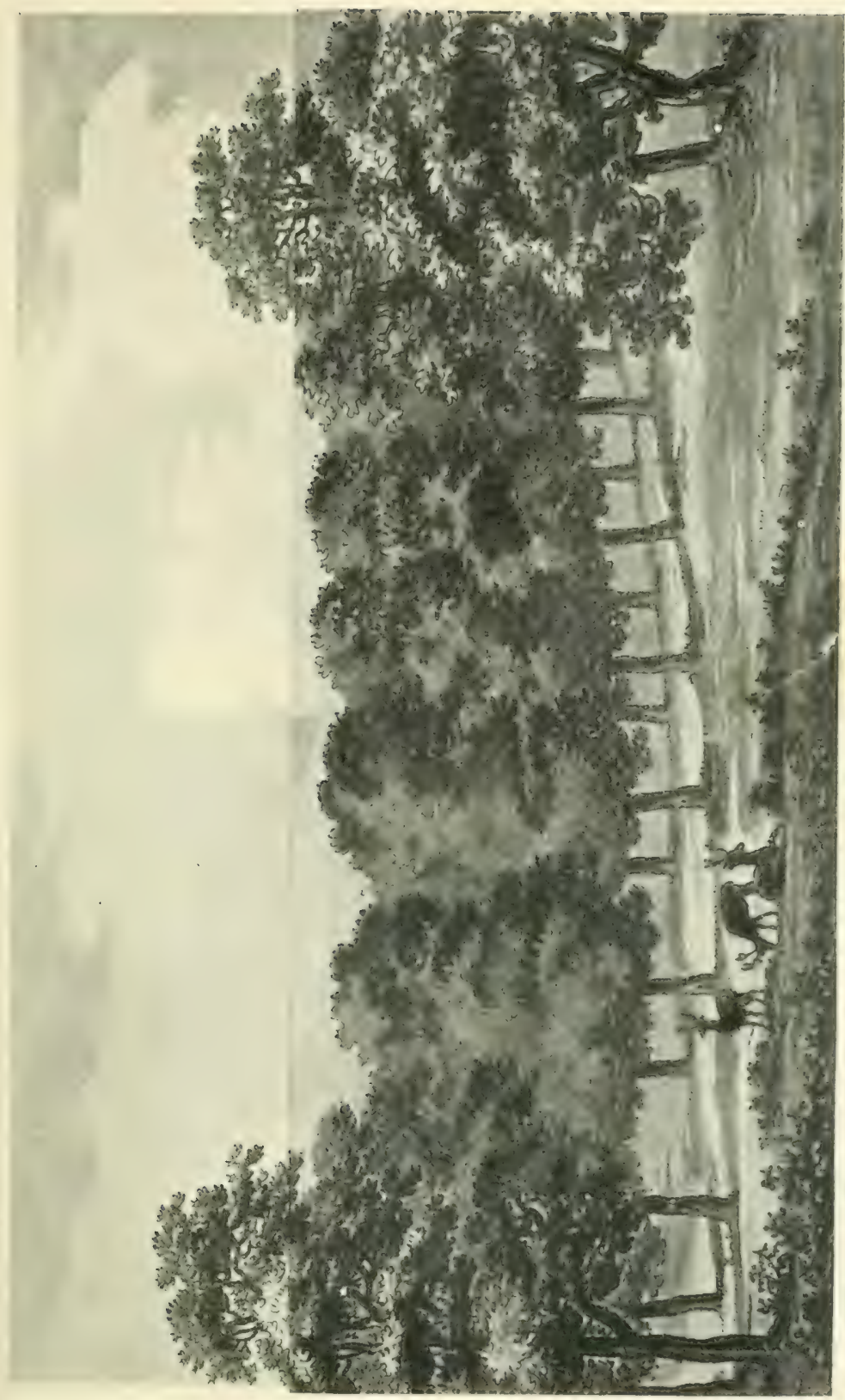



disturbed, especially as the views on each side are sufficiently capable of yielding beauty; and, when seen from the end rooms of the house, the avenue will act as a foreground to either landscape.

Hanslope. Most of the large trees at Hanslope stand in avenues, yet their pleasant shade forbids the cutting down many of them, merely because the false taste of former times has planted them in rows; at least till those plantations which are now made shall better replace the shelter which the avenues in some measure afford. The breaking of an avenue to the north is not to be done by merely taking away certain trees, but also by planting a thicket before the trunks of those at a distance; as we may be thus induced to forget that they stand in rows. The addition of a few single trees, guarded by cradles, though often used as an expedient to break a row, never produces the desired effect: the original lines are for ever visible. ${ }^{5}$

WELBECK. Besides the character which the style and size of the house will confer on a place, there is a natural character of country which must influence the site and disposition of a house; and though, in the country, there is not the same occasion as in towns for placing offices under ground, or for setting the principal apartments on a basement storey, as it is far more desirable to walk from the house on the same level with the ground, yet there are situations which require to be raised above the natural surface: this is the case at Welbeck, where the park not only abounds with bold and conspicuous inequalities, but in many places there are almost imperceptible swellings in the ground, which art would in vain attempt to remedy, from their vast breadth; though they are evident defects whenever they appear to cut across the stems of trees and hide 
only half their trunks; for if the whole trunk were perfectly hid by such a swell, the injury would be less, because the imagination is always ready to sink the valley and raise the hill, if not checked in its efforts by some actual standard of measurement. In such cases the best expedient is to view the ground from a gentle eminence, that the eye may look over and, of course, lose these trifling inequalities.

The family apartments are to the south, the principal suite of rooms to the east, and the hall and some rooms of less importance to the west; when, therefore, the eating-room and kitchen offices shall be removed to the north, it is impossible to make a better disposition of the whole, with regard to aspect. I shall therefore proceed to the fourth general head proposed for consideration, viz. the shape of the ground near the house: and as the improvement at Welbeck, originally suggested by His Grace the Duke of Portland, has, I confess, far exceeded even my own expectations, I shall take the liberty of drawing some general conclusions on the subject, from the success of this bold experiment. At the time I had the honour to deliver my former opinion, my idea of raising the ground near the house was confined to the west front alone; and, till it had been exemplified and executed, few could comprehend the seeming paradox of burying the bottom of the house as the means of elevating the whole structure; or, as it was very wittily expressed, " moulding up the roots of the venerable pile, that it might shoot up in fresh towers from its top.'

All natural shapes of ground must necessarily fall under one of these descriptions, viz., convex, concave, plane, or inclined plane, as represented in the following sections [Fig. 3]. I will suppose it granted that, 
except in very romantic situations, all the rooms on the principal floor ought to range on the same level; and that there must be a platform, or certain space of ground, with a gentle descent from the house every way. If the ground be naturally convex, or what is generally called a knoll, the size of the house must

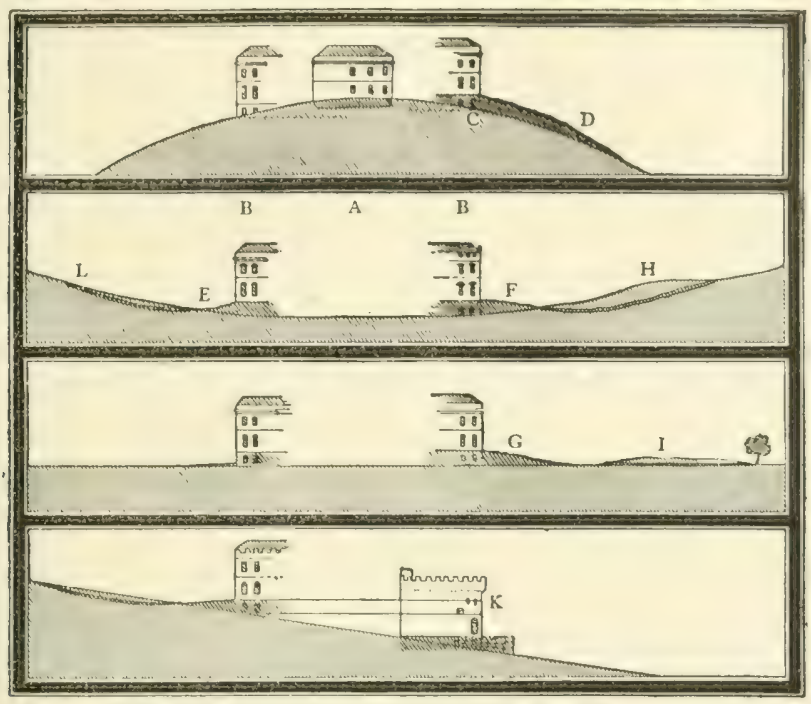

Fig. 3. Sections to shew the manner of adapting houses to different natural shapes of ground.

be adapted to the size of the knoll: this is shown by the small building $A$, supposed to be only one hundred feet in front, which may be placed upon such a hillock, with a sufficient platform round it; but if a building of three hundred feet long, as B B, should be required, it is evident that the crown of the hill must be taken off, and then the shape of the ground becomes very different from its original form: for although the small house would have a sufficient platform, the large one will be on the brink of a very steep 
bank at c; and this difficulty would be increased by raising the ground to the dotted line $D$, to set the large house on the same level with the smaller one. It therefore follows that if the house must stand on a natural hillock, the building should not be larger than its situation will admit; and where such hillocks do not exist in places proper for a house in every other respect, it is sometimes possible for art to supply what nature seems to have denied. But it is not possible in all cases; a circumstance which proves the absurdity of those architects who design and plan a house, without any previous knowledge of the situation or shape of the ground on which it is to be built. Such errors I have had too frequent occasion to observe.

When the shape is naturally either concave or perfectly flat, the house would not be habitable unless the ground sloped sufficiently to throw the water from it. This is often effected, in a slight degree, merely by the earth that is dug from the cellars and foundations; but if, instead of sinking the cellars, they were to be built upon the level of the ground, they may afterwards be so covered with earth as to give all the appearance of a natural knoll, the ground falling from the house to any distance where it may best unite with the natural shape, as shewn at E, F, and G: or, as it frequently happens that there may be small hillocks, $H$ and $I$, near the house, one of them may be removed to effect this purpose. This expedient can also be used in an inclined plane, falling towards the house, where the inclination is not very great, as shewn at L; but it may be observed of the inclined plane that the size of the house must be governed in some measure by the fall of the ground; since it is evident that although a house of a hundred feet deep might stand at $\mathrm{k}$, yet it would 
require an artificial terrace on that side; because neither of the dotted lines shewn there would connect with the natural shape; and where the ground cannot be made to look natural, it is better, at all times, to avow the interference of art than to attempt an ineffectual concealment of it. Such situations are peculiarly applicable to the Gothic style, in which horizontal lines are unnecessary.

These sections can only describe the shape of the ground as it cuts across in any one direction. But another shape is also to be considered: thus it generally happens that a knoll is longer one way than the other, or it may even extend to a natural ridge, of sufficient length for a long and narrow house; but such a house must be fitted to the ground, for it would be absurd in the architect to place it either diagonally or directly across such a ridge. The same holds good of the inclined plane, which is, in fact, always the side of a valley whose general inclination must be consulted in the position of the building. A square house would appear awry unless its fronts were made to correspond with the shape of the adjacent ground.

I shall conclude this digression by observing that on a dead flat or plain the principal apartments ought to be elevated, as the only means of shewing the landscape to advantage. Where there is no inequality, it will be very difficult to unite any artificial ground with the natural shape: it will in this case be advisable either to raise it only a very few feet or to set the house on a basement storey. But wherever a park abounds in natural inequalities, even though the ground near the house should be flat, we may boldly venture to create an artificial knoll, as it has been executed at Welbeck. 


\section{Chapter IV}

Water

THERE being no part of my profession so cap1 tivating in its effect, and oftentimes so readily executed, as making a large piece of artificial water, it may be proper, in this volume, to give a few specimens of different improvements presumed to have been produced by it: though, if all that I have written to explain and elucidate this subject were to be inserted, the whole of the volume would be engrossed by it. I must, therefore, for the present, only mention a few places where artificial pieces of water have been ornamented under my directions: ${ }^{6}$ viz. at Holkham, the magnificent lake has been dressed by walks on its banks, and a peculiar ferryboat invented to unite the opposite shores.

Welbeck. From the number of small promontories and bays, together with its termination full in view of the house, the water at Welbeck had acquired the character, and indeed the name, of a lake: but as a large river is always more beautiful than a small lake, the character has been changed, not only by continuing it beyond the house, but also by altering its line, and taking off those projections which were inconsistent with the course of a natural river.

Tatton Park. It has often been asserted by authors on gardening that all pieces of fresh water must come under one of these descriptions, - a lake, a pool, a river, or a rivulet: but since my acquaintance with Cheshire, 
I am inclined to add the meer, as an intermediate term between the lake and the pool; it being, frequently, too large to be deemed a pool, and too small as well as too round in its form to deserve the name of a lake: for the beauty of a lake consists not so much in its size as in those deep bays and bold promontories which prevent the eye from ranging over its whole surface. What is best respecting the two large meers in Tatton Park is a question of some difficulty, and on which there has been a variety of opinions. I shall now proceed to deliver mine, and endeavour to explain the reasons on which it is founded.

Unity of design in all compositions is, confessedly, one of the first principles in each of the polite arts; and nothing, perhaps, evinces more strongly the love of unity acting on the mind in landscape gardening than the following fact, - viz. that the most superficial observer of any park scene will be displeased by the view of two separate pieces of water; and he will probably ask, without reflecting on the difference of levels, why they are not formed into one? The first opinion seems, therefore, that these two waters should be united: but if the union is not clearly possible, it certainly ought not to be attempted. The second opinion is that the upper pool ought to be destroyed, or, as some express themselves, should be filled up: but the latter would be an Herculean labour to very little purpose, and the former, though practicable, would not be advisable, because so deep a hollow immediately in front of the house would be a yawning chasm, very difficult to convert into an object of beauty. My opinion, therefore, is that the two waters should, from the house, appear to be connected with each other, although in reality they are very far asunder; and the means of 
effecting such a deception will require some theoretical reasoning to explain.

The deception at present operates to the disadvantage of the waters, for I was myself greatly deceived in the size of this pool when I looked at it from the house; and as it produces a similar effect on every person who first sees it, I must explain the causes of the deception.

First. The net fence through which the water appears is so near the windows that, by the laws of perspective (of which I will explain some general rules in the sequel), it acts as a false standard, and by it we measure the size of the pool. It was for this reason that I desired some cattle might be driven on the tanks, which, as I have elsewhere shewn, are the best standard for assisting the judgement with respect to the distance, and, of course, the dimensions of other objects.

Secondly. The pool is almost circular, and the eye darts round its border with such instantaneous imperceptible velocity that it is impossible to suppose its circumference to be nearly a mile, unless we can see cattle on the opposite shores; and then, by their respective dimensions, we judge of the comparative distance. The sheep on one side the water appear to be larger than the cows on the other. The bay or creek may be hid by shrubs, which will give the eye a check in its circuitous progress.

To explain the uses of the other bay (which seems to connect the water in the foreground with the water in the distance), I must take the liberty to describe some effects in perspective, not, I believe, generally attended to in gardening. Perspective, in painting, is known to be of two kinds: the first is called linear perspective, and is that by which objects appear to diminish in proportion to the distance at which they are viewed. 
This $I$ have here already mentioned, in referring to the use of cattle as a scale of measurement : a horse, a cow, or a sheep is very nearly of the same size, and with this size the mind is perfectly acquainted; but trees, bushes, hills, or pools of water are so various in their dimensions that we are never able to judge exactly of their size or at what distance they appear to us.

The second kind of perspective is aerial, as it depends on the atmosphere; since we observe that objects not only diminish in their size but in their distinctness, in proportion to the body of air betwixt the eye and the objects: those nearest are strongly represented, while other parts, as they recede, become less distinct, till at last the outline of a distant hill seems melting into the air itself. Such are the laws of aerial perspective on all objects, but not on all alike; since it is the peculiar property of light, and the reflection of light, unmixed by colour, to suffer much less by comparison than any other object. It is for this reason that we are so much deceived in the distance of perfectly white objects: the light reflected from a whitewashed house makes it appear out of its place; snow, at many miles' distance, appears to be in the next field; indeed, so totally are we unable to judge of light that a meteor within our atmosphere is sometimes mistaken for a lantern; at others, for a falling star. Water, like a mirror, reflecting the light, becomes equally uncertain in its real distance; and, therefore, an apparent union of the two meers in Tatton Park may be effected by attending to this circumstance. The large piece of water crosses the eye in the view from the house; consequently it looks much less considerable than it really is, and its effect is of little advantage to the scene, being too distant, and too widely separated by the vast tract of low ground 
betwixt the pool and the lake. I propose that this water should be rendered more interesting, by making it appear as if the arm of a river proceeded from the lake; and its termination will easily be hid in the (distant) valley. I hope it will appear that the ideal connexion of the two waters may be accomplished, although the actual junction is impracticable. The facility of deception arises from the causes already stated, viz. that water is a mirror from which light is strongly reflected, and that of the distance betwixt any light and the eye we form a very inaccurate judgement: it is, therefore, impossible to know, by looking on the surfaces of two distinct waters, whether they are of the same level, unless some ground betwixt them assists the measurement. We have, therefore, only to bring the two meers nearer to each other, and give their forms such curvature as I have described, to produce that effect of apparent unity, which is all that is necessary in this instance.

I am aware of the common objection to all efforts that may be deemed deceptions; but it is the business of taste, in all the polite arts, to avail itself of stratagems by which the imagination may be deceived. The images of poetry and of painting are then most interesting when they seduce the mind to believe their fictions; and in landscape gardening everything may be called a deception by which we endeavour to conceal the agency of art and make our works appear the sole product of nature. The most common attempts to improve may, indeed, be called deceptions: we plant a hill to make it appear higher than it is; we open the banks of a brook, to give it the appearance of a river; or stop its current, to produce an expanse of surface; we sink the fence betwixt one lawn and another, to 
give imaginary extent, without inconvenience or confinement; and every piece of artificial water, whether it take the shape of a lake, a river, or a pool, must look natural or it will fail to be agreeable. Nor is the imagination so fastidious as to take offence at any wellsupported deception, even after the want of reality is discovered. When we are interested at a tragedy, we do not inquire whence the characters are copied; on the contrary, we forget that we see a Garrick or a Siddons, and join in the sorrows of a Belvidere or a Beverley, though we know that no such persons ever existed: it is enough if so much as we are shewn of the character appears to be a just resemblance of nature. In the same manner the magnificent water at Blenheim strikes with wonder and delight, while we neither see its beginning nor end; and we do not view it with less pleasure after we are told that it was not originally a natural lake, but that Mr. Brown, stopping the current of a small river, collected this vast body of water into the beautiful shape we now admire.

Mr. Burke very justly observes " that a true artist should put a generous deceit on the spectators, and effect the noblest designs by easy methods. Designs that are vast only by their dimensions are always the sign of a common and low imagination. No work of art can be great but as it deceives; to be otherwise is the prerogative of nature only."? 


\section{Chapter V}

\section{Large Private Places ${ }^{8}$.}

ELBECK. The view from the principal apart-
ments should bear some proportion to the importance of the house itself; not so much in the quantity or extent of the prospect as in the nature of the objects which compose the scenery; an extensive prospect being only applicable to a castle, a villa, or a belvedere. The landscape from a palace should everywhere appear appropriate to the magnificence or pleasure of its inhabitants: the whole should be, or at least appear to be, a park, unlimited and unconfined by those lines of division or boundary which characterize the large grass-fields of a dairy-farm. Yet a park has a character distinct from a forest; for while we admire and even imitate the romantic wildness of nature, we ought never to forget that a park is the habitation of men, and not solely devoted to beasts of the forest. I am convinced that some enthusiasic admirers of uncultivated nature are too apt to overlook this distinction. Park scenery compared with forest scenery is like an historical picture compared with a landscape; nature must alike prevail in both, but that which relates to man should have a higher place in the scale of arts.

The objects which nature has furnished at Welbeck are of the most beautiful kind, and truly in character with the dignity of the place. The vast range of woods, the extensive lawns, the broad expanse of river, and the astonishing oaks scattered about the park seem to 


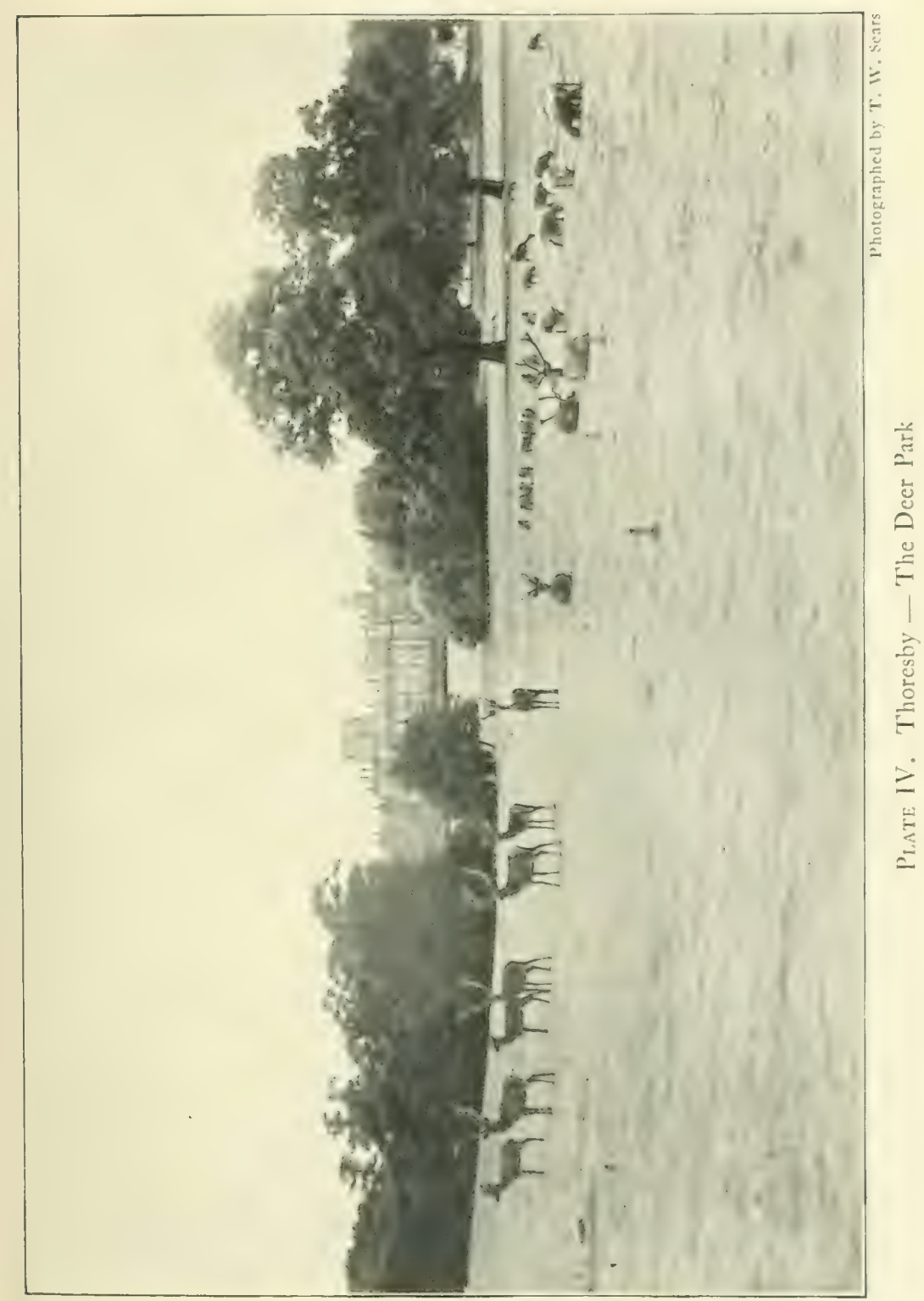



require but a little attention from art to mark the residence of a noble possessor; yet, as there are a few instances in which the interference of art can openly be acknowledged, those few should not be neglected. Buildings, however simple, if in character and not too numerous, will more than anything contribute to display magnificence.

Woods enriched by buildings, and water enlivened by a number of pleasure-boats, alike contribute to mark a visible difference betwixt the magnificent scenery of a park and that of a sequestered forest: the trees, the water, the lawns, and the deer are alike common to both.

There is another distinction betwixt park and forest scenery on which I shall beg leave to state my opinion, as it has been a topic of some doubt and difficulty amongst the admirers of my profession, viz. how far gravel roads are admissible across the lawns of a park: yet surely very little doubt will remain on this subject when we consider a park as a place of residence; and see the great inconvenience to which grass roads are continually liable.

I have endeavoured to discover two reasons which may have given rise to the common technical objection that a gravel road cuts up a lawn: the first arises from the effect observed after an avenue has been destroyed, where the straight line of gravel, which formerly was less offensive while accompanied by trees, becomes intolerable when it divides a small lawn directly through the middle. The other arises from the effect which even a winding turnpike road has in destroying the sequestered and solemn dignity of forest scenery : but in a park a road of convenience and of breadth proportioned to its intention as an approach to the house for visitors will often be a circumstance of great beauty; and is a 
characteristic ornament of art, allowable in the finest inhabited scenes of nature.

Wembly. The park ${ }^{9}$ at Wembly is only defective in two circumstances: the first is the common defect of all places where hedges have been recently removed and too many single trees are left; the natural reluctance felt by every man of taste and experience to cut down large trees, at the same time that he sees the unpleasant effect of artificial rows, is very apt to suggest the idea of breaking those rows by planting many young trees; and thus the whole composition becomes frittered into small parts, which are neither compatible with the ideas of the sublime nor beautiful. The masses of light and shade, whether in a natural landscape or a picture, must be broad and unbroken, or the eye will be distracted by the flutter of the scene; and the mind will be rather employed in retracing the former lines of hedgerows than in admiring the ample extent of lawn and continuity of wood which alone distinguishes the park from the grass- or dairy-farm. This defect will of course easily be remedied when the new plantations shall have acquired a few years' growth, and many of the old trees shall be either taken down or blended into closer groups by young ones planted very near them: but there can be little occasion for dotting young trees with such profusion, and I do not hesitate to affirm that of several hundred such trees now scattered upon the lawn not more than twenty can be absolutely necessary.

The other defect of Wembly arises from a sameness of objects; and this is a defect common to all the countries where the grass-land is more generally mowed than fed. It proves, what no landscape painter ever doubted, that a scene consisting of vegetable productions only can seldom make a pleasing picture. The 
contrasted greens of wood and lawn are not sufficient to gratify the eye; it requires other objects, and those of different colours, such as rocks, water, and cattle; but where these natural objects cannot easily be had, the variety may be obtained by artificial means, such as a building, a tent, or a road; and, perhaps, there is no object more useful in such countries than a goodcoloured gravel road, gracefully winding, and of course describing those gentle swells of the ground which are hardiy perceptible from the uniform colour of grassland. The approach-road to the house will be a feature on the lawn, both as seen from thence and also from the high ground about the park. Cattle might be more frequently introduced than seems to be the custom of this country, especially sheep, than which nothing contributes more to enliven a lawn and even to improve and fertilize its verdure; and though some objections may arise, from the nature of the soil, they are by no means insurmountable.

Castle Hill. A scene, however beautiful in itself, will soon lose its interest unless it is enlivened by moving objects. [Plate v.] This may be effected by sunk fences; and from the shape of the ground, there is another material use in having cattle to feed the lawn before the windows. The eye forms a very inaccurate judgement of extent, unless there be some standard by which it can be measured; bushes and trees are of such various sizes that it is impossible to use them as a measure of distance; but the size of a horse, a sheep, or a cow varies so little that we immediately judge of their distance from their apparent diminution, according to the distance at which they are placed; and as they occasionally change their situation, they break that surface over which the eye passes, without observ- 
ing it, to the first object it meets to rest upon. It has been objected to the slides with which I elucidate my proposed alterations that I generally introduce in the improved view boats on the water and cattle on the lawns. To this I answer that both are real objects of improvement, and give animation to the scene; indeed it cannot be too often inculcated that a large lake without boats is a dreary waste of water, and a large lawn without cattle is one of the melancholy appendages of solitary grandeur observable in the pleasure-grounds of the past century.

Wembly. The expedient of producing variety at Wembly, by buildings, is perhaps the most difficult, and requires the greatest attention; because one source of our admiration is that in the neighbourhood of the metropolis a place should exist so perfectly secluded and detached from the "busy haunts of men": we must, therefore, be particularly cautious that every building should appear to be an appendage or inmate of the place, and not a neighbour intruding on its privacy. From hence arose some difficulty in the style of building proper for the prospect on the hill - a very small one would have been inadequate to the purpose of containing such companies as may resort thither, as well as forming a dwelling-house for those who should have the care of the prospect rooms and the dairy; yet in building a large house there was danger of making it appear to belong to some other person.

To the common observer, the beauties of Wembly may appear to need no improvement; but it is the duty of my profession to discover how native charms may be heightened by the assistance of taste: and that even beauty itself may be rendered more beautiful, this place will furnish a striking example. 


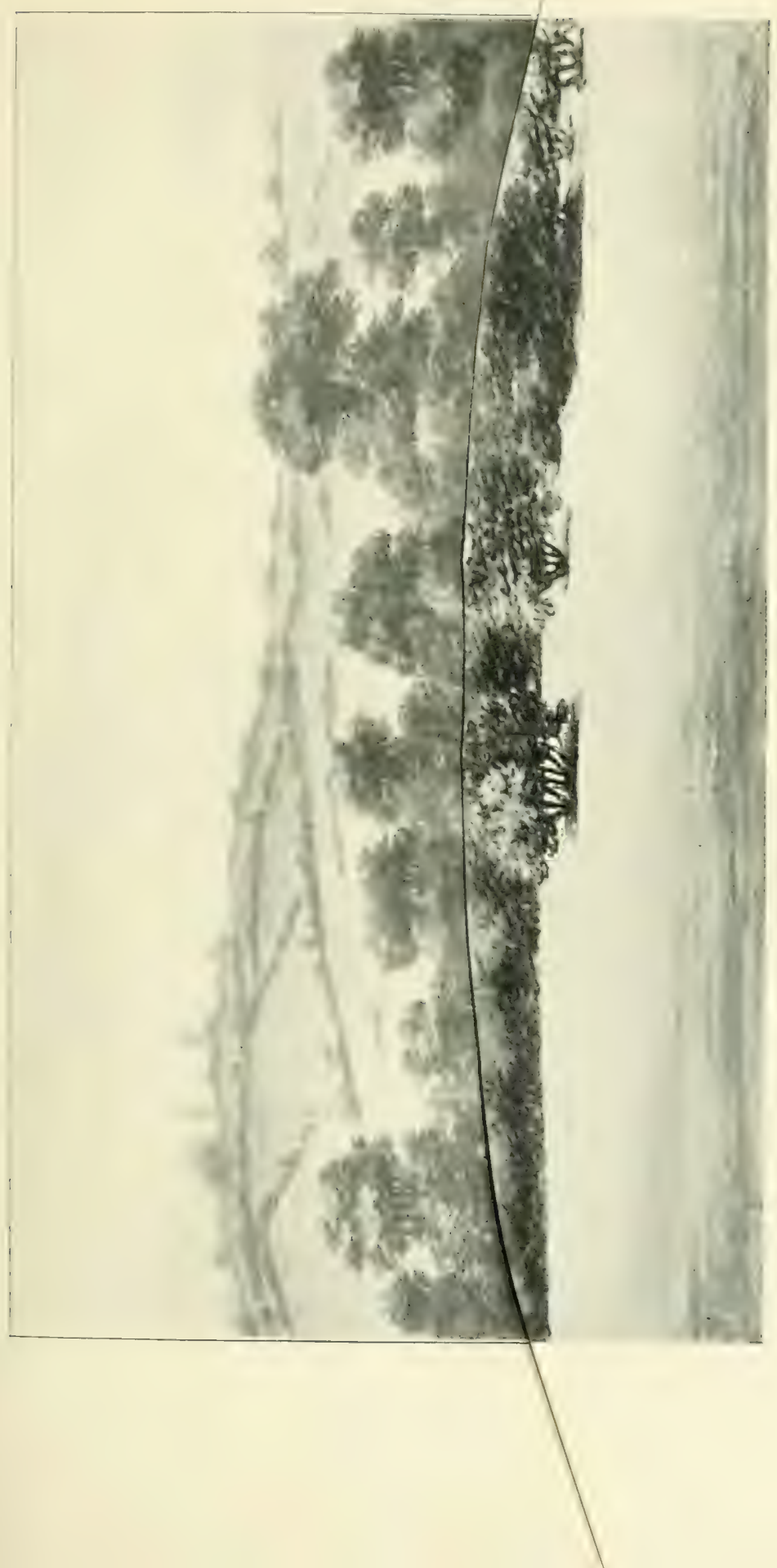





\section{Chapter VI}

Formal Gardening

7 HERE is no part of my profession more difficult

1 and troublesome than the attempt to modernise, in part only, those places which have been formerly decorated by the line and square of geometric taste. To explain this difficulty, I will briefly state the difference between the principles on which improvements are now conducted and those which governed the style of former periods.

The perfection of landscape gardening consists in the four following requisites: First, it must display the natural beauties and hide the natural defects of every situation. Secondly, it should give the appearance of extent and freedom, by carefully disguising or hiding the boundary. Thirdly, it must studiously conceal every interference of art, however expensive, by which the scenery is improved, making the whole appear the production of nature only; and, fourthly, all objects of mere convenience or comfort, if incapable of being made ornamental, or of becoming proper parts of the general scenery, must be removed or concealed. Convenience and comfort, I confess, have occasionally misled modern improvers into the absurdity of not only banishing the appearance but the reality of all comfort and convenience to a distance; as I have frequently found in the bad choice of a spot for the kitchen-garden.

Each of the four objects here enumerated is directly 
opposite to the principles of ancient gardening, which may thus be stated. First, the natural beauties or defects of a situation had no influence, when it was the fashion to exclude, by lofty walls, every surrounding object. Secondly, these walls were never considered as defects; but, on the contrary, were ornamented with vases, expensive iron gates, and palisades, to render them more conspicuous. Thirdly, so far from making gardens appear natural, every expedient was used to display the expensive efforts of art, by which nature had been subdued: - the ground was levelled by a line; the water was squared, or scollopped into regular basins; the trees, if not clipped into artificial shape, were at least so planted by line and measurement that the formal hand of art could nowhere be mistaken. And, lastly, with respect to objects of convenience, they were placed as near the house as possible:- the stables, the barns, and the kitchen-garden were among the ornaments of a place; while the village, the almshouse, the parish school, and churchyard were not attempted to be concealed by the walls or palisades that divided them from the embellished pleasure-ground.

LAтном. Congruity of style, uniformity of character, and harmony of parts with the whole are different modes of expressing that unity, without which no composition can be perfect: yet there are few principles in gardening which seem to be so little understood. This essential unity has often been mistaken for symmetry, or the correspondence of similar parts; as where

"Grove nods at grove, each alley has a brother, And half the platform just reflects the other."

Pope.

Indeed, this symmetry in the works of art was perfectly justifiable under that style of gardening which confined, 
within lofty walls, the narrow enclosure appropriated to ancient grandeur.

When the whole design is meant to be surveyed at a single glance, the eye is assisted in its office by making its divisions counterparts of each other; and as it was confessedly the object of the artist to display his labour, and the greatness of the effort by which he had subdued nature, it could not possibly be more conspicuous than in such shapes of land and water as were most unnatural and violent. Hence arose the flat terrace, the square and octagon pool, and all those geometric figures which were intended to contrast and not to assimilate with any scenes in nature. Yet within this small enclosure an unity of design was strictly preserved, and few attempts made to extend it farther than the garden wall.

From the prodigious difference of taste in gardening betwixt the last and the present century, it seems, at first sight, almost impossible to lay down any fixed principles; but, on duly considering the subject, it will be found that in this instance, as well as in many others, mankind are apt to fly from one extreme to the other; thus, because straight lines, and highly finished and correspondent parts prevailed in the ancient style, some modern improvers have mistaken crookedness for the line of beauty, and slovenly carelessness for natural ease; they call every species of regularity formal, and, with the hackneyed assertion that " nature abhors a straight line," they fatigue the eye with continual curvatures.

There appears to be in the human mind a natural love of order and symmetry. Children who at first draw a house upon a slate generally represent it with correspondent parts. It is so with the infancy of taste; those who, during the early part of life, have given little attention to objects of taste, are captivated with the reg- 
ularity and symmetry of correspondent parts, without any knowledge of congruity or a harmony of parts with the whole. This accounts for those numerous specimens of bad taste which are too commonly observable in the neighbourhood of great towns, where we see Grecian villas spreading their little Gothic wings, and red-brick castles supported by Grecian pavilions; but though congruity may be banished, symmetry is never forgotten. If such be the love of symmetry in the human mind, it surely becomes a fair object of inquiry, how far it ought to be admitted or rejected in modern gardening. The following observation from Montesquieu, on Taste, ${ }^{10}$ seems to set the matter in a fair light:

"Wherever symmetry is useful to the soul, and may assist her functions, it is agreeable to her; but wherever it is useless, it becomes distasteful, because it takes away variety. Therefore, things that we see in succession ought to have variety, for our soul has no difficulty in seeing them; those, on the contrary, that we see at one glance, ought to have symmetry: thus, at one glance we see the front of a building, a parterre, a temple; in such things there is always a symmetry which pleases the soul by the facility it gives her of taking in the whole object at once."

It is upon this principle that I have frequently advised the most perfect symmetry in those small flower-gardens which are generally placed in the front of a greenhouse, or orangery, in some inner part of the grounds; where, being secluded from the general scenery, they become a kind of episode to the great and more conspicuous parts of the place. In such small enclosures irregularity would appear like affectation. Symmetry is also allowable, and indeed necessary, at or near the front of a regular building; because, where 


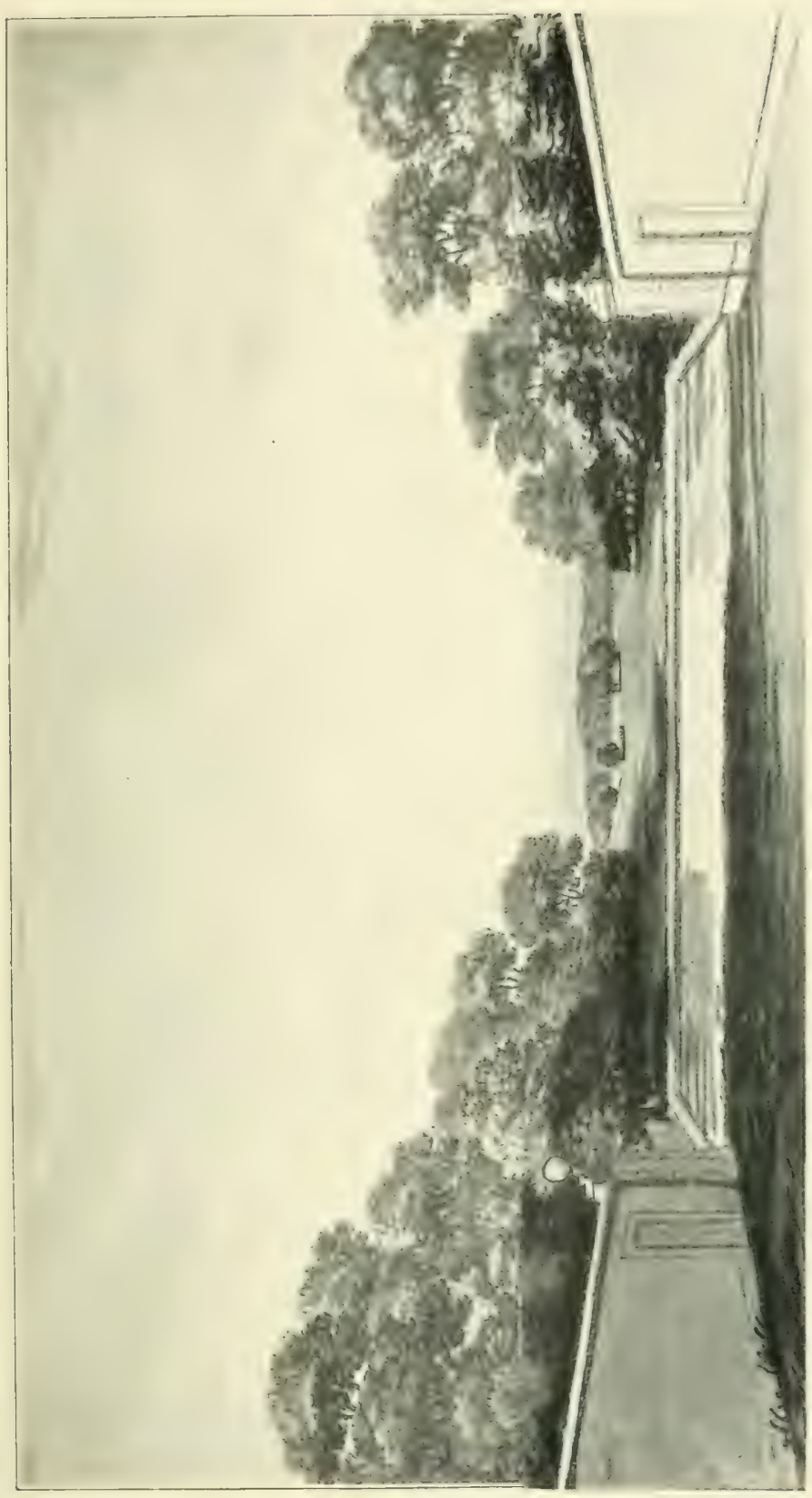



that displays correspondent parts, if the lines in contact do not also correspond, the house itself will appear twisted and awry. Yet this degree of symmetry ought to go no farther than a small distance from the house, and should be confined merely to such objects as are confessedly works of art for the uses of man; such as a road, a walk, or an ornamental fence, whether of wood or iron; but it is not necessary that it should extend to plantations, canals, or over the natural shape of the ground. "In forming plans for embellishing a field, an artist without taste employs straight lines, circles, and squares, because these look best upon paper. He perceives not that to humour and adorn nature is the perfection of his art; and that nature, neglecting regularity, distributes her objects in great variety, with a bold hand. (Some old gardens were disposed like the human frame; alleys, like legs and arms, answering each other; the great walk in the middle representing the trunk of the body.) Nature, indeed, in organised bodies comprehended under one view, studies regularity; which, for the same reason, ought to be studied in architecture; but in large objects, which cannot be surveyed but in parts, and by succession, regularity and uniformity would be useless properties, because they cannot be discovered by the eye. Nature, therefore, in her large works, neglects these properties; and in copying nature, the artist ought to neglect them." "

Lathom. It is hardly to be conceived how much this view to the north will be improved by the removal of the large square pond. [Platevi.] Water reflecting only the sky (which is the case with this and every other pond raised above the level of the natural ground) acts like a mass of light placed betwixt the eye and the more distant objects. Every one knows the effect that a lan- 
tern or a torch has, to prevent our seeing what is beyond it; and this same cause operates in all cases in proportion to the quantity of rays reflected, whether from water, from snow, from white paling, or any other luminous object. This accounts for the pleasure we derive from seeing water at a proper distance, and of a natural shape. Water is said to attract our notice with irresistible power; but the pond at Lathom, placed in the foreground, engrosses too much of the landscape, and is neither sufficiently pleasing in its shape nor natural in its situation to deserve the place it holds as the leading feature of the scene.

The management of the view to the north will further serve to elucidate another general principle in gardening, viz. that although we do not require a strict symmetry in the two sides of the landscape, yet there is a certain balance of composition, ${ }^{12}$ without which the eye is not perfectly satisfied. The two screens of wood beyond the pond may be varied and contrasted; that to the west may be left as a thick and impenetrable mass of trees and underwood, while a great part of that to the east should be converted into an open grove; thus destroying the formality, while the balance of composition may still be preserved. 


\section{Chapter VII}

Approaches ${ }^{\times 3}$

7 HE road by which a stranger is supposed to pass

1 through the park or lawn to the house is called an approach; and there seems the same relation betwixt the approach and the house externally that there is internally betwixt the hall or entrance and the several apartments to which it leads. If the hall be too large or too small, too mean or too much ornamented for the style of the house, there is a manifest incongruity in the architecture, by which good taste will be offended; but if the hall be so situated as not to connect well with the several apartments to which it ought to lead, it will then be defective in point of convenience.

So it is with respect to an approach :- it ought to be convenient, interesting, and in strict harmony with the character and situation of the mansion to which it belongs.

There seems to be as much absurdity in carrying an approach round, to include those objects which do not naturally fall within its reach, as there was formerly in cutting through a hill, to obtain a straight line pointing to the hall door. A line of red gravel across a lawn is apt to offend, by cutting it into parts, and destroying the unity of verdure, so pleasing to the eye. But I have in some places seen the aversion of showing a road carried to such a length, that a gap has been dug in the lawn, by way of road; and, in order to hide it, 
the approach to a palace must be made along a ditch. In other places, I have seen what is called a grass approach, which is a broad, hard road, thinly covered with bad verdure, or even moss, to hide it from the sight; and thus, in a dusky evening, after wandering about the park in search of a road, we suddenly find ourselves upon grass, at the door of the mansion, without any appearance of mortals ever having before approached its solitary entrance.

Thus do improvers seem to have mistaken the most obvious meaning of an approach, which is simply this - a road to the house. If that road be greatly circuitous, no one will use it when a much nearer is discovered: but if there be two roads of nearly the same length, and one be more beautiful than the other, the man of taste will certainly prefer it; while, perhaps, the clown, insensible to every object around him, will indifferently use either.

The requisites to a good approach may be thus enumerated:

First. An approach is a road to the house; and to that principally.

Secondly. If it is not naturally the nearest road possible, it ought artificially to be made impossible to go a nearer.

Thirdly. The artificial obstacles which make this road the nearest ought to appear natural.

Fourthly. Where an approach quits the highroad, it ought not to break from it at right angles, or in such a manner as robs the entrance of importance; but rather at some bend of the public road, from whence a lodge, or gate, may be more conspicuous; and where the highroad may appear to branch from the approach, rather than the approach from the highroad. 
Fifthly. After the approach enters the park, it should avoid skirting along its boundary, which betrays the want of extent or unity of property.

Sixthly. The house, unless very large and magnificent, should not be seen at so great a distance as to make it appear much smaller than it really is.

Seventhly. The house should be at first presented in a pleasing point of view.

Eighthly. As soon as the house is visible from the approach, there should be no temptation to quit it which will ever be the case if the road be at all circuitous - unless sufficient obstacles, such as water or inaccessible ground, appear to justify its course.

I shall not here speak of the convenience or inconvenience of a large town situated very near a park, but of the influence that the proximity of a large town has on the character of a park, which is very considerable, because it must either serve to increase or to diminish its importance; the latter is at present the case with respect to Tatton and Knutsford.

The first essential of greatness in a place is the appearance of united and uninterrupted property, and it is in vain that this is studied within the pale, if it is too visibly contradicted without it. It is not to be expected that a large manufacturing town, like Knutsford, can be the entire property of one individual; but the proportion of interest belonging to the adjoining family should impress the mind with a sense of its influence.

There are various ways by which this effect is occasionally produced, and I will mention some of them, viz. the church and churchyard may be decorated in a style that shall in some degree correspond with that of the mansion; - the market-house, or 
52 The Art of Landscape Gardening

other public edifice, an obelisk, or even a mere stone, with distances, may be made an ornament to the town, and bear the arms of the family; or the same arms may be the sign of the principal inn of the place. 


\section{Chapter VIII}

Affinity betwixt Painting and Gardening

T $\mathrm{T}$ has already been remarked in this volume that I there ought to be some difference betwixt a park and a forest; and as the whole of that false and mistaken theory, which Mr. Knight endeavours to introduce by confounding the two ideas, proceeds from not duly considering the degree of affinity betwixt painting and gardening, I shall transcribe a few passages from manuscripts, written long before I saw his poem; although the inquiry was originally suggested by conversations I have occasionally had, both with Mr. Knight and Mr. Price, at their respective seats in the county of Hereford.

A great difference betwixt a scene in nature and a picture on canvas will arise from the following considerations:

First. The spot from whence the view is taken is in a fixed state to the painter, but the gardener surveys his scenery while in motion, and from different windows in the same front he sees objects in different situations; therefore, to give an accurate portrait of the gardener's improvement would require pictures from each separate window, and even a different drawing at the most trifling change of situation, either in the approach, the walks, or the drives, about each place.

Secondly. The quantity of view, or field of vision, is much greater than any picture will admit.

Thirdly. The view from an eminence down a steep 
hill is not to be represented in painting, although it is often one of the most pleasing circumstances of natural landscape.

Fourthly. The light which the painter may bring from any point of the compass must, in real scenery, depend on the time of day. It must also be remembered that the light of a picture can only be made strong by contrast of shade; while in nature every object may be strongly illumined without destroying the composition or disturbing the keeping. And,

Lastly. The foreground, which, by framing the view, is absolutely necessary to the picture, is often totally deficient, or seldom such as a painter chooses to represent; since the neat gravel walk or close-mown lawn would ill supply the place, in painting, of a rotten tree, a bunch of docks, or a broken road, passing under a steep bank, covered with briers, nettles, and ragged thorns.

Real landscape, or that which my art professes to improve, is not always capable of being represented on paper or canvas; for although the rules for good natural landscape may be found in the best painters' works, in which

$$
\text { "we ne'er shall find }
$$

Dull uniformity, contrivance quaint,

Or labour'd littleness; but contrasts broad, And careless lines, whose undulating forms Play though the varied canvas"';

\section{MASON.}

yet Monsieur Gerardin ${ }^{14}$ is greatly mistaken when he directs that no scene in nature should be attempted till it has first been painted. And I apprehend the cause of his mistake to be this: in an artificial landscape the foreground is the most important object; indeed, some 
Affinity Between Painting anid Gardening 55

of the most beautiful pictures of Claude de Lorraine consist of a dark foreground, with a very small opening to distant country. But this ought not to be copied in the principal view from the windows of a large house, because it can only have its effect from one window out of many; and, consequently, the others must all be sacrificed to this sole object. In a picture, the eye is confined within certain limits, and unity is preserved by artificial means, incapable of being applied to real landscape, in all the extent which Monsieur Gerardin recommends.

By landscape, I mean a view capable of being represented in painting. It consists of two, three, or more well-marked distances, each separated from the other by an unseen space, which the imagination delights to fill up with fancied beauties that may not perhaps exist in reality.

" Of Nature's various scenes, the painter culls

That for his favourite theme, where the fair whole

Is broken into ample parts, and bold ;

Where, to the eye, three well-mark' d distances

Spread their peculiar colouring."

Mason.

Here Mr. Mason supposes an affinity between painting and gardening, which will be found, on a more minute examination, not strictly to exist.

The landscape painter considers all these three distances as objects equally within the power of his art; but his composition must have a foreground; and though it may only consist of a single tree, a rail, or a piece of broken road, it is absolutely necessary to the painter's landscape.

The subjects of the landscape gardener are very different; though his scenery requires, also, to be broken 
into distinct parts or distances, because the eye is never long delighted, unless the imagination has some share in its pleasure: an intricacy and entanglement of parts heighten the satisfaction. The landscape gardener may also class his distances under three distinct characters, but very different from those of the painter. The first includes that part of the scene which is in his power to improve; the second, that which is not in his power to prevent being injured; and the third, that which is not in the power of himself, or any other, either to injure or improve. The part which the painter calls his middle distance is often that which the landscape gardener finds under the control of others; and the foreground of the painter can seldom be introduced into the composition of the gardener's landscape, from the whole front of a house, because the best landscapes of Claude will be found to owe their beauty to that kind of foreground which could only be applied to one particular window of a house, and would exclude all view from that adjoining.

The enthusiasm for picturesque effect seems to have so completely bewildered the author of the poem. already mentioned that he not only mistakes the essential difference between the landscape painter and the landscape gardener, but appears even to forget that a dwelling-house is an object of comfort and convenience, for the purposes of habitation, and not merely the frame to a landscape, or the foreground to a rural picture. The want of duly considering the affinity between painting and gardening is the source of those errors and false principles which I find too frequently prevailing in the admirers of or connoisseurs in painting : and I do not hesitate to acknowledge that I once supposed the two arts to be more intimately connected 
Affinity Between Painting and Gardening 57

than my practice and experience have since confirmed. I am not less an admirer of those scenes which painting represents; but I have discovered that utility must often take the lead of beauty, and convenience be preferred to picturesque effect, in the neighbourhood of man's habitation. Gardening must include the two opposite characters of native wildness and artificial comfort, each adapted to the genius and character of the place, yet ever mindful that, near the residence of man, convenience, and not picturesque effect, must have the preference, wherever they are placed in competition with each other. 


\section{Chapter IX}

Sources of Pleasure in Landscape Gardening

A FTER sedulously endeavouring to discover the 1 causes of the pleasure that the mind receives from landscape gardening, I think it may occasionally be attributed to each of the following different heads:

I. Congruity; or a proper adaptation of the several parts to the whole; and that whole to the character, situation, and circumstances of the place and its possessor.

II. Utility. This includes convenience, comfort, neatness, and everything that conduces to the purposes of habitation with elegance.

III. Order. Including correctness and finishing; the cultivated mind is shocked by such things as would not be visible to the clown: thus, an awkward bend in a walk, or lines which ought to be parallel, and are not so, give pain; as a serpentine walk through an avenue, or along the course of a straight wall or building.

IV. Symmetry; or that correspondence of parts expected in the front of buildings, particularly Grecian, which, however formal in a painting, require similarity and uniformity of parts to please the eye, even of children. So natural is the love of order and of symmetry to the human mind that it is not surprising it should have extended itself into our gardens, where nature itself was made subservient by cutting trees into regular shapes, planting them in rows, or at exact 
equal distances, and frequently of different kinds in alternate order.

These first four heads may be considered as generally adverse to picturesque beauty, yet they are not, therefore, to be discarded. There are situations in which the ancient style of gardening is very properly preserved: witness the academic groves and classic walks in our universities; and I should doubt the taste of any improver, who could despise the congruity, the utility, the order, and the symmetry of the small garden at Trinity College, Oxford, because the clipped hedges and straight walks would not look well in a picture.

V. Picturesque Effect. This head, which has been so fully and ably considered by Mr. Price, furnishes the gardener with breadth of light and shade, forms of groups, outline, colouring, balance of composition, and occasional advantage from roughness and decay, the effect of time and age.

VI. Intricacy. A word frequently used by me in my Red Books, which Mr. Price has very correctly defined to be "that disposition of objects, which, by a partial and uncertain concealment, excites and nourishes curiosity."

VII. Simplicity; or that disposition of objects which, without exposing all of them equally to view at once, may lead the eye to each by an easy gradation, without flutter, confusion, or perplexity.

VIII. Variety. This may be gratified by natural landscape, in a thousand ways that painting cannot imitate; since it is observed of the best painters' '; orks that there is a sameness in their compositions, and even their trees are all of one general kind, while the variety of nature's productions is endless, and ought to be duly studied. 
IX. Nowelty. Although a great source of pleasure, this is the most difficult and most dangerous for an artist to attempt; it is apt to lead him into conceits and whims which lose their novelty after the first surprise.

X. Contrast supplies the place of novelty, by a sudden and unexpected change of scenery, provided the transitions are neither too frequent nor too violent.

XI. Continuity. This seems evidently to be a source of pleasure, from the delight expressed in a long avenue and the disgust at an abrupt break between objects that look as if they ought to be united, as in the chasm betwixt two large woods, or the separation betwixt two pieces of water; and even a walk, which terminates without affording a continued line of communication, is always unsatisfactory.

XII. Association. This is one of the most impressive sources of delight, whether excited by local accident, as the spot on which some public character performed his part; by the remains of antiquity, as the ruin of a cloister or a castle; but more particularly by that personal attachment to long-known objects, perhaps indifferent in themselves, as the favourite seat, the tree, the walk, or the spot endeared by the remembrance of past events. Objects of this kind, however trifling in themselves, are often preferred to the most beautiful scenes that painting can represent or gardening create. Such partialities should be respected and indulged, since true taste, which is generally attended by great sensibility, ought to be the guardian of it in others.

XIII. Grandeur. This is rarely picturesque, whether it consists in greatness of dimension, extent of prospect, or in splendid and numerous objects of magnificence; but it is a source of pleasure mixed with the sublime. There is, however, no error so common as an attempt 
to substitute extent for beauty in park scenery, which proves the partiality of the human mind to admire whatever is vast or great.

XIV. Appropriation. A word ridiculed by Mr. Price as lately coined by me, to describe extent of property; yet the appearance and display of such extent is a source of pleasure not to be disregarded, since every indiridual who possesses anything, whether it be mental endowments, or power, or property, obtains respect in proportion as his possessions are known, provided he does not too vainly boast of them; and it is the sordid miser only who enjoys for himself alone, wishing the worid to be ignorant of his wealth. The pleasure of appropriation is gratified in viewing a landscape which cannot be injured by the malice or bad taste of a neighbouring intruder: thus an ugly barn, a ploughed field, or any obtrusive object which disgraces the scenery of a park, looks as if it belonged to another, and therefore robs the mind of the pleasure derived from appropriation, or the unity and continuity of unmixed property.

$\mathrm{XV}$. Animation; or that pleasure experienced from seeing life and motion, whether the gliding or dashing of water, the sportive play of animals, or the wayy motion of trees; and particularly the playsomeness peculiar to youth, in the two last instances, affords additional delight.

XVI. And lastly, the seasons, and times of day, which are very different to the gardener and the painter. The noontide hour has its charms, though the shadows are neither long nor broad, and none but a painter or a sportsman will prefer the sear and yellow leaves of autumn to the fragrant blossoms and reviving delights of spring, "the youth of the year." 

II

THEORY AND PRACTICE OF LANDSCAPE GARDENING 



\section{Preface}

TO

\section{THEORY AND PRACTICE}

T $\mathrm{N}$ every other polite art there are certain established rules or general principles to which the professor may appeal in support of his opinions, but in landscape gardening every one delivers his sentiments or displays his taste as whim or caprice may dictate, without having studied the subject, or even thought it capable of being reduced to any fixed rules. Hence it has been doubted whether each proprietor of his own estate may not be the most proper person to plan its improvement.

Had the art still continued under the direction of working gardeners, or nurserymen, the proprietor might supersede the necessity of such landscape gardeners, provided he had previously made this art his study; but not (as it is frequently asserted) because the gentleman who constantly resides at his place must be a much better judge of the means of improving it than the professor whose visits are only occasional: for if this reason for a preference were granted, we might with equal truth assert that the constant companion of a sick man has an advantage over his physician.

Improvements may be suggested by any one, but the professor only acquires a knowledge of effects before they are produced, and a facility in producing them by various methods, expedients, and resources, 
the result of study, observation, and experience. He knows what can and what cannot be accomplished within certain limits. He ought to know what to adopt and what to reject; he must endeavour to accommodate his plans to the wishes of the person who consults him, although, in some cases, they may not strictly accord with his own taste. ${ }^{\mathrm{x}}$

Good sense may exist without good taste, ${ }^{\mathrm{x}}$ yet, from their intimate connexion, many persons are as much offended at having their taste as their únderstanding disputed; hence, the most ignorant being generally the most obstinate, I have occasionally found that, as "a little learning is a dangerous thing," a little taste is a troublesome one.

Both taste and understanding require cultivation and improvement. Natural taste, like natural genius, may exist to a certain degree, but without study, observation, and experience, they lead to error. There is, perhaps, no circumstance which so strongly marks the decline of public taste as the extravagant applause bestowed on early efforts of unlettered and uncultivated genius. Extraordinary instances of prematurity deserve to be patronised, fostered, and encouraged, provided they excite admiration from excellence, independent of peculiar circumstances; but the public taste is endangered by the circulation of such crude productions as are curious only from the youth or ignorance of their authors. Such an apology to the learned will not compensate for the defects of grammar in poetry, nor to the scientific artist for the defects of proportion and design in architecture; while the incorrectness of such efforts is hardly visible to the bulk of mankind, incapable of comparing their excellence with works of established reputation. Thus in poetry, in 
painting, and in architecture, false taste is propagated by the sanction given to mediocrity.

Its dangerous tendency, added to its frequency, must plead my excuse for taking notice of the following vulgar mode of expression: "I do not profess to understand these matters, but I know what pleases me." This may be the standard of perfection with those who are content to gratify their own taste without inquiring how it may affect others; but the man of good taste endeavours to investigate the causes of the pleasure he receives, and to inquire whether others receive pleasure also. He knows that the same principles which direct taste in the polite arts direct the judgement in morality; in short, that a knowledge of what is good, what is bad, and what is indifferent, whether in actions, in manners, in language, in arts, or science, constitutes the basis of good taste and marks the distinction between the higher ranks of polished society and the inferior orders of mankind, whose daily labours allow no leisure for other enjoyments than those of mere sensual, individual, and personal gratification.

Those who delight in depreciating the present by comparisons with former times may, perhaps, observe a decline of taste in many of the polite arts; but surely in architecture and gardening, the present era furnishes more examples of attention to comfort and convenience than are to be found in the plans of Palladio, Vitruvius, or Le Nôtre, who, in the display of useless symmetry, often forgot the requisites of habitation. The leading feature in the good taste of modern times is the just sense of general utility.

A few observations are subjoined to mark those errors, or absurdities in modern gardening and architecture, to which I have never willingly subscribed, and 
from which it will easily be ascertained how much of what is called the improvement of any place in the list, ${ }^{17}$ may properly be attributed to my advice. It is rather upon my opinions in writing than on the partial and imperfect manner in which my plans have sometimes been executed that I wish my fame to be established.

I. There is no error more prevalent in modern gardening, or more frequently carried to excess, than taking away hedges to unite many small fields into one extensive and naked lawn, before plantations are made to give it the appearance of a park; and where ground is subdivided by sunk fences, imaginary freedom is dearly purchased at the expense of actual confinement.

2. The baldness and nakedness round the house is part of the same mistaken system, of concealing fences to gain extent. A palace, or even an elegant villa, in a grass-field, appears to me incongruous; yet I have seldom had sufficient influence to correct this common error.

3. An approach which does not evidently lead to the house, or which does not take the shortest course, cannot be right. This rule must be taken, with certain limitations. The shortest road across a lawn to a house will seldom be found graceful, and often vulgar. A road bordered by trees in the form of an avenue may be straight without being vulgar; and grandeur, not grace or elegance, is the expression expected to be produced.

4. A poor man's cottage, divided into what is called a pair of lodges, is a mistaken expedient to mark importance in the entrance to a park.

5. The entrance-gate should not be visible from the mansion, unless it opens into a courtyard.

6. The plantation surrounding a place, called a belt, I have never advised; nor have I ever willingly marked 
a drive, or walk, completely round the verge of a park, except in small villas, where a dry path round a person's own field is always moreinteresting to him than any other walk.

7. Small plantations of trees, surrounded by a fence, are the best expedients to form groups, because trees planted singly seldom grow well; neglect of thinning and removing the fence has produced that ugly deformity called a clump.

8. Water on an eminence, or on the side of a hill, is among the most common errors of Mr. Brown's followers: in numerous instances I have been allowed to remove such pieces of water from the hills to the valleys, but in many my advice has not prevailed.

9. Deception may be allowable in imitating the works of nature. Thus artificial rivers, lakes, and rock scenery can only be great by deception, and the mind acquiesces in the fraud after it is detected; but in works of art every trick ought to be avoided. Sham churches, sham ruins, sham bridges, and everything which appears what it is not, disgusts when the trick is discovered.

IO. In buildings of every kind the character should be strictly observed. No incongruous mixture can be justified. To add Grecian to Gothic, or Gothic to Grecian, is equally absurd; and a sharp-pointed arch to a garden-gate or a dairy-window, however frequently it occurs, is not less offensive than Grecian architecture in which the standard rules of relative proportion are neglected or violated.

I I. The perfection of landscape gardening consists in the fullest attention to these principles, - Utility, Proportion, and Unity, or harmony of parts to the whole. 



\section{Chapter I}

Introduction - General Principles - Utility Scale - Examples of Comparative ProportionUse of Perspective

$7 \mathrm{HE}$ theory and practice of landscape gardening 1 have seldom fallen under the consideration of the same author; because those who have delivered their opinions in writing on this art have had little practical experience, and few of its professors have been able to deduce their rules from theoretical principles. To such persons indeed had its practice been committed that it required no common degree of fortitude and perseverance to elevate the art of landscape gardening to its proper rank and amongst those which distinguish the pleasures of civilised society from the pursuits of savage and barbarous nations.

Not deterred by the sneer of ignorance, the contradiction of obstinacy, the nonsense of vanity, or the prevalence of false taste, I made the attempt; and with the counsels and advice of men of science, and the countenance of some of the first characters in the kingdom, a very large portion of its scenery has been committed to my care for improvement. Hence it might be expected that, with some degree of confidence, I now should deliver the result of my observations; yet, from the difficulties continually increasing with my knowledge of the subject, I submit this work to the public with far more diffidence than I did my former 
volume : because in this, as in every other study, reflection and observation on those things which we do know teach us to regret our circumscribed knowledge, and the difficulty of reducing to fixed principles the boundless variety of the works of nature.

If any general principles could be established in this art, I think that they might be deduced from the joint consideration of relative fitness or utility and comparative proportion or scale; the former may be referred to the mind, the latter to the eye, yet these two must be inseparable.

Under relative fitness I include the comfort, the convenience, the character, and every circumstance of a place that renders it the desirable habitation of man and adapts it to the uses of each individual proprietor; for it has occasionally happened to me to have been consulted on the same subject by two different proprietors, when my advice has been materially varied, to accord with the respective circumstances or intentions of each.

The second is that leading principle which depends on sight, and which I call comparative proportion; because all objects appear great or small by comparison only, or as they have a reference to other objects with which they are liable to be compared.

At Holkham, about twenty years ago, the lofty obelisk seen from the portico appeared to be surrounded by shrubbery, but on a nearer approach I found that these apparent shrubs were really large trees, and only depressed by the greater height of the obelisk. A similar instance occurs at Welbeck; the large grove of oaks, seen from the house across the water, consists of trees most remarkable for their straight and lofty stems; yet, to a stranger, their 
magnitude is apparently lessened by an enormous large and flourishing ash, which rises like a single tree out of a bank of brushwood. When I was first consulted respecting Wentworth House, the lawn behind it appeared circumscribed, and the large trees which surrounded that lawn appeared depressed by four tall obelisks: these have since been removed, the stately trees have assumed their true magnitude, and the effect of confinement is done away.

I have illustrated these observations by the example of an obelisk [Fig. 4], because its height being inde-

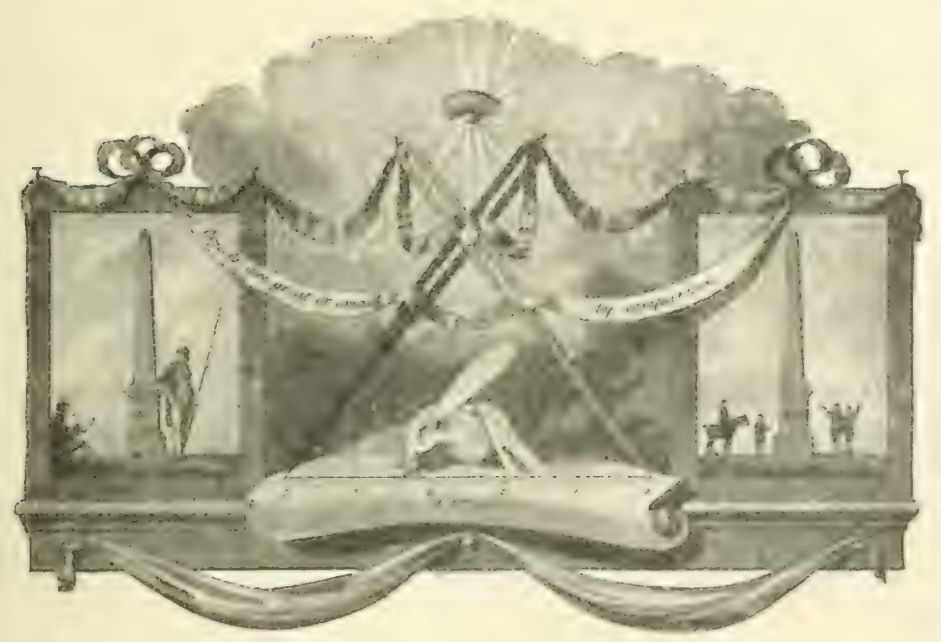

Fig. 4. Diagram to shew the use of the human figure as a scale for measuring objects.

terminate, it may mislead the eye as a scale; since, according to its size and situation, the very same design may serve for a lamp-post, a milestone in the marketplace of a city, an ornament to a public square, or it may be raised on the summit of a hill, a monument to a nation's glory. 
The necessity of observing scale or comparative proportion may be further elucidated by a reference to West Wycombe, a place generally known, from its vicinity to the road to Oxford. Amongst the profusion of buildings and ornament which the false taste of the last age lavished upon this spot, many were correct in design, and, considered separately, in proportion; but even many of the designs, although perfect in themselves, were rendered absurd from inattention either to the scale or situation of the surrounding objects. The summit of a hill is covered by a large mass of Grecian architecture, out of which apparently rises a smail square projection, with a ball at the top, not unlike the kind of cupolas misplaced over stables; ${ }^{\prime s}$ but in reality this building is the tower of a church, and the ball a room sufficiently large to contain eight or ten people.

This comparative proportion, or, in other words, this attention to scale or measurement, is not only necessary with regard to objects near each other, but it forms the basis of all improvement depending on perspective, by the laws of which it is well known that objects diminish in apparent size in proportion to their distance: yet the application of this principle may not, perhaps, have been so universally considered. I shall, therefore, mention a few instances in which I have availed myself of its effects.

At Hurlingham, on the banks of the Thames, the lawn in front of the house was necessarily contracted by the vicinity of the river, yet being too large to be kept under the scythe and roller, and too small to be fed by a flock of sheep, I recommended the introduction of Alderney cows only. The effect is that of giving imaginary extent to the place, which is thus measured below a true standard, because if distance will make 
a large animal appear small, so the distance will be apparently extended by the smallness of the animal.

The same reasoning induced me to prefer, at Stoke Pogies, a bridge of more arches than one over a river which is the work of art, whilst in natural rivers a single arch is often preferable, because in the latter we wish to increase the magnitude of the bridge, whilst in the former we endeavour to give importance to the artificial river.

Another instance of the necessity of attending to comparative scale occurred near the metropolis, where a gentleman wished to purchase a distant field for the purpose of planting out a tile-kiln, but I convinced him that during the life of man the nuisance could never be hid from his windows by planting near the kiln, whilst a few trees, judiciously placed within his own ground, would effect the purpose the year after they were planted.

The art of landscape gardening is in no instance more intimately connected with that of painting than in whatever relates to perspective, or the difference between the real and apparent magnitude of the objects, arising from their relative situations; for without some attention to perspective, both the dimensions and the distances of objects will be changed and confounded. Few instances having occurred to me where this can be more forcibly elucidated than in the ground at the fort near Bristol, I shall avail myself of the following observations to shew what can and what cannot be done by a judicious application of the laws of perspective.

When I first visited the fort, I found it surrounded by vast chasms in the ground, and immense heaps of earth and broken rock: these had been made to form the cellars and foundations to certain additions to the city of Bristol, which were afterwards relinquished. The first idea that presented itself was to restore the ground 
to its original shape; but a little reflection on the character and situation of the place naturally led me to inquire whether some considerable advantage might not be derived from the mischief which had thus been already done.

Few situations command so varied, so rich, and so extensive a view as the fort. Situated on the summit of a hill which looks over the vast city of Bristol, it formerly surveyed the river and the beautiful country surrounding it without being incommoded by too much view of the city itself; but the late prodigious increase of buildings had so injured the prospect of this house

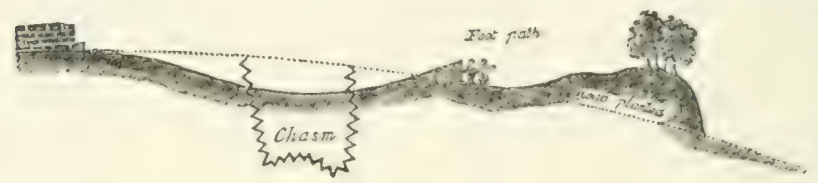

Fig. 5.

that its original advantages of situation were almost destroyed, and there was some reason to doubt whether it could ever be made desirable either as a villa or as a country residence, because it was not only exposed to the unsightly rows of houses in Park Street and Berkeley Square, but it was liable to be overlooked by the numerous crowds of people who claimed a right of footpath through the park immediately before the windows. It was, therefore, as public as any house in any square or street of Bristol. If the earth had been simply put back to the places from whence it had been taken, the expense of its removal would have been greater than the method which occurred to me as more advisable; viz. to fill up the chasms partly, by levelling the sides into them, and raising a bank with a wall to exclude the footpath, as shewn in the accompanying section [Fig. 5], 
where the dotted line shews the original shape of the ground; the zigzag line, holes from fifteen to twenty feet deep; the shaded line, the shape of the ground as altered.

By this expedient we hide the objectionable part of the view, and by planting the raised heap of earth we produce a degree of privacy and seclusion in this newly created valley within the pleasure-grounds which was never before known or expected in this open situation. The pleasure-ground, immediately near the house, is separated from the park by a wall, against which the earth is everywhere laid as before described, so as to carry the eye over the heads of persons who may be walking in the adjoining footpath. This wall not only hides them from the house, but also prevents their overlooking the pleasure-ground. Yet, notwithstanding this great utility, this absolute necessity, the appearance of such a wall, from the park, gives an air of confinement, and the only expedient by which this might be well remedied would be a total change in the character of the place, or, rather, by altering the house to make it what its name and situation denote: for if the fort were restored to its original character of a castle or fortress, this wall, instead of being objectionable, would then act as a terrace, and contribute to the general effect of extent and the magnificence of the whole.

Although, from the nature of this work, it is difficult to preserve any connecting series of arrangement, yet it may not be improper, in this place, to mention a few remarkable instances of removing earth and altering the shape of the surface of ground, especially as there is no part of my profession attended with so much expense, or more frequently objected to, because so often mismanaged. 
Where a ridge of ground very near the eye intercepts the view of a valley below, it is wonderful how great an effect may be produced by a very trifling removal of the ridge only; thus, at Moccas Court, a very small quantity of earth concealed from the house the view of that beautiful reach of the River Wye, which has since been opened. At Oldbury Court the view is opened into a romantic glen by the same kind of operation. At Catchfrench the same thing is advised, to shew the opposite hills; and in this instance it may appear surprising that the removal of a few yards of earth was sufficient to display a vast extent of distant prospect.

But this effect must depend on the natural shape of the surface near the eye; for example, if the shape be that of the upper line $A[$ Fig. 6], the object at F can-

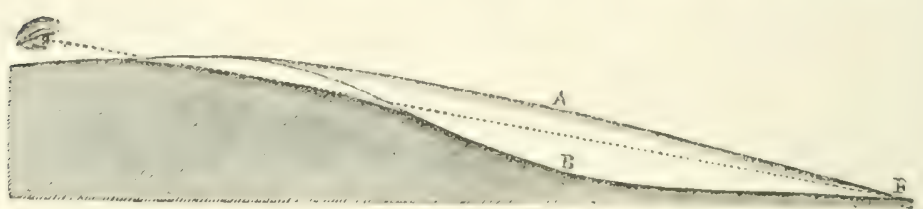

Fig. 6.

not be seen without the removal of all the earth between the dotted line and the surface, but if the shape be that of $\mathrm{B}$, the removal of the part not shaded will not be sufficient to shew the valley; and it is not always desirable to see the whole surface; on the contrary, it is better that a part should be concealed than that the whole should be shewn foreshortened, which is always the case in looking down or up an inclined plane.

The most arduous operations of removing ground are generally those where the geometric taste of garden- 
ing had distorted the natural surface, and where it would now be attended with much greater trouble and expense to restore the ground to its original shape than had been formerly dedicated to make those slopes and regular forms, which are more like the works of a military engineer than of a painter or a gardener.

Few instances have occurred to me where great expense in moving ground was requisite to produce pleasing effects, and it is always with reluctance that I advise much alteration in the surface of ground, because, however great the labour or expensive the process, it is a part of the art from which the professor can derive but littie credit, since his greatest praise must be that the ground looks, when finished, as if art had never interfered.

When I was first consulted, at Sundridge Park, by Mr. Lind, the former possessor, the house, which has since been pulled down, stood on the south side of the valley; and those who knew the spot despaired of finding a situation for a house on the opposite side of the valley, that the rooms might have a southern aspect, as the bank was too steep to admit of any building. My much respected friend, the present possessor, was aware of this circumstance, and by art we have produced a situation which nature denied. The earth was lowered thirty feet perpendicularly, at the spot on which the house was built, and so disposed at the foot of the hill that no trace of artificial management is now to be discovered.

Among the greatest examples of removing ground may be mentioned the work going on at Bulstrode, under the direction of His Grace the Duke of Portland himself; whose good taste will not suffer any part of that beautiful park to be disguised by the misjudging 
taste of former times, and who, by opening the valleys and taking away a great depth of earth from the stems of the largest trees, which had been formerly buried, is, by degrees, restoring the surface of the ground to its original and natural shape.

As connected with the subject of moving ground, I shall extract from my Red Book of Wentworth the following observations concerning the great work at that place which had so long been carrying on under the direction of the late Marquis of Rockingham.

Of the view from the portico at Wentworth House [Figs. 7 and 8 ], my opinion is so contrary to that of

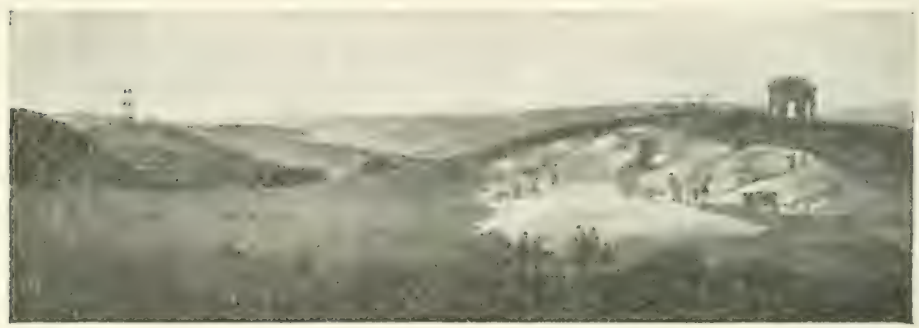

Fig. 7. View from Wentworth House, before it was improved, and while the improvements were going forward.

many others who have adrised a farther removal of the hill that I hope it will not be improper to state very fully the reasons on which I ground this opinion, viz. that so far from such an operation being equivalent to the trouble by which it must be executed, I would not advise its removal, if it could be much more easily effected, because -

I. The outline of the horizon beyond this hill is almost a straight line, and would be very offensive when shewn over another straight line parallel to it.

2. The view of the valley beyond, however rich in itself, is too motley to form a part of the proper 
landscape from such a palace as Wentworth House, although, from many situations in the park, it is a very interesting feature.

3. The vast plain, which has with so much difficulty been obtained in front of the house, is exactly proportionate to the extent of the edifice, and tends to impress the ideas of magnificence which so great a work of art is calculated to inspire. Such a plain forms an ample base for the noble structure which graces its extremity; the building and the plain are evidently made for each other, and, consequently, to increase the dimensions of either seems unnecessary.

The foregoing reasons relate to the hill as considered from the house only; I shall now consider it in other points of view.

Wentworth Park consists of parts, in themselves truly great and magnificent. The woods, the lawns, the water, and the buildings are all separately striking; but, considered as a whole, there is a want of connexion and harmony in the composition, because parts, in themselves large, if disjoined, lose their importance. This, I am convinced, is the effect of too great an expanse of unclothed lawn, but when the young trees shall have thrown a mantle over this extensive knoll, all the distant parts will assume one general harmony, and the scattered masses of this splendid scenery will be connected and brought together into one vast and magnificent whole.

The use of a plantation on this hill, in the approach from Rotherham, is evident, from the effect of a small clump which will form a part of this great mass, and which now hides the house, till, by the judicious bend round that angle, the whole building bursts at once upon the view. 
It can readily be conceived that before the old stables were removed there might appear some reason for not planting this hill; not because it was too near the front, but because the view, thus bounded by a wood on one side, and the large pile of old stables on the other, would be too confined. That objection is removed with the stables, and now a wood on this hill will form a foreground, and lead the eye to each of those scenes, which are too wide apart ever to be considered as one landscape. In the adjoining sketch [Fig. 8] I have endeavoured to shew the effect of planting

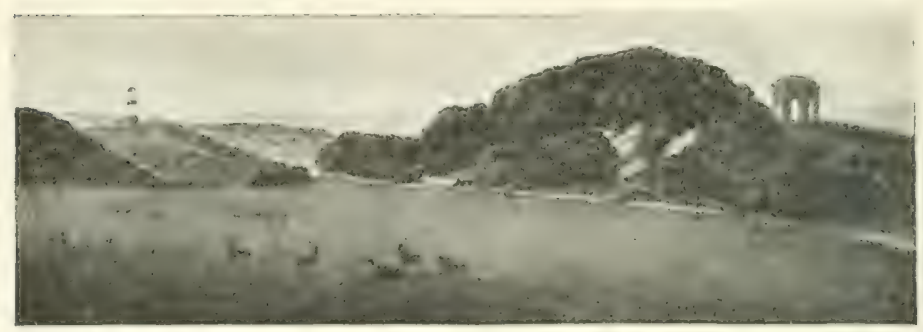

Fig. 8. View from Wentworth House, shewing the effect intended to be produced by the proposed alterations.

this hill, leaving part of the rock to break out among the trees. In a line of such extent, and where the angle nearest the house will be rather acute, it may be necessary to hide part and to soften off the corner of the plantation by a few scattered single trees, in the manner I have attempted to represent.

Among the future uses of the hill plantation, it may be mentioned that the shape which the ground most naturally seems to direct, for the outline of this wood, is such as will hereafter give opportunity to form the most interesting walk that imagination can suggest; because, from a large crescent of wood, on a knoll, the 
views must be continually varying; while, by a judicious management of the small openings, and the proper direction of the walks, the scenery in the park will be shewn under different circumstances of foreground, with increased beauty. 


\section{Chapter II}

Ground apparently altered by the Situation of the Spectator-Reflections from the Surface of W W ater. explained and applied - Different Effects of Light on Different Objects

7 HE field of vision, or the portion of landscape 1 which the eye will comprehend, is a circumstance frequently mistaken in fixing the situation for a house; since a view seen from the windows of an apartment will materially differ from the same view seen in the open air. In one case, without moving the head, we see from sixty to ninety degrees, or, by a single motion of the head, without moving the body, we may see every object within one hundred and eighty degrees of vision. In the other case the portion of landscape will be much less, and must depend on the size of the window, the thickness of the walls, and the distance of the spectator from the aperture. Hence it arises that persons are frequently disappointed, after building a house, to find that those objects which they expected would form the leading features of their landscape are scarcely seen, exccpt from such a situation in the room as may be inconvenient to the spectator; or, otherwise, the object is shewn in an oblique and unfavouraple point of view. This will be more clearly explained by the following diagram [Fig. 9].

It is evident that a spectator at A can only see, through an aperture of four feet, those objects which fall within 
the opening $\mathrm{B} \mathrm{c}$, in one direction, and $\mathrm{I} \mathrm{E}$ in the other, neither comprehending more than twenty or thirty degrees. But if he removes to $a$ near the windows, he will then see all the objects, within the angle $\mathrm{F} \mathrm{G}$, in one direction, or $\mathrm{H} \mathrm{I}$ in the other; yet it is obvious that, even from these spots, that part of the landscape which lies

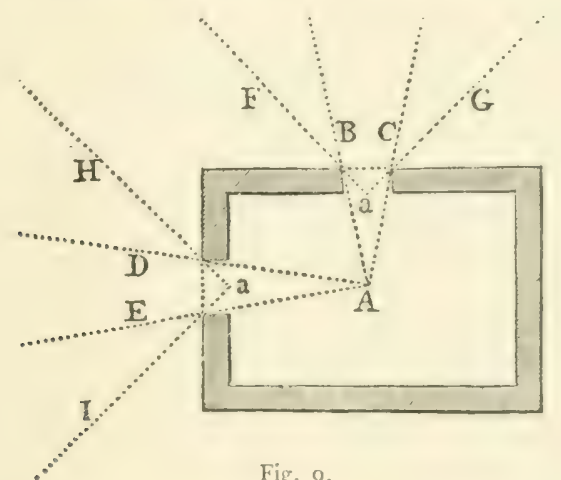

betwixt the extreme lines of vision $\mathrm{F}$ and $\mathrm{H}$ will be invisible, or at least seen with difficulty, by placing the eye much nearer to the window than is always convenient.

From hence it follows that, to obtain so much of a view as may be expected, "it it is not sufficient to have a cross-light, or windows, in two sides of the room, at right angles with each other, but there must be one in an oblique direction, which can only be obtained by a bow-window: and although there may be some advantage in making the different views from a house distinct landscapes, yet as the villa requires a more extensive prospect than a constant residence, so the bow-window is peculiarly applicable to the villa. I must acknowledge that its external appearance is not always ornamental, especially as it is often forced upon obscure buildings, where no view is presented, near great towns, 
and oftener is placed like an uncouth excrescence upon the bleak and exposed lodging-houses at a wateringplace; but in the large projecting windows of old Gothic mansions, beauty and grandeur may be united to utility.

The apparent shape of the ground will be altered by the situation of the spectator. This is a subject of much importance to the landscape gardener, although not generally studied.

In hilly countries, where the banks are bold, a road in a valley is always pleasing, because it seems natural, and carries with it the idea of ease and safety; but in a country that is not hilly, we ought rather to shew the little ${ }^{20}$ inequalities of ground to advantage. The difference betwixt viewing ground from the bottom of a valley or the side of a hill will be best explained by the following diagram [Fig. IO], where the rules of perspective again assist the scientific improver.

The spectator at A, in looking up the hill towards c, will lose all the ground that is foreshortened; and every object which rises higher than five feet (i. e. the height of his eye), will present itself above his horizon if the slope is exactly an inclined plane or hanging level; but as the shape of ground here delineated more frequently occurs, he will actually see the sky, and consequently the utmost pitch of the hill beneath the body of the animal placed at $\mathrm{B}$ and part of the thorn at $\mathrm{C}$ become invisible.

This accounts for the highest mountains losing their importance when seen only from the base; while, on the contrary, a plain or level surface (for instance the sea) appears to rise considerably when viewed from an eminence. Let us suppose another spectator to be placed at I) ; it is evident that this person will see no ground 
foreshortened but that below him, while the opposite hill will appear to him far above the head of the man at $A$, and above the cow at $B$. In the section, the dotted lines are the respective horizons of the two spectators,

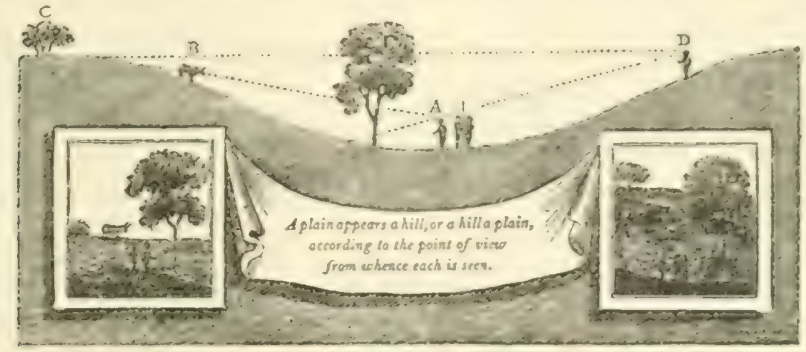

Fig. $x 0$.

and the sketches shew the landscape seen by each, in which the forked tree may serve as a scale to measure the height of each horizon.

The reflections of objects in water are no less dependent on the laws of perspective, or of vision, than the instances already enumerated.

If the water be raised to the level of the ground beyond it, we lose all advantage of reflection from the distant ground or trees: this is the case with pieces of water near the house in many places, for all ponds on high ground present a constant glare of light from the sky; but the trees bevond can never be reflected on the surface, because the angle of incidence and the angle of reflection are always equal, and the surface of the water will always be a perfect horizontal plane. This I shall farther explain by the following lines [Fig. I I].

The spectator at $A$, in looking on the upper water, will see only sky, because the angle of incident, $\mathrm{B}$, and that of reflection, c, being equal, the latter passes over the top of the trees, D, on lower ground: but the same 
spectator, A, in looking on the lower water, will see the trees, E, reflected on its surface, because the line of reflec-

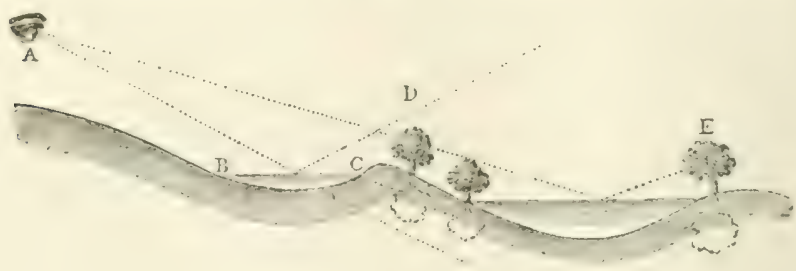

Fig. II .

tion passes through them, and not over them, as in the first instance.

There are other circumstances belonging to reflection on the surface of water which deserve attention, and of which the landscape gardener should avail himself in the exercise of his art. Water in motion, whether agitated by wind or by its natural current, produces little or no reflection; but in artificial rivers, the quiet surface doubles every object on its shores, and for this

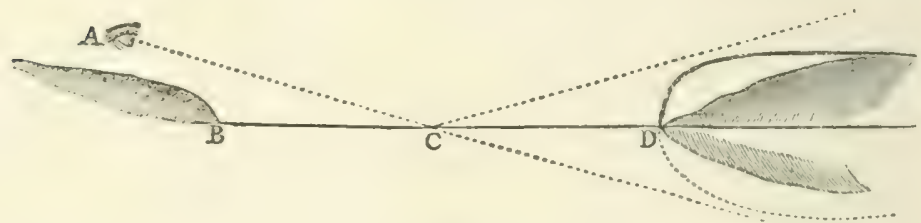

Fig. 12.

reason I have frequently found that the surface could be increased in appearance by sloping its banks: not only that which actually concealed part of the water but also the opposite bank; because it increased the quantity of sky reflected on the surface.

Ixample. The spectator at A [Fig. I 2] sees the sky reflected only from $\mathrm{B}$ to $\mathrm{c}$, while the opposite bank is 


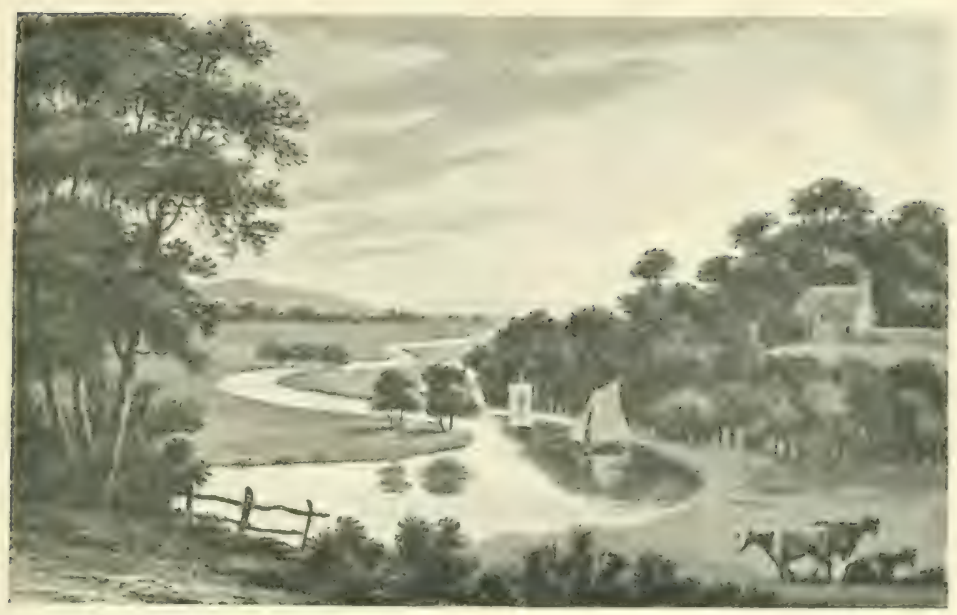

Morning Effect of Light

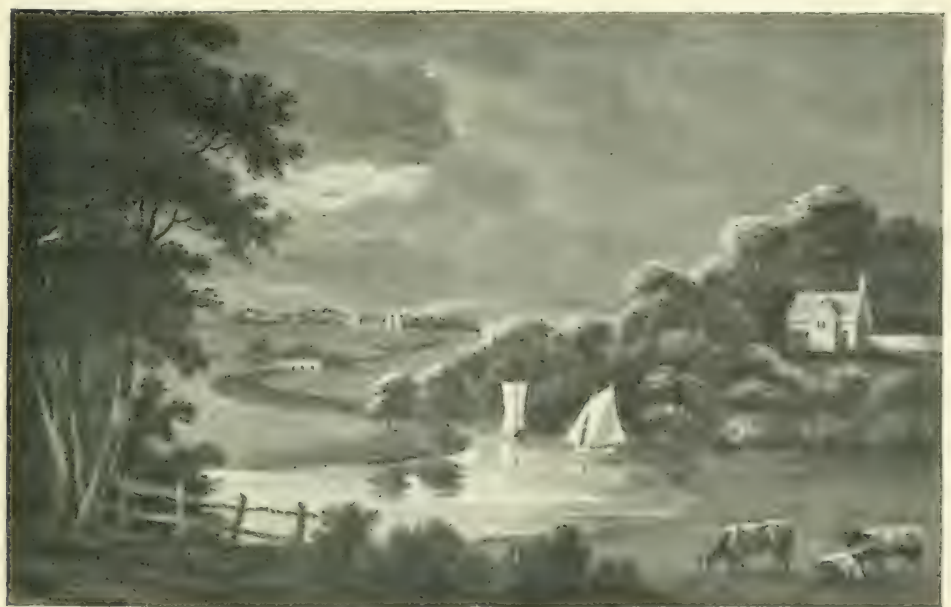

Evening Effect of Light

Plate VII. The Thames, from Purley 

round; but if sloped to the shaded line, less of the bank will be reflected in the water, and the quantity of sky seen in the water will be from 13 to 1 ); and as the brilliancy of still water depends on the sky reflected on its surface, the quantity of water will be apparenty increased.

As properly belonging to this chapter may be mentioned a curious observation which occurred in the view of the Thames from Purley. In the morning [see Plate VII], when the sun was in the east, the landscape appeared to consist of wood, water, and distant country, with few artificial accompaniments; but in the evening, when the sun was in the west, objects presented themselves which were in the morning scarcely visible. In the first instance the wood was in a solemn repose of shade; the water, reflecting a clear sky, was so brilliantly illuminated that I could trace the whole course of the river; the dark trees were strongly contrasted by the vivid green of the meadows, and the outline of distant hills was distinctly marked by the brightness of the atmosphere. I could scarcely distinguish any other objects; but these formed a pleasing landscape, from the breadth or contrast of light and shade.

In the evening [Plate viI] the scene was changed; dark clouds reflected in the water rendered it almost invisible, the opposite hanging wood presented one glare of rich foliage, not so beautiful in the painter's eye as when the top of each tree was relieved by small catching lights: but the most prominent features were the buildings, the boat, the path, the pales, and even the distant town of Reading, now strongly gilded by the opposite sun. [Plate vir.]

On comparing this effect with others which I have 
frequently since observed, I draw this conclusion: that certain objects appear best with the sun behind them, and others with the sun full upon them; and it is rather singular that to the former belong all natural objects, such as woods, trees, lawn, water, and distant mountains, while to the latter belong all artificial objects, such as houses, bridges, roads, boats, arable fields, and distant towns or villages.

In the progress of this work I shall have occasion to call the reader's attention to the principles here assumed, and which, in certain situations, are of great importance and require to be well considered. 


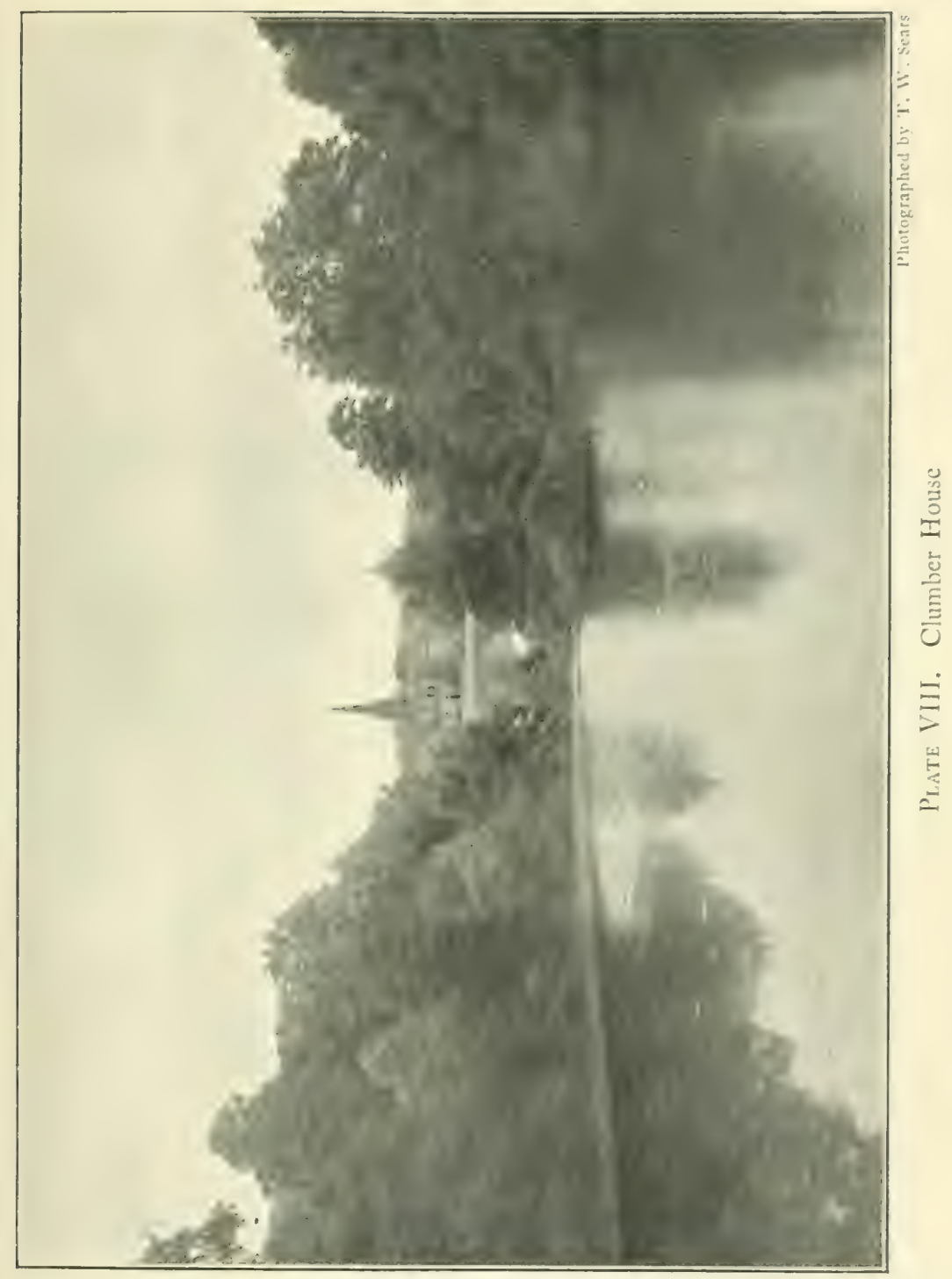





\section{Chapter III}

Water - Its General Treatment - Art must deceive to imitate Nature - Water at Wentworth described - A River easier to imitate than a Lake

$7 \mathrm{HE}$ observations in the preceding chapter concern-

1 ing the reflection of sky on the surface of water will account for that brilliant and cheerful effect produced by a small pool, frequently placed near a house, although in direct violation of nature: for since the ground ought to slope and generally does slope from a house, the water very near it must be on the side of a hill, and of course artificial. Although I have never proposed a piece of water to be made in such a situation, I have frequently advised that small pools so unnaturally placed should be retained, in compliance with that general satisfaction which the eye derives from the glitter of water, however absurd its situation.

It requires a degree of refinement in taste bordering on fastidiousness to remove what is cheerful and pleasing to the eye, merely because it cannot be accounted for by the common laws of nature; I was, however, not sorry to discover some plea for my compliance, by considering that although water on a hill is generally deemed unnatural, yet all rivers derive their sources from hills, and the highest mountains are known to have lakes or pools of water near their summits.

We object, therefore, not so much to the actual situation as to the artificial management of such water. We 
long to break down the mound of earth by which the water is confined, although we might afterwards regret the loss of its cheerful glitter; and hence, perhaps, arises that baldness in artificial pools, so disgusting to the painter and yet so pleasing to the less accurate observer. The latter delights in a broad expanse of light on the smooth surface, reflecting a brilliant sky; the former expects to find that surface ruffled by the winds, or the glare of light in parts obscured by the reflection of trees from the banks of the water; and thus, while the painter requires a picture, the less scientific observer will be satisfied with a mirror.

During a great part of last century West Wycombe was deemed a garden of such finished beauty that to those who formerly remembered the place it will seem absurd to suggest any improvement. But time will equally extend its changing influence to the works of nature and to those of art, since the planter has to contend with a power -

"A hidden power! at once his friend and foe!

' $\mathrm{T}$ is Vegetation! Gradual to his groves

She gives their wished effects, and that displayed,

$\mathrm{O}$ ! that her power would pause ; but, active still,

She swells each stem, prolongs each vagrant bough,

And darts, with unremitting vigour bold,

From grace to wild luxuriance."

MASON.

Thus, at West Wy combe, those trees and shrubs which were once its greatest ornament, have now so far outgrown their situation that the whole character of the place is altered; and instead of that gaiety and cheerfulness inspired by flowering shrubs and young trees, gloom and melancholy seem to have reared their standard in the branches of the tallest elms and to shed their influence on every surrounding object: on the house, by lessen- 
ing its importance; on the water, by darkening its surface; and on the lawn, by lengthened shadows.

The prodigious height of the trees near the house has not merely affected the character, but also the very: situation of the house. Instead of appearing to stand on a dry bank, considerably above the water (as it actually does), the house oppressed by the neighbouring trees became damp, and appeared to have been placed in a gloomy bottom, while the water was hardly visible, from the dark reflection of the trees on its surface, and the views of the distant hills were totally concealed from the house.

It is a fortunate circumstance for the possessor, where improvement can be made rather by cutting down than by planting trees. The effect is instantly produced, and as the change in the scenery at this place has actually been realised before I could make a sketch to explain its necessity, the following drawing serves to record my reason for so boldly advising the use of the axe. I am well aware that my advice may subject me to the criticism of some, who will regret the loss of old trees, which, like old acquaintances, excite a degree of veneration, even when their age and infirmity have rendered them useless, perhaps offensive, to all but their youthful associates. The tedious process of rearing and planting woods and the dreadful havoc too often made by injudiciously felling large trees ought certainly to inspire caution and diffidence; but there is in reality no more temerity in marking the trees to be taken down than those to be planted, and I trust there has not been a single tree displaced at West Wycombe, which has not tended to improve the healthfulness, the magnificence, and the beauty of the place. 
Most of the principal rooms having a north aspect, the landscape requires peculiar management not generally understood. Lawn, wood, and water are always seen to the greatest advantage with the sun behind them, because the full glare of light between opposite trees destroys the contrast of wood and lawn; while water never looks so brilliant and cheerful when reflecting the northern as the southern sky. A view, therefore, to the north would be dull and uninteresting without some artificial objects, such as boats or buildings, or distant corn-fields, to receive the opposite beams of the sun. A sketch shewed the effect of taking down trees to admit the distant woods, and by removing those on the island, and of course their reflection, the water became more conspicuous; in addition, the proposed road of approach, with carriages occasionally passing near the banks of the lake, will give animation to the view from the saloon.

The views of West Wycombe, being taken from the proposed approach, I shall here beg leave to make a short digression, explaining my reasons for that line, founded on some general principles respecting an approach, although it has no other reference to the water than as it justifies its course in passing the house to arrive at its object.

If the display of magnificent or of picturesque scenery in a park be made without ostentation, it can be no more at variance with good taste than the display of superior affluence in the houses, the equipage, the furniture, or the habiliments of wealthy individuals. It will, therefore, I trust, sufficiently justify the line of approach here proposed, to say that it passes through the most interesting parts of the grounds, and will display the scenery of the place to the greatest advantage, 
without making any violent or unnecessary circuit to include objects that do not naturally come within its reach. 'This I deem to be a just and sufficient motive, and an allowable display of property without ostentation.

The former approach to the house was on the south side of the valley, and objectionable for two reasons: Ist, it ascended the hill, and, after passing around the whole of the buildings, it descended to the house, makit appear to stand low; 2d, by going along the side of the hill, little of the park was shewn, although the road actually passed through it, because, on an inclined plane, the ground which either rises on one side or falls on the other, becomes foreshortened and little observed, while the eye is directed to the opposite side of the valley, which in this instance consisted of enclosures beyond the park. On the contrary, the proposed new approach, being on the north side of the valley, will shew the park on the opposite bank to advantage, and, by ascending to the house, it will appear in its true and desirable situation upon a sufficient eminence above the water: yet, backed by still higher ground, richly clothed with wood, this view of the house will also serve to explain and, I hope, to justify the sacrifice of those large trees which have been cut down upon the island, and whose dark shadows, being reflected on the water, excluded all cheerfulness.

The water at West Wycombe, from the brilliancy of its colour, the varieties of its shores, the different courses of its channel, and the number of its wooded islands, possessed a degree of pleasing intricacy which I have rarely seen in artificial pools or rivers; there appears to be only one improvement necessary to give it all the variety of which it is capable. The glassy surface of a still, calm lake, however delightful, is not more 
interesting than the lively brook rippling over a rocky bed, but when the latter is compared with a narrow stagnant creek, it must have a decided preference; and as this advantage might easily be obtained in view of the house, I think it ought not to be neglected.

It may perhaps be objected that to introduce rock scenery in this place would be unnatural; but if this artifice be properly executed, no ere can discover the illusion, and it is only by such deceptions that art can imitate the most pleasing works of nature. By the help of such illusion we may see the interesting struggles of the babbling brook, which soon after

\section{- "spreads}

Into a liquid plain, then stands unmov'd, Pure as the expanse of heaven."

This idea has been realised in the scenery at Adlestrop, where a small pool, very near the house, was supplied by a copious spring of clear water. The cheerful glitter of this little mirror, although on the top of the hill, gave pleasure to those who had never considered how much it lessened the place, by attracting the eye and preventing its range over the lawn and falling ground beyond. This pool has now been removed; a lively stream of water has been led through a flower-garden, where its progress down the hill is occasionally obstructed by ledges of rocks, and after a variety of interesting circumstances it falls into a lake at a considerable distance, but in full view both of the mansion and the parsonage, to each of which it makes a delightful, because a natural, feature in the landscape.

Few persons have seen the formal cascade at Thoresby in front of the house and heard its solemn roar, without wishing to retain a feature which would be one of the 
most interesting scenes in nature, if it could be divested of its disgusting and artificial formality; but this can only be effected by an equally violent, though less apparent, interference of art; because, without absolutely copving any particular scene in nature, we must endeavour to imitate the causes by which she produces her effects, and the effects will be natural.

The general cause of a natural lake or expanse of water is an obstruction to the current of a stream by some ledge or stratum of rock which it cannot penetrate; but as soon as the water has risen to the surface of this rock, it tumbles over with great fury, wearing itself a channel among the craggy fragments, and generally forming an ample basin at its foot. Such is the scenery we must attempt to imitate at Thoresby.

Having condemned the ill-judged interference of art in the disposition of the ground and water at Thoresby, it may, perhaps, be objected, that I now recommend an artificial management not less extravagant, because I presume to introduce some appearance of rock scenery in a soil where no rock naturally exists; but the same objection might be made with equal propriety to the introduction of an artificial lake in a scene where no lake before existed. When under the guidance of Le Nôtre and his disciples, the taste for geometric gardening prevailed, nature was totally banished or concealed by the works of art. Now, in defining the shape of land or water, we take nature for our model; and the highest perfection of landscape gardening is to imitate nature so judiciously that the interference of art shall never be detected.

A rapid stream, violently agitated, is one of the most interesting objects in nature. Yet this can seldom be enjoyed except in a rocky country; since the more im- 
petuous the stream, the sooner will it be buried within its banks, unless they are of such materials as can resist its fury. To imitate this natural effect, therefore, in a soil like that of Thoresby, we must either force the stream above its level and deprive it of natural motion, or introduce a foundation of stones disposed in such a manner as to appear the rocky channel of the mountain stream. The former has been already done in forming the lake, and the latter has been attempted, according to the fashion of geometric gardening, in the regular cascade, where a great body of water was led underground from the lake to move downstairs, into a scalloped basin, between two bridges immediately in front of the house.

The violence done to nature by the introduction of rock scenery at Thoresby is the more allowable, since it is within a short distance of Derbyshire, the most romantic county in England; while, from the awful and picturesque scenery of Creswell Crags, such strata and ledges of stone, covered with their natural vegetation, may be transported thither, that no eye can discover the fraud.

It is scarcely possible for any admirer of nature to be more enthusiastically fond of her romantic scenery than myself; but her wildest features are seldom within the common range of man's habitation. The rugged paths of alpine regions will not be daily trodden by the foot of affluence, nor will the thundering cataracts of Niagara seduce the votaries of pleasure frequently to visit their wonders; it is only by a pleasing illusion that we can avail ourselves of those means which nature herself furnishes, even in tame scenery, to imitate her bolder effects; and to this illusion, if well conducted, the eye of genuine taste will not refuse its assent. 
"La Nature fuit les lieux fréquentés; c'est au sommet des montagnes, au fond des forêts, dans les isles désertes, qu'elle étale ses charmes les plus touchants; ceux qui l'aiment et ne peuvent l'aller chercher si loin, sont réduits à lui faire violence, et à la forcer en quelque sorte à venir habiter parmi eux, et tout cela ne peut se faire sans un peu d'illusion." - J. J. Rousseau.

[Nature files from frequented places; it is on the summit of mountains, in the depths of forests, and in desert islands that she displays her most affecting charms; those who love her, and who cannot go so far in search of her, are reduced to the necessity of constraining her, and forcing her to take up her habitation among them; but this cannot be done without a certain degree of illusion.]

One of the views from the house at Thoresby looked towards

" the long line

Deep delv'd of flat canal, and all that toil,

Misled by tasteless fashion, could achieve,

To mar fair Nature's lineaments divine."

MASON.

As, in this instance, I shall have occasion to propose a different idea to that suggested by Mr. Brown, I must beg leave to explain the reasons on which I ground $m y$ opinion.

Amidst the numerous proofs of taste and judgement which that celebrated landscape gardener has left for our admiration, he frequently mistook the character of running water; he was too apt to check its progress, by converting a lively river into a stagnant pool, nay, he even dared to check the progress of the furious Derwent at Chatsworth, and transform it into a tame and sleepy river unworthy the majesty 
of that palace of the mountains. Such was his intention with respect to the stream of water which flows through Thoresby Park; but since the lake presents a magnificent expanse of water, the river below the cascade should be restored to its natural character: a rivulet in motion.

At Wentworth, although the quantity of water is very considerable, yet it is so disposed as to be little seen from the present approach, and when it is crossed in the drive on the head between two pools, the artificial management destroys much of its effect: they appear to be several distinct ponds, and not the series of lakes which nature produces in a mountainous country. But the character of this water should rather imitate one large river than several small lakes; especially as it is much easier to produce the appearance of continuity than of such vast expanse as a lake requires. The following sketch [Plate $I x]$ is a view of the scenery presenting itself under the branches of trees, which act as a frame to the landscape.

To preserve the idea of a river, nothing is so effectual as a bridge; instead of dividing the water on each side, it always tends to lengthen its continuity by shewing the impossibility of crossing it by any other means, provided the ends are well concealed, which is fortunately the case with respect to this water. Although the upper side of the bridge would be very little seen, because the banks are everywhere planted, yet, as the bridge would not be more than fifty yards long, it would be more in character with the greatness of the place to have such a bridge as would nowhere appear a deception, and in this case the different levels of the water (being only five feet) would never he discovered. 


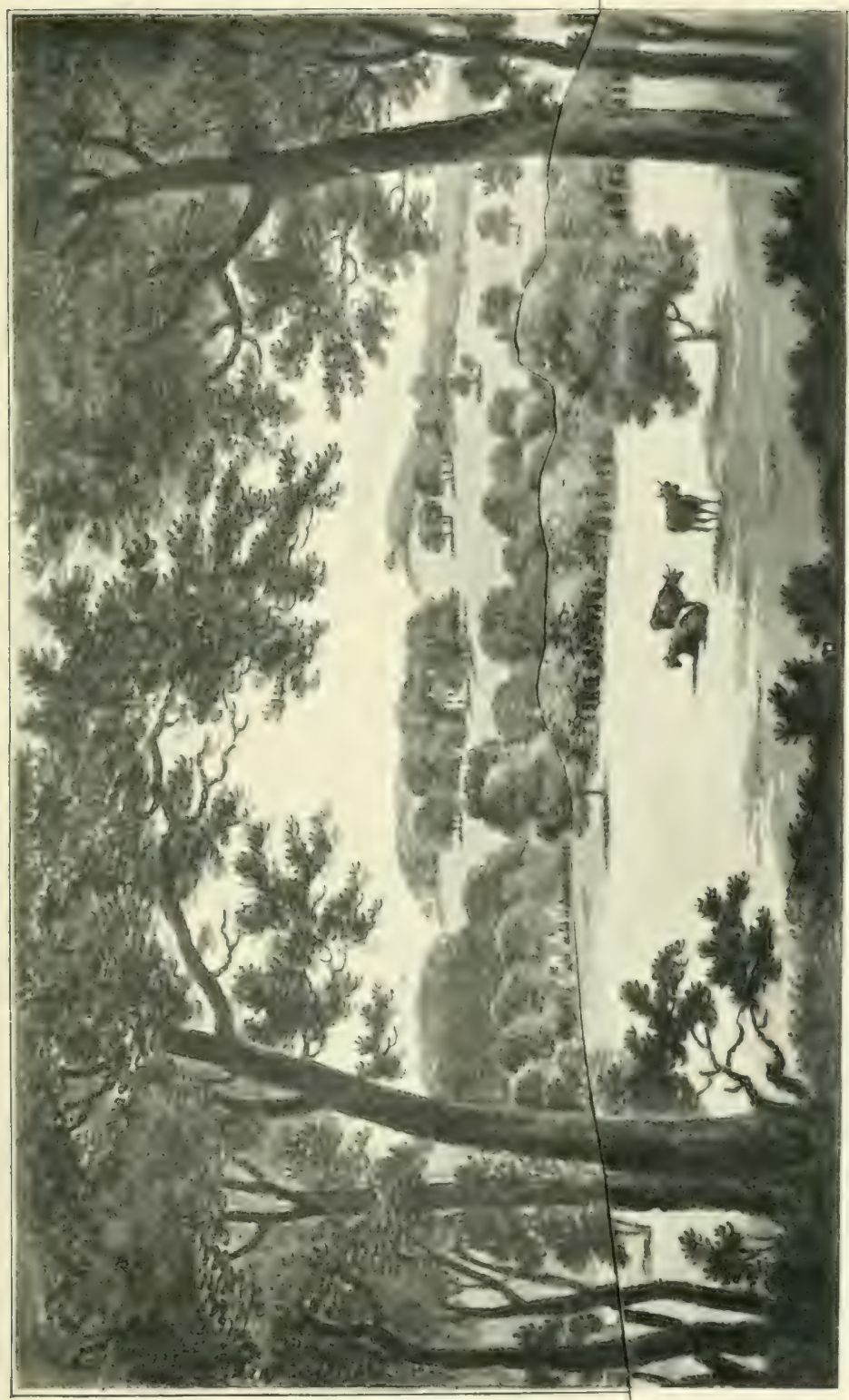



The rippling motion of water is a circumstance to which improvers have seldom paid sufficient attention. They generally aim at a broad expanse and depth, not considering that a narrow shallow brook in motion over a gravelly bottom is not less an object of beauty and worthy of imitation; the deep dell betwixt the boathouse and the bridge might be rendered very interesting by bringing a lively brook along the valley; the embouchure of this brook should be laid with gravel, to induce cattle to form themselves in groups at the edge of the water, which is one of the most pleasing circumstances of natural landscape. It sometimes happens, near large rivers, that a clear spring bubbles from a fountain, and pours its waters rapidly into the neighbouring stream; this is always considered a delightful object in nature, yet I do not recollect it has ever been imitated by art. It would be very easy to produce it in this instance by leading water in a channel from the upper pool, and after passing underground by tubes for a few yards, let it suddenly burst through a bed of sand and stones, and being thus filtered by ascent, it would ripple along the valley till it joined the great water. Milton was aware of this contrast betwixt the river and the rill, where he mentions, amongst the scenery of his Allegro,

"Shallow brooks and rivers wide."

Where two pieces of water are at some distance from each other, and of such different levels that they cannot easily be made to unite in one sheet, if there be a sufficient supply to furnish a continual stream, or only an occasional redundance in winter, the most picturesque mode of uniting the two is by imitating a common process of nature in mountainous countries, 


\section{IO2 The Art of Landscape Gardening}

where we often see the water, in its progress from one lake to another, dashing among broken fragments or gently gliding over ledges of rock which form the bottom of the channel. This may be accomplished at Harewood, where the most beautiful stone is easily procured, but in disposing the ledges of rock, they should not be laid horizontally, but with the same slanting inclination that is observed, more or less, in the bed of the neighbouring river. 


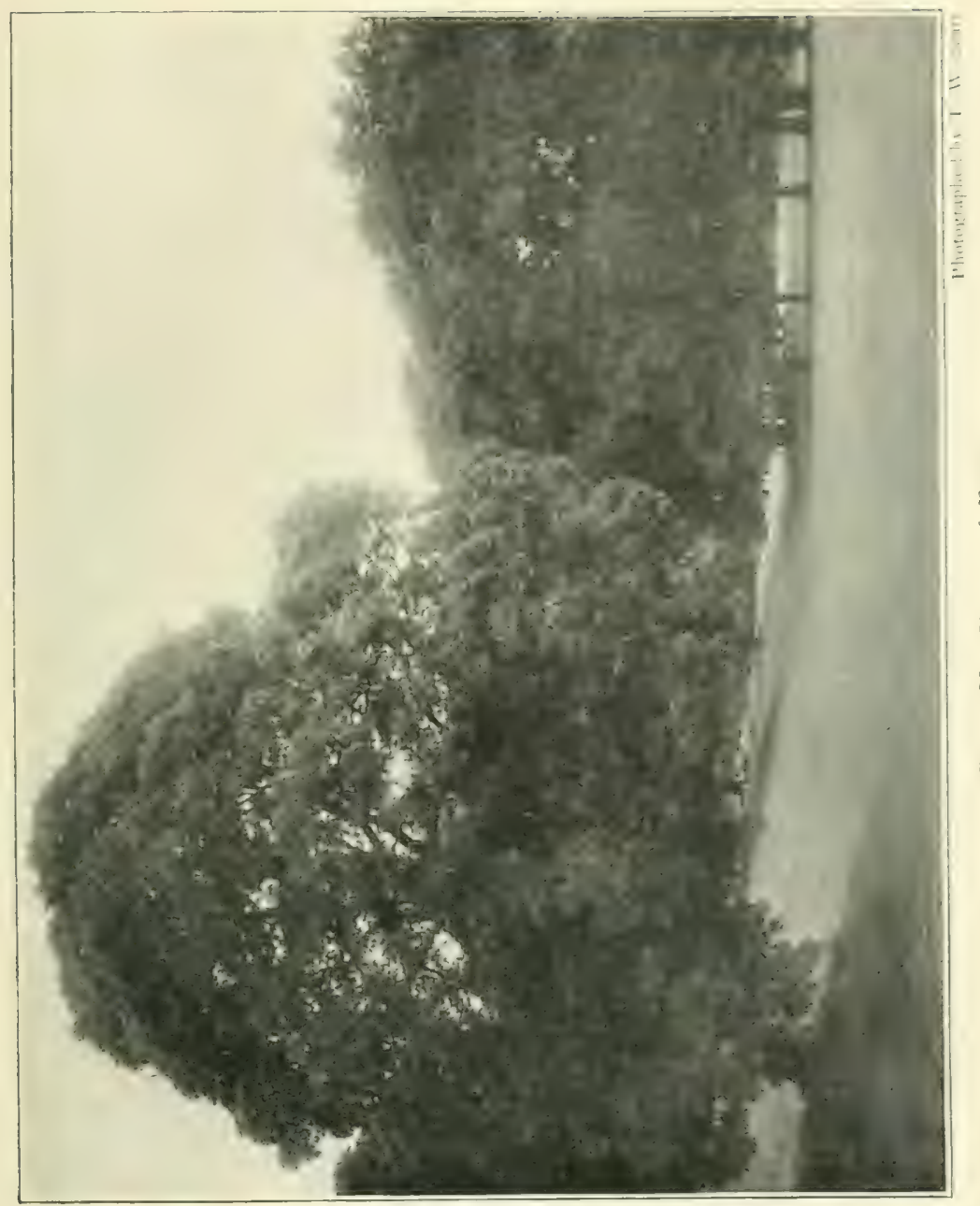

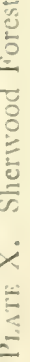





\section{Chapter IV}

Planting - Immediate and Future Effect - Clumps Groups - Masses - The Browsing-Line described-Combination of Masses to produce Great Woods - Character and Shape of Ground to be studied - Outline of New Plantations

THE following observations on planting are not 1 intended to pursue the minute detail so copiously and scientifically described in Evelyn's "Sylva," and so frequently quoted, or rather repeated from him, in modern publications; I shall merely consider it as a relative subject : and being one of the chief ornaments in landscape gardening when skilfully appropriated, I shall divide it into two distinct heads : the first including those single trees or groups which may be planted of a larger size to produce present effect; the second comprehending those masses of plantations destined to become woods or groves for future generations.

Since few of the practical followers of Mr. Brown possessed that force of genius which rendered him, according to Mason,

\section{Great Nature,"}

" the living leader of thy powers,

it is nowonder that they should have occasionally copied the means he used, without considering the effect which he intended to produce. Thus Brown has been treated with ridicule by the contemptuous observation that all his improvements consisted in belting, clumping, and 
dotting. But I conceive the two latter ought rather to be considered as cause and effect than as two distinct ideas of improvement, for the disagreeable and artificial appearance of young trees, when protected by what is called a cradle fence, together with the difficulty of making them grow thus exposed to the wind, induced Mr. Brown to form small clumps fenced round, containing a number of trees calculated to shelter each other and to promote the growth of those few which might be ultimately destined to remain and form a group. This I apprehend was the origin and intention of those clumps, and that they never were designed as ornaments in themselves, but as the most efficacious and least disgusting manner of producing single trees and groups to vary the surface of a lawn, and break its uniformity by light and shadow.

In some situations, where great masses of wood and a large expanse of open lawn prevail, the contrast is too violent, and the mind becomes dissatisfied by the want of unity. We are never well pleased with a composition in natural landscape, unless the wood and lawn are so blended that the eye cannot trace the precise limits of either, yet it is necessary that each should preserve its original character in broad masses of light and shadow; for although a large wood may be occasionally relieved by clearing small openings to break the heaviness of the mass, or vary the formality of its outline, yet the general character of shade must not be destroyed.

In like manner the too great expanse of light on a lawn must be broken and diversified by occasional shadow, but if too many trees be introduced for this purpose, the effect becomes frittered, and the eye is offended by a deficiency of composition, or, as the painter would express it, of a due breadth of light and 
shade. Now it is obvious that, in newly formed places, such a redundance of trees will generally remain from former hedge-rows that there can seldom be occasion to increase the number of single trees, though it will often be advisable to combine them into proper groups.

It is a mistaken idea, scarcely worthy of notice, that the beauty of a group of trees consists in odd numbers, such as five, seven, or nine; a conceit which I have known to be seriously asserted. I should rather pronounce that no group of trees can be natural in which the plants are studiously placed at equal distances, how-

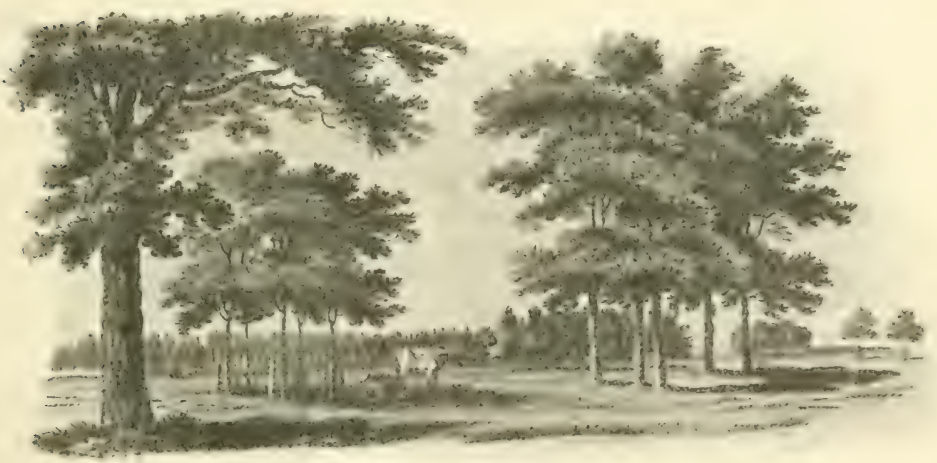

Fig. 13. Artificial Scenery.

ever irregular in their forms. Those pleasing combinations of trees which we admire in forest scenery will often be found to consist of forked trees, or at least of trees placed so near each other that the branches intermix, and by a natural effort of vegetation the stems of the trees themselves are forced from that perpendicular direction which is always observable in trees planted at regular distances from each other. No groups will therefore appear natural unless two or more trees are planted very near each other, ${ }^{2 s}$ whilst the perfection of a group consists 
io6 The Art of Landscape Gardening

in the combination of trees of different age, size, and character.

The two sketches annexed exemplify this remark; the first [Iig. I 3] represents a few young trees protected

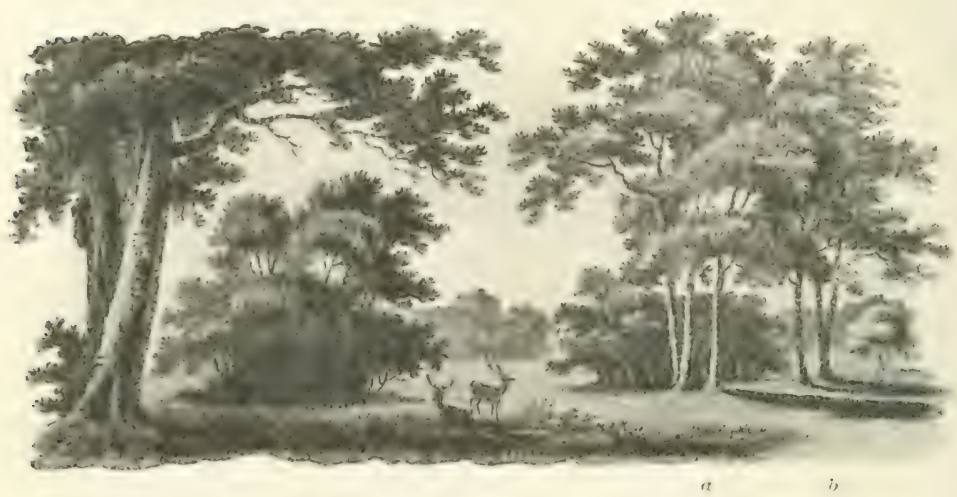

Fig. 14. Natural Scenery.

by cradles, and though some of them appear nearer together than others, it arises from their being seen in perspective, for I suppose them to be planted (as they usually are) at nearly equal distances. In the same landscape I have supposed the same trees grown to a considerable size, but from their equi-distance the stems are all parallel to each other, and not like the group in Fig. 14, where being planted much nearer, the trees naturally recede from each other. A few low bushes or thorns produce the kind of group in the second sketch [Fig. 14], consisting of trees and bushes of various growth. It may be observed that the single tree, and every part of the first sketch, is evidently artificial, and that the second one is natural, and like the groups in a forest.

Another source of variety may be produced by such opaque masses of spinous plants as protect themselves from cattle; thus stems of trees seen agzinst lawn or water 
are comparatively dark, while those contrasted with a background of wood appear light. This difference is shewn in both these sketches: the stems of the trees $a$ appear light, and those at $b b$ are dark, merely from the power of contrast, although both are exposed to the same degree of light.

Where a large tract of waste heath or common is near the boundary of a park, if it cannot be enclosed, it is usual to dot certain small patches of trees upon it, with an idea of improvement; a few clumps of miserable Scotch firs, surrounded by a mud wall, are scattered over a great plain, which the modern improver calls " clumping the common." It is thus that Hounslow Heath has been clumped; and even the vast range of country formerly the Forest of Sherwood has submitted to this meagre kind of misnamed ornament.

It may appear unaccountable that these examples, which have not the least beauty either of nature or art to recommend them, should be so generally followed; but alteration is frequently mistaken for improvement, and two or three clumps of trees, however bad in themselves, will change the plain surface of a flat common. 'This I suppose has been the cause of planting some spruce firs on Maiden Early Common, which fortunately do not grow; for if they succeeded, the contrast is so violent between the wild surface of a heathand the spruce appearance of firs that they would be misplaced: besides, the spiral firs are seldom beautiful, except when their lower branches sweep upon the ground, and this could never be the case with those exposed to cattle on a common.

A far better method of planting waste land, where enclosures are not permitted, has been adopted with great success in Norfolk, by my much valued friend the late 
Robert Marsham, Lisq., of Stratton. Instead of firs surrounded by a mud bank, he placed deciduous trees of every kind, but especially birch, intermixed with thorns, crabs, and old hollies, cutting off their heads and all their branches about eight feet from the ground: these are planted in a puddle and the earth laid round their roots in small hillocks, which prevent the cattle from standing very near to rub them; and thus I have seen groups of trees which looked like bare poles the first year, in a very short time become beautiful ornaments to a dreary waste.

Mr. Gilpin, in his "Forest Scenery," has given some specimens of the outlines of a wood, one of which is not unlike that beautiful screen which bounds the park to the north of Milton Abbey, and which the first of the annexed sketches [Plate xI] more accurately represents. We have here a very pleasing and varied line formed by the tops of trees, but, from the distance at which they are viewed, they seem to stand on one straight base-line, although many of the trees are separated from the others by a considerable distance: the upper outline of this screen is so happily varied that the eye is not offended by the straight line at its base. But there is another line which is apt to create disgust in flat situations, and for this reason - all trees unprotected from cattle will be stripped of their foliage to a certain height, and where the surface of the ground is perfectly flat and forms one straight line, the stems of trees thus brought to view by the browsing of cattle will present another straight line parallel to the ground, at about six feet high, which I shall call the browsing-line.

Whether trees be planted near the eye or at a distance from it, and whether they be very young plants or of the 


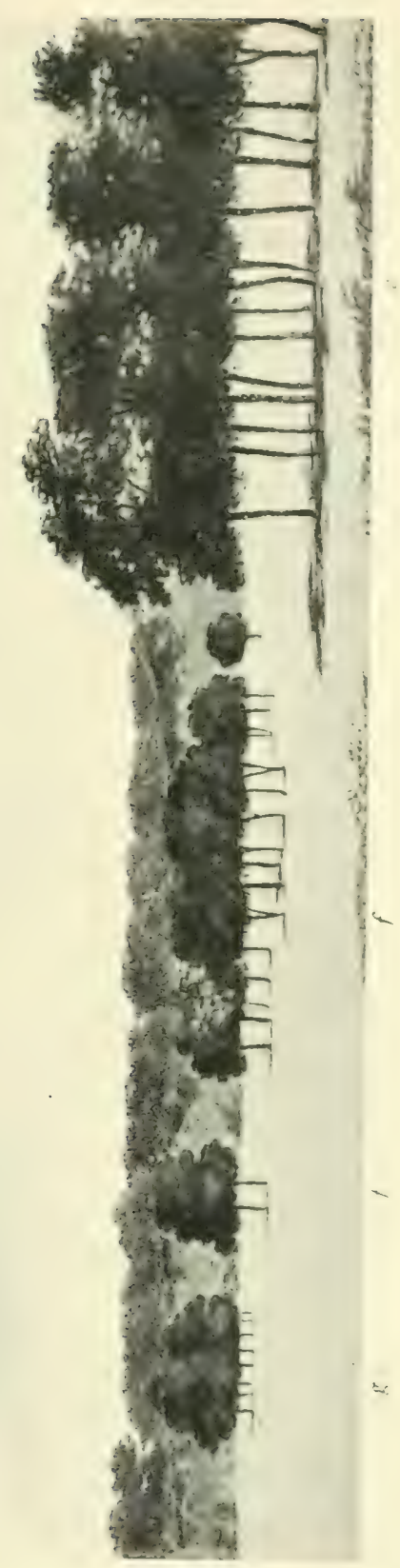




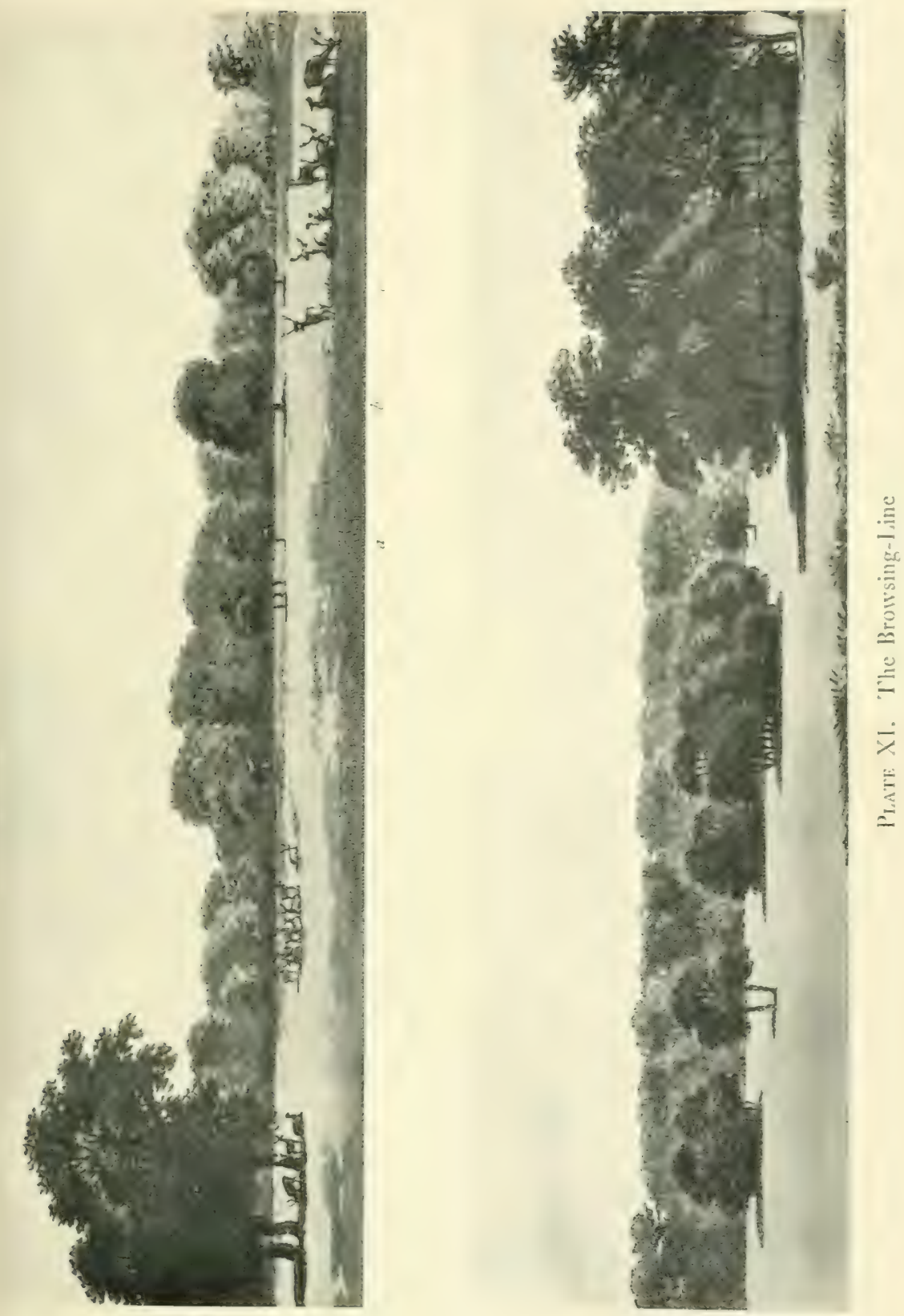

greatest stature, this browsing-line will always be parallel to the surface of the ground, and being just above the eye, if the heads of single trees do not rise above the outline of more distant woods, the stems will appear only like stakes of different sizes scattered about the plain; this is evidently the effect of those single thorns or trees in the sketch [Plate XI] marked $a, b, c$.

In the sketches [Plate $\mathrm{XI}$ ] I have represented a view of that long screen at Milton Abbey which shuts out Castor field, and which is certainly not a pleasing feature, from its presenting not only a straight line at the bottom, but the trees being all of the same age, the top outline is also straight. Thisscreen forms the background of a view taken from the approach, and represents the difference between an attempt to break the uniformity of the plain by open or by close plantations.

The trees of this screen are of such a height that we can hardly expect, in the life of man, to break the upper outline by any young trees, except they are planted very near the eye, as at $e$, because those planted at $f$ or $g$ [in the same figure] will, by the laws of perspective, sink beneath the outline of the screen; it is therefore not in our power to vary the upper line, and if the plantations be open the browsing-line will make a disagreeable parallel with the even surface of the ground; this can only be remedied by preventing cattle from browsing the underwood, which should always be encouraged in such situations; thus, although we cannot vary the upper line of this screen, we may give such variety to its base as will, in some measure, counteract the flatness of its appearance.

The browsing-line being always at nearly the same distance of about six feet from the ground, it acts as a scale by which the eye measures the comparative height 
of trees at any distance; for this reason the importance of a large tree may be injured by cutting the lower branches above this usual standard. It is obvious that the foregoing trees [see Iig. I 5] are of different ages,

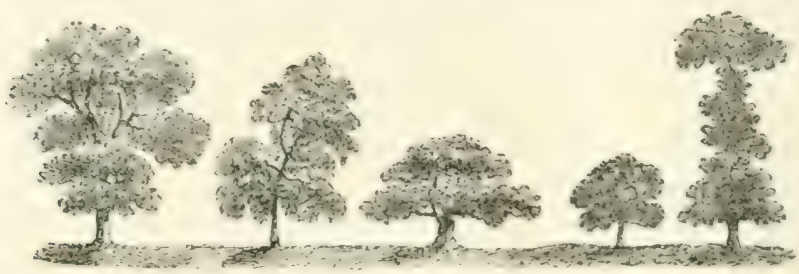

Fig. 15.

characters, and heights, yet the browsing-line is the same in all, and furnishes a natural scale by which we at once decide on their relative heights at various distances.

Let us suppose the same trees pruned or trimmed by man [as in Fig. 16], and not by cattle, and this scale will be destroyed: thus, a full grown oak may be made to look like an orchard-tree, or by encouraging the under branches to grow lower than the usual standard, a thorn

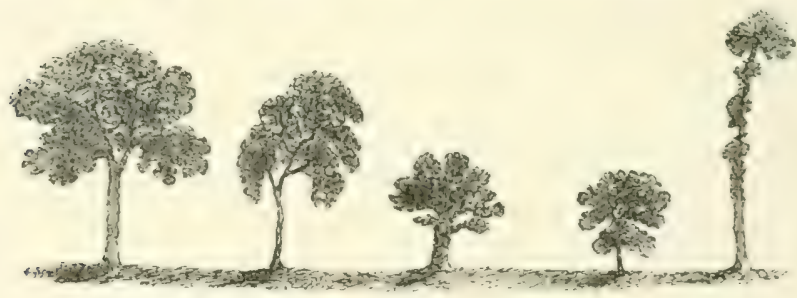

Fig. 16.

or a crab-tree may be mistaken for an oak, at a distance.

Single trees, or open groups, are objects of great beauty when scattered on the side of a steep hill, because they may be made to mark the degree of its declivity, and the shadows of the trees are very conspicuous; but on 
a plain the shadows are little seen, and therefore single trees are of less use.

I am now to speak of plantations for future, rather than for immediate effect, and instead of mentioning large tracts of land which have been planted under my directions, where a naked or a barren country has been clothed without difficulty or contrivance, I shall rather instance a subject requiring peculiar management, especially as, from its vicinity to a highroad, I cannot perhaps produce a better example than the following extract furnishes :

Coombe Lodge, seen from the turnpike road, does not at present give a favourable impression; for though the view from the house, consisting of the opposite banks of Basildon, is richly wooded, the place itself is naked; and it is difficult to remove this objection without sacrificing more land to the purposes of beauty than would be advisable or even justifiable. Both the situation and the outline of the house at Coombe Lodge have been determined with judgement: the situation derives great advantage from its southern aspect and from the views which it commands; and the house derives importance from its extended front. Both these circumstances, however, contribute to the bad opinion conceived of the place when viewed from the road, which is the point from whence its defects are most apparent.

The front towards the road faces the south, and is therefore lighted by thesun during the greatest part of the day; but being backed by lawn and arable land, and not relieved by wood, the effect of sunshine is equally strong on the background as on the house, because there is not a sufficient opposition of colour to separate these different objects; but if, on the contrary, the house be opposed to 
wood, it will then appear light and conspicuous, the attention being principally directed to the mansion, while the other parts of the scene will be duly subordinate.

It is also proper that the grounds should accord with the size and style of the place, and that the mansion be surrounded by its appropriate appendages. At present the character of the house and that of the place are at variance: the latter is that of a farm, but the character of the house is that of a gentleman's residence, which should be surrounded by pleasure-grounds, wood and lawn; and although great credit is due to those gentlemen who patronise farming by their example as well as by their influence, it would be a reflection on the good taste of the country to suppose that the habitation of the gentleman ought not to be distinguished from that of the farmer, as well in the character of the place as by the size of the house.

I shall not on this occasion enter into a discussion of the difference between a scene in nature and a landscape on the painter's canvas; nor consider the very different means by which the painter and the landscape gardener produce the same effect: I shall merely endeavour to shew how far the same principles would direct the professors of either art in the improvement of Coombe Lodge, and more particularly in the form and character of the wood to the north of the house.

Breadth, which is one of the first principles of painting, would prompt the necessity of planting the whole of the hill behind the house; but the improver, who embellishes the scene for the purposes of general utility and real life, must adopt what is convenient as well as beautiful. The painter, when he studies the perfection of his art, forms a correct picture and takes beauty for his guide. The improver consults the genius of the scene and con- 
nects beauty with those useful supporters, economy and convenience; and as Coombe lodge would not be relieved by one large wood without a great sacrifice of land, the effect must be produced by planting a part only, whilst the judgement must be influenced by two principles belonging to the sister art, breadth and intricacy.

Breadth directs the necessity of large masses or continued lines of plantation, whilst intricacy suggests the shape and direction of the glades of lawn, and teaches how to place loose groups of trees and separate masses of brushwood, where the outline might otherwise appear hard; and by occasional interruptions to the flowing lines of grass, with suitable recesses and projections of wood, intricacy contrives to "lead the eye a wanton chase," producing variety without fritter, and continuity without sameness.

There is another principle to guide the improver in planting the hill in question, which may be derived from the art of painting and belongs to perspective. It is evident that if the whole bank were planted its effect would be good from every point of view : it is no less evident that where it is necessary to regard economy in planting, and, as in the present instance, to produce the effect of clothing by several lines of wood, instead of one great mass, that efiect from some points of sight may be good, from some indifferent, and from others bad; it is therefore necessary to consider how those lines of plantation which produce a good effect from the house will appear in perspective from different heights and from different situations, and this question has been determined by various circumstances of the place itself.

This subject was elucidated by as many drawings as there were stations described; but as most of them were taken from the public road between Reading and Wal- 
lingford, the effect of these plantations will be seen from thence; and I have availed myself, as much as possible, of those examples which, from their proximity to a public road, are most likely to be generally observed.

If the more common appearances in naturewere objects of ourimitation we should certainly plant the valleys and not the hills, since nature generally adopts this rule in her spontaneous plantations ; but it is "la belle nature," or those occasional effects of extraordinary beauty, which nature furnishes as models to the landscape gardener. And although a wood on the summit of a bleak hill may not be so profitable, or grow so fast, as one in the sheltered valley, yet its advantages will be strongly felt on the surrounding soil. The verdure will be improved when defended from winds and fertilised by the successive fall of leaves, whilst the cattle will more readily frequent the hills when they are sheltered and protected by sufficient screens of plantations. ${ }^{23}$

In recommending that the hills should be planted, I do not mean that the summits should be covered by a patch or clump; the woods of the valleys should, on the contrary, seem to climb the hills by such connecting lines as may neither appear meagre nor artificial, but, following the natural shapes of the ground, produce an apparent continuity of wood falling down the hills in various directions.

" Rich the robe,

And ample let it flow, that Nature wears

On her thron'd eminence! where'er she takes

Her horizontal march, pursue her step

With sweeping train of forest; hill to hill

Unite with prodigality of shade."

MASON.

During the first few years of large plantations in a naked country, the outline, however graceful, will ap- 
pear hard and artificial; but when the trees begin to require thinning, a few single trees or groups may be brought forward. The precise period at which this may be advisable must depend on the nature of the soil : but so rich is the ground in which plantations were made at Aston, about ten years since, that this management has already been adopted with effect.

Although it will again be repeated in the chapter treating of fences, I must observe in this place that, instead of protecting large plantations with hedges and ditches, I have generally recommended a temporary fence of posts and rails, or hurdles on the outside, and either advise a hedge of thorns to be planted at eight or ten yards distance from the outline, or rather that the whole plantation be so filled with thorns and spinous plants that the cattle may not penetrate far when the temporary fences shall be removed, and thus may be formed that beautiful and irregular outline so much admired in the woods and thickets of a forest. 


\section{Chapter V}

\section{Woods - Intricacy - Variety - 1 Belt - On thonning Woods - Leaving Groups - Opening a Lawn in Great Woods}

BSERVATIONS on Modern Gardening," by the late Mr. Whateley, contain some remarks peculiarly applicable to the improvement of woods, and so clearly expressive of my own sentiments that I beg to introduce the ample quotation inserted in the note, ${ }^{24}$ especially as the annexed drawings [Plate xiI] convey specimens of these rules, which require but little further elucidation.

The beech woods in Buckinghamshire derive more beauty from the unequal and varied surface of the ground on which they are planted than from the surface of the woods themselves; because they have generally more the appearance of copses than of woods: and as few of the trees are suffered to arrive to great size, there is a deficiency of that venerable dignity which a grove always ought to possess.

These woods are evidently considered rather as objects of profit than of picturesque beauty ; and it is a circumstance to be regretted that pecuniary advantage and ornament are seldom strictly compatible with each other. The underwood cannot be protected from cattle without fences, and if the fence be a live hedge the trees lose half their beauty, while they appear confined within the unsightly boundary. To remedy this defect, the quick-fence at Shardeloes has, in many places, been removed, and 
a rail placed at a little distance within the wood; but the distance is so small that the original outline is nearly as distinct as if the fence were still visible, and the regular undulations of those lines give an artificial appearance to the whole scenery.

A painter's landscape depends upon his management of light and shade: if these be too smoothly blended with each other, the picture wants force; if too violently contrasted, it is called hard. The light and shade of natural landscape require no less to be studied than that of painting. The shade of a landscape gardener is wood, and his lights proceed either from a lawn, from water, or from buildings. If on the lawn too many single trees be scattered, the effect becomes frittered, broken, and diffuse; on the contrary, if the general surface of the lawn be too naked, and the outline of the woods form a uniform heavy boundary between the lawn and the horizon, the eye of taste will discover an unpleasing harshness in the composition which no degree of beauty, either in the shape of the ground or in the outline of the woods, can entirely counteract. In this state the natural landscape, like an unfinished picture, will appear to want the last touches of the master; this would be remedied on the canvas, in proportion as the picture became more highly finished; but on the ground it can only be effected by taking away many trees in the front of the wood, leaving some few individually and more distinctly separated from the rest: this will give the finishing touches to the outline, where no other defect is apparent.

The eye, or rather the mind, is never long delighted with that which it surveys without effort at a single glance, and therefore sees without exciting curiosity or interest. It is not the vast extent of lawn, the great expanse of water, or the long range of wood that yields satisfaction; 
for these, if shapeless, or, which is the same thing, if their exact shape, however large, be too apparent, only attract our notice by the space they occupy, "to fill that space with objects of beauty, to delight the eye after it has been struck, to fix the attention where it has been caught, to prolong astonishment into admiration, are purposes not unworthy of the greatest designs."

This can only be effected by intricacy, the due medium between uniformity on the one hand and confusion on the other; which is produced by throwing obstacles in the way to amuse the eye and to retard that celerity of vision, so natural where no impediments occur to break the uniformity of objects. Yet while the hasty progress of the eye is checked, it ought not to be arrested too abruptly. The mind requires a continuity, though not a sameness; and while it is pleased with succession and variety, it is offended by sudden contrast, which destroys the unity of composition.

There is a small clump at в [Plate XII], which is of great use in breaking the outline of the wood beyond it; and there is a dell or scar in the ground at $c$ that may also be planted for the like purpose. It is a very common expedient to mend an outline by adding new plantation in the front of an old one; but although the improver may plant large woods with a view to future ages, yet something appears due to the present day. If by cutting down a few trees in the front of a large wood the shape of its outline may immediately be improved in a better manner than can be expected from a solitary clump a century hence, it is surely a more rational system of improvement than so long to endure a patch, surrounded by an unsightly fence, in the distant hope of effects which the life of man is too short to realise.

There is a part of the wood at I) so narrow as to admit 

the light between the stems of the trees; this naturally suggests the idea of adding new plantation. But the horizon is already uniformly bounded by wood, and the mind is apt to affix the idea of such boundary being the limit of the park as strongly as if the pale itself were visible; on the contrary, the ground falling beyond this part and a range of wood sweeping over the brow of the hill, it is better to clear away some of the trees, to increase the apparent extent of lawn. Instead of destroying the continuity of wood, this will increase its quantity; because the tops of the trees being partly seen over the opening, the imagination will extend the lawn beyond its actual boundary, and represent it as surrounded by the same chain of woods.

I have often heard it asserted, as a general maxim in gardening, that hills should be planted and valleys cleared of wood. This idea perhaps originated and ought only to be implicitly followed in a flat or tame country, where the hills are so low as to require greater height by planting, and the valleys so shallow that trees would hide the neighbouring hills: but whenever the hills are sufficiently bold to admit of ground being seen between large trees in the valley and those on the brow of the hill, it marks so decided a degree of elevation that it ought sedulously to be preserved. Instead, therefore, of removing the trees in the valley, at E, I should prefer shewing more of the lawn above them by clearing away some of the wood on the knoll at $\mathrm{F}$, which I have distinguished by the pavilion shewn in Plate xir: such a building would have many uses, besides acting as an ornament to the scenery, which seems to require some artificial objects to appropriate the woods to the magnificence of plare; because wood and lawn may be considered as the natural features of Buckinghamshire. 
The Red Book of Shardeloes contains a minute description of the rides made in the woods, with the reasons for every part of their course; but as this subject is more amply treated in my remarks on Bulstrode, the following extract is accompanied with a map, on which the course of an extensive drive is minutely described. This park must be acknowledged one of the most beautiful in lingland, yet I doubt whether Claude himself could find, in its whole extent, a single station from whence a picture could be formed. I mention this as a proof of the little affinity between pictures and scenes in nature.

It is not uncommon to conduct a drive either round a park or into the adjoining woods, without any other consideration than its length; and 1 have frequentiy been carried through a belt of plantation, surrounding a place, without one remarkable object to call the attention from the trees, which are cverywhere mixed in the same unvaried manner.

Although the verdure, the smoothness of the surface, and nature of the soil at Bulstrode are such as to make every part of the park pleasant to drive over, yet there is a propriety in marking certain lines of communication which may lead from one interesting spot to another; and though a road of approach to a house ought not to be circuitous, the drive is necessarily so; yet this should be under some restraint. By the assistance of the map [Plate xir], I shall describe in a note the course of the drive at Bulstrode; and however devious it may appear on paper, it will, I trust, be found to possess such a variety as few drives can boast, and that no part of it is suggested without sufficient reasons for its course.

I would not here be understood to infer that every park can boast those advantages which Bulstrode possesses, or that every place offers sufficient extent and 


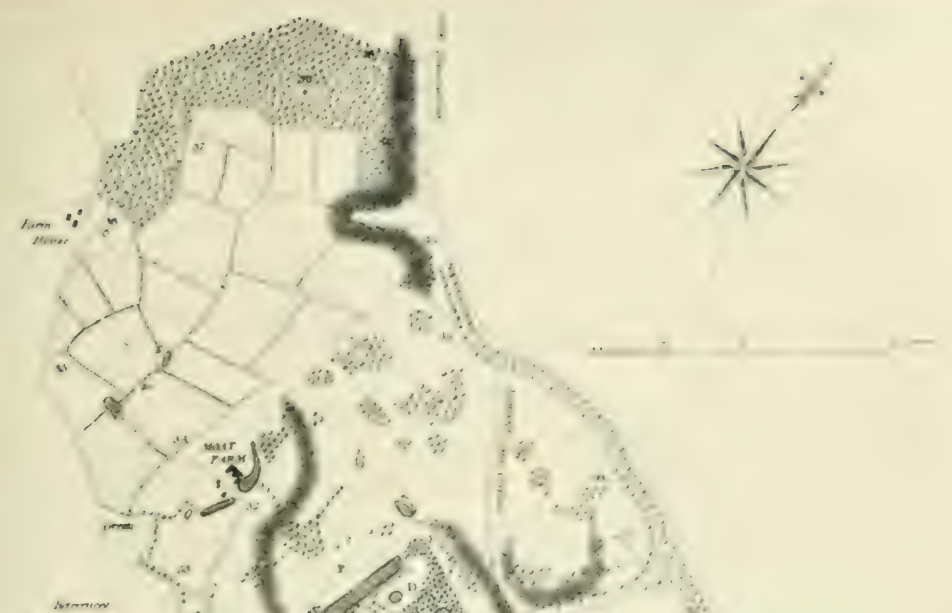

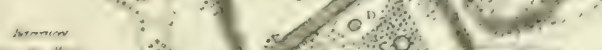

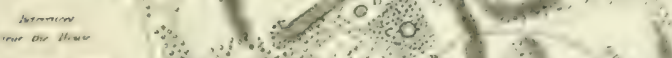

is is theress

it 5 an and ane

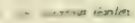

1. $\quad$. emin

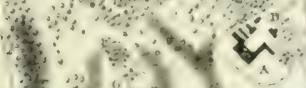
मै। $\because 2, \therefore$

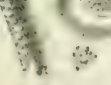

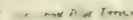

C. Terst tanax

minem
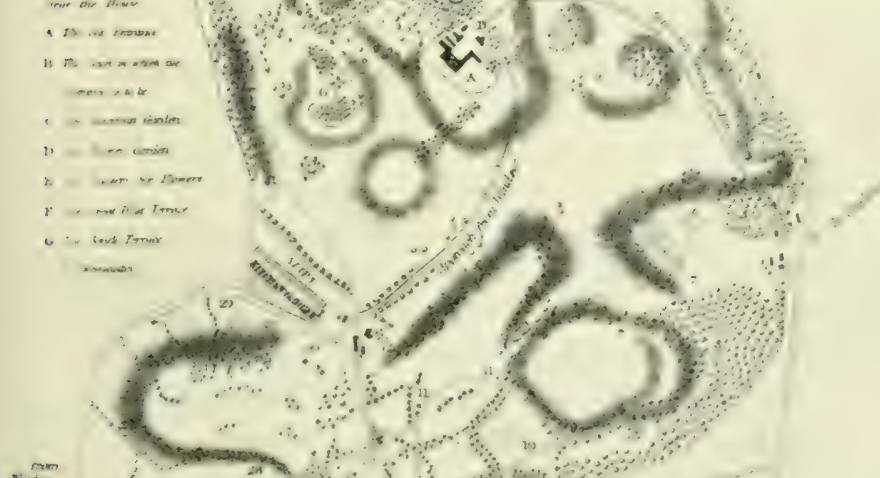

variety for such a drive appropriated to pleasure only; but this is introduced as an archetype or example, from whence certain principles are reduced to practice. Some of my observations, in the course of this description, may appear to have been anticipated by Mr. Whateley, and if I may occasionally deliver them as my own sentiments, I hope the coincidence in opinion with so respectable a theorist will not subject me to the imputation of plagiarism. ${ }^{25}$

Heathfield Park is one of those subjects from whence my art can derive little credit : the world is too apt to mistake alteration for improvement, and to applaud every change, although no higher beauty is produced. The character of this park is strictly in harmony with its situation; both are splendid and magnificent; yet a degree of elegance and beauty prevails, which is rarely to be found where greatness of character and loftiness of situation are predominant, because magnificence is not always united with convenience, nor extent of prospects with interesting and beautiful scenery. The power of art can have but little influence in increasing the natural advantages of Heathfield Park. It is the duty of the improver to avail himself of those beauties which nature has profusely scattered, and by leading the stranger to the most pleasing stations, to call his attention to those objects which, from their variety, novelty, contrast, or combination, are most likely to interest and delight the mind. On this foundation ought to be built the future improvement of Heathfield Park; not by doing violence to its native genius, but by sedulously studying its true character and situation : certain roads, walks, or drives may collect the scattered beauties of the place, and connect them with each other in lines, easy, natural, and graceful. 
A common error, by which modern improvers are apt to be misled, arises from the mistake so often made by adopting extent for beauty. Thus the longest circuit is frequently preferred to that which is most interesting; not indeed by the visitors, but by the fancied improver of a place. This, I apprehend, was the origin, and is always the tedious effect, of what is called a Belt; through which the stranger is conducted, that he may enjoy the drive, not by any striking points of view or variety of scenery, but by the number of miles over which he has traced its course, and instead of leading to those objects which are most worthy our attention, it is too common to find the drive a mere track round the utmost verge of the park; and if any pleasing features excite our notice, they arise rather from chance than design.

To avoid this popular error, therefore, I shall endeavour to avail myself of natural beauties in this drive, without any unnecessary circuit calculated to surprise by its extent. I shall rather select those points of view which are best contrasted with each other, or which discover new features, or the same under different circumstances of foreground; beguiling the length of the way by a succession of new and pleasing objects.

If the circuitous drive round a place becomes tedious by its monotony, we must equally avoid too great sameness or confinement in any road which is to be made a path of pleasure: a short branch from the principal drive, although it meets it again at a little distance, relieves the mind by its variety and stimulates by a choice between two different objects; but we must cautiously avoid confusion, lest we cut a wood into a labyrinth. The principal road at Heathfield leads towards the tower, the other is no less interesting where it bursts out on one of those magnificent landscapes so pleasing in nature, yet so diffi- 
cult to be represented in painting; because quantity and variety are apt to destroy that unity of composition which is expected in an artificial landscape: for it is hardly possible to convey an adequate and distinct idea of those numerous objects so wonderfully combined in this extensive view; the house, the church, the lawns, the woods, the bold promontory of Beachy Head, and the distant plains bounded by the sea, are all collected in one splendid picture, without being crowded into confusion.

This view is a perfect landscape, while that from the tower is rather a prospect. It is of such a nature as not to be well represented by painting, because its excellence depends upon a state of the atmosphere which is very hostile to the painter's art. An extensive prospect is most admired when the distant objects are most clear and distinct; but the painter can represent his distances only by a certain haziness and indistinctness, which is termed aerial perspective.

In the woodland counties, such as Hertfordshire, Herefordshire, Hampshire, etc., it often happens that the most beautiful places may rather be formed by felling than by planting trees; but the effect will be very different, whether the axe be committed to the hand of genius or the power of avarice. The land steward, or the timber-merchant, would mark those trees which have acquired their full growth and are fit for immediate use, or separate those which he deems to stand too near together, but the man of science and of taste will search with scrutinising care for groups and combinations, such as his memory recalls in the pictures of the best masters; these groups he will studiously leave in such places as will best display their varied or combined forms. He will also discover beauties in a tree which the others would 
condemn for its decay ; he will rejoice when he finds two trees whose stems have long grown so near each other that their branches are become interwoven; he will examine the outline formed by the combined foliage of many trees thus collected in groups, and removing others near them, he will give ample space for their picturesque effect. Sometimes he will discover an aged thorn or maple at the foot of a venerable oak; these he will respect, not only for their antiquity, being perhaps coeval with the father of the forest, but knowing that the importance of the oak is comparatively increased by the neighbouring situation of these subordinate objects; this will sometimes happen when young trees grow near old ones, as when a light airy ash appears to rise from the same root with an oak or an elm. These are all circumstances dependent on the sportive accidents of nature; but even where art has interfered, where the long and formal line of a majestic avenue shall be submitted to his decision, the man of taste will pause, and not always break their venerable ranks, for his hand is not guided by the levelling principles or sudden innovations of modern fashion; he will reverence the glory of former ages, while he cherishes and admires the ornament of the present, nor will he neglect to foster and protect the tender sapling, which promises, with improving beauty, to spread a grateful shade for future " tenants of the soil."

Togive, however, such general rules for thinning woods as might be understood by those who have never attentively and scientifically considered the subject would be like attempting to direct a man who had never used a pencil, to imitate the groups of a Claude or a Poussin. ${ }^{26}$

On this head I have frequently found my instructions opposed and my reasons unintelligible to those who look at a wood as an object of gain; and for this reason I am 
not sorry to have discovered some arguments in favour of my system, of more weight, perhaps, than those which relate to mere taste and beauty : these I shall heg leave to mention, not as the foundation on which my opinion is built, but as collateral props to satisfy those who require such support. ist. When two or more trees have long grown very near each other, the branches form themselves into one mass, or head; and if any part be removed, the remaining trees will be more exposed to the power of the wind, by being heavier on one side, having lost their balance. $2 \mathrm{~d}$. If trees have long grown very near together, it will be impossible to take up the roots of one without injuring those of another. And lastly, although trees at equal distances may grow more erect and furnish planks for the use of the navy, yet not less valuable to the shipbuilder are those naturally crooked branches, or knees, which support the decks or form the ribs, and which are always most likely to be produced from the outside trees of woods or the fantastic forms which arise from two or more trees having grown very near each other in the same wood, or in hedge-rows. It is therefore not inconsistent with the considerations of profit as well as picturesque effect to plant or to leave trees very near each other, and not to thin them in the usual manner without caution.

In some places belonging to ancient noble families, it is not uncommon to see woods of vast extent intersected by vistas and glades in many directions; this is particularly the case at Burley and at Cashiobury. It is the property of a straight glade or vista to lead the eye to the extremity of a wood, without attracting the attention to its depth.

I have occasionally been required to fell great quantities of timber, from other motives than merely to 
improve the landscape, and in some instances this work of necessity has produced the most fortunate improvements. I do not hesitate to say that some woods might be increased fivefold in apparent quantity, by taking away a prodigious number of trees, which are really lost to view; but unless such necessity existed, there is more difficulty and temerity in suggesting improvement by cutting down, however profitable, and however suddenly the effect is produced, than by planting, though the latter be tedious and expensive.

I have seldom found great opposition to my hints for planting, but to cutting down trees innumerable obstacles present themselves; as if, unmindful of their value and heedless of their slow growth, I should advise a military abatis, or one general sweep, denuding the face of a whole country. What I should advise, both at Burley and at Cashiobury, would be to open some large areas within the woods, to produce a spacious internal lawn of intricate shape and irregular surface, preserving a sufficient number of detached trees or groups to continue the general effect of one great mass of wood. 


\section{Chapter VI}

Fences - The Boundary - The Separation

HAT the boundary-fence of a place should be con1 cealed from the house is among the few general principles admitted in modern gardening; but even in this instance, want of precision has led to error. The necessary distinction is seldom made between the fence which encloses a park and those fences which are adapted to separate and protect the subdivisions within such enclosure. For the concealment of the boundary various methods have been adopted, on which I shall make some observations.

I. A plantation is certainly the best expedient for hiding the pales; but in some cases it will also hide more than is required. And in all cases, if a plantation surround a place in the manner commonly practised under the name of a belt, it becomes a boundary scarce less offensive than the pale itself. The mind feels a certain disgust under a sense of confinement in any situation, however beautiful; as Dr. Johnson has forcibly illustrated, in describing the feeling of Rasselas in the happy valley of Abyssinia.

2. A second method of concealing a fence is by making it of such light materials as to render it nearly invisible; such are fences made of slender iron and wire painted green.

3. A third method is sinking the fence below the surface of the ground, by which means the view is not impeded and the continuity of lawn is well preserved. 
Where this sunk fence or fosse is adopted, the deception ought to be complete, but this cannot be where grassand corn-lands are divided by such a fence. If it is used betwixt one lawn and another, the mind acquiesces in the fraud even after it is discovered, so long as the fence itself does not obtrude on the sight. We must therefore so dispose a fosse or ha! ha! that we may look across it and not along it. For this reason a sunk fence must be straight and not curving, and it should be short, else the imaginary freedom is dearly bought by the actual confinement, since nothing is so difficult to pass as a deep sunk fence.

4. A fourth expedient I have occasionally adopted, and which (if I may use the expression) is a more bold deception than a sunk fence, viz. a light hurdle instead of paling; the one we are always used to consider as a fixed and immoveable fence at the boundary of a park or lawn; the other only as an occasional division of one part from the other. It is a temporary inconvenience, and not a permanent confinement.

It is often necessary to adopt all these expedients in the boundaries and subdivisions of parks; but the disgust excited at seeing a fence may be indulged too far, if in all cases we are to endeavour at concealment, and therefore the various situations and purposes of different sorts of fences deserve consideration.

However we may admire natural beauties, we ought always to recollect that, without some degree of art and management it is impossible to prevent the injury which vegetation itself willoccasion: the smooth bowling-green may be covered by weeds in a month, while the pastured ground preserves its neatness throughout the year. There is no medium between the keeping of art and of nature. It must be either one or the other, art or nature; that is, 
either mowed, or fed by cattle; and this practical part of the management of a place forms one of the most difficult points of the professors of art, because the line of fence which separates the dressed ground from the pasture is too often objectionable; yet there is not less impropriety in admitting cattle to feed in a flowergarden than in excluding them from such a tract of land as might be fed with advantage.

At Sheffield Place, the beautiful and long meadow in Arno's Vale is a striking example of what 1 have mentioned; because, if it were possible, or on the principle of economy advisable, to keep all this ground as neatly rolled and mowed as the lawn near the house, by which it would always appear as it does the first week after the hay is carried off, yet I contend that the want of animals and animation deprives it of half its real charms; and although many beauties must be relinquished by curtailing the number of walks, yet others may be obtained, and the whole will be more easily kept with proper neatness by judicious lines of demarcation which shall separate the grounds to be fed from the grounds to be mown; or rather by such fences as shall, on the one hand, protect the woods from the encroachments of cattle, and, on the other, let the cattle protect the grass-land from the encroachment of woods, for such is the power of vegetation at Sheffield Place that every berry soon becomes a bush and every bush a tree.

From this luxuriant vegetation the natural shape of the vale is obliterated, the gently sloping banks are covered with wood, and the narrow glade in the bottom is choked with spreading larches. It is impossible to describe by words, and without a map, how this line of demarcation should be effected; but I am sure many acres might be given to cattle and the scenery be im- 


\section{I30 The Art of Landscape Gardening}

proved, not only by such moving objects, but also by their use in cropping those vagrant branches which no art could watch with sufficient care and attention. It is to such accidental browsing of cattle that we are indebted for those magical effects of light and shade in forest scenery, which art in vain endeavours to imitate in pleasure-grounds.

Perhaps the brook might be made the natural boundary of Arno's Vale, where a deep channel immediately at the foot of the hill, with or without posts and rails, would make an effectual fence. It will perhaps be objected that a walk by the side of such a fence would be intolerable, yet surely this watercourse, occasionally filled with a lively stream, is far preferable to a dry channel; and yet the only walk from the house at present is by the side of what may be so called: and, far from considering this a defect, I know it derives much of its interest from this very circumstance. A gravel walk is an artificial convenience, and that it should be protected is one of its first requisites: therefore, so long as good taste and good sense shall coincide, the eye will be pleased where the mind is satisfied. Indeed, in the rage for destroying all that appeared artificial in the ancient style of gardening, I have frequently regretted the destruction of those majestic terraces which marked the precise line betwixt nature and art.

To describe the various sorts of fences suitable to various purposes would exceed the limits and intentions of this work: every county has its peculiar mode of fencing, both in the construction of hedges and ditches, which belong rather to the farmer than the landscape gardener, and in the different forms and materials of pales, rails, hurdles, gates, etc.; my object is rather to describe such application of common expedients as may have some degree of use or novelty. 
A mongst these I shall first mention that, instead of surrounding a young plantation with a hedge and ditch, with live quick or thorns, I generally recommend as many or even more thorns than trees, to be intermixed in the plantation and the whole to be fenced with posts and rails, more or less neat, according to the situation. But, except near the house, I never suppose this rail to continue after the trees (with the aid of such intermixed thorns) are able to protect themselves against cattle; and thus, instead of a hard marked outline, the woods will acquire those irregularities which we observe in forest scenery, where in some few instances the trees are choked by the thorns, though in many they are nursed and reared by their protection.

In the course of this work, I may have frequent occasion to mention the necessity of providing a fence near the house, to separate the dressed lawn from the park or feeding-ground: various ingenious devices have been contrived to reconcile, with neatness and comfort, the practice introduced by Mr. Brown's followers, of setting a house in a grass-field.

The sunk fence or ha! ha! in some places answers the purpose; in others a light fence of iron or wire, or even a wooden rail, has been used with good effect, if not too high; but generally near all fences the cattle make a dirty path, which, immediately in view of the windows, is unsightly; and where the fence is higher than the eye, as it must be against deer, the landscape seen through its bars becomes intolerable. After various attempts to remedy these defects by any expedient that might appear natural, I have at length boldly had recourse to artificial management, by raising the ground near the house about three feet, and by supporting it with a wall of the same materials as the house. In 
addition to this, an iron rail on the top, only three feet high, becomes a sufficient fence, and forms a sort of terrace in front of the house making an avowed separation between grass kept by the scythe and the park fed by deer or other cattle, while at a little distance it forms a base-line or deep plinth, which gives height and consequence to the house. This will, I know, be objected to by those who fancy that everything without the walls of a house should be natural; but a house is an artificial object, and, to a certain distance around the house, art may be avowed: the only difference of opinion will be, where shall this line of utility, separating art from nature, commence? Mr. Brown said, at the threshold of the door, yet he contradicted himself when he made, as he always did, another invisible line beyond it. On the contrary, I advise that it be near the house, though not quite so near: and that the line should be artificially and visibly marked. ${ }^{27}$

When Mr. Brown marked the outline of a great wood sweeping across hill and valley, he might indulge his partiality for a serpentine or graceful curve, which had been then newly introduced by Hogarth's idea respecting the line of beauty; but it may be observed that a perfectly straight line, drawn across a valley diagonally, appears to the eye the same as this line of fancied beauty, and therefore, in many cases, the line should be straight. I have already hinted in this chapter that the fence of a wood or plantation should be considered as merely temporary, that is, till the thorns planted among the trees can supersede its use. Wherefore, it is of little consequence in what manner a hurdle, or rough posts and rails, without any hedge or ditch, may be placed : a straight line is ever the shortest, and 
I have often preferred it, especially as I know that a few trees or bushes at each end of such a line will prevent the eye from looking along its course.

Sometimes it happens, from the intermixture of property or other causes, that the fence is obliged to make a very acute angle; this may occasionally be remedied by another line of fence fitting to its greatest projection ; and as this same principle may be extended to roads, walks, or rivers, I shall explain it.

The sharp elbow or projection of the fence $A$ [Fig. 17] ceases to be offensive if another fence can be joined

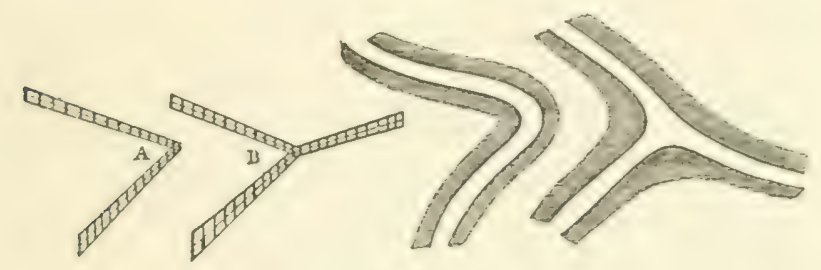

Fig. 17

to it, as at $B$, and the same with the line of road or walk; the branch obviates the defect.

It has been observed by the adversaries of the art that exactly the same line will serve either for a road or a river, as it may be filled with gravel or with water. This ridicule may perhaps be deserved by those engineers who are in the habit of making navigable canals only, but the nice observer will see this material difference:

The banks of a natural river are never equidistant; the water in some places will spread to more than twice the breadth it does in others. This pleasing irregularity depends on the shape of the ground through which it flows : a river seldom proceeds far along the middle of a valley, but generally keeps on one side, or boldly stretches across to the other, as the high ground resists 
or the low ground invites its course. These circumstances in natural rivers should be carefully imitated in those of art, and not only the effects, but even the causes, if possible, should be counterfeited, especially in the form of the shores: thus, the convex side of the river at $A$ [in Fig. I 8 ] should have its shores con-

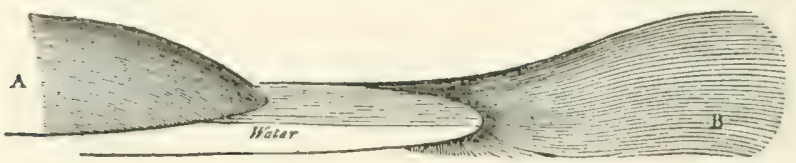

Fig. 18.

vex or steep; and the concave side of the river at $\mathrm{B}$ should have its shores concave or flat; because, by this means, the course of the river is accounted for.

There is another circumstance, with respect to lines, deserving attention. The course of a river may frequently shew two or more different bends, which do not so intersect each other as to impede the view along it; and these may be increased in proportion to the breadth of the river: but in a road, or a walk, especially if it passes through a wood or plantation, a second bend should never be visible. The degree of curve in a walk or road will therefore depend on its width; thus looking along the narrow line of walk, you will not see the second bend: but in the same curve,

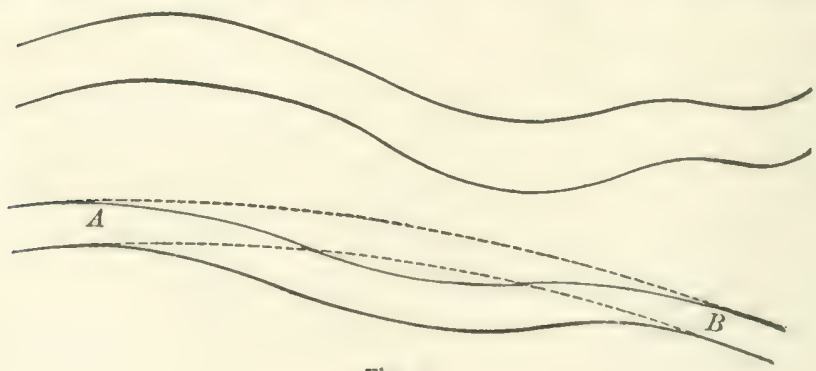

Fig. 19. 
if the road be broader, we should naturally wish to make the curve bolder by breaking from it, according to the dotted line from A to B in the diagram [Fig. I9].

When two walks separate from each other, it is always desirable to have them diverge in different directions, as at $\mathrm{A}$ [in Fig. 20], rather than give the idea of reuniting, as at $\mathrm{B}$.

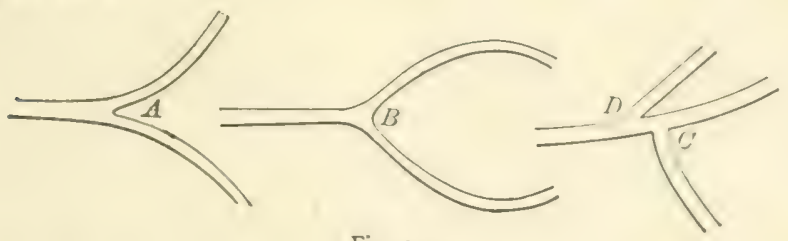

Fig. 20.

Where two walks join each other, it is generally better that they should meet at right angles, as at c, than to leave the sharp point, as in the acute angle at $D$.

The most natural course for a road or walk is along the banks of a lake or river, yet I have occasionally observed great beauty in the separation of these two lines; as where the water sweeps to the left, and the road to the right, or vice versa. The true effect of this circumstance I have often attempted to represent on paper, but it is one of the many instances in which the reality and the picture excite different sensations.

This chapter might have included every necessary remark relative to fences, whether attached to parks or farms; but as I wish to enlarge upon the distinction between the improvements designed for ormament and those for profit or gain, I shall endeavour to explain these different objects, as they appear to me opposite in their views and distinct in their characteristics. Both are, indeed, subjects of cultivation; but the cultivation in the one is husbandry, and in the other decoration. 


\section{Chapter VII}

\section{Farm and Park Distinct Objects - Beauty and Profit seldom compatible}

THE French term Ferme ornée was, I believe, in1 vented by Mr. Shenstone, who was conscious that the English word "Farm" would not convey the idea which he attempted to realise in the scenery of the Leasowes. That much celebrated spot, in his time, consisted of many beautiful small fields, connected with each other by walks and gates, but bearing no resemblance to a farm as a subject of profit. I have never walked through these grounds without lamenting, not only the misapplication of good taste, but that constant disappointment which the benevolent Shenstone must have experienced in attempting to unite two objects so incompatible as ornament and profit. Instead of surrounding his house with such a quantity of ornamental lawn or park only as might be consistent with the size of the mansion or the extent of the property, his taste, rather than his ambition, led him to ornament the whole of his estate, vainly hoping that he might retain all the advantages of a farm, blended with the scenery of a park. Thus he lived under the continual mortification of disappointed hope, and, with a mind exquisitely sensible, he felt equally the sneer of the great man, at the magnificence of his attempt, and the ridicule of the farmer, at the misapplication of his paternal acres.

Since the removal of courtyards and lofty gardenwalls from the front of a house, the true substitute for 
the ancient magnificence destroyed is the more cheerful landscape of modern park scenery; and although its boundary ought in no case to be conspicuous, yet its actual dimensions should bear some proportion to the command of property by which the mansion is supported. If the yeoman destroys his farm by making what is called a Ferme ornée, he will absurdly sacrifice his income to his pleasure, but the country gentleman can only ornament his place by separating the features of farm and park; they are so totally incongruous as not to admit of any union but at the expense either of beauty or profit. The following comparative view will tend to confirm this assertion.

The chief beauty of a park consists in uniform verdure; undulating lines contrasting with each other in variety of forms; trees so grouped as to produce light and shade to display the varied surface of the ground; and an undivided range of pasture. The animals fed in such a park appear free from confinement, at liberty to collect their food from the rich herbage of the valley, and to range uncontrolled to the drier soil of the hills.

The farm, on the contrary, is forever changing the colour of its surface in motley and discordant hues; it is subdivided by straight lines of fences. The trees can only be ranged in formal rows along the hedges; and these the farmer claims a right to cut, prune, and disfigure. Instead of cattle enlivening the scene by their peaceful attitudes or sportive gambols, animals are bending beneath the yoke or closely confined to fatten within narrow enclosures, objects of profit, not of beauty [Plate XIv].

This reasoning may be further exemplified by an extract from the Red Book of Antony. The shape of the ground at Antony is naturally beautiful, but at- 
tention to the farmer's interest has almost obliterated all traces of its original form; since the line of fence, which the farmer deems necessary to divide arable from pasture land, is unfortunately that which, of all others, tends to destroy the union of hill and valley. It is generally placed exactly at the point where the undulating surface changes from convex to concave, and of course is the most offensive of all intersecting lines; for it will be found that a line of fence, following the shape of the ground, or falling in any direction from the hill to the valley, although it may offend the eye as a boundary, yet it does not injure, ard, in some instances, may even improve the beautiful form of the surface. No great improvement, therefore, can be expected at Antony, until almost all the present fences be removed, although others may be placed in more suitable directions. [Plate XIv.]

I am aware that, in the prevailing rage for agriculture, it is unpopular to assert that a farm and a park may not be united; but after various efforts to blend the two, without violation of good taste, I am convinced that they are and must be distinct objects, and ought never to be brought together in the same point of view.

To guard against misrepresentation, let me be allowed to say each may fill its appropriate station in a gentleman's estate; we do not wish to banish the nectarine from our desserts, although we plant out the wall which protects it; nor would I expunge the common farm from the pleasures of the country, though I cannot encourage its motley hues and domestic occupations to disturb the repose of park scenery. It is the union not the existence of beauty and profit, of laborious exertion and pleasurable recreation, against which I would interpose the influence of my art; nor let the fastidious 


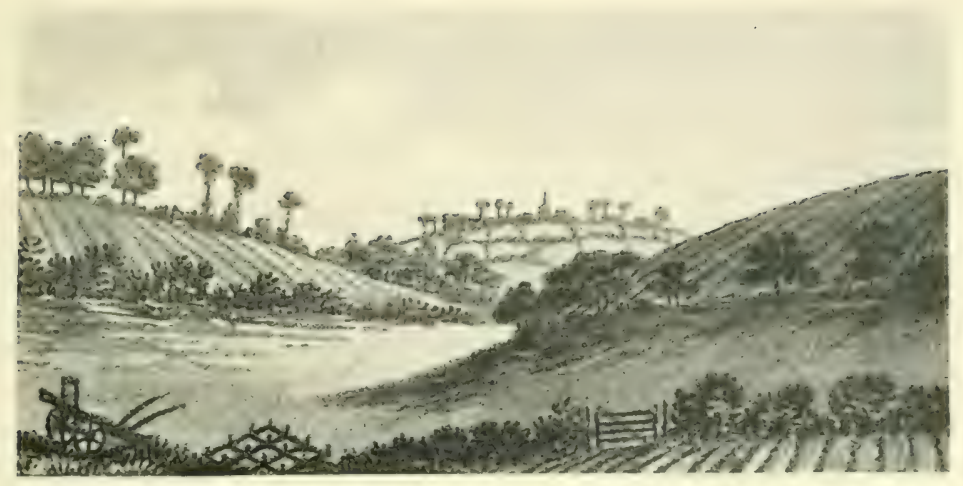

Farm

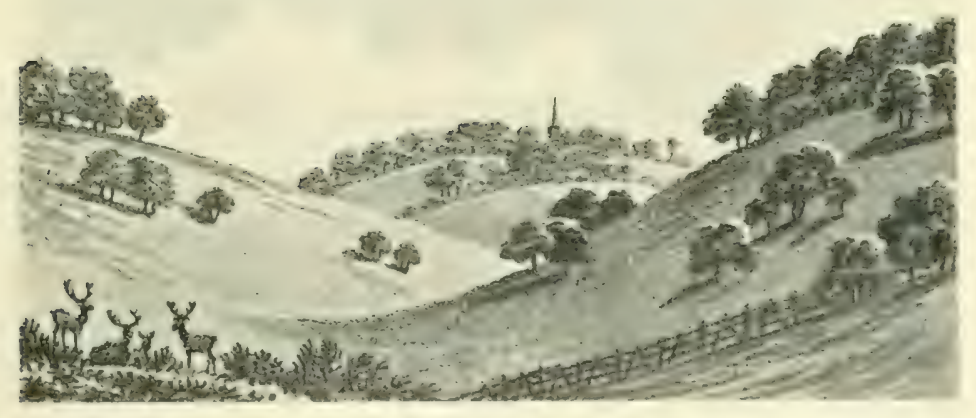

Park

Plate XIV. Farm and Park 

objector condemn the effort till he can convince the judgement that, without violation of good taste, he could introduce the dairy and the pig-sty (those useful appendages of rural economy) into the recesses of the drawingroom or the area of the saloon. The difficulty of uniting a park and a farm arises from this material circumstance, that the one is an object of beauty, the other of profit. The scenery of both consists of ground, trees, water, and cattle; but these are very differently arranged. And since a park is less profitable than arable land, the more we can diminish the quantity of the former, provided it still be in character with the style of the mansion, the less we shall regret the sacrifice of profit to beauty.

The shape and colour of corn-fields and the straight lines of fences are so totally at variance with all ideas of picturesque beauty that I shall not venture to suggest any hints on the subject of a farm as an ornament; yet I think there might be a distinction made between the farm of a tenant, who must derive benefit from every part of his land, and that occupied by a gentleman for the purposes of amusement or experiment.

It is usual in Hampshire, and, indeed, in the neighbourhood of many forests, to divide the enclosures of a farm by rows of copse-wood and timber, from ten to twenty yards wide; at a little distance these rows appear united, and become one rich mass of foliage. This kind of subdivision I should wish to be generally adopted on experimental farms. The advantages of such plantations will be : shady and pleasant walks through the farm; to afford shelter to corn and protect the cattle which are grazed on the farm; to give the whole, at a distance, the appearance of one mass of wood; to make an admirable cover for game; and, lastly, if it should ever hereafter be thought advisable to extend the lawn, such plantations 
will furnish ample choice of handsome trees to remain single or in groups, as taste or judgement shall direct.

In some counties the farms consist chiefly of grassland, but even a dairy-farm must be subdivided into small enclosures; and although it is not necessary that a lawn near a mansion should be fed by deer, yet it is absolutely necessary that it should have the appearance of a park, and not that of a farm ; because, in this consists the only difference betwixt the residence of a landlord and his tenant, the gentleman and the farmer: one corsiders how to make the greatest immediate advantage of his land; the other must, in some cases, give up the idea of profit for the sake of that beauty which is derived from an air of liberty, totally inconsistent with those lines of confinement and subdivision which are charasteristic of husbandry.

Since the beauty of pleasure-ground and the profit of a farm are incompatible, it is the business of taste and prudence so to disguise the latter and to limit the former that park scenery may be obtained without much waste or extravagance; but I disclaim all idea of making that which is most beautiful also most profitable: a ploughed field and a field of grass are as distinct objects as a flower-garden and a potato-ground. The difference between a farm and a park consists not only in the number of fences and subdivisions, but also in the management of the lines in which the fences of each should be conducted. The farmer, without any attention to the shape of the ground, puts his fences where they will divide the uplands from the meadows; and in subdividing the ground, he aims only at square fields, and consequently straight lines, avoiding all angles or corners. This is the origin of planting those triangular recesses in a field surrounded by wood, which the 
farmer deems useless; but which, to the eye of taste, produce effects of light and shade.

There is no mistake so common as that of filling up a recess in a venerable wood with a miserable patch of young plantation. The outline of a wood can never be too boldly indented or too irregular; to make it otherwise, by cutting off the projections or filling up the hollows, shews a want of taste, and is as incongruous as it would be to smooth the furrowed bark of an agred oak.

In a park the fences cannot be too few; the trees too majestic, or the views too unconfined. In a farm small enclosures are often necessary; the mutilated pollard or the yielding willow, in the farmer's eye, are often preferable to the lofty elm or spreading oak, whilst a full crop of grain or a copious swath of clover is a more gladdening prospect than all the splendid scenery of wood and lawn from the windows of a palace. Small detached farms, adapted to useful and laborious life, unmixed with the splendours of opulence, but supporters of national wealth, are indeed objects of interest in every point of view; they want not the adrentitious aid of picturesque effect to attract peculiar notice; to a benevolent mind they are more than objects of beauty : they are blessings to socicty; nor is it incompatible with the pursuit of pleasure sometimes to leave the boundaries of the park, and watch the exertions of laudable industry or visit the cottages

"Where cheerful tenants bless their yearly toil."

The monopolist only can contemplate with delight his hundred acres of wheat in a single enclosure; such expanded avarice may enrich the man, but will impor.. erish and distress and (I had almost added) will ultimately starve mankind. 


\section{Chapter VIII}

Pleasure-Grounds - Flower-Gardens - Greenbouse and Conservatories - Various Modes of attacbing them to a House

I $\mathrm{N}$ the execution of my profession, I have often ex1 perienced great difficulty and opposition in attempting to correct the false and mistaken taste for placing a large house in a naked grass-field, without any apparent line of separation betwixt the ground exposed to cattle and the ground annexed to the house, which I consider as peculiarly under the management of art. This line of separation being admitted, advantage may be easily taken to ornament the lawn with flowers and shrubs, and to attach to the mansion that scene of embellished neatness, usually called a pleasure-ground. The quantity of this dressed ground was formerly very considerable. The royal gardens of Versailles or those of Kensington Palace, when filled with company, want no other animation; but a large extent of ground without moving objects, however neatly kept, is but a melancholy scene. If solitude delight, we seek it rather in the covert of a wood or the sequestered alcove of a flower-garden than in the open lawn of an extensive pleasure-ground.

I have therefore frequently been the means of restoring acres of useless garden to the deer or sheep, to which they more properly belong. This is now carrying on with admirable effect at Bulstrode, where the gardens of every kind are on a great scale, and where, from the 
choice and variety of the plants, the direction of the walks, the enrichment of art, and the attention to every circumstance of elegance and magnificence, the pleasureground is perfect as a whole, while its several parts may furnish models of the following different characters of taste in gardening: the ancient garden, the American garden, the modern terrace-walks, and the flower-garden. The latter is, perhaps, one of the most varied and extensive of its kind, and therefore too large to be otherwise artificial than in the choice of its flowers and the embellishments of art in its ornaments.

Flower-gardens on a small scale may, with propriety, be formal and artificial; but in all cases they require neatness and attention. On this subject I shall transcribe the following passage from the Red Book of Valley Field. ${ }^{28}$

To common observers, the most obvious difference between Mr. Brown's style and that of ancient gardens was the change from straight to waving or serpentine lines. Hence many of his followers had supposed good taste in gardening to consist in avoiding all lines that are straight or parallel, and in adopting forms which they deem more consonant to nature, without considering what objects were natural and what were artificial.

This explanation is necessary to justify the plan which I recommended for the canal in this flower-garden [Plate xv]; for while I should condemn a long straight line of water in an open park, where everything else is natural, I should equally object to a meandering canal or walk, by the side of a longstraight wall, where everything else is artificial.

A flower-garden should be an object detached and distinct from the general scenery of the place; and, whether large or small, whether varied or formal, it 
ought to be protected from hares and smaller animals by an inner fence: within this enclosure rare plants of every description should be encouraged and a provision made of soil and aspect for every different class. Beds of bog-earth should be prepared for the American plants: the aquatic plants, some of which are peculiarly beautiful, should grow on the surface or near the edges of water. The numerous class of rock-plants should have beds of rugged stone provided for their reception, without the affectation of such stones being the natural production of the soil; but, above all, there should be poles or hoops for those kinds of creeping plants which spontaneously form themselves into graceful festoons, when encouraged and supported by art. Yet, with all these circumstances, the flower-garden, except where it is annexed to the house, should not be visible from the roads or general walks about the place. It may therefore be of a character totally different from the rest of the scenery, and its decorations should be as much those of art as of nature.

The flower-garden at Nuneham, ${ }^{29}$ without being formal, is highly enriched, but not too much crowded with seats, temples, statues, vases, or other ornaments, which, being works of art, beautifully harmonize with that profusion of flowers and curious plants which distinguish the flower-garden from natural landscape, although the walks are not in straight lines.

But at Valley Field, where the flower-garden is in front of a long wall, the attempt to make the scene natural would be affected; and, therefore, as two great sources of interest in a place are variety and contrast, the only means by which these can be introduced are in this flower-garden, which, as a separate object, becomes a sort of episode to the general and magnificent scenery. 


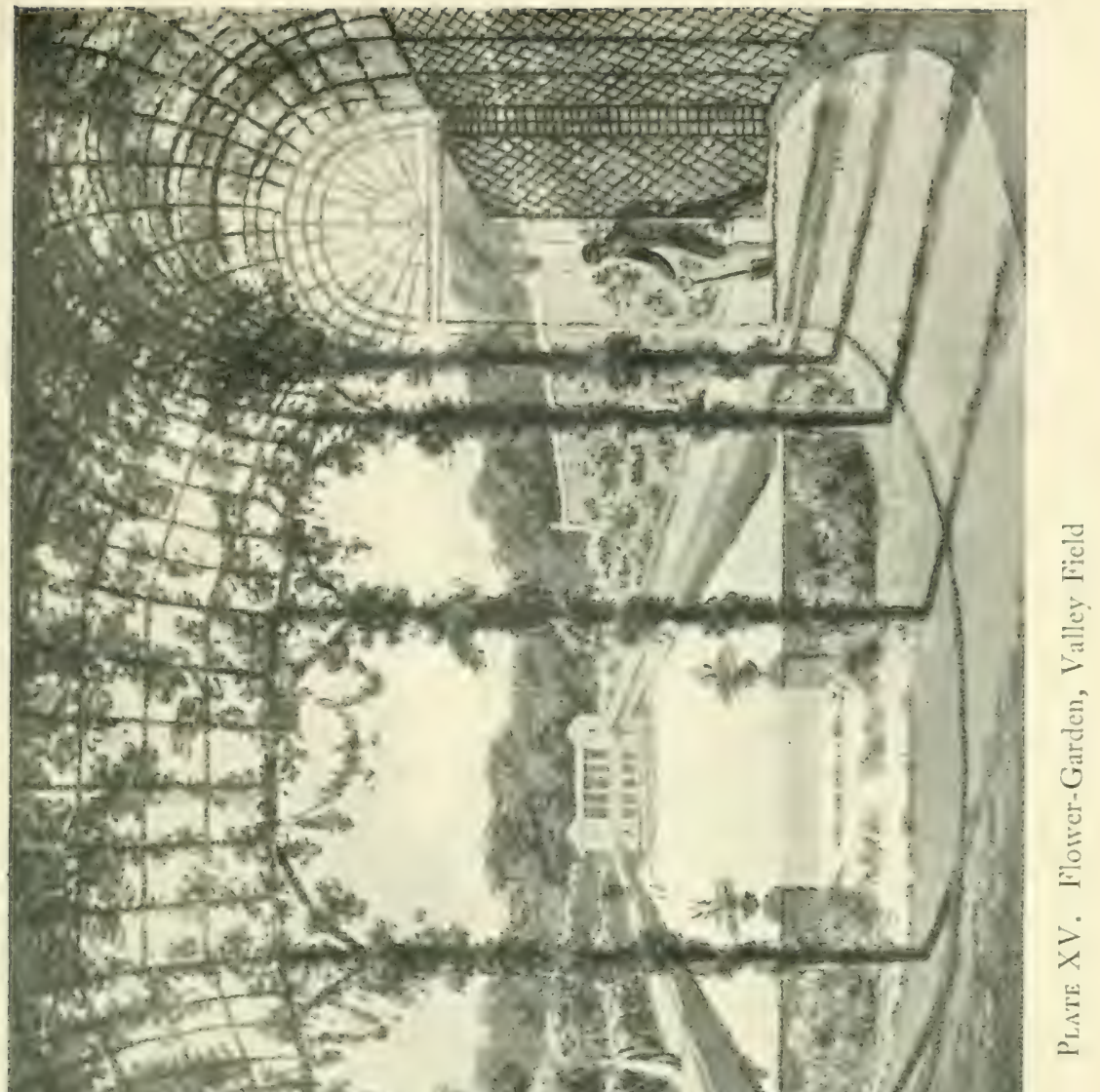



The river being everywhere else a lively stream, rattling and foaming over a shallow bed of rock or gravel, a greater contrast will arise from a smooth expanse of water in the flower-garden: to produce this must be a work of art, and, therefore, instead of leading an open channel from the river to supply it or making it appear a natural branch of that river, I recommend that the water should pass underground, with regulating sluices or shuttles to keep it always at the same height. Thus the canal will be totally detached from the river and become a distinct object, forming the leading feature of the scene to which it belongs; a scene purely artificial, where a serpentine canal would be as incongruous as a serpentine garden-wall or a serpentine bridge; and, strange as it may appear, I have seen such absurdities introduced, to avoid nature's supposed abhorrence of a straight line. The banks of this canal or fish-pond may be enriched with borders of curious flowers, and a light fence of green laths will serve to train such as require support, while it gives to the whole an air of neatness and careful attention.

But, as the ends of this water should also be marked by some building or covered seat, I have supposed the entrance to the flower-garden to be under a covered passage of hoops, on which may be trained various sorts of creeping plants; and the farther end may be decorated by an architectural building, which I suppose to consist of a covered seat between two aviaries. It will perhaps be objected that a long straight walk can have little variety; but the greatest source of variety in a flower-garden is derived from the selection and diversity of its shrubs and flowers.

There is no ornament of a flower-garden more appropriate than a conservatory or a greenhouse, where the 
flower-garden is not too far from the house; but amongst the refinements of modern luxury may be reckoned that of attaching a greenhouse to some room in the mansion, a fashion with which I have so often been required to comply that it may not be improper, in this work, to make ample mention of the various methods by which it has been effected in different places.

At Bowood, at Wimpole, at Bulstrode, at Attingham, at Dyrham Park, at Caenwood, at Thoresby, and some other large houses of the last century, greenhouses were added to conceal offices behind them, and they either became a wing of the house or were in the same style of architecture: but these were all built at a period when only orange-trees and myrtles or a very few other greenhouse plants were introduced, and no light was required in the roof of such buildings. In many of them, indeed, the piers between each window are as large as the windows. Since that period the numerous tribe of geraniums, ericas, and other exotic plants, requiring more light, have caused a very material alteration in the construction of the greenhouse; and perhaps the more it resembles the shape of a nurseryman's stove, the better it will be adapted to the purposes of a modern greenhouse. Yet such an appendage, however it may increase its interior comfort, will never add to the external ornament of a house of regular architecture: it is therefore generally more advisable to make the greenhouse in the flowergarden, as near as possible to without forming a part of the mansion; and in these situations great advantage may be taken of treillage ornaments to admit light, whilst it disguises the ugly shape of a slanting roof of glass.

There is one very material objection to a greenhouse immediately attached to a room constantly inhabited, viz. that the smell and damp from a large body of earth 
in the beds or pots is often more powerful than the fragrance of the plants; therefore the conservatory should always be separated from the house by a lobby or small anteroom. But the greatest objection arises from its want of conformity to the neighbouring mansion, since it is difficult to make the glass roof of a conservatory architectural, whether Grecian or Gothic. An arcade is ill adapted to the purpose, because, by the form of an arch, the light is excluded at the top, where it is most essential in a greenhouse; for this reason the flat Gothic arch of Henry the Eighth is less objectionable, yet in such buildings we must suppose the roof to have been taken away to make room for glass; of this kind is the conservatory in front of Rendlesham House.

In the adaptation of ancient forms to modern uses and inventions, we are often under the necessity of deviating from the rules of true Gothic. Under such circumstances it is perhaps better to apply old expedients to new uses than to invent a new and absurd style of Gothic or Grecian architecture. At Plas-Newyd, where the house partakes of a Gothic character, I suggested the addition of a greenhouse, terminating a magnificent enfilade through a long line of principal apartments. The hint for this model is taken from the chapter-rooms to some of our cathedrals, where an octagon roof is supported by a slender pillar in the middle, and if this were made of cast-iron, supporting the ribs of a roof of the same material, there would be no great impropriety in filling the interstices with glass, while the side window-frames might be removed entirely in summer, making a beautiful pavilion at that season, when, the plants being removed, a greenhouse is generally a deserted and unsightly object. 


\section{Chapter IX}

Landscape Gardening and Painting - Pictures may imitate Nature, but Nature is not to copy Pictures

$\mathrm{A}^{\mathrm{T}}$ the time my former publication was in the press, A the art of landscape gardening was attacked by two gentlemen, Mr. Knight, ${ }^{3 \circ}$ of Herefordshire, and Mr. Price, ${ }^{31}$ of Shropshire; and I retarded its publication till I could take some notice of the opinions of these formidable, because ingenious, opponents. Having since been consulted on subjects of importance in those two counties, I willingly availed myself of opportunities to deliver my sentiments as particular circumstances occurred, and therefore, with permission of the respective proprietors, I insert the following observations from the Red Books of Sufton Court, in Herefordshire, and Attingham, in Shropshire:

My opinion concerning the improvement of Sufton Court involving many principles in the art of landscape gardening, I take this opportunity of justifying my practice, in opposition to the wild theory which has lateiy appeared; and shall therefore occasionally allude to this new system when it bears any relation to our objects at Sufton Court. Having already published a volume on the subject of landscape gardening, it will be unnecessary to explain the motives which induced me to adopt this name for a profession as distinct from the art of landscape painting as it is from the art of planting cabbages or pruning fruit-trees. The slight 
and often gaudy sketches by which I have found it necessary to elucidate my opinions are the strongest proofs that I do not profess to be a landscape painter, but to represent the scenes of nature in her various hues of blue sky, purple mountains, green trees, etc., which are often disgusting to the eye of a connoisseur in painting.

The best painters in landscape have studied in Italy or France, where the verdure of England is unknown: hence arises the habit acquired by the connoisseur of admiring brown tints and arid foregrounds in the pictures of Claude and Poussin, and from this cause he prefers the bistre sketches to the green paintings of Gainsborough. One of our best landscape painters studied in Ireland, where the soil is not so yellow as in England; and his pictures, however beautiful in design and composition, are always cold and chalky.

Autumn is the favourite season of study for landscape painters, when all nature verges towards decay, when the foliage changes its vivid green to brown and orange, and the lawns put on their russet hue. But the tints and verdant colouring of spring and summer will have superior charms to those who delight in the perfection of nature, without, perhaps, ever considering whether they are adapted to the painter's landscape.

It is not from the colouring only but the general composition of landscapes that the painter and landscape gardener will feel the difference in their respective arts; and although each may occasionally assist the other, yet I should no more advise the latter, in laying out the scenery of a place, to copy the confined field of vision or affect the careless graces of Claude or Poussin than I should recommend, as a subject proper for a landscape painter, the formal rows or quincunx position of trees in geometric gardening. It has been wittily 
observed that "the works of nature are well executed, but in a bad taste"; this, I suppose, has arisen from the propensity of good taste to display the works of nature to advantage, but it does not hence follow that art is to be the standard for nature's imitation. Neither does it disgrace painting to assert that nature may be rendered more pleasing than the finest picture, since the perfection of painting seldom aims at exact or individual representation of nature. A panorama gives a more natural idea of ships at sea than the best picture of Vandervelde; but it has little merit as a painting, because it too nearly resembles the original to please as an effort of imitative art. My sketches, if they were more highly finished, would be a sort of panorama, or facsimile, of the scenes they represent, in which little effect is attempted on the principle of composition in painting; but like a profile shadow or silhouette, they may please as portraits, while they offend the connoisseur as paintings. The art I profess is of a higher nature than that of painting, and is thus very aptly described by a French author: "Il est à la poésie et à la peinture, ce que la réalité est à la déscription et l'original à la copie."

The house at Sufton Court having been built long before I had the honour of being consulted, its aspects, situation, and general arrangement do not properly come under my consideration. Yet, as I shall suggest a hint for altering the windows in the drawingroom, I must consider the different landscapes in each direction. The views towards the south and west are extensive, and, under certain circumstances of light and weather, often wonderfully beautiful; but, as distant prospects depend so much on the state of the atmosphere, I have frequently asserted that the views 
from a house, and particularly those from the drawingroom, ought rather to consist of objects which evidenty belong to the place. To express this idea, I have used the word appropriation, by which I mean such a portion of wood and lawn as may be supposed to belong to the proprietor of the mansion, occupied by himself, not so much for the purposes of gain as of pleasure and convenience: this, of course, should be grass, whether fed by deer, by sheep, or by other cattle, and its subdivisions, if there be any, ought not to be permanent. I am ready to allow that this part of modern gardening has often been egregiously mistaken and absurdly practised; I find no error so difficult to counteract as the general propensity for extent, without sufficient attention to the size, style, or character of the house or of the surrounding estate.

Extent and beauty have ever appeared to me distinct objects; and a small place, in which the boundary is not obtrusive, may be more interesting and more consonant to elegance and convenience than a large tract of land, which has no other merit than that it consists of many hundred acres or is encompassed by a pale of many miles in circuit, while, perhaps, within this area, half the land is ploughed in succession.

The drawing-room, at present, looks towards the south, but there appear to be several reasons for altering its aspect: Ist, because the hall and dining-room command the same prospect, but more advantageously; $2 \mathrm{~d}$, because the windows, being near the hall-door, a carriage-road, which must occasionally be dirty, becomes a bad foreground; and, lastly, the view toward the east will not only be different from the others, but is of such a nature as to appear wholly appropriate to the place, and, therefore, in strict harmony with the 
quiet home scene of a country residence. It consists of a beautiful lawn or valley, having its opposite bank richly clothed with wood, which requires very little assistance to give it an irregular and pleasing outline, and is one of the many subjects more capable of delighting the eye in nature than in a picture.

It has been laid down, by a recent author before named, as a general rule for improvement, to plant largely and cut down sparingly. This is the cautious advice of timidity and inexperience, for, in some situations, improvement may be effected by the axe rather than by the spade, of which Sufton Court furnishes an instance: the trees in a straight line, at the bottom of the hill, have in vain been encumbered by young trees, planted with a view of breaking their formal row, while in reality they produce the contrary effect. I rather advise boldly taking away all the young trees and part of the old ones, but particularly an oak, which not only hides the forked stem of a tree behind, but from its situation depresses the other trees and lessens the magnitude and importance both of the hill and of the grove by which its brow is covered.

The situation of Attingham is at variance with its character, since it is impossible to annex ideas of grandeur and magnificence to a mansion with little apparent domain. The flat lawn between the highroad and the house, although very extensive, yet, possessing no variety in the size of the trees, and but little in the shape of ground, the eye is deceived in its real distance.

By the laws of perspective, the nearer any object is to the eye, the larger it will appear; also, the larger any object is, the nearer it will appear to the eye: consequently, the magnitude of the house makes it appear 
nearer than it really is, there being no intervening objects to divert the attention or to act as a scale and assist the eye in judging of the distance. For this reason every stranger who sees this house from the turnpike road would describe it as a large house with very little ground between it and the road. The first idea of improvement would be, either to remove the house or the road; but as neither of these expedients is practicable, we must have recourse to art to do away with this false impression. This I shall consider as forming the basis of the alteration proposed at Attingham.

In ancient Gothic structures, where lofty walls and various courts intervened between the palace and the neighbouring village, there was sufficient dignity or seclusion, without that apparent extent of domain which a modern mansion requires; but since the restraint of ancient grandeur has given place to modern elegance, which supposes greater ease and freedom, the situation of a house in the country is more or less defective, in proportion as it is more or less bounded or incommoded by alien property. Thus a highroad, a ploughed field, a barn, or a cottage adjoining a large house, has a tendency to lessen its importance; and hence originates the idea of extending park, lawn, or pleasure-grounds in every direction from the house; hence, also, arises the disgust we feel at seeing the park-pales and grounds beyond, when they are so near or so conspicuous as to impress the mind with an idea of not belonging to the place.

Perhaps the love of unity may contribute to the pleasure we feel in viewing a park where the boundary is well concealed. This desire of hiding the boundary introduced the modern practice of surrounding almost every park with a narrow plantation or belt, which, if 
consisting of trees planted at the same time, becomes little better than a mere hedge-row, and is deservedly rejected by every man of taste; yet there are many situations where a plantation becomes the natural boundary of a park: such is the screen of wood on the highest ground to the east of Attingham, where it forms a pleasing outline to the landscape, without exciting a wish to know whether it is the termination of the property.

In consequence of the apparent want of extent in the park or lawn at Attingham, it was suggested to add many hundred acres of land to the east, by removing the hedges of the adjoining fields. This would have increased the real without extending the apparent magnitude of the park: but I contend that oftentimes it is the appearance and not the reality of extent which is necessary to satisfy the mind; for the size of the park has little reference to that of the estate of the proprietor. The land attached to a villa, near a city, may with propriety be surrounded by pales, or a wall, for the sake of privacy and seclusion, but it is absurd to enclose more of a distant domain than is necessary for the beauty of the place; besides, if this park or lawn had been extended a mile farther to the east, the confinement to the south, which is in the front of the house, would not have been done away, and, consequently, to the traveller passing the road the apparent extent would not have been increased; and without some striking or beautiful feature, extent alone is seldom interesting.

If large trees, river scenery, or bold inequality of ground can be included by enlarging a park, they are sufficient motives; but views of distant mountains, which may be seen as well from the highroad, are not features that justify extensive lawn over a flat surface. ${ }^{32}$ 
'To do away with the impression of confinement at Attingham, the park should be extended across the road, and thus the stranger will be induced to believe he passes through and not at the extremity of the park. Secondly, some striking and interesting features should be brought into notice, such as the junction of the Severn and the Terne, which may be actually effected within the limits of the park; and particularly the great arch across the Terne, of which no adequate advantage is at present taken. There are, also, some large trees and many interesting points of view, which well deserve attention in a plan professing to increase the number of beautiful circumstances rather than the number of acres in the park.

In opposition to Mr. Price's idea, that all improvement of scenery should be derived from the works of

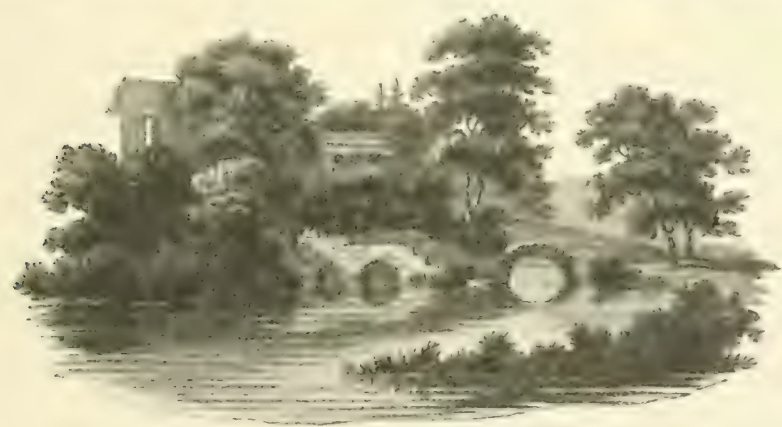

Fig. 2x. Scene in the grounds at Attingham

great painters, I shall observe that there are, at present, very near the house, some fragments of an old mill and brick arches [see Fig. 21] which make a charming study for a painter; the composition is not unlike a beautiful picture of Ruisdale's, at Attingham, which every man of taste must admire: of this scene, as it now exists, I have endeavoured to give a faint idea. 
Among the trees is seen part of the colonnade that joins the east wing to the body of the house: from the general character of this scenery, we cannot but suppose this to be a fragment of some ruined Grecian temple, and no part of a modern inhabited palace. Hence it is evident that the mind cannot associate the ideas of elegance with neglect or perfect repair and neatness with ruin and decay: such objects, therefore, however picturesque in themselves, are incongruous and misplaced if near such a palace as Attingham.

Another mistake of the admirers of painters' landscape is the difference in the quantity of a natural and an artificial composition: the finest pictures of Claude (and here again I may refer to a picture at Attingham) seldom consist of more than one fifth of that field of vision which the eye can with ease behold, without any motion of the head, viz. about 20 degrees out of 90 ; and we may further add that without moving the body our field of vision is extended to 180 degrees.

Now it is obvious that the picture of Claude, already mentioned, which is between four and five feet long, if it had been extended to 20 or 30 feet, would not have been so pleasing a composition; because, instead of a picture, it would have resembled a panorama. This I may further instance, in the view from the breakfastroom, consisting of a distant range of mountains, by far too long for any picture. Yet a small part of this view might furnish a subject for the painter, by supposing a tree to form the foreground of the landscape. Are we then to plant such a tree, or a succession of such trees, to divide the whole field of vision into separate landscapes? and would not such an attempt at improvement be like placing five or six pictures of Claude in one long frame? The absurdity of the idea 
proves the futility of making pictures our models for natural improvements: however I may respect the works of the great masters in painting, and delight to look at nature with a painter's cye, yet I shall never be induced to believe that " the best landscape painter would be the best landscape gardener." 33

The River Terne, being liable to floods from every heavy shower of rain which falls upon the neighbouring hills, has formed a number of different channels and islands: some of these channels are dry when the water is low, and some of the islands are covered when the water is high. These irriguous appearances have charms in the eye of a landscape painter, who, from some detached parts, might select a study for a foreground, at a happy moment when the water is neither too high nor too low. But the landscape gardener has a different object to effect; he must secure a constant and permanent dispiay of water, which may be seen at a distance, and which shall add brilliancy and grandeur to the character of the scenery : it is not an occasionally meandering brook that such a palace or such a bridge requires, but it is an ample river, majestically flowing through the park, and spreading cheerfulness on all around it.

Mr. Price has written an essay to describe the practical manner of finishing the banks of artificial water, but I confess, after reading it with much attention, I despair of making any practitioner comprehend his meaning; indeed, he confesses that no workman can be trusted to execute his plans. It is very true that large pieces of water may be made too trim and neat about the edges, and that often, in Mr. Brown's works, the plantations are not brought near enough to the water; but if the banks are finished smoothly at first, 
the treading of cattle will soon give them all the irregularity they require; and with respect to plantations, we must always recollect that no young trees can be planted without fences, and every fence near the water is doubled by reflection; consequently, all rules for creating bushes to enrich the banks are nugatory, except where cattle are excluded.

The difficulty of clothing the banks of artificial water has been a source of complaint made against Mr. Brown, for having left them bare and bald; bat the river at Attingham will be sufficiently enriched by the few trees already growing on its margin, and by the plantations proposed on the island.

There is a part of the River Terne, above the house, where both its banks are richly clothed with alders, and every person of discernment must admire the beauty of this scene, but if the same werc continued quite to the bridge the river would be invisible from the house and from every part of the park : how, then, is it possible that the banks of water should everywhere be covered with wood? I contend that a broad ample channel, in proportion to the bridge, will be far more in character with the style of the house and the bridge than the more intricate, which, on paper, is perhaps more picturesque. If it is ridiculous to imitate nature badly in a picture, how much more ridiculous will it appear to imitate a picture badly in nature; an imitation which, after all, must be left for half a century, to be finished by the slow process of "neglect and accident."

The water at Attingham having been completed, and a new channel made to connect the River Terne with the Severn, the improvement is obvious to every person who travels the great road to Shrewsbury : it is 
therefore needless to elucidate these observations by any views of the place, especially as painting can give but an imperfect idea of the situation commanding that extensive range of hills which separates England from Wales. 


\section{Chapter X}

Ancient and Modern Gardening-Change of Style - Art and Nature considered

$T^{T}$ is not my intention to enter into a minute history I f gardening, or, pursuing the course of some other writers, to trace back the gradual progress of the art from Brown to Kent, from Kent to Le Nôtre, from him to the Italians, the Romans, the Grecians, and, ultimately, to Adam, who was "the first gardener"; but I shall confine myself to a few observations on the change in the fashion of gardens, to shew how much of each different style may be preserved or rejected with advantage; and lest it should appear to some readers that my allusions are too frequent to the late theoretical writers on landscape gardening, it is necessary to observe that many of the manuscripts whence I now transcribe were written long before Mr. Knight's and Mr. Price's works appeared; of course the allusions relate to other authors on the subject, whose sentiments these gentlemen seem to have taken up without acknowledging that they had ever read them.

It may not be uninteresting here to mention a few of the authors who have written on gardening, especially as the works of some are become scarce, and are not generally known.

I scarcely need mention the late Horace Walpole, who, in his lively and ingenious manner, has given both the history and the rules of the art better than any other theorist. 
The history of gardening is very learnedly discussed, in a brief inquiry into the knowledge the ancients possessed of the art, by Dr. Faulkner; and the same subject is more lightly but not less correctly or elegantly treated by my late ingenious friend, Daniel Malthus, Esq., in a preface to his translation of "D'Ermenonville de la Composition des Paysages."

Every person the least interested in this study must have read the beautiful Poems of Mason, and De Lisle, the "Oriental Gardening" of Sir William Chambers, and the "Observations on Modern Gardening," by Mr. Whately; but, perhaps, few have seen that elaborate performance, in five volumes quarto, published in German and also in French, under the title of "Théorie de l'Art des Jardins," by M. Hirschfeld, a work in which are collected extracts from almost every book, in every European language, that has any reference to the scenery of nature or to the art of landscape gardening. ${ }^{34}$

When gardening was conducted by the geometric principles of the school of Le Notre, the perfection of planting was deemed to consist in straight lines of trees, or regular corresponding forms of plantation; and as the effect of this style of gardening greatly depended on alevel surface of ground, we often find that prodigious labour was employed to remove those inequalities which nature opposed to this ill-judging taste.

At Wimpole the natural shape of the surface seemed to invite this fashion for geometric forms; the ground was covered in every direction with trees in straight lines, circles, squares, triangles, and in almost every mathematical figure. These had acquired the growth of a century when the taste of gardening changed, and as every absurd fashion is apt to run from one extreme to 
another, the world was then told that "Nature abhorred a straight line"; that perfection in gardening consisted in waving lines; and that it was necessary to obliterate every trace of artificial interference. And now many a lofty tree, the pride and glory of our ancient palaces, was rooted up, because it stood on the same line with its fellows and contemporaries; and hecause these ranks of sturdy veterans could not, 35 like a regiment of soldiers, be marched into new shapes, according to the new system of tactics, they were unmercifully cut down ; not to display beautiful scenery behind them, hut merely to break their ranks: while a few were spared which could be formed into platoons: - this was called clumping an avenue.

The position of all the large trees on the plain near the house at Wimpole shews the influence of fashion in these different styles; the original lines may be easily traced by the trees which remain, and the later formcd clumps are scattered about, like the ghosts of former avenues, or monstrous shapes which could not be subdued.

One great advantage of Wimpole arises from its comparative beauty, or the contrast between the place and its environs. The counties of Cambridge and Huntingdon consist generally of flat ground, while the hi!ls are open corn-fields thinly intersected by hedges. But Wimpole abounds in beautiful shapes of ground and is richly clothed with wood; it is, therefore, like a flower in the desert, beautiful in itself, but more beautiful by its situation. Yet no idea of this beauty can be formed from the approach to the house, because the plain is everywhere covered with lofty trees which hide not only the inequalities of the ground, but aiso the depth of wood in every direction; and although the original straight lines of the trees have been partially 
broken, the intervals shew none of the varied scenery beyond. I do not, therefore, hesitate to say that, by judiciously removing some hundred trees, the place would be made to appear more wooded: for it frequently happens that a branch near the eye may hide a group of twenty trees, or a single tree conceal a whole grove.

In thus recommending the liberal use of the axe, I hope I shall not be deemed an advocate for that bare and bald system of gardening which has been so justly ridiculed. I do not profess to follow either Le Notre or Brown, but, selecting beauties from the style of each, to adopt so much of the grandeur of the former as may accord with a palace and so much of the grace of the latter as may call forth the charms of natural landscape. Each has its proper situation ; and good taste will make fashion subservient to good sense.

The modern rage for natural landscape has frequently carried its admirers beyond the true limits of improvement, the first object of which ought to be convenience, and the next picturesque beauty.

My taste may, perhaps, be arraigned for asserting that the straight terrace at the Hasells ought not to be disturbed: although it is a remnant of geometric gardening of the last century, yet it is an object of such comfort and convenience that it would be unpardonable to destroy it for no other reason than because a straight walk is out of fashion; this would be acknowledging (what I protest against) that the art of landscape gardening ought to be under the dominion of fashion.

If this terrace were constantly an object of view, or very materially offensive to the general scenery of the place, its linear direction might cut the composition 
and destroy its effect as a natural landscape: in its present situation it is merely a foreground or frame to a pleasing picture, and the view from hence is so fine, so varied, and so interesting that the spectator must be fastidious indeed who could turn away disgusted, because it is seen over a clipt hedge, or with a broad flat walk in its foreground. A beautiful scene will always be beautiful, whether we view it from an alcove, a window, or a formal terrace: and the latter, in the height of summer, may sometimes answer the purpose of an additional room or gallery when there is much company, who delight to saunter on such an esplanade; while the intricacies of a winding path are better calculated for a solitary walk.

The ancient dignity of character in the house at Cobham would be violated by the too near intrusion of that gay prettiness which generally accompanies a garden-walk; yet convenience and comfort require such a walk at no great distance from the house. ${ }^{3^{6}}$ I shall, perhaps, astonish some of the improvers in modern serpentine gardening by declaring that, as an appendage to this ancient mansion, I would prefer the broad and stately mall along a straight line of terrace to their too frequently repeated waving line of beauty.

This sort of walk may, I think, be still further encouraged, where it already in some degree exists, to the north of the kitchen-garden, which, falling from the eye, might easily be concealed from the park by a shrubbery kept low; not to intercept the view towards the opposite bank in the park, while it would give an imaginary increase of depth to the vale beneath. And to remove the objection of returning by the same walk, a second terrace might be carried still higher on the bank, and by the style and accompaniment of its planta- 
tion, all sameness would easily be obviated, perhaps, by making one of them a winter walk, planted chiefly with evergreens and shrubs. To justify my opinion it is necessary to guard against a misconstruction of what I have advanced, lest I may be accused of reviving the old taste of gardening. I do not recommend the terrace as an object of beauty in all cases, but of convenience; for the same reason that I advise the proximity of a kitchen-garden, provided the principal apartments do not look upon either.

Our ancestors were so apt to be guided by utility that they at length imagined it was in all cases a substitute for beauty; and thus we frequently see ancient houses surrounded not only by terraces, avenues, and fish-ponds, but even stables and the meanest offices formed a part of the view from the windows of their principal rooms. I am far from recommending a return to these absurdities; yet, in the rage for picturesque beauty, let us remember that the landscape holds an inferior rank to the historical picture: one represents nature, the other relates to man in a state of society. If we banish winter comforts from the country-seats of our nobility, we shall also banish their inhabitants, who generally reside there more in winter than in summer; and there is surely no object of greater comfort and utility belonging to a garden and a country mansion, than a dry spacious walk for winter, sheltered by such trees as preserve their clothing, while all other plants are destitute of foliage.

I will add the opinion of a very able commentator, who, mentioning "this self-evident proposition, that a rural scene in reality and a rural scene on canvas are not precisely one and the same thing," says, "that point in which they differ here is not itself without a guiding 
principle: utility sets up her claim and declares that, however concurrent the genuine beauty of nature and picture may be, the garden scene is hers, and must be rendered conformable to the purposes of human life; if to these every consonant charm of painting be added, she is pleased; but by no means satisfied, if that which is convertible to use he given absolutely to wildness." 37

The natural situation of Burley differs from that of every other large place which has fallen under my consideration. To say that the house stands on a lofty hill would be giving a very imperfect idea of its situation; on the contrary, it ought rather to be described as a magnificent palace, built on the extremity of a vast plain, or, what is called by geographers, a table mountain, from the brow of which it boldly commands an assemblage of wood, water, lawn, and distant country, spread magnificently at its base.

The view from the principal suite of apartments, however rich and varied in itself, becomes much more interesting by the power of contrast, because the great plain to the north affords no promise of such views, and, therefore, the surprise occasioned by this unexpected scenery, is a subject worthy the attention of the improver: the effects of surprise are seldom to be produced by art, and those who attempt to excite it by novelty or contrast are in danger of falling into puerile conceits. ${ }^{3}$ But where, as in the present instance, much of the natural sublime exists, this effect should be increased by every means which does not betray the insignificance of art, when compared with the works of nature. For this reason, if the approach were brought along the straight line of avenue, gradually ascending, the situa- 
tion of Burley would lose much of its sublimity by anticipation.

The prevalence of fashion, in all subjects of taste, will at times have its influence, but as fashion is more the effect of whim and caprice than of reason and argument, it has been my great object to rescue landscape gardening from its fascinating power; and while accommodating myself to the wishes of those who consult me, to the customs of the times, or to the peculiarity of various situations and characters, I hope never to lose sight of the great and essentia! object of my profession, the elegance, the magnificence, and the convenience of rural scenes, appropriated to the uses of a gentleman's habitation. ${ }^{39}$

'This may be equally effected, whether we revert to the formal fashion of straight walled gardening or adopt the serpentine lines of modern improvers, under the pretended notion of imitating nature. But there is a certain dignity of style in Burler, which, like the cumbrous robes of our nobility, neither can nor ought to he sacrificed to the innovation of fashion or the affectation of ease and simplicity.

Mr. Burke justly observes that "a true artist should put a generous deceit on the spectators and effect the noblest designs by easy methods. Designs that are vast only by their dimensions are always the sign of a common and low imagination. No work of art can be great but as it deceives; to he otherwise is the prerogative of nature only." This precept seems to have been overlooked in the attempt to modernise Burler: the spacious court surrounded by a colonnade has been frequently quoted as a wonderful effort of art: and when the distant country was excluded by a wall, by the village, and by trees beyond it, this ample area was 
undoubtedly one of the most striking appendages of a palace. But the moment one side of the quadrangle is opened to the adjacent country, it shrinks from the comparison, and the long fronts of opposite offices seem extended into the vast expanse, without any line of connexion. This comparative insignificancy of art is nowhere more strongly exemplified than in the large wet docks of Liverpool and Hull: while the margins of the river are left dry by the ebbing tides, we look with astonishment at the capacious basins filled with a vast body of water, but when the tide flows to the same level, and the floodgates are thrown open, the extent and importance of the river convert these artificial basins into creeks or mere pools. It is, therefore, only by avoiding a comparison with the works of nature that we can produce the effect of greatness in artificial objects; and a large court surrounded by buildings can have no pretensions to be deemed a natural object.

After removing the wall which formed the front of the court, a doubt arose whether the present gate and porter's lodge should or should not remain, and how to approach the house to the greatest advantage.

There is a certain point of distance from whence every object appears at its greatest magnitude: but in cases where symmetry prevails, the distance may be rather greater, because exact correspondence of parts assists the mind in forming an idea of the whole. I should therefore conceive that the effect of surprise, of magnificence, and of the sublime, in this effort of art, is greatly injured by seeing the interior of this ample court before we arrive at the entrance gate; because that is nearly the spot where the eye is completely filled 
and gratified by the surrounding objects. But as this view should not be momentary, I suppose the road to continue from the gate in a straight line, till it falls into a circle with the colonnade; and here the broad road may be intercepted with posts and chains, to direct carriages into that course which displays the whole area to the greatest advantage, passing nearer to the side colonnade, shewing that in perspective, and presenting the house at the angle to shew its depth. The manner in which this is effected by sweeping round the court is not to be described by painting, because every step varies the position of the several parts, as they advance or recede perspectively.

Hitherto I have spoken of the north or entrance front and courtyard of Burley, the whole of which I would treat only as a work of art, and, if possible, exclude all view of the country. But to the south, the prospect or natural landscape is the leading feature for our consideration. The steep descent from the house has been cut into a number of terraces, each supported by a red brick wall; and if these several walls had been of stone, or architecturally finished like the old costly hanging-gardens of France and Italy, they might perhaps have added more magnificence to the house than any improvement which modern gardening could suggest, but they are mean in their forms, diminutive in their height, and out of harmony in their colour. Yet the style of the house and the steepness of the declivity will not admit of their heing all taken away to slope the ground, in the manner too often practised by modern improvers.

I therefore make a compromise between ancient and modern gardening, between art and nature, and by increasing the height, or rather the depth, from the upper 


\section{I70 The Art of Landscape Gardening}

terrace to the lower level of the ground, I make that the line of demarcation beween the dressed ground and the park; and happy would it be for the magnificence of English scenery if many such stately terraces near a palace had been thus preserved. 


\section{Chapter XI}

Endless Variety of Situation and Cibaracter-First Impressions - Roads - Entrances - Adaptation of Ornamental Buildings

T HAVE occasionally been asked, when visiting a I beautiful spot, which, of all the places I had seen, was the most beautiful? It is impossible to define those circumstances which, on different persons, make different impressions at first sight; perfection is no more to be found in the works of nature than in those of art. Such is the equal providence of the great Author of nature that every place has its beauties and its deformities, and, whether situated among the mountains of Wales or on the margin of Clapham Common, it will not only be endeared to its proprietor, but to the discerning stranger, by some peculiar features of beauty.

The materials of natural landscape are ground, wood, and water, to which man adds buildings, and adapts them to the scene. It is therefore from the artificial considerations of utility, convenience, and propriety, that a place derives its real value in the eyes of a man of taste: he will discover graces and defects in every situation; he will be as much delighted with a bed of flowers as with a forest thicket, and he will be as much disgusted by the fanciful affectation of rude nature in tame scenery as by the trimness of spruce art in that which is wild: the thatched hovel in a flower-garden and the treillis bocage [grove trellis, trellis-work arched overhead] in a forest are equally misplaced. 
General principles, or general designs, which may be applicable to all situations, would be alike impossible. The painter copies, in their respective places, the eyes, the nose, and mouth of the individual, but, without adding character, his picture will not be interesting. The landscape gardener finds ground, wood, and water, but with little more power than the painter, of changing their relative position; he adds character, by the point of view in which he displays them, or by the ornaments of art with which they are embellished. To describe by words the various characters and situations of all the places in which I have been consulted would be tedious, and to give views of each would alter the design of this work: I shall, therefore, dedicate this chapter to a miscellaneous assemblage of extracts from different Red Books, without aiming at connexion or alrangement. These may furnish examples of variety in the treatment of various subjects; while the reasons on which their treatment is founded will, I hope, be deemed so far conclusive that some general principles may be drawn from them, tending to prove that there are rules for good taste.

There is no principle of the art so necessary to be studied as the effects produced on the mind by the first view of certain objects, or, rather, that general disposition of the human mind by which it is capable of strongly receiving first impressions. We frequently decide on the character of places, as well as of persons, with no other knowledge of either than what is acquired by the first glance of their most striking features; and it is with difficulty or with surprise that the mind is afterwards constrained to adopt a contrary opinion. Thus, if the approach to a house he over a flat plain 
we shall pronounce the situation to be flat also, although the ground immediately near the house be varied and uneven; whilst, on the contrary, if the road winds its course over gentle hills and dales and at length ascends a steep bank to the house, we shall always consider it as standing on an eminence, although the views from the house may be perfectly flat.

I have, therefore, watched with nice attention the first ideas which have occurred to me in visiting any new subject; and if a more intimate knowledge of it induces me afterwards to alter my opinion, I then inquire into the causes which influenced my former false judgement, that I may by this means increase or diminish them accordingly.

One of the first objects of improvement should be to adapt the character of the grounds to that of the house; and both should bear some proportion to the extent of property by which they are surrounded.

At Stoke, in Herefordshire, the house and park are as perfectly separated from each other by a turmpike road as if they were the property of different persons; and both are seen from that road in the most unfarourable points of view. Of the house little is visible except the roof and chimneys; and with respect to the park, which naturally abounds with the most pleasing shapes of ground, richly clothed with wood, the road passes so immediately at the foot of the declivity that the whole appears foreshortened, and all its beauties are entirely lost. To divert the course of this road, therefore, becomes the first object of improvement.

I have, on several occasions, ventured to condemn as false taste that fatal rage for destroying villages or depopulating a country, under the idea of its being 
necessary to the importance of a mansion: from the same Red Book the following extract is taken:

As a number of labourers constitutes one of the requisites of grandeur, comfortable habitations for its poor dependants ought to be provided. It is no more necessary that these habitations should be seen immediately near the palace than that their inhabitants should dine at the same table; but if their humble dwellings can be made a subordinate part of the general scenery, they will, so far from disgracing it, add to the dignity that wealth can derive from the exercise of benevolence. Under such impressions and with such sentiments I am peculiarly happy in being called upon to mark a spot for new cottages, instead of those which it is necessary to remove, not absolutely because they are too near the house, for that is hardly the case with those cottages in the dell, but because, the turnpike road being removed, there will be no access for the inhabitants but through a part of the park, which cannot then be private. I must advise, however, that some one or more of the houses in this dell be left, and inhabited either as a keeper's house, a dairy, or a menagerie, that the occasional smoke from the chimneys may animate the scene. The picturesque and pleasing effect of smoke ascending, when relieved by a dark hanging wood in the deep recess of a beautiful glen like this, is a circumstance by no means to be neglected.

As an example of a place in a mountainous country the following extract from the Red Book of Rüg, in North Wales, is subjoined:

At a period when the ancient family honours of a neighbouring country are rooted out with savage barbarity, I rejoice in an opportunity of contributing my assist - 
ance to preserve in this, every vestige of ancient or hereditary dignity; and I should feel it a kind of sacrilege in taste to destroy an atom of that old, ruinous, and almost uninhabitable mansion at $R \ddot{u g}$, if it were to be replaced by one of those gaudy scarlet houses, which we see spring up, like mushrooms, in the neighbourhood of large manufacturing towns. I am, however, restrained from indulging to its full extent my veneration for antiquity, by reflecting that modern comfort and convenience are the first objects to be consulted in the improvement of a modern residence; and therefore I trust I shall neither incur the censure of those who know and feel the comforts of the age we live in nor offend the genius of the place by "calling from the vasty deep the angry spirits" of ()wen Glendwr of Burgontumi, who formerly inhabited this domain.

In a country like that of North Wales, abounding in magnificent scenery, the views from the house should rather aim at comfort and appropriation of landscape than extensive prospect; because the latter may be had from every field or public road on the mountains, and the attempt to make a large park or domain would be fruitless where a lawn of a thousand acres would appear but a small spot, compared with the wide expanse of country seen from the neighbouring hills. I should therefore advise the lawn to be confined within the compass of forty or fifty acres; yet from the variety of its surface and the diversity of objects it contains there will be more real beauty and even magnificence within this small enclosure than in other parks of many hundred acres.

However partial we may be to grand and extensive prospects, they are never advisable for the situation of a house, in which convenience and comfort should doubt- 
less take the lead of every other consideration. The frequent rains and violent storms of wind to which all mountainous countries are exposed, have taught the mhabitants not only to choose warm valleys for their houses, but have also introduced a style of architecture peculiarly suited to those situations: the small towns of Llangollen and Corwen, as well as those in the mountains of Switzerland, have all low sheds or penthouses, under which the inhabitants may take shelter from occasional driving storms. The arcade of Gothic architecture is infinitely more applicable to such situations than the lofty portico of Greece, which is rather calculated for those warm regions where man wants protection from the vertical beams of a burning sum. I hope, therefore, that both the character and situation of Rüg will justify a design for a new house, which may possess a degree of grandeur and magnificence not incompatible with modern convenience.

There is no circumstance in which bad taste is so conspicuous as in the misuse of ornaments and decorations; an observation equally applicable to all the polite arts, and not less true with respect to eloquence, poetry, music, and painting than to architecture and gardening. Thus, for instance, a rural scene may be delightful without any building or work of art, yet, if judiciously embellished by artificial objects in character with the scene, the landscape will be more perfect; on the contrary, if encumbered by buildings in a bad taste, or crowded by such as are too large, too small, or in any respect inapplicable, however correct they may be as works of art, the scene will be injured, and thus a thatched hovel may be deemed an ornament, where a Corinthian temple would be misplaced, or wice versa. 
In this miscellaneous chapter may properly be inserted some specimens of various buildings, to elucidate the truth of an observation, which hardly seems to require enforcing; yet the frequent introduction of ornamental buildings, copied from books, without reference to the character and situation of the scenery, is not less fatal to the good taste of the country than it would be to the life of individuals to use medical prescriptions without inquiring into the nature and cause of diseases.

The facility with which a country carpenter can erect sma!l buildings intended for ornament may perhaps account for their frequency; but I am not ashamed to confess that I have often experienced more difficulty in determining the form and size of a hovel or a park entrance than in arranging the several apartments of a large mansion; indeed, there is no subject on which $I$ have so seldom satisfied my own judgement as in that of an entrance to a park.

The custom of placing a gate between two square boxes, or, as it is called, a "pair of lodges," has always appeared to me absurd, because it is an attempt to give consequence to that which in itself is mean; the habitation of a single labourer, or perhaps of a solitary old woman to open the gate, is split into two houses for the sake of childish symmetry. As this absurd fashion of a pair of lodges deserves to be treated with ridicule, I cannot help mentioning the witty comment of a celebrated lady, who, because they looked like tea-caddies, wrote on two such lodges, in large letters, "Green" and "Bohea." And very often the most squalid misery is found in the person thus banished from society, who inhabits a dirty room of a few feet square. It is the gate, and not the dwelling of the person who opens it, that ought to partake of the character of the house, 


\section{i 78 The Art of Landscape Garuening}

where architectural display is necessary; and this principle seems to point out the true mode of marking the entrance to a place.

An arched gateway at the entrance of a place is never used with so much apparent propriety as when it forms a part of a town or village; at least it should be so flanked by lofty walls as to mark the separation between the public and the park and increase the contrast, but when seen in contact with a low park-pale, or even an iron palisade, it appears to want connexion: it looks too ostentatious for its utility, and I doubt whether it would not lessen the pleasure we derive from viewing the magnificent Grecian arches at Burlington House and at Blenheim if the side walls were lower.

In recommending the use of an arch, I must guard against being misunderstood, by mentioning several circumstances which I deem objectionable.

Ist. The arch should not be a mere aperture in a single wall, but it should have depth in proportion to its breadth.

$2 \mathrm{~d}$. It should have some visible and marked connexion either with a wall or with the town to which it belongs, and not appear insulated.

$3 \mathrm{~d}$. It should not be placed in so low a situation that we may rather see over it than through it.

4th. Its architecture should correspond with that of the house, in style, if not in order; that is, the Grecian and Gothic should be kept separate, although the design may not be copied from the house. And,

Lastly. Neither the house should be visible from the entrance nor the entrance from the house, if there be sufficient distance between them to make the approach through a park and not immediately into a courtyard; the two last general rules are equally applicable 
to every sort of entrance, as well as that through an arch, yet there are certain situations where the latter cannot be avoided. () f this, an instance occurred ir Stoke Park, Herefordshire, where the gate and the cottage near it were disguised by the portico, represented in the following sketch [Fig. 22], which forms a pavilion, or covered seat, adjoining to the walk in the shrubbery.

In various situations various expedients have been adopted; thus, at Antony, I recommended, near the gate, a cottage, over which is a room, to command the fine view of the harbour, etc. At St. John's, in the Isle of Wight, two cottages covered with flowering creepers attract the notice of all who visit the island; and while one is a comfortable residence for a family, the other consists of a room near the roadside, from whence the mind derives peculiar satisfaction in seeing the constant succession of visitors who leave their homes in search of happiness. In some places the cottage is more conspicuous, by dividing the road to the house from the public road, as at Milton; but, in most cases, I have endeavoured to conceal the cottage, when it is quite solitary, among the trees, only shewing the gate of entrance.

Concerning gates, it may not he improper to mention my opinion, with reasons for it.

Ist. As an entrance near a town, I prefer close wooden gates, for the sake of privacy, except where the view is only into a wood, and not into the open lawn.

2d. The gates should be of iron, or close boards, if hanging to piers of stone, or brick-work; otherwise an open or common field-gate of wood appears mean, or as if only a temporary expedient. 
3d. If the gates are of iron, the posts or piers ought to be conspicuous, because an iron gate hanging to an iron pier of the same colour is almost invisible; and the principal entrance to a park should be so marked that no one may mistake it.

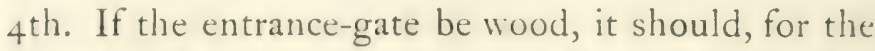
same reason, be painted white, and its form should rather tend to shew its construction than aim at fanciful ornament of Chinese, or Gothic, for reasons to be explained in speaking of decorations.

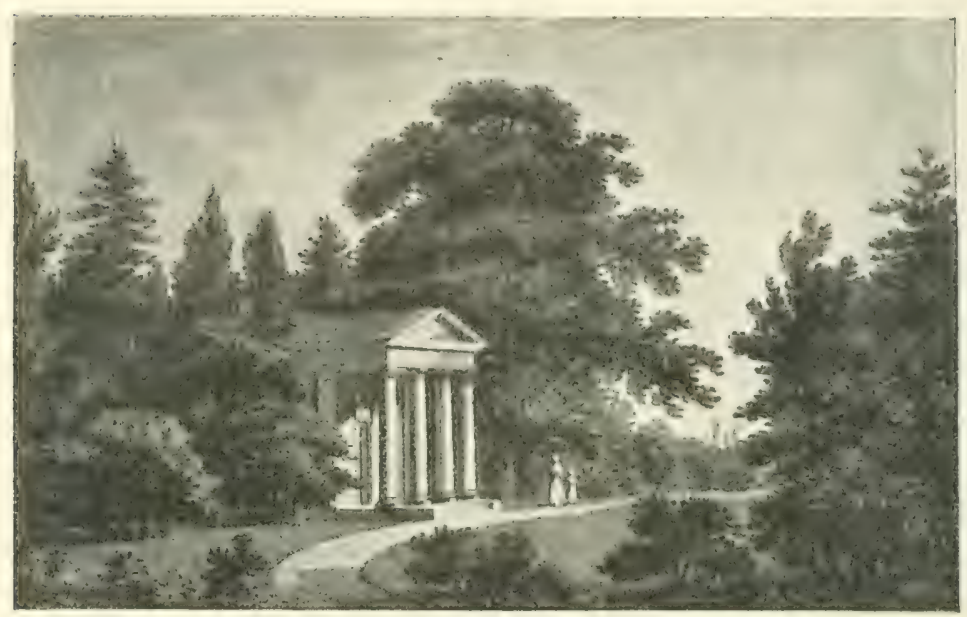

Fig. 22. Stoke Park, Herefordshire.

It is not sufficient that a building should be in just proportions with itself; it should bear some relative proportion to the objects near it. The example given [Fig. 22] is the Doric portico at Stoke Park, in Herefordshire, where the size of the building was regulated by a large oak and a young plantation near it: had this building been more lofty, it would have overpowered the young trees by which it is surrounded, and a smaller 
building would have appeared diminutive so near to the neighbouring large oak; I therefore judered that the best rule for the dimensions of the columns was rather less than the diameter of the oak, and this, of course, determined the whole proportion of the Doric portico.

So prevalent is the taste for what is called Gothic, in the neighbourhood of great cities, that we see buildings of every description, from the villa to the pig-sty, with little

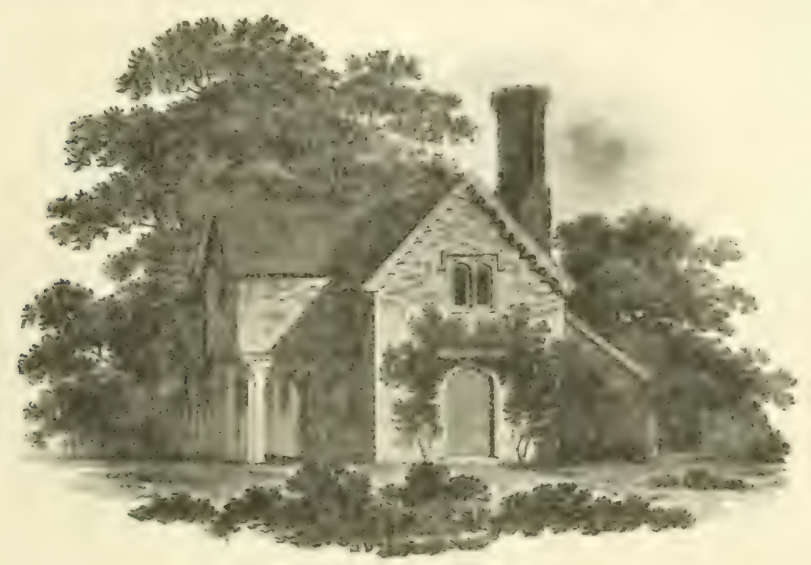

Fig. 23. Gothic Cottage

pointed arches or battlements, to look like Gothic; and a Gothic dairy is now become as common an appendage to a place as were formerly the hermitage, the grotto, or the Chinese pavilion. Why the dairy should be Gothic, when the house is not so, I cannot understand, unless it arises from that great source of bad taste, to introduce what is called a pretty thing without any reference to its character, situation, or uses. Even in old Gothic cottages we never see the sharp-pointed arch, but often the flat arch of Henry VIII, and perhaps there is no form more picturesque for a cottage than buildings of that 
date, especially as their lofty perforated chimneys not only contribute to the beauty of the outline, but tend to remedy the curse of the poor man's fireside, a smoky house [see Fig. 23].

There are few situations in which any building, whether of rude materials or highly finished architecture, can be properly introduced without some trees near it. Yet the summit of a naked brow, commanding views in every direction, may require a covered seat or pavilion; for such a situation, where an architectural building is proper, a circular temple with a dome, such as the temple of the Sybils, or that of Tivoli, is best calculated; but in rude scenery, as on a knoll or promontory in a forest, the same idea may be preserved in a thatched hovel supported by rude trunks of trees; yet, as the beauty of such an object will greatly depend on the vegetation, it should be planted with ivy or vines, and other creeping plants should be encouraged to spread their foliage over the thatch.

The principal view from the house at Blaize Castle is along that rich glen of wood through which the approach has been made, as already described: in this view, the castle, although perfectly in harmony with the solemn dignity of the surrounding woods, increases rather than relieves that apparent solitude which is too sombre for the character of a villa.

Some object was wanting to enliven the scenery: a temple, or a parilion, in this situation, would have reflected light, and formed a contrast with the dark woods; but such a building would not have appeared to he inhabited; this cottage [Plate xvI] therefore derives its chief beautyfrom that which cannot easily be expressed by painting - the ideas of motion, animation, 


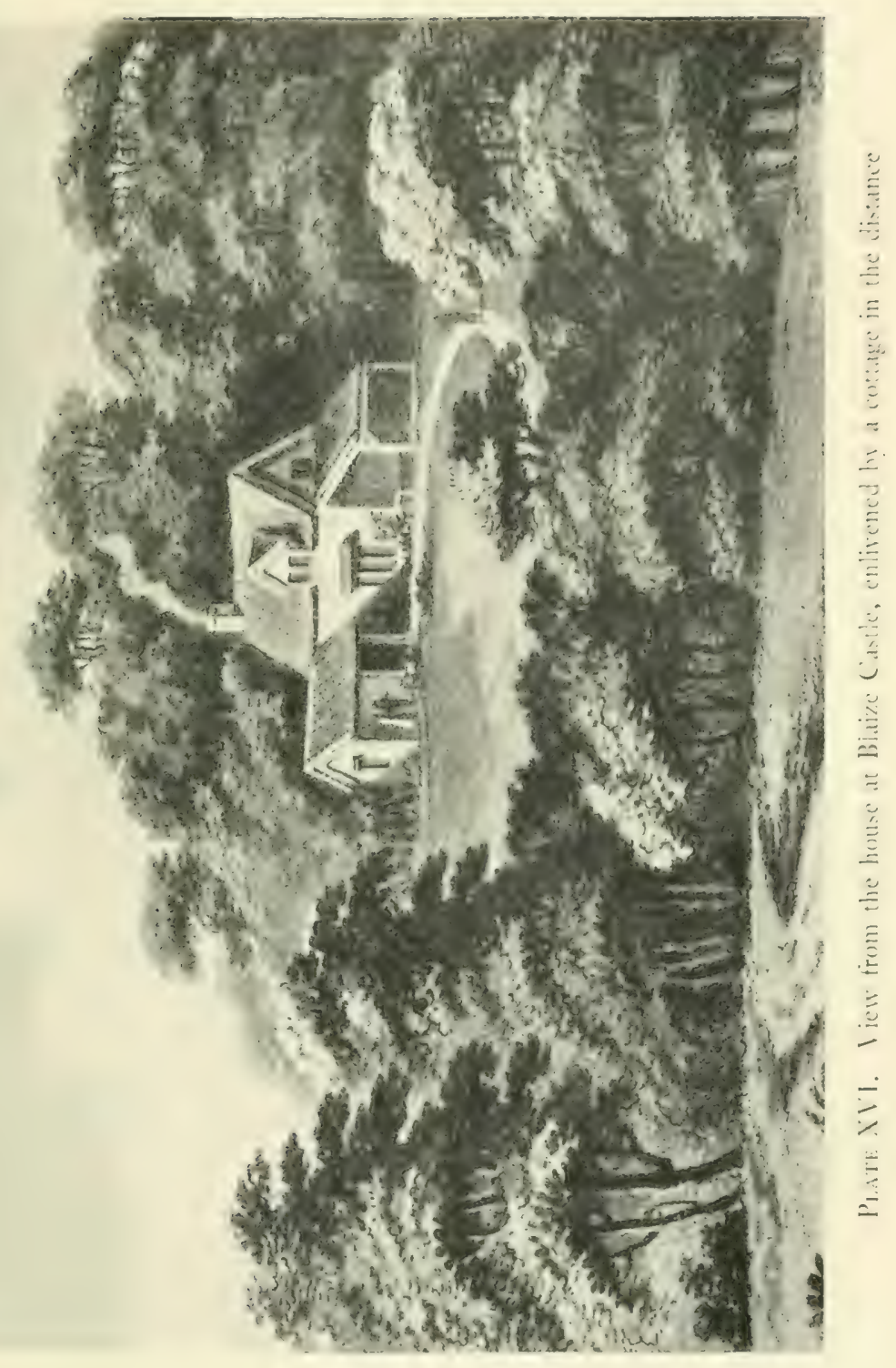



and inhabitancy, contrasted with those of stillness and solitude. Its form is meant to be humble, without meanness; it is and appears the habitation of a labourer who has the care of the neighbouring woods; its simplicity is the effect of art, not of neglect or accident; it seems to belong to the mansion, and to the more conspicuous tower, without affecting to imitate the character of either.

The propensity for imitation, especially where no great trouble or expense is incurred, has made treillage ornaments so common that some observations concerning them may be expected in this work, especially as I believe I may have contributed originally to their introduction; but I little thought how far this flimsy ornament might be misapplied.

The treillages of Versailles and Fontainebleau were of substantial carpentry, preserving architectural proportions, in which plants were confined and clipped to form a sort of vegetable and architectural bercean or cabinet de ierdure; these being made of strong wood and painted were more costly and more durable; and as they only formed a frame for the plants, they might perish without injuring the forms of these leafy buildings; but the Iinglish treillage is made of such slight materials and so slightly put together that they can hardly outlive the season for which they are erected. This, however, is no objection where they are used in flower-gardens, or where they are merely to be considered as garden-sticks supporting plants; but when added to architectural houses and made the supporters of a heavy roof or even a canvas awning, it looks as if the taste of the country were verging to its decline, since shade might be obained by the same awning 
supported by iron, if architectural forms and projections are to be despised or discarded.

I should therefore suppose that no treillage ought to be introduced except in situations where creeping plants may be fastened to the framing, which should be stout in proportion to its height or its intentions: it is a common mistake to suppose a thing will look light by being slender; if it be not equal to its office by its apparent substance, it will look weak, not light; but the latticework is supposed to support nothing, and may therefore be of any dimensions, and, being always painted, it will be invisible at a distance.

I could wish, in speaking of architecture, if the use of language would admit of such distinction, to make a difference between the words ornament and decoration. The former should include every enrichment bearing the semblance of utility; the latter is supposed to have no relation whatever to the uses or construction of the building; thus, for instance, a house may answer all the purposes of habitation withont a column, a pilaster, an entablature, a pediment, a dome, an arcade, or a balustrade, which I call the external ornaments of Grecian architecture. I include under the word decorations statues, vases, basso-relievos, sculpture, etc., which have no use but as additional enrichments to the ornaments of architecture; on the contrary, where these decorations are applied to plain buildings without ornaments, they are marks of bad taste.

The ornaments of architecture must be correct in design, since no degree of costliness in their materials or their workmanship can compensate for any defect in proportion, order, or disposition. The eyc of good taste will be equally offended with columns too larege or too 
small, too near or too far apart; in short, with every deviation from the established rules of the respective orders, whether such column be composed of marble, of stone, or of plastered brick-work, the costliness of the material makes no difference in the design. But this is not the case with decorations. The cheapness and facility with which good designs may be multiplied in papier mâcbé or putty composition have encouraged bad taste in the lavish profusion of tawdry embellishment.

This consideration leads me to assert that every species of enrichment or decoration ought to be costly, either in its materials or in its workmanship: and if we attend to the common opinion of all, except children and savages, we shall find that no real value is attached to any decoration, except upon this principle; on the contrary, it becomes contemptible in proportion as it affects to seem what it is not.

The idea of costliness in ornament is increased by its rarity, or, rather, by its being used only where it is most conspicuous, and this sort of economy is observable even in the works of nature; for instance, the most beautiful coloured feathers of birds are on the surface, while those for use, rather than for shew, are generally of a dirty brown; it may also be observed that those butterfies or moths, whose wings are ornamented on the under side, generally bear them erect, while those which have the upper side most beautiful generally spread them flat. The same remark may be extended to all the vegetable tribe; every flower and every leaf has one side more ornamented, more glossy, more rivid, or more highly finished than the other, and this is always the side presented to the eye. Hence we are taught, by the example of nature, not to lavish decorations where they cannot generally be seen. 
While treating on the subject of ornaments and decorations, I must not omit to mention colours, since improper colouring may destroy the intended effect of the most correct design and render ridiculous what would otherwise be beautiful. Both the form and the colour of a small house in Langley Park rendered it an object unworthy of its situation; yet, from peculiar circumstances, it was not deemed advisable either to remove it or to hide it by plantations. I therefore recommended a Doric portico to cover the front; and thus a building formerly unsightly, because out of character with the park, became its brightest ornament, doing honour to the taste and feelings of the noble proprietor, who preserved the house for having been a favourite retreat of his mother, and which, thus ornamented, may be considered as a temple sacred to filial piety.

In the following instances there is something more than harmony of colours; there is an association from habit, which causes part of our pleasure or disgust.

A compact red house displeases from the meanness of its materials, because we suppose it to be of common red bricks, although it may perhaps be of the red stone of Herefordshire.

On the contrary, a large pile of red buildings is not so displeasing; witness the houses of Cobham, Glemham, etc., and the royal palaces of St. James's, Hampton Court, Kensington, etc.; but perhaps the weather-stains of time may have contributed more than the quantity to reconcile us to the colour of these large masses.

Lime-whitened houses offend the eye, partly from the violent glare and partly from the associated meanness of a lath and plaster building, but if a little black and yellow be mixed with the lime, the resemblance to the colour of stone satisfies the eye almost as much as if it 
were built of the most costly materials; witness Woodley, Babworth, Taplow, etc.

To produce effect by difference of colour in buildings, such as red and yellow bricks, black and white flints, or even edging brick-work with dressings of stone, is the poor expedient of the mere bricklayer; the same may be observed of that paltry taste for pointing the joints of brick-work to render them more conspicuous, and, of course, more offensive.

As a general principle I should assert that no external effect or light and shade on a building ought to be attempted, except by such projections or recesses as will naturally produce them, since every effect produced by colour is a trick or sham expedient ; and on the same principle a recess in the wall is preferable to a painted window, unless it is actually glazed.

With respect to the colour of sashes and windowframes, I think they may be thus determined with propriety, first observing that from the inside of the room the landscape iooks better through bars of a dark colour; but on the outside, in small cottages, they may be green, because it is a degree of ornament not incompatible with the circumstances of the persons supposed to inhabit them, and even in such small houses as may be deemed cottages, the same colour may be proper. But in proportion as it approaches to a mansion, it should not derive its decoration from so insignificant an expedient as colour, and, therefore, to a gentleman's house the outside of the sashes should be white, whether they be of mahogany, of oak, or of deal, because, externally, the glass is fastened by a substance which must be painted, and the modern sash-frames are so light that unless we see the bars the houses appear at a distance unfinished and as having no windows. In 
palaces or houses of the highest description, the sashframes should be gilt, as at Holkham, Wentworth, etc. The effect of gold in such situations can hardly be imagined by those who have never observed it; and even at Thoresby, where the house is of red brick, the gilding of the sashes has wonderfully improved its importance.

There is a circumstance with respect to gold and gilding, of which few are aware who have not studied the subject. The colour of gold, like its material, seems to remove all difficulties and makes everything pleasing; this is evident on viewing a finely coloured picture on a crimson hanging, with or without a gold frame; two discordant colours may be rendered more harmonious by the intervention of gilding; it is never tawdry or glaring, the yellow light catches on a very small part of its surface, while the brown shadows melt into the adjoining colours, and form a quiet tint, never offensive : gold ornament may be applied to every colour and every shade, and is equally brilliant, whether in contact with black or white. All ornaments of gold should be more plain and simple than those of silver; not only because the costliness of the material renders the costliness of workmanship less necessary, but because the carved or enriched parts reflect very little light or brilliancy, compared with those that are plain.

On the contrary, in silver ornaments, if the surface be too plain, we annex the ideas of tin or pewter, and it is only by the richness or the embossing that its intrinsic value becomes apparent. These remarks are applicable to gold and silver plate,,$^{40}$ as well as to every species of ornament in which those metals can be used. Since the improvement in the manufactory of cast-iron has brought that material into more frequent use, it 
may not be improper to mention something concerning the colour it ought to be painted. Its natural colour, after it is exposed to wet, is that of rusty iron, and the colour of rust indicates decay ; when painted of a slate colour it resembles lead, which is an inferior metal to iron; and if white or green, it resembles wood: but if we wish it to resemble metal, and not appear of an inferior kind, a powdering of copper or gold dust on a green ground makes a bronze, and perhaps it is the best colour for all ornamental rails of iron. In a castiron bridge at Whitton the effect of this bronze colour, mixed with gilding, is admirable; and for the handrails of staircases it is peculiarly appropriate.

With respect to wooden fences or rails it is hardly necessary to say that the less they are seen the better; and therefore a dark, or, as it is called, an invisible green, for those intended to be concealed, is the proper colour; perhaps there can hardly be produced a more striking example of the truth, "that whatever is cheap is improper for decorations," than the garish ostentation of white paint, with which, for a few shillings, a whole country may be disfigured by milk-white gates, posts, and rails. 


\section{Chapter XII}

Arcbitecture and Gardening inseparable - Forms and Arrangements of Different Eras - Change in Customs alters Uses of Rooms

T $\mathrm{T}$ has been objected to my predecessor, Mr. Brown, I that he fancied himself an architect. The many good houses built under his direction prove him to have been no mean proficient in an art, the practice of which he found, from experience, to be inseparable from landscape gardening. He had not early studied those necessary but inferior branches of architecture, better known, perhaps, to the practical carpenter than to Paliadio himself, yet, from his access to the principal palaces of this country, and his intercourse with men of genius and science, added to his natural quickness of perception and his habitual correctness of observation, he became acquainted with the higher requisites of the art relating to form, to proportion, to character, and, above all, to arrangement. ${ }^{4 r}$

These branches of architecture are attainable without much early practice, as we have seen exemplified in the designs of certain noblemen, who, like Lord Burlington, had given their attention to this study. A knowledge of arrangement or disposition is, of all others, the most useful; and this must extend to external appendages as well as to internal accommodation.

This knowledge cannot be acquired without observing and comparing various houses under various circumstances; not occasionally only, but the architect 
must be in the habit of living much in the country and with the persons for whom he is to build, by which alone he can know their various wants with respect to comfort as well as to appearance; otherwise he will, like an ordinary builder, be satisfied in shewing his skill by compressing the whole of his house and offices under one compact roof, without considering aspect, views, approaches, gardens, or even the shape of the ground on which the house is to be built.

It is impossible to fix or describe the situation applicable to a house without at the same time describing the sort of house applicable to the situation. This is so evident that it scarcely requires to be pointed out; yet I have often witnessed the absurdity of designs for a house where the builder had never seen the situation. 1 have, therefore, long been compelled to make architecture a branch of my own profession.

Having occasionally observed the various modes by which large houses and their appendages have been connected at various periods, it may not be uninteresting if I attempt to describe them by reference to the annexed plans. [Plate xvir.]

No. I. The earliest form of houses, or, rather, of palaces, in the country, prior to the reign of Elizabeth, consisted of apartments built round a large square court. These were formerly either castles or abbeys, and often received all their light from the inner courts; but, when afterwards converted into habitations, windows were opened on the outside of the building. The views from a window were of little consequence at a time when glass was hardly transparent, and in many of the ancient castles the small lozenge panes were glazed with coloured glass or painted with the armorial bearings, which admitted light without any prospect. 
Perhaps there is no form better calculated for convenience of habitation than a house consisting of one or more of these courts, provided the dimensions are such as to admit free circulation of air, because, in such a house, the apartments are all easily connected with each other, and may have a passage of communication for servants from every part. Of this kind are the old palaces at Hampton Court and St. James's, of Penshurst and Knowle in Kent, Warwick Castle, and various other ancient mansions.

No. 2. Houses of the next form I consider as of later date, although, from the various subsequent alterations, it is difficult to define their original shapes: they seem to have had one side of the quadrangle opened, and thus the line of communication being cut off, this sort of house becomes less commodious in proportion to the length of its projecting sides. Of this description were Cobham Hall and Cashiobury, to both of which have been judiciously added square courts of offices, under the direction of Mr. James Wyatt.

No. 3 is a form introduced in the reign of James I, with the quadrangle so small that it is often damp and dark; of this kind are Crewe, Hill Hall, Gayhurst, and Culford; although the latter has been modernised and changed to the form, No. 7. Houses of this shape may sometimes be greatly improved by covering the inner court entirely, and converting it into a hall of communication; this I advised at Sarsden, a house of later date. The offices are generally attached to the side of these houses. In mansions of the foregoing three descriptions, a mixture of Grecian with Gothic is often observed, particularly in those repaired by Inigo Jones. 

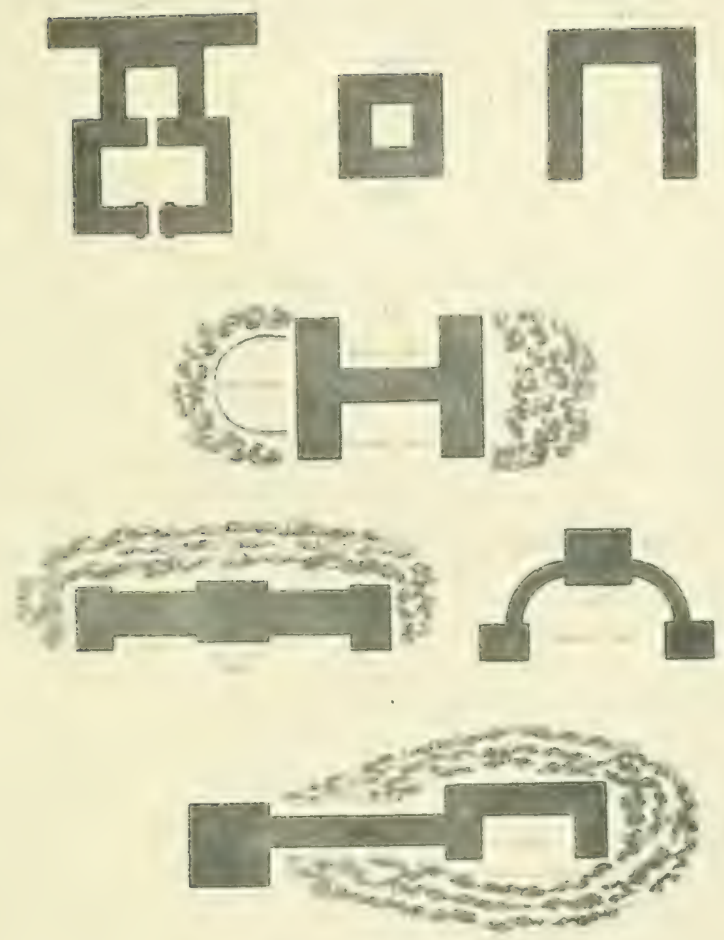

Plate XVII. Plans of houses of various dates 

No. 4, the form next in succession, was of the date of William III and George I, and has been commonly called an $\mathrm{H}$, or half $\mathrm{H}$. This kind of house is often rendered very inconvenient by the centre being one great hall, which breaks the connexion of apartments abovestairs. It is also further objectionable because it is a mere single house in the centre and must have offices attached on one side: of this description are Stoke Park, Langley, Glemham Hall, Dullingham, and Condover.

No. 5. When the Italian or Grecian architecture became more general, a greater display of façade was introduced than the body of the house required; the offices and appendages were, therefore, made in wings to extend the design, as at Wentworth House, Wimpole, Attingham, Dyrham Park, and numerous others.

A house on this plan, if it commands only one view, may be less objectionable; but when applied to situations where the windows are to look in opposite directions, it becomes very inconvenient, because the offices want that uninterrupted communication which is absolutely necessary to the comfort of a dwelling. After the views from the windows became an object of consideration, it was not deemed sufficient to preserve the views to the north and to the south, but even the views to the east and to the west were attempted to be preserved, and this introduced the plan, No. 6.

No. 6 has wings, not in the same line with the house, but receding from it, which, of course, destroy the symmetry proposed by wings, unless the whole be viewed from one particular point in the centre; of this form are Merley, Newton Park, Normanton, Lathom House, etc. The houses built by Paine and Leadbetter 
are frequent instances of want of comfort in the two latter forms.

No. 7 is a form so generally adopted in modern houses that I will not mention any particular instances, especially as they are the works of living architects; yet I hope I shall be pardoned in also making some observations on their construction.

This last invented form consists in a compact square house, with three fronts, and to the back are attached offices, forming a very long range of buildings, courts, walls, etc., supposed to be hid by plantation. These I have been often required to hide by planting, while, in fact, during the lives of the architect and the proprietor, the buildings can never be concealed, and in the lives of their successors the trees must be cut down to give a free circulation of air to the buildings.

Notwithstanding the danger of giving offence, when I am obliged to speak of the works of living artists, I shall venture to point out some objections to the compact form, No. 7, as applied to a large mansion, which have not an equal weight when applied to a villa or a house near the city, where land is valued by the foot, and not by the acre; for however ingenious it may be in such places to compress a large house within a small compass, or to cover under the same roof a great number of rooms, yet a mansion in a park does not require such management or warrant such economy of space.

Of all the forms which can be adopted, there is none so insignificant as a cube, because, however large it may be, the eye can never be struck with its length, its depth, or its height, these being all equal; and the same quantity of building which is often sunk underground, raised in the air, or concealed in plantation, might have been 
extended, to appear four times as large, with less expense and more internal convenience.

A house in the country is so different from a house in town that I never could see any grood reason for disposing the living-rooms abovestairs. It may perhaps be said that the views are more perfect from the higher level, but the same degree of eleration may be obtained by building the cellars aboveground, and afterwards raising the earth above them, as I advised at Donnington and Blaize Castle; and surely the inconvenience of an external staircase can scarcely be compensated by any improvement of the views. To counteract this error in modern houses, I have, in some instances, raised the earth to the principal floor; and, in others, where the architecture would not allow this expedient, I have advised a gallery to be added, as at Hooton and Higham Hill.

Few subjects having occurred in which I have so fully discussed the proper situation for a house and all its appendages as that of Michel Grove, I shall subjoin the following extract from that Red Book:

There is no circumstance connected with my profession in which I find more error of judgement than in selecting the situation for a house, yet it is a subject every one fancies easy to determine. Not only visitors and men of taste fall into this error, but the carpenter, the land-steward, or the nurseryman feels himself equally competent to pronounce on this subject. No sooner has he discovered a spot commanding an extensive prospect than he immediately pronounces that spot the true situation for a house; as if the only use of a mansion, like that of a prospect-tower, was to look out of the windows. ${ }^{42}$ 
After long experiencing the many inconveniences to which lofty situations are exposed; after frequently witnessing the repentance and vexation of those who have hastily made choice of such situations, under the flattering circumstances of a clear atmosphere and brilliant sky; after observing how willingly they would exchange prospect for shade and shelter, and, after vainly looking forward to the effect of future groves, I am convinced that it is better to decide the situation of a house when the weather is unfavourable to distant prospects, and when the judgement may be able to give its due weight to every circumstance which ought to be considered in so material an object, that the comforts of habitation may not be sacrificed to the fascinating glare of a summer's day. From these considerations, I do not hesitate to assert that if no house existed at Michel Grove, the sheltered situation of the present magnificent and singular mansion [Plate XviII] is greatly to be preferred to any spot that could be found on the hill, every part of which is more or less exposed to the force of the winds from the southwest. I shall, therefore, inquire into the character of the present house, and consider how far the old mansion may be rendered convenient and adapted to modern comforts.

There are few old mansions in England which have not been either castles or monasteries altered into houses, but there is no trace of this house ever having been either; and, indeed, its situation in a dry valley is unlike that of any abbey, and it is so immediately commanded by the surrounding hills that it never could have been a castle or place of defence.

The proposed addition of a drawing-room, an anteroom, and an eating-room of large dimensions will alter those relative proportions now so pleasing. It is not, 


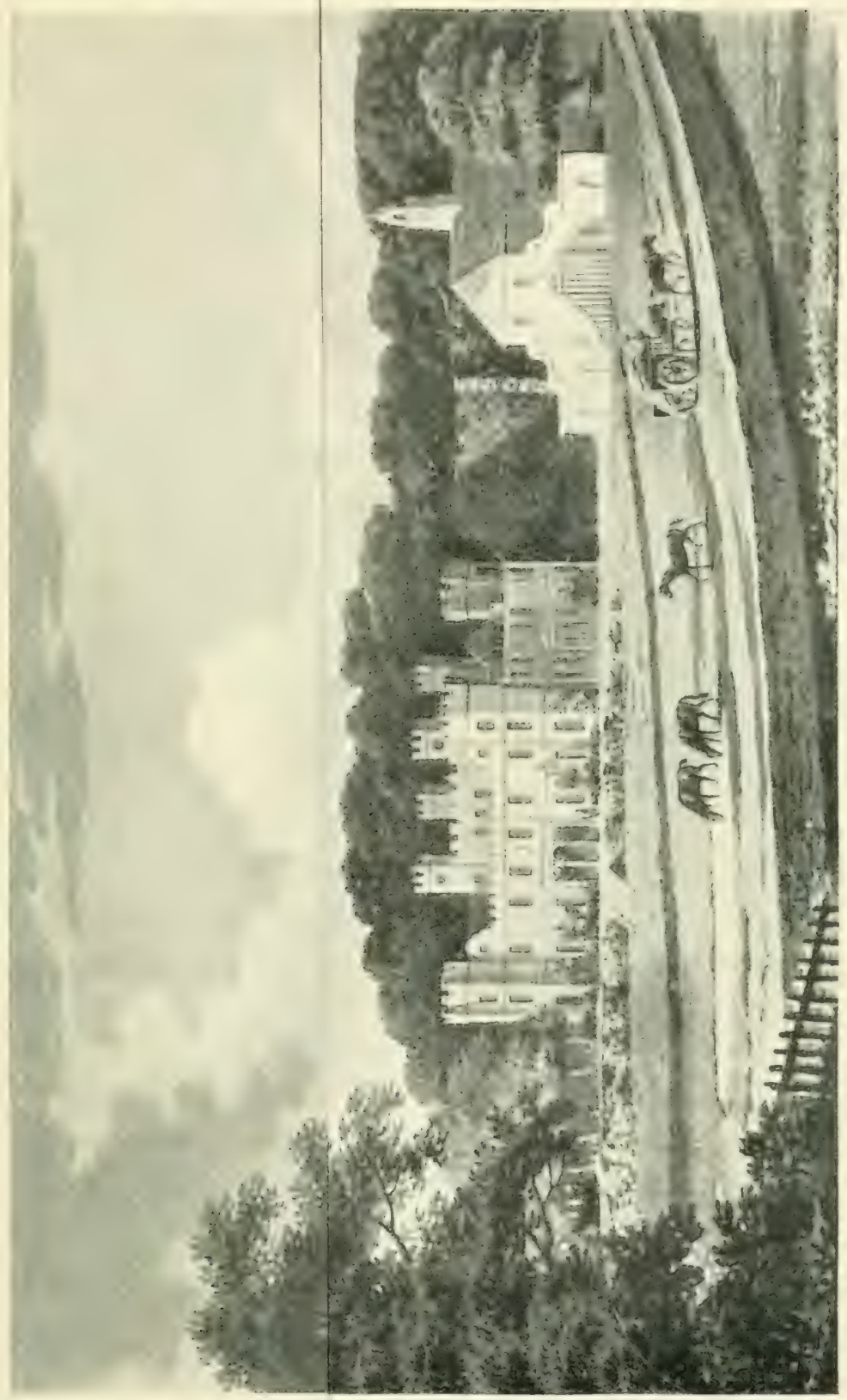



therefore, with a view of improving, but with that of doing as little injury as possible to its appearance that I venture to suggest the additions in the annexed sketch; because the terrace will tend to preserve the apparent height, which the additions to the east tend to destroy.

The present style of living in the country is so different from that of former times that there are few houses of ancient date which would be habitable, without great alterations and additions. Such, indeed, is the constant fluctuation in the habits and customs of mankind, and so great the change in the luxuries, the comforts, and even the wants of a more refined people, that it is, in these times, impossible to live in the baronial castle, the secularized abbey, or even in the more modern palaces, built in the reign of Queen Elizabeth, preserving all the apartments to their original uses.

The chief rooms formerly required in a house of that date were:

The Hall, for the entertainment of friends and vassals; a large and lofty room, having the floor at one end raised above the common level, as at present in the halls of our colleges; this was to mark some distinction in the different ranks of the guests.

The next large room required was a Gallery, for the reception of company in a morning, for dancing in the evening, and for the exercise of the family within doors. Very few books were then in use; and, instead of the newspapers and pamphlets of the present day, the general information was collected in conversations held in those long galleries, which had large recesses, or bays, sometimes called bowre-windows, and now bow-windows; into which some of the company would occasionally withdraw, for conversation of a more private 
nature, as we frequently read in the "Mémoires de Sully," etc.

But the apartment, of all others, which was deemed indispensable in former times, and in which the magnificence of the proprietor was greatly displayed, was the Chapel.

The other apartments were one or more small parlours, for the use of the ladies and their female attendants, in which they carried on their various works of embroidery, etc., and, instead of the present dressingroom and sitting-rooms, which are added to each modern bedroom, there was generally a small closet to each, with perhaps an oriel window for private morning devotions.

After thus mentioning the uses of ancient apartments, it is necessary to enumerate those additions which modern life requires. Ist. The eating-room, which does not exactly correspond with the ancient hall, because it is no longer the fashion to dine in public; $2 \mathrm{~d}$, the library, into which the gallery may sometimes be changed with propriety; $3 \mathrm{~d}$, the drawing-room, or saloon ; 4 th, the

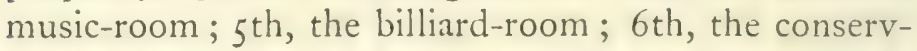
atory attached to the house; and, lastly, the boudoirs, wardrobes, hot and cold baths, etc., which are all modern appendages, unknown in Queen Elizabeth's days. Under these circumstances, it is difficult to preserve the ancient style of a mansion without considerable additions. For this reason we see few specimens of Gothic buildings which have not been mixed and corrupted with the architecture of various dates; and whilst every casual observer may be struck with the incongruity of mixing the Grecian with the Gothic styles, yet the nice antiquarian alone discovers, by the contour of a moulding, or the shape of a battlement, that mix- 
ture of the castle and abbey Gothic, which is equaliy incorrect with respect to their different dates and purposes.

The view of this house will, I hope, justify my anxiety to preserve it, as far as may be consistent with modern habitation: for although it can neither be deemed a castle, an abbey, or a house of any Gothic character with which we are acquainted, yet its form is singularly picturesque; and the plate shews the effect of removing the present road, walls, and stables, which would obstruct the view from the new apartments.

In determining the situation for a large house in the country, there are other circumstances to be considered besides the offices and appendages immediately contiguous. These have so often occurred that I have established, in imagination, certain positions for each, which I have never found so capable of being realized as at Michel Grove.

I would place the house with its principal front towards the south or southeast.

I would build the offices behind the house; but, as they occupy much more space, they will, of course, spread wider than the front.

I would place the stables near the offices.

I would place the kitchen-garden near the stables.

I would put the home-farm buildings at rather a greater distance from the house; but these several objects should be so connected by back roads as to be easily accessible.

I would bring the park to the very front of the house.

I would keep the farm, or land in tillage, whether for use or for experiment, behind the house. 
I would make the dressed pleasure-ground, to the right and left of the house, in plantations which would screen the unsightly appendages, and form the natural division between the park and the farm, with walks communicating to the garden and the farm.

It will be found that these are exactly the positions of all the appendages at Michel Grove. But, in support of my opinion, it may be proper to give some reasons for the choice of these general positions.

I. The aspect of a house requires the first consideration, since no beauty of prospect can compensate for the cold exposure to the north, the glaring blaze of a setting sun, or the frequent boisterous winds and rains from the west and southwest; while, in a southern aspect, the sun is too high to be troublesome in summer, and during the winter it is seldom an unwelcome visitant in the climate of England.

2 , 3. It can hardly be necessary to enumerate the advantages of placing the offices near and stables at no great distance from the house.

4. The many interesting circumstances that lead us into a kitchen-garden, the many inconveniences which I have witnessed from the removal of old gardens to a distance, and the many instances in which $I$ have been desired to bring them back to their original situations, have led me to conclude that a kitchen-garden cannot be too near, if it be not seen from the house.

5. So much of the comfort of a country residence depends on the produce of its home-farm that even if the proprietor of the mansion should have no pleasure in the fashionable experiments in husbandry, yet a farm, with all its appendages, is indispensable: but when this is considered as an object of profit, the gentlemanfarmer commonly mistakes his aims; and as an object 
of ornament, I hope the good taste of the country will never confound the character of a park with that of a farm.

To every dwelling there must belong certain unsightly premises which can never be properly ornamental, such as yards for coal, wood, linen, etc., and these are more than doubled when the farmhouse is contiguous; for this reason I am of opinion that the farming premises should be at a greater distance than the kitchen-garden or the stables, which have a more natural connexion with each other.

The small pool in front of the house has been purposely left, not as an object of beauty in itself, but as the source of great beauty to the scenery; for in the dry valleys of Sussex such a pond, however small, will invite the deer and cattle to frequent the lawn in front of the house, and add to the view, motion, and animation.

Those who only remember the former approaches to this house, over lofty downs, with a dangerous road to descend, will hardly believe that this venerable mansion is not situated in the bottom, but at the extremity of a valley; for in reality the house is on the side of a hill, and by the proposed line of approach it will appear that it actualiy stands on a considerable eminence, the road ascending along the whole course of the valley for more than a mile. ${ }^{43}$

A house extended in length may be objectionable in many situations, but when built on the side of a hill, if the ground rises boldly behind it, the objection to it as a single house is removed.

Where a house, like that at Garnons, by its situation and southern aspect, will constantly be a marked feature from the surrounding country, presenting only 
one front embosomed in wood, that front should be so extended as to distinguish the site of the mansion with adequate importance.

In such a situation it would be difficult to produce the same greatness of character by a regular Grecian edifice; that will be effected by the irregularity of outline in the proposed house, offices, and stables; and in defence of this picturesque style I shall take the liberty to transcribe, in a note, ${ }^{44}$ the very judicious remarks of R. L. Girardin, Viscomte d'Ermenonville.

A plan of the house proposed for this situation is added [Fig. 24], to shew how conveniently the com-

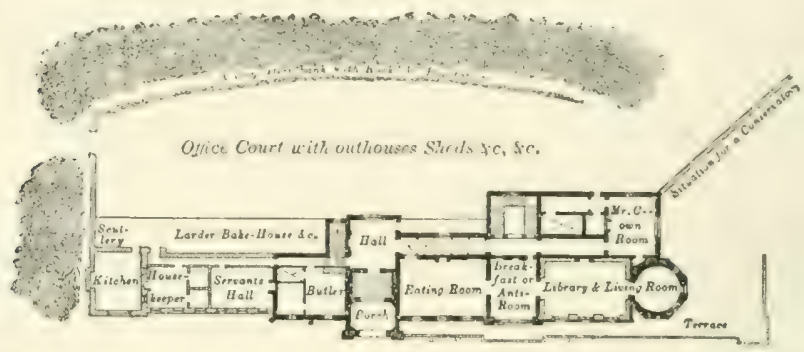

Fig. 24. Examples of a plan for an extended front on the steep side of a hill.

forts of modern habitations may be adapted to ancient magnificence; and I rejoice in observing that many large houses are at this time building, or altering, in this irregular style, under the direction of one of our most eminent architects. I may mention those of Cashiobury and Wickham Market, which disdain the spruce affectation of symmetry so fatal to the Gothic character.

When a house, as in the foregoing instance, is to be built on the side of a hill or on an inclined plane, it is hardly possible to dispose it in any other form than that of an extended front: but this supposes a certain 
degree of property to helong to the house, or it is apt to appear too large for the annexed estate. This oljection is, however, less forcible in a villa than in a mansion; yet even a villa which covers too much of its own field or lawn partakes more of ostentation than good taste.

A field of a few acres, called Brentry Hill, near Bristol, commands a most pleasing and extensive view. In the foreground are the rich woods of King's Weston and Blaize Castle, with the picturesque assem-

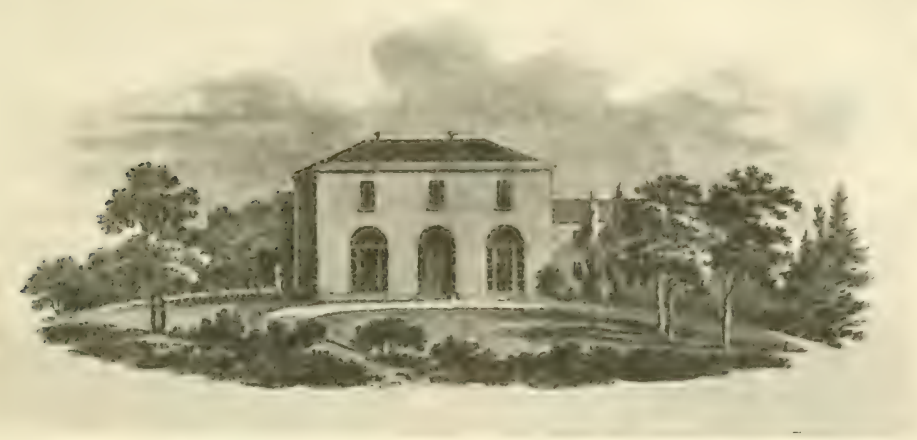

Fig. 25. Villa at Brentry Hill, shewing specimens of economy with compactness adapted to its situation, character, and uses.

blage of gardens and villas in Henbury and Westbury; beyond which are the Severn and Bristol Channel, and the prospect is bounded by the mountains of South Wales. This view is towards the west, and I have generally observed that the finest prospects in England are all towards this point. ${ }^{45}$ Yet this, of all aspects, is the most unpleasant for a house; it was not, therefore, advisable to give an extended front in this direction, yet it would have been unpardonable not to have taken advantage of so fine a prospect.

A compact plan often demands more trouble and 
contrivance than a design for a palace, in which the rooms may be so numerous that different apartments may be provided for summer and for winter use; but where compactness and economy are studied, some contrivance is necessary to avail ourselves of views and aspects, without sacrificing convenience and relative fitness to the beauty of the prospect.

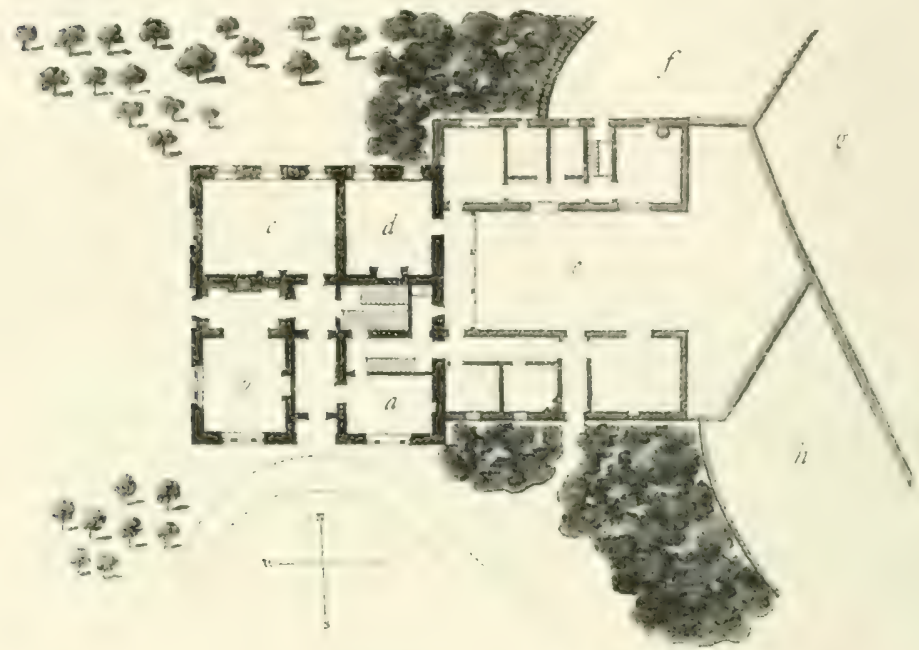

Fig. 26. Ground-plan of Villa at Brentry Hill.

$a$, Breakfast-room; $b$, drawing-room, opening, with folding doors, to a small library ; $c$, eating. room; $d$, kitchen; $e$, kitchen court; $f$, drying-ground; $g$, part of the kitchen-garden; $h$, stable court

Under this restraint perhaps few houses have been built with more attention to the situation and circumstances of the place than the villa at Brentry [Figs. 25 and 26]. The eating-room is to the north, with one window towards the prospect, which may be opened or shut out by Venetian blinds at pleasure. The breakfast-room is towards the south, and the drawing-room towards the prospect.

Modem habits have altered the uses of a drawing- 
room; formerly, the best room in the house was opened only a few days in each year, where the guests sat in a formal circle, but now the largest and best room in a gentleman's house is that most frequented and inhabited: it is filled with books, musical instruments, tables of every description, and whatever can contribute to the comfort or amusement of the guests, who form themselves into groups at different parts of the room; and in winter, by the help of two fireplaces, the restraint and formality of the circle is done away.

This has been often happily effected in old houses by laying two rooms together, preserving the fireplaces in their original situations, without regard to correspondence in size or place. But two fires not being wanted in summer, a provision is made in this villa to preserve an additional window towards the fine prospect at that season of the year; and the panel which ornaments the end of the room may be removed in winter, when the window will be less desirable than a fireplace; thus the same room will preserve, in every season, its advantages of aspects and of views, while its elegance may be retained without increasing the number of rooms for different purposes. This attention to the wants of different seasons has been too little studied in this country, whilst in France almost every large house has its garçon tapissier, whose business it is to change the furniture of the apartments for summer and winter. Those who have compared the fitting-up of rooms in France with that of any other country of Europe must, doubtless, give the preference to French taste, as far as it relates to the union of internal magnificence and comfort; but those architects who copy both the inside and outside of Italian houses should at least provide for such occasional alterations as our climate may require. 
Another circumstance may be mentioned, in which economy has been consulted at this small villa. More rooms are generally required on the chamber than on the ground floor; yet, except the kitchen, there is no part of a house which ought properly to be so lofty as the principal rooms; instead, therefore, of increasing the quantity of offices, by what a witty author calls "turning the kitchen out of doors for smelling of victuals," this offence is here avoided by the external passage of communication.

The operations of landscape gardening have ofien been classed under the general term of improvement; but there are three distinct species. The first relates to places where the grounds are altered, and adapted to a house already existing; the second to those where the houses, by additions, having changed their original character or aspect, renders it necessary to make alterations in the ground also; the third includes those places where no house previously exists, and where the entire plan of the house, appendages, and grounds has sometimes been called a creation. Of the first kind it is needless to enumerate examples. Among the second may be mentioned those in which the entrance of the house being changed, new rooms added, or barns, stables, and kitchen-gardens removed, new arrangements have taken place, as at Abington Hall, Clayberry, Wallhall, West-Coker, Betchworth, Highlands, Brandsbury, Holwood, etc. Of those places which may be called creations, the number is necessarily small, yet I may refer to the following examples. In some, where new houses were built, I was consulted by the respective architects on the situation and appendages; as at Bracondale, Milton House, Donnington, Buckminster, Courteen Hall, Bank Farm, Chilton 
Lodge, Dulwich Casina, Holme Park, Streatham, The Grove, Southgate, Luscombe, etc. In others, I gave general plans for the whole, with the assistance of my son only in the architectural department, as at Brentry Hill, Cobham Bank, Organ I Jall, Stapleton, Stratton Park, Scarrisbrick, Panshanger, Bayham, etc. 


\section{Chapter XII}

Formation of a new Place - Application of Gardening and Arcbitecture - Cbaracteristic Arcbitecture - How far it sbould prevail internally

$7 \mathrm{HE}$ necessity of uniting architecture and land-

1 scape gardening is so strongly elucidated in the Red Book of Bayham that I gladly avail myself of the permission of its noble possessor to insert the following observations; but as the ruins of Bayham Abbey are generally known to those who frequent Tunbridge Wells, it is necessary to premise that the situation proposed for a new house is very different from that of the abbey.

No place concerning which I have had the honour to be consulted possesses greater variety of water, with such difference of character as seldom occurs within the limits of the same estate. The water near the abbey, now intersecting the meadow in various channels, should be brought together into one river, winding through the valley in a natural course: this may be so managed as to drain the land while it improves the scenery; and I suppose the whole of this valley to be a more highly dressed lawn, fed by sheep and cattle, but without deer.

Above this natural division the water will assume a bolder character; that of a lake or a broad river, filling the entire bottom of the valley, between two wooded shores, and dashing the foot of that steep bank on which the mansion is proposed to be erected. This 


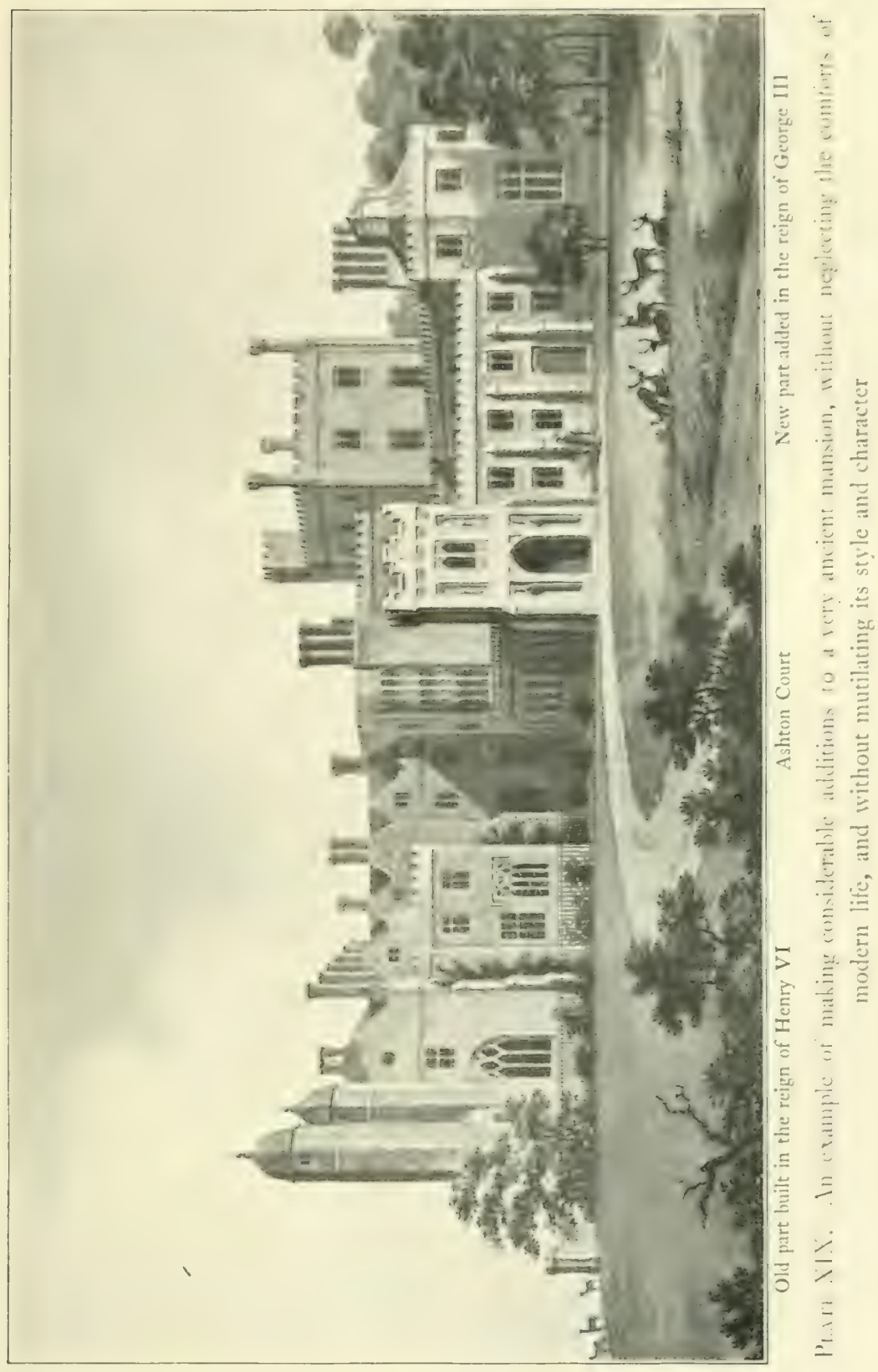



valley is so formed by nature that an inconsiderable dam will cause a lake or rather broad river of great apparent extent: for when I describe water, I never estimate its effects by the number of acres it may cover, but by its form, its continuity, and the facility with which its termination is concealed.

Where a place is rather to be formed than improved, that is, where no mansion already exists, the choice of situation for the house will in some measure depend on the purpose for which it is intended and the character it ought to assume: thus a mansion, a villa, and a sporting-seat require very different adaptation of the same principles, if not a variation in the principles themselves. The purpose for which the house at Bayham is intended must decide its character: it is not to be considered as a small villa, liable to change its proprietor, as good or ill success prevails, but as the established mansion of an English nobleman's family. Its character, therefore, should be that of greatness and of durability. The park should be a forest, the estate a domain, the house a palace. Now, since magnificence and compactness are as diametrically opposite to each other as extension and contraction, so neither the extended scale of the country nor the style nor the character of the place will admit of a compact house.

In determining effects, it is not sufficient to consider merely the size of the building; but as all objects appear great or small only by comparison, it is also necessary to consider the size and character of those by which this mansion will be accompanied.

The surrounding scenery of Bayham must influence the character of the house; we must therefore consider what style of architecture will here be most appropriate. There has ever appeared to me something 
wrong or misunderstood in the manner of adapting Grecian architecture to our large mansions in the country: our professors, having studied from models in a different climate, often forget the difference of circumstances and shew their classic taste, like those who correctly quote the words, but misapply the sense of an author. The most striking feature of Grecian architecture is a portico, and this, when it forms part of a temple or a church, may be applied with propriety and grandeur; but when added to a large house and intersected by two or three rows of windows, it is evidently what, in French, is called an appliqué, something added, an afterthought; and it has but ton often the appearance of a Grecian temple affixed to an Finglish cotton-mill.

There is also another circumstance belonging to Grecian architecture, viz. symmetry, or an exact correspondence of the sides with each other. Symmetry appears to constitute a part of that love of order so natural to man; the first idea of a child, in drawing a house, is to make the windows correspond, and perhaps to add two correspondent wings.

There are, however, some situations where great magnificence and convenience are the result of a building of this description; yet it can only be the case where the house is so large that one of the wings may contain a complete suite of private apartments, connected with the house by a gallery or library, while the other may consist of a conservatory, etc.

Every one who has observed the symmetrical elevations scattered round the metropolis, and the small houses with wings in the neighbourhood of manufacturing towns, wili allow that symmetry so applied is apt to degenerate into spruceness; and of the in- 

convenience of a house, separated from its offices by a long passage (however dignified by the name of colonnade), there cannot surely be a question. There is yet another principle which applies materially to Bayham, viz. that symmetry makes an extensive huilding look small, while irregularity will, on the contrary, make a small building appear large: a symmetrical house would, therefore, ill accord with the character of the surrounding country.

Having expressed these objections against the application of Grecian architecture, before I describe any other style of house, I shall introduce some remarks on a subject which has much engaged my attention, viz. the adaptation of buildings not only to the situation, character, and circumstances of the scenery, but also to the purposes for which they are intended; this I shall call characteristic architecture.

Although it is obvious that every building ought "to tell its own tale," and not to look like anything else, yet this principle appears to have been lately too often violated: our hospitals resemble palaces, and our palaces may be mistaken for hospitals; our modern churches look like theatres, and our theatres appear like warehouses. In surveying the public buildings of the metropolis, we admire St. Luke's Hospital as a madhouse, and Newgate as a prison, because they both announce their purposes by their appropriate appearance, and no stranger has occasion to inquire for what uses they are intended.

From the palace to the cottage, this principle should be observed. Whether we take our models from a Grecian temple or from a Gothic abbey, from a castle or from a college, if the building does not look like a house and the residence of a nobleman, it will be out of char- 
acter at Bayham. It may perhaps be objected that we must exactly follow the models of the style or date we mean to imitate, or else we make a pasticcio or confusion of discordant parts. Shall we imitate the thing and forget its application? No: let us rather observe how, in Warwick Castle, and in other great mansions of the same character, the proud baronial retreat "of the times of old" has been adapted to the purposes of modern habitation. Let us preserve the massive strength and durability of the castle, and discard the gloom which former tyranny and cruelty inspired; let us preserve the light elegance of Gothic abbeys in our chapels, but not in our houses, where such large and lofty windows are inadmissible; let us, in short, never forget that we are building a house, whether we admire and imitate the bold irregular outline of an ancient castle, the elegant tracery in the windows of a Gothic church, or the harmony of proportions and the symmetrical beauty of a Grecian temple.

Of the three distinct characters, the Castle, the Abbey, and the House-Gothic, the former of these appears best calculated for Bayham [Plates xxi and xxir]. Yet, as the ohject is not to build a castle, but a house, it is surely allowable to blend with the magnificence of this character the advantages of the other two, as well as the elegance, the comfort, and the convenience of modern habitation. It may be urged that the first purpose of a castle is defence; that of a house, habitation; but it will surely be allowed that something more is required than the mere purposes of habitation. An ordinary carpenter may build a good room ; a mechanic, rather more ingenious, may connect a suite of rooms together, and so arrange their several offices and appendages as to make a good house, that is, a house sufficient for all the purposes of 


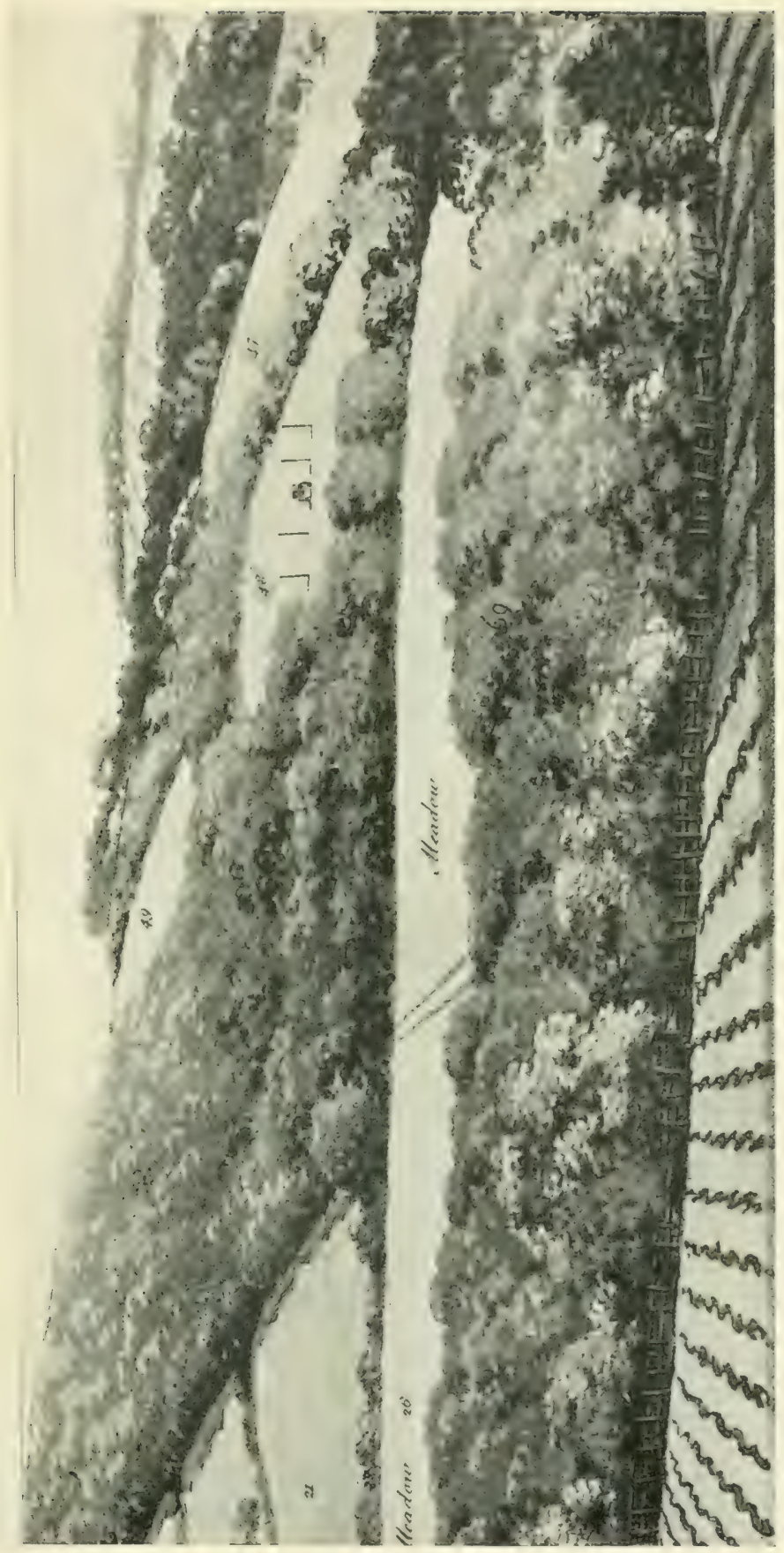



habitation. But an architect will aim at something higher; he will add to the internal convenience, not merely external beauty but external propriety and character; he will aim not only to make a design perfect in itself but perfect in its application.

Where the lawn, the woods, the water, the whole place, and the general face of the surrounding country are on so extensive a scale the only means of preserving the same character is by extending the plan of the house also. How can this be effected unless we adopt the Gothic style of architecture? In Grecian or modern buildings it has been considered an essential part of the plan to conceal all the subordinate appendages of the mansion, such as the stables, the offices, the gardenwalls, etc.; and why? Because they neither do nor can partake of the character of the house; and the only method by which this extension of site is usually acquired in a Grecian building is by adding wings to the house. Thus the same mistaken principle obtains and is considered material, for it is a part of the duty of these wings to conceal the offices. But if continuity be an essential cause of the sublime, if extension be an essential cause of magnificence, whatever destroys continuity weakens the sublime, and whatever destroys extension lessens magnificence; therefore, as the offices and courtyards attached to a house are generally five times more extensive than the house itself, where magnificence is the object, why neglect the most effectual means of creating it? viz. continuity and extension, blended with unity of design and character; or, in other words, when it is desirable to take advantage of every part of the buildings, why conceal five parts in six of them?

If the truth of this principle be allowed, I trust the 
propriety of its application will be obvious; and, for its effect, I appeal to the accompanying sketch [Plate xxr] where both the actual size of the house and its comparative proportion to the surrounding scenery are correctly ascertained.

However pleasing these representations may appear, I should consider myself as having planned a "castle in the air," unless it should be proved that this design is not only practicable but that it actually contains no more building than is absolutely necessary for the purposes of modern habitation. By the plan, it appears to contain :

A Gothic hall, for the sake of ancient grandeur, but leading through a passage lower than the rooms, for the sake of not depressing their comparative height. The hall and passages should be rather dimly lighted by painted glass, to impress a degree of gloom essential to grandeur, and to render the entrance into the rooms more brilliant and cheerful.

This, it may be objected, is in character with those houses which Gray describes as having

"Windows that exclude the light, And passages that lead to nothing."

Yet I trust these passages will be found no less useful than magnificent; they lead to the several rooms, which form a complete suite of apartments, consisting of eatingroom, breakfast-room, drawing-room, and library. The rooms all open by windows to the floor on a terrace, which may be enriched with orange-trees and odouriferous flowers, and will form one of the greatest luxuries of modern as well as one of the most magnificent features of ancient habitation.

It now remains for me to shew that I have not suggested a design more expensive than a house of any 


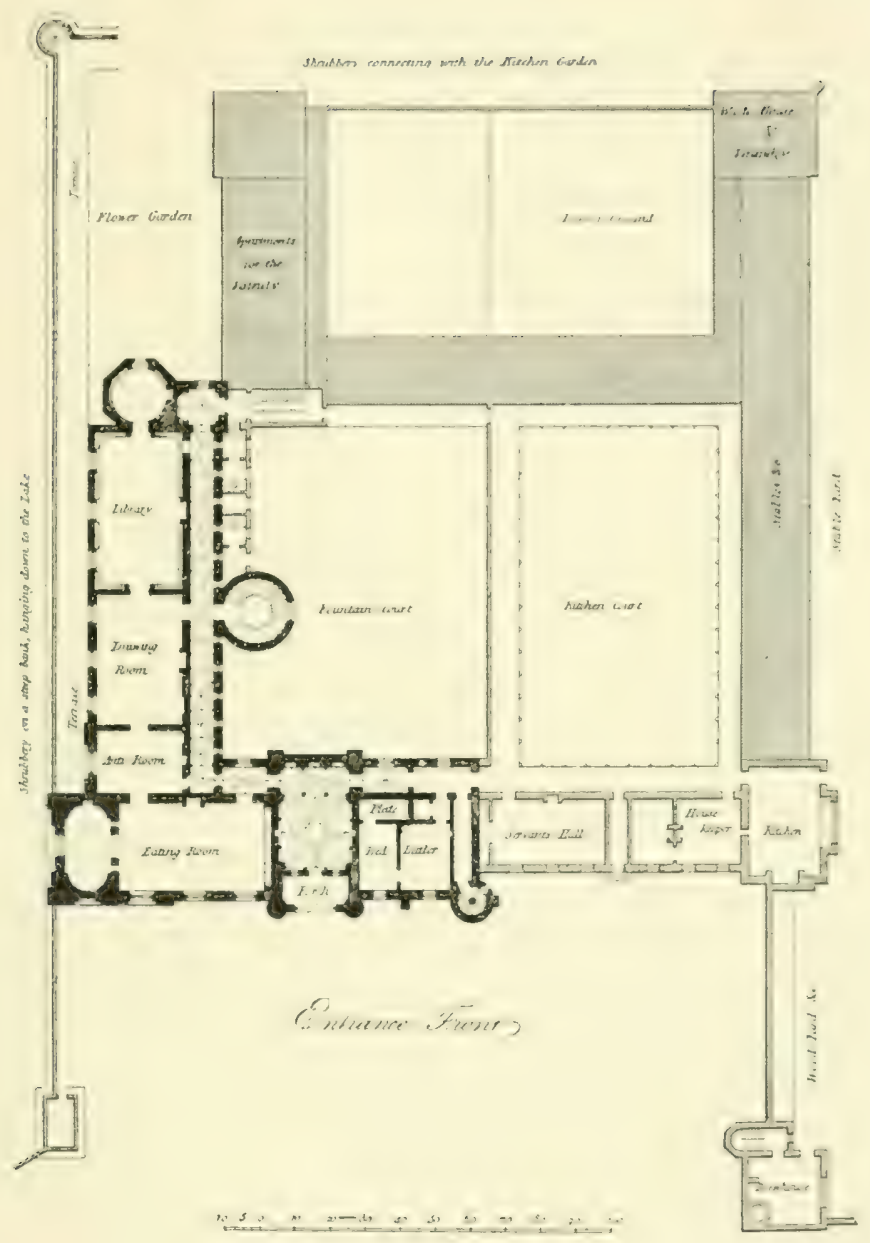

Prate XXII. Plan of Bayham 

other character, containing the same number of apartments. 'The chief difficulty of huilding arises from the want of materials: a house of l'ortland stone would be very expensive; a red-brick house, as Mr. Brown used to sav, "puts the whole valley in a fever"; a house of yellow brick is little better; and the great Lord Mansfield often declared that had the front of Kenwood been originally covered with Parian marble he should have found it less expensive than stucco. Yet one of these must be used in any building except a castle; but for this the rude stone of the country, lined with bricks, or faced with battens, will answer every purpose; because the enrichments are few, except to the battlements and the entrance-tower, which are surely far less expensive than a Grecian portico.

The attached offices, forming a part of the front, are so disposed as to lie perfectly convenient to the principal floor and to the private apartments, while the detached offices, the courtyards, and even the gardenwalls, may be so constructed and arranged as to increase in dimensions the extent of the castle. This unity of design will be extended from the house to the water, by the boat-house, the cold-bath, and the walls, with steps leading to a bridge, near which the enginehouse may form a harbican, and contribute to the magnificent effect of the picture as well as to the general congruity of character.

When we look back a few centuries and compare the habits of former times with those of the present, we shall be apt to wonder at the presumption of any person who shall propose to build a house that may suit the next generation. Who, in the reign of Queen Elizabeth, would have planned a library, a music-room, a billiard-room, or a conservatory? Yet these are now 
deemed essential to comfort and magnificence: perhaps, in future ages, new rooms for new purposes will be deemed equally necessary. But to a house of perfect symmetry these can never be added: yet it is principaliy to these additions, during a long succession of years, that we are indebted for the magnificent irregularity and splendid intricacy observable in the neighbouring palaces of Knowle and Penshurst. Under these circumstances that plan cannot be good which will admit of no alteration.

"Malum consilium est, quod non mutari potest."

[It is a bad counsel which cannot be changed.]

But in a house of this irregular character, every subsequent addition will increase the importance: and if I have endeavoured to adopt some of the cumbrous magnificence of former times, I trust that no modern conveniences or elegances will be unprovided for.

It has been doubted how far a house, externally Gothic, ${ }^{46}$ should internally preserve the same character; and the most ridiculous fancies have been occasionally introduced in libraries and eating-rooms, to make them appear of the same date with the towers and battlements of a castle, without considering that such rooms are of modern invention, and, consequently, the attempt becomes an anachronism: perhaps the only rooms of a house which can, with propriety, be Gothic, are the hall, the chapel, and those long passages which lead to the several apartments; and in these the most correct detail should be observed. 


\section{Chapter XIV}

Conclusion - Concerning Colour - Diffculty of

Comparisons betwixt Art and Nature

$7 \mathrm{HE}$ art of painting has been usually treated 1 under four distinct heads, viz.: Composition; Design, or Drawing; Expression; and Colouring,each of which may, in some measure, be applied to landscape gardening, as it has been treated in this work.

Composition includes those observations on utility, scale, perspective, etc., contained in Chapters I and II.

Design may be considered as belonging to the remarks on water, woods, fences, lines, etc., contained in Chapters III, IV, V, VI, and VII.

Expression includes all that relates to character, situation, arrangement, and the adaptation of works of art to the scenery of nature, which have been discussed in the remaining Chapters of this work; and, lastly, Colouring, so far as it relates to certain artificial objects, has been mentioned in Chapter XI.

Having since been led to consider this subject more attentively, in consequence of a conversation with $\mathrm{Mr}$. Wilberforce concerning a new theory of colours and shadows, I have, through his intervention, obtained permission to enrich my work with the following curious remarks: and as Mr. Wilberforce, in his letter which enclosed them, observes of their reverend and 
learned author that " he is a man unequalled" "for the store of knowledge he possesses, for the clearness with which he views, and the happy perspicuity with which he communicates his conceptions," so I shall give this theory in his own words. ${ }^{47}$

This curious and satisfactory theory demonstrates that the choice of colours which so often distinguishes good from bad taste in manufactures, furniture, dress, and in every circumstance where colour may be artificially introduced, is not the effect of chance or fancy, but guided by certain general laws of nature.

Sir Isaac Newton discovered a wonderful coincidence between sound and colours, and proves mathematically that the spaces occupied by the colours in the prismatic spectrum correspond with the parts of a musical chord when it is so divided as to sound the notes of an octave. So this resemblance may now be considered as extending further, for, as in music, so likewise in colours, it will be found that harmony consists in distance and contrast, not in similitude or approximation. Two notes near each other are grating to the ear, and are called discords; in like manner, two colours very near each other are unpleasing to the sight, and may be called discordant; this may be proved by covering all the colours in the diagram (See Note 47, p.246) except the two adjoining, which, in every part of the scale, will appear discordant; while, on the contrary, if the two sides be covered in any direction so as only to shew the two opposite colours, they will appear in perfect harmony with each other; and this experiment confirms the good taste of those who, in the choice of colours, oppose reds to greens, yellows to purples, and blues to oranges, etc. But instead of contrasting these colours, they are mixed or so blended as not to appear each distinctly, as in 
silks or linens where the stripes are too narrow; when seen at a little distance, instead of relieving, they will destroy each other. In the application of this theory to some familiar instances, particularly in the furniture of rooms, I have observed that two colours, here deemed discordant, may be used without offending the eye, as green and blue, or green and yellow; but I have always considered such assortment intolerable, unless one were very dark and the other very light; and thus the effect is again produced by contrast, although on a different principle: it is the contrast, not between colours, but between light and darkness.

So far this theory is perfectly satisfactory with respect to works of art, but, when carried to those of nature, I confess my inability to reconcile a conviction of its truth with certain appearances which seem to contradict it.

$\mathrm{By}$ the universal consent of all who have considered the harmony of colours, it is allowed that in works of art the juxtaposition of bright blues and greens is discordant to the eye, and the reason of this discordance has been shewn by the foregoing remarks. Yet these are the two prevailing colours in nature; and no person ever objected to the want of harmony in a natural landscape, because the sky was blue and the surface of the earth covered with greens, except he viewed it with a painter's eye, and considered the difficulty or even impossibility of exciting the same pleasurable sensations by transferring these colours to his canvas; the only way in which I can solve this seeming paradox is by observing that the works of nature and those of art must ever be placed at an immeasurable distance, from the different scale of their proportions; and whether we compare the greater efforts of man with the system 
in which the world he inhabits forms but an inconsiderable speck, or the most exquisite miniature of mechanism with the organs of sense and motion in an insect, we must equally feel the deficiency of comparison, the incompetency of imitation, and the imperfection of all human system. Yet, while lost in wonder and amazement, the man of taste and the true philosopher will feel such agreement existing in the laws of nature as can only be the consequence of Infinite Wisdom and Design; while to the sceptic, whether in moral or in natural philosophy, the best answer will be in the words of the poet :

"All nature is but art unknown to thee;

All chance, direction which thou canst not see :

All discord, barmony not understood;

All partial evil, universal good." 
NOTES 



\section{Notes}

[ Launcelot Brown, landscape gardener and architect, was born in 1715 at Harle-Kirk, Northumberland, England. He was originally a kitchen-gardener in the employment of Lord Cobham, at Stowe. His remarkable faculty for prejudging landscape effects procured him the patronage of persons of rank and taste. Repton speaks of Brown as the founder of the English style of landscape gardening, but the real founder was not Brown, but William Kent (b. I684; d. I748). Brown, however, worked with greater genius and wider success. He realized a large fortune, and by his amiable manners and high character supported with dignity the station of a country gentleman. He died in $1783 .-N$.

\section{CATAlogue OF RED BOOKS}

From whence the extracts in Skerches and Hints are made; or which are mentioned as containing further elucications of the subjects introduced in this first volume.

PLACE COUNTY A SEAT OF

Antony House....... Cornwall............ Reginald Pole Carew, Esq., M. P.

Babworth ........... Nottinghamshire...... Honourable John Bridgman Simpson.

Bessacre Manor...... Yorkshire............ D. IV. Cook, Esq.

Brandsbury.......... Middleser... ......... Honourable Lady Salusbury.

Brocklesby.......... Lincolnshire... ...... Right Honourable Lord Yarborough.

Brookmans. .........Herts............... R. Gaussen, Esq.

Buckminster... . . . . Leicestershire......... Sir William Manners, Bart.

Castle Hill..........Middlesex............ Beaufoy, Esq., M. P.

Catchfrench........ Cornwall............ Glanville, Esq.

Claybury.......... Essex............. James Hatch, Esq.

Cobham Park........Kent. ............ Earl Darnley.

Courteen Hall... ..... Northamptonshire... . Sir William Wake, Bart.

Crewe Hall... . . . . . . Cheshire.. ... . . . . . . John Crewe, Esq., M. P.

Culford........... Suffolk. ............Marquis Cornwallis.

Donington.......... Leicestershire........ Earl Moira.

Ferney Hall ......... Shropshire........... Late Sam. Phipps, Esq.

Finedon........... Northamptonshire..... J. English Dolben, Esq.

Garnons............Herefordshire........J. G. Cotterell, Esq. [In 18 88, Sir J. G. Cotterell, Bart.]

Gayhurst...........Bucks.............. George Wrighte, Esq.

Glevering........... Suffolk. .......... Chaloner Arcedeckne, Esq.

Hanslope Park....... Bucks............. Edward Watts, Esq.

Hazells Hall........ Bedfordshire........ Francis Pym, Esq. 
Herriard's House.....Hampshire........... Purefoy Jerroise, Esq.

Holkham...........Norfolk ........... T. W. Coke, Esq., M. P. [In I $88_{3} 8$, the Earl of Leicester.]

Holme Park.........Berkshire.......... Richard Palmer, Esq.

Holwood..........Kent.............Right Honourable W. Pitt. [In $18_{3} 8$, John Ward, Esq.]

Lamer... . . . . . . . . Herts... ............ Lieutenant-Colonel C. Drake Garrard.

Langley Park........Kent.............. Sir Peter Burrell, Bart., M. P. [In $18_{3} 8$ E. Goodhart, Esq.]

Lathom...........Lancashire......... Wilbraham Bootle, Esq.

Little Green........ Sussex............ Thomas Peckham Phipps, Esq.

Jivermere Park. ..... Suffolk. .............. Lee Acton, Esq.

Milton........... Cambridgeshire...... Samuel Knight, Esq.

Milton Park......... Northamptonshire.... Earl Fitzwilliam.

Nacton... ..........Suffolk. ............ B. Broke, Esq..

Northrepps. ......... Norfolk............... Bartlet Gurney, Esq.

Ouston............ Yorkshire........... Bryan Cook, Esq.

Port Eliot........... Cornwall... . . . . . . . Right Honourable Lord Eliot.

Prestwood........... Staffordshire......... Honourable Edward Foley, M. P.

Purley........... Berkshire........... Anthony Morris Storer, Esq.

Riven Hall. ......... Essez.............. C. C. Western, Esq., M. P.

Rudding Hall........ Yorkshire........... Lord Loughborough, L. H. Chancellor.

Scrielsby. .......... Lincolnshire... . . . . . Honourable the Champion Dymock.

Sheffield Place....... Sussex............. Right Honourable Lord Sheffield.

Stoke Park. ......... Herefordshire.........Honourable E. Foley, M. P.

Stoke Pogies........ Bucks........... John Penn, Esq.

Stoneaston......... Somersetshire........ Hippesley Coxe, Esq., M. P.

Sundridge.......... Kent. ............ E. G. Linde, Esq. [In 1838 , Sir Saml. Scott, Bart.]

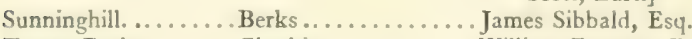

Tatton Park........ Cheshire............William Egerton, Esq., M. P.

Thoresby........... Nottinghamshire...... Charles Pierrepont, Esq., M. P.

Trewarthenick....... Cornwall............Fr. Gregor, Esq., M. P.

Tyrringham .........Bucks............William Praed, Esq., M. P.

Waresley. ...........Essex... ............ Sir Geo. Allanson Winn, Bart., M. P.

Welbeck............ Nottinghamshire...... His Grace the Duke of Portland.

Wembly..........Middlesex..........Richard Page, Esq.

Whersted.......... Suffolk. .......... Sir Robert Harland, Bart.

Widdial Hall........Herts............. J. T. Ellis, Esq.

3 Having always had these considerations in view whenever I have been consulted on the site of a new house, or on the preservation of the old one, I shall take the liberty of mentioning several instances, in some of which the original Red Books may possibly be consulted, to shew the variety of manner in which these general rules have been applied to particular purposes: Sunninghill, Sundridge, Courteen Hall, Whersted, Waresley Park, Ouston, Bessacre Manor, Northrepps, Buckminster, Little Green, Holme Park, Purley.

4 [Professional architects and landscape architects would not agree with this view of Repton. It indicates a narrowness with 
regard to formal design and a failure to appreciate the satisfaction to be obtained from an approprately terminated vista. Moreover, Repton's estimate of the avenue at Langley Park is most unusual and not in accordance with the present principles of landscape design. - N.]

5 It is of little consequence from what spot a drawing is taken, since all avenues bear so great a resemblance to each other. I shall here enumerate a few instances in which avenues have been submitted to my consideration. At Cobham Park I give reasons for preserving one, and destroying the rest; at Prestwood, for retaining the avenue; at Tatton Park, for quitting the avenue, and planting it up; at Trewarthenick, an avenue was very easily broken, from its having been planted on uneven ground; and at Brookmans, I elucidate the necessity of fixing on proper trees to form the outline in breaking an avenue; or if the trees have stood so long near each other that no good outline can be formed, then the tops of some neighbouring trees may be so introduced as in some degree to supply the defect.

An avenue of firs is the most obstinate to break, because they leave no lateral branches; and, therefore, in the stupendous double row of large silver firs, which the false taste of the last century has planted at Herriard's house, I have advised the destruction of one half, leaving the other as a magnificent specimen of the ancient style in gardening.

6 This subject has also been mentioned in the following Red Books, viz. Ferney Hall, Rudding Hall, Widdial Hall, Babworth, Scrielsby, Milton, Livermere, Garnons, Crewe Hall, Brocklesby, Thoresby, Stoneaston, Nacton, etc.

7 Essay on the Sublime, part II, section 10.

8 [In the original edition this chapter was entitled "Concerning Park Scenery." It has been changed to "Large Private Places" because the word "park" has come to mean something different from what Repton had in mind. $-\mathrm{N}$.]

9 There is at present no word by which we express that sort of territory adjacent to a country mansion, which, being too large for a garden, too wild for pleasure-ground, and too 
neat for a farm, is yet often denied the name of a park, because it is not fed by deer. I generally waive this distinction, and call the wood and lawns, near every house, a park, whether fed by deer, by sheep, or heavy cattle.

so [See An Essay on Taste. By A. Gerard, D.D. To which are prefixed three Dissertations on the same subject by M. de Voltaire, M. d'Alembert, and M. de Montesquieu. Edinburgh, I764. I2mo. - J. C. L.]

"I Lord Kaims's Elements of Criticism.

12 The subject has been more fully treated in my remarks on Holwood, in Kent, a seat of the Right Hon. Wm. Pitt; and Stoke, in Herefordshire, a seat of the Hon. Edw. Foley.

${ }^{13}$ It was not my original intention to have treated of " Approaches" in this volume, as it is a subject that requires to be elucidated by many plates; but the publication of a didactic poem, The Landscape: a Poem, by R. P. Knight, Esq., addressed to Uvedale Price, Esq., where much is said on that subject under the sanction and authority of two gentlemen of acknowledged taste, obliges me to defend not only my own principles and the reputation of my late predecessor, Mr. Brown, but also the art itself, from attacks which are the more dangerous from the manner in which they are conveyed; and because they are accompanied by some doctrines to which every person of true taste must give his assent. Yet, while I pay this tribute due to the merit of a work containing many things worthy of admiration, and while I acknowledge my personal obligation for being the only individual in $\mathrm{my}$ profession to whom any degree of merit is allowed by the author of it, I feel it a kind of duty to watch with a jealous cye every innovation on the principles of taste in landscape gardening, since I have been honoured with the care of so many of the finest places in the kingdom.

${ }^{14}$ Gerardin, Viscomte d'Ermenonville, sur le Pay'sage. A work containing many just observations; but often mixed with whimsical conceits, and impracticable theories of gardening. [The work alluded to is translated under the title of $A n$ Essay on Landscape; or, on the means of Improving and Embel- 
lisbing the Country round our Habitations. Translated from the French of R. L. Gerardin, Viscomte d'Ermenonville. London, I 783. I $2 \mathrm{mo}-\mathrm{J}$. C. L.]

15 Thus, before a house is planned, the proprietor must describe the kind of house he wishes to build. The architect is to consider what must be had and what may be dispensed with. He ought to keep his plan as scrupulously within the expense proposed as within the limits of the ground he is to build upon : he is, in short, to enter into the views, the wishes, and the ideas of the gentleman who will inhabit the house proposed.

16 The requisites of taste are well described by Dr. Beattie, under five distinct heads: "I. A lively and correct imagination; 2, the power of distinct apprehension; 3, the capacity of being easily, strongly, and agreeably affected with sublimity, beauty, harmony, correct imitation, etc. ; 4, sympathy, or sensibility of heart; and, 5, judgement, or good sense, which is the principal thing, and may not very improperly be said to comprehend all the rest."

\section{CATALOGUE OF RED BOOKS}

From whence the extracts in Theory and Practice are made.

PLACE COUNTY

A SEAT OF

Abington Hall ....... Cambridgeshire...... John Mortlock, Esq. Adlestrop........... Gloucestershire........ . . H. Leigh, Esq. Antony............ Cornwall............ R. P. Carew, Esq., M. P. Ashton Court....... Somersetshire........ Sir Hugh Smyth, Bart. Aston............. Cheshire........... Honourable Mrs. Harvey Aston. Attingham......... Shropshire..........Right Honourable Lord Berwick. Babworth ........... Nottinghamshire...... Honourable J. B. Simpson, M. P. Bank Farm.......... Surry.............. Honourable General St. John. Bayham.......................... Earl Camden.

Betchworth......... Surry.............. Honourable W. H. Bouverie, M. P.

Blaize Castle........ Gloucestershire...... J. S. Harford, Esq.

Bowood...........Wiltshire............ Marquis Lansdown.

Brandsbury.......... Middlesex........... Honourable Lady Salusbury.

Bracondale..........Noriolk.............. Martineau, Esq.

Brentry Hill. ,...... Gloucestershire......Wm. Payne, Esq.

Buckminster.. .......Leicestershire......... Sir Wm. Manners, Bart.

Bulstrode.......... Buckinghamshire..... His Grace the Duke of Portland.

Burleigh on the Hill. Rutlandshire.........Earl Winchelsea.

Catton............ Norfolk............ Jer. Ives, Esq.

Cashiobury. ..........Hertfordshire.. ........ Earl of Essex.

Catchfrench........ Cornwall............ Francis Glanville, Esq., M. P. 
Chilton Lodge....... Berkshire. .......... John Pearse, Esq.

Clayberry Hall.. ..... Essex... ............ James Hatch, Esq.

Cobham............Kent.............Earl Darnley.

Courteen Hall... .... Northamptonshire... . . Sir William Wake, Bart.

Corsharn House..... Wiltshire.............Paul Cob. Methuen, Esq.

Condover Park....... Shropshire.......... Owen Smyth Owen, Esq.

Coombe Lodge....... Berks \& Orfordshire..Samuel Gardener, Esq.

Cote Bank.......... Gloucestershire......William Broderip, Esq.

Crewe............ Cheshire........... John Crewe, Esq., M. P.

Culford............ Suffolk. ...........Marquis Cornwallis

Donington Park...... Leicestershire......... Earl Moira.

Dulwich Casina...... Surry.............. Richard Shawe, Esq.

Dullingham House...Cambridgeshire....... Colonel Jeaffreson.

Dyrham Park....... Gloucestershire.......William Blathwayte, Esq.

Fort.............................. Tyndall, Esq.

Garons... ..........Herefordshire......... J. G. Cotterel, Esq., M. P.

Gayhurst..........Buckinghamshire..... George Wright, Esq.

Glemham .......... Suffolk. ........... Dudley North, Esq., M. P.

Grove The. ........ Southgate.........Walker Gray, Esq.

Hasells............ Bedfordshire......... Francis Pym, Esq.

Harewood House..... Yorkshire........... Right Honourable Lord Harewood,

Heathfield.. ........ Sussex............. Francis Nerwberry, Esq.

High Legh.........Cheshire............. J. L.egh, Esq.

Higham Hills....... Esscx............. John Harman, Esq.

Highlands.......... Essex............... C. H. Kortright, Esq.

Hill Hall. .......... Essex... ........... Sir William Smyth, Bart.

Holkham.......... Norfolk............T. W. Coke, Esq., M. P.

Holwood......................... Right Honourable William Pitt.

Holme Park........ Berkshire........... Richard Palmer, Esq.

Hooton........... Cheshire.......... Sir Thomas Stanley, Bart

Hurlingham ........ in Fulham......... John Ellis, Esq.

Kenwood............Middlesex... .........Earl Mansfield.

Langley Park........Kent............. Right Honourable Lord Gwydr.

Lathom House.. .... Lancashire...........Wilbraham Bootle, Esq., M. P.

Langleys. ..........Essex..............W. Tuffnel, Esq.

Livermere.......... Suffolk. ............. Lee Acton, Esq.

Luscombe.......... Devonshire.......... Ch. Hoare, Esq.

Maiden Early........ Berkshire............ Golding, Esq., M. P.

Magdalen College. ... Oxford............. President and Fellows.

Merly House........ Dorsetshire..........W. Willet Willet, Esq.

Milton House....... Camabridgeshire.. .... Samual Knight, Esq.

Milton Abbey ....... Northamptonshire..... Earl Wentworth Fitzwilliam.

Michel Grove........Sussex.............Richard Walker, Esq.

Moccas Court........Herefordshire........ Sir George Cornewall, Bart., M. P.

Mulgrave........... Yorkshire.......... Right Honourable Lord Mulgrave.

Newton Park....... Somersetshire.........W. Gore Langton, Esq., M. P.

Normanton........ Rutlandshire........ Sir Gilbert Heathcote, Bart, M. P.

Oldbury Court....... Gloucestershire.......T. Græme, Esq.

Organ Hall......... Hertfordshire........William Togwood, Esq.

Panshanger.........Hertfordshire........Earl Cowper.

Port Eliot.......... Cornwall........... Right Honourable Lord Crags Eliot.

Prestwood.......... Staffordshire........ Honourable Edward Foley, M. P.

Plas Newdy .........Anglesea............ Earl of Usbridge.

Purley. ............ Berkshire. ......... J. Ant. Storer, Esq.

Rendlesham........ Suffolk. ............ P. Thellusson, Esq., M. P.

Rüg. .............. North Wales........ Colonel E. V. W. Salesbury. 
PLACE

COUNTY

A SEAT OF

Sarsden........... Oxfordshire......... J. Langston, Esq., M. P.

Scarrisbrick.........Lancashire..........T. Scarrisbrick Eccleston, Esq.

Sheffield Place....... Sussex.............. Right Honourable Lord Shèffield.

Shardeloes.......... Buckinghamshire.....William Drake, Esq., M. P.

Stoke Park........... Herefordshire........ Honourable E. Foley, M. P.

Stoke Pogies.........Berkshire.......... John Penn, Esq.

Stoneaston.......... Somersetshire......... Hippesley Core, Esq., M. P.

St. John's.......... Isle of Wight......... E.dward Simeon, Esq.

Stapleton........... Gloucestershire....... Dr. Lovell, M. D.

Stratton Park....... Hampshire.......... Sir Francis Baring, Bart, M. P.

Streatham Villa......Surry.............Robert Brown, Esq.

Sufton Court......... Herefordshire........ James Hereford, Esq.

Sundridge Park. .....Kent. .............Claude Scott, Esq., M. P.

Suttons............ Essex............. Charles Smith, Esq., M. P.

Taplow...........Buckinghamshire..... J. Fryer, Esq.

Tendring........... Suffolk........... Sir William Rowley, Bart.

Thoresby........... Nottinghamshire...... Lord Viscount Newark.

Valleyfield..........Perthshire........... Sir Robert Preston, Bart., M. P.

Wall Hall...........Hertfordshire......... G. W. Thellusson, Esq., M. P.

West Wycombe. ..... Buckinghamshire..... Sir J. Dashwood King, Bart.

Wentworth House. ... Yorkshire............ Earl Wentworth Fitzwilliam.

Welbeck............ Nottinghamshire...... His Grace the Duke of Portland.

Whitton Park........Middlesex........... Samuel Prime, Esq.

Wimpole.......... Cambridgeshire.......Earl Hardwicke.

Woodley........... Berkshire...........Right Honourable H. Addington, M. P. Wycombe ........... Buckinghamshire..... Right Honourable Lord Carrington.

is On the summit of another building, viz. a sawmill in the park, was a figure of a man in a brown coat and a broadbrimmed hat, representing the great Penn, of Pennsylvania, which being much larger than the natural proportion of a man, yet having the appearance of a man upon the roof of the building, diminished the size of every other object by which it was surrounded. It has since been removed, and is now in the possession of Mr. Penn, at Stcke Pogies, where, placed in a room, it seems a colossal figure. Another instance of false scale at this place was the diminutive building with a spire at the end of the park, which, perhaps, when the neighbouring trees were small, might have been placed there with a view of extending the perspective. This artifice may be allowable in certain cases and to a certain degree, yet a cathedral in miniature must in itself be absurd; and when we know that it was only the residence of a shoemaker, and actually dedicated to St. Crispin, it becomes truly ridiculous.

I have drawn these examples of defects from West $\mathrm{Wy}$ combe, because they are obvious to every passenger on a very 
public road, and because I shall, in the course of this volume, have occasion to mention the many beauties of this place.

in Of this I observed a curious instance at Hooton House, from whence a distant view of Liverpool and its busy scenery of shipping is not easily seen without opening the windows, while the difference of a few yards in the original position of the house would have obviated the defect, while it improved its general situation.

20 That I may not be misunderstood, as recommending a road over hill and dale to shew the extent or beauty of a place, I must here observe that nothing can justify a visible deviation from the shortest line in an approach to a house but such obstacles as evidently point out the reason for the deviation.

${ }^{21}$ To produce this effect two or more trees should sometimes be planted in the same hole, cutting their roots so as to bring them nearer together; and we sometimes observe great beauty in a tree and a bush thus growing together, or even in trees of different characters, as the great oak and ash at Welbeck and the oak and beech in Windsor Forest. Yet it will generally be more consonant to nature if the groups be formed of the same species of trees.

${ }^{22}$ All trees exposed to cattle are liable to this browsingline, although thorns, crabs, and other prickly plants will sometimes defend themselves: the alder, from the bitterness of its leaves, is also an exception; but where sheep only are admitted, the line will be so much below the eye that it produces a different effect, of which great advantage may sometimes be taken, especially in flat situations.

${ }_{23}$ This remark is verified at Aston, where it is found that more cattle are fed in the park from the improved quality of the pasture, since the quantity has been reduced by the ample plantations made within the last ten years.

${ }^{24}$ " The outline of a wood may sometimes be great and always be beautiful; the first requisite is irregularity. That a mixture of trees and underwood should form a long straight line can never be natural, and a succession of easy sweeps and gentle rounds, each a portion of a greater or less circle, 
composing altogether a line litcrally serpentine, is, if possible, worse: it is but a number of regularities put together in a disorderly manner, and equally distant from the beautiful, both of art and of nature. The true beauty of an outline consists more in breaks than in sweeps; rather in angles than in rounds; in variety, not in succession.

"The outline of a wood is a continued line, and small variations do not save it from the insipidity of sameness; one deep recess, one bold prominence, has more effect than twenty little irregularities: that one divides the line into parts, but no breach is thereby made in its unity; a continuation of wood always remains, the form of it only is altered, and the extent is increased: the eye, which hurries to the extremity of whatever is uniform, delights to trace a varied line through all its intricacies, to pause from stage to stage, and to lengthen the progress.

"The parts must not, however, on that account be multiplied till they are too minute to be interesting and so numerous as to create confusion A few large parts should be strongly distinguished in their forms, their directions, and their situations; each of these may afterwards be decorated with subordinate varieties, and the mere growth of the plants will occasion some irregularity; on many occasions more will not be required.

"Every variety in the outline of a wood must be a prominence or a recess; breadth in either is not so important as length to the one and depth to the other; if the former ends in an angle or the latter diminishes to a point, they have more force than a shallow dent or a dwarf excrescence, how wide soever: they are greater deviations from the continued line which they are intended to break and their effect is to enlarge the wood itself.

"An inlet into a wood seems to have been cut if the opposite points of the entrance tally, and that shew of art depreciates its merit : but a difference only in the situation of those points, by bringing one more forward than the other, prevents the appearance, though their forms be similar. 
"Other points which distinguish the great parts, should, in general, be strongly marked; a short turn has more spirit in it than a tedious circuity; and a line, broken by angles, has a precision and firmness which in an undulated line are wanting: the angles should, indeed, be a little softened; the rotundity of the plant which forms them is sometimes sufficient for that purpose; but if they are mellowed down too much they lose all meaning.

" Every variety of outline, hitherto mentioned, may be traced by the underwood alone; but frequently the same effects may be produced with more ease, and much more beauty, by a few trees standing out from the thicket, and belonging, or seeming to belong, to the wood, so as to make a part of its figure." [From Observations on Modern Gardening, by Thomas Whateley.]

25 Course of the drive at Bulstrode. Taking the departure from the house, along the valley, towards the north, it passes the situation proposed for a cottage at [Plate xiIr] No. I, from thence ascends to the summit of the chalk cliff that overhangs the dell at No. 2, and making a sharp turn at No. 3, to descend with ease, it crosses the head of the valley, and enters the rough broken ground, which is curious for the variety of plants at No. 4.

From the several points, Nos. I, 2, and 3, the view along the great valley is nearly the same, but seen under various circumstances of foreground: at No. 4 it crosses the approach from London, and passes through an open grove, No. 5 .

The drive now sweeps round on the knoll at No. 6, along a natural terrace, from which the opposite hill and the house appear to great advantage. From hence, crossing the valley, No. 7 , among the finest trees in the park, it passes a deep romantic dell at No. 8, which might be enlivened by water, as a drinking-pool for the deer, and then, as it will pass at No. 9, near the side of the Roman camp, I think the drive ${ }^{x}$ should be made on one of the banks of the Vallum; because it is

1 This great work being in a progressive state, the reader will observe that some parts of this drive are mentioned as not yet completed. 
a circumstance of antiquity worthy to be drawn into notice ; and, by being elevated above the plain, we shall not only see into the intrenchment, but remark the venerable trees which enrich its banks; these trees are the growth of many centuries, yet they lead the mind back to the far more ancient date of this encampment, when the ground must have been a naked surface. Another advantage will also be derived from carrying the drive above the level of the plain. The eye being raised above the browsing-line, ${ }^{1}$ the park wall will be better bid by the lower branches of intermediate trees. At No. Io the drive is less interesting, because the surface is Aat; but suib occasional tameness gives repose, ${ }^{2}$ and serves to heighten the interest of subsequent scenery; yet at this place, if the drive be made to branch along the Vallum, it will pass over the most beautiful part of the park, on a natural terrace, at No. I I, and this will join the inner drive, returning down the valley towards the kitchen-garden.

I am now to speak of the great woods called Fentum's, Piper's, Column's, Walk Wood, and Shipman's, in which a serpentine drive has been formerly cut, which no one would desire to pass a second time, from its length, added to the total absence of interest or variety of objects; but following the taste which supposes "Nature to abhor a straight line," this drive meanders in uniform curves of equal lengths, and the defect is increased by there being only one connexion with the park, while the other end of the drive finishes at a great distance across Fulmer Common. The first object, therefore, of improvement will be to form such a line of connexion with the park as may make it seem a part of the same domain, and this would be more easily done if the hollow wayroad under the park wall could be removed; because otherwise the drive must cross the road twice at No. I2, as I suppose it to enter a field at No. I 3, which might be planted to connect it with the Broomfield copse, No. I4, from whence,

"The browsing-line is explained in "Theory and Practice," chap. Iv, p. 809.

2 The excess of variety may become painful, and therefore, in a long drive, some parts should be less interesting, or, if possible, should excite no interest, and be indifferent without exciting disgust. 
after crossing several interesting small enclosures, with forestlike borders, it enters and sweeps through the wood, Little Fentums, No. I6, to join the old drive, or at least such parts of it as can be made subservient to a more interesting line. After crossing a valley and streamlet at No. 17, and another at No. I8, it should ascend the hill of Piper's IVood, in which there are at present no drives, and at No. 19, a branch may lead on to the common, as a green way to London. The drive, sweeping round to No. 20, opens on a view of the village and valley of Fulmer, with a series of small ponds, which, in this point of view, appear to be one large and beautiful piece of water: this scene may be considered the most pleasing subject for a picture during the whole course of the drive. This would be a proper place for a covered seat, with a shed behind it for horses or open carriages; ${ }^{1}$ but it should be set so far back as to command the view under the branches of trees, which are very happily situated for the purpose at No. 20.

From hence the drive descends the hill, in one bold line, No. 2I, with a view towards the opposite wood across the valley. Having again ascended the hill, in wood, there are some parts of the present drive which might be made interesting by various expedients. At No. 22, one side of the drive might be opened to shew the opposite hanging wood in glades along the course of the drive. At No. 23, a shorter branch might be made to avoid the too great detour, though there is a view into the valley of Fulmer, at No. 24, worthy to be preserved. ${ }^{2}$ In some parts the width of the drive might be varied and some of the violent curvatures corrected; in others, the

I In long drives such attention to convenience is advisable; a thatched hovel of Doric proportions may not only be made an ornament to the scenery, but it will often serve for a shelter from sudden storms in our uncertain climate; for this reason it should be large enough to contain several open carriages.

2 I have distinguished, by italics, some peculiar circumstances of variety, from having observed great sameness in the usual mode of conducting a drive through a belt of young plantation, where trees of every species are mixed together. There is actually more variety in passing from a grove of oaks to a grove of firs or a scene of brushwood than in passing through a wood composed of a hundred different species of trees as they are usually mixed together. 
best trees might be singled out and little openings made, to be fed by sheep occasionally; and another mode of producing variety would be to take away certain trees and leave others, where any particular species abound: thus in some places the birches only might be left, and all the oaks and beech and other plants removed, to make, in time, a specimen of Birkland forest, while there are some places where the bolly and bawtborn might be encouraged, and all taller growth give place to these low shrubs, with irregular shapes of grass flowing among them. This would create a degree of variety that it is needless to enlarge upon.

The course of the drive through Shipman's Wood, No. 26, may be brought lower down the hill, to keep the two lines as far distant from each other as possible, and also to make the line easier round the knoll at No. 28 , though an intermediate or shorter branch may also diverge, at No. 27, towards the valley. There is some difficulty in joining this drive with the park without going round the gardener's house; but as the kitchen-garden must be seen from this part of the drive, and as it forms a leading feature in the establishment of Bulstrode, it will sometimes become part of the circuit to walk through it, and the carriages may enter the drive again at No. 31; I have, therefore, described two ways, No. 29 and No. 30, as I suppose the bottom of this valley to be an orchard, through which the drive may pass, or make the shorter line along the garden-wall, to No. 3 I.

The course along the valley is extremely interesting; and as some consider the farm-yard and premises a part of the beauty as well as the comfort of a residence in the country, I have supposed one branch of the drive, No. 32, to pass near a large tree, and the other to go on the bank at No. 33, and cross the corner of Hedgerley Green, which I suppose might be planted round the gravel-pit; but achen the drive enters the farm enclosures, it ought, if possible, to follow the course of the bedges, and not to cross a field diagonally. From No. 34 to No. 35 is perfectly flat, and follows the line of the hedges to the corner at No. 35, where a new scene presents itself, viz. 
a view toward the village of Hedgerley, in a valley, surrounded with woody banks. The drive now skirts along the hedge, and passes, at No. 36, a farmhouse, which might be opened to the field, and then enters Wapsey's Wood, in which the first bold feature will present itself at No. 37, where the drive may come so near the edge as to shew the view along the valley and the amphitheatre of wood surrounding thesc small enclosures: it then passes through the wood to a very large oak, at No. 38 , which may be brought into notice by letting the drive go on each side of it, and afterwards, following the shape of the ground, it sweeps round the knoll at No. 39 , with a rich view of the opposite bank, across the highroad, seen under large trees; it then ascends the hill by the side of a deep dell at No. 40, and makes a double at No. 4I, to cross the valley, that it may skirt round the knoll on the furze hill at No. 42, from whence it descends into the valley at No. 43, and either returns to the house, by the approach from Oxford, or is continued under the double line of elms at No. 44, to ascend by the valley from whence the drive began.

To some persons this description may appear tedious; to others it will perhaps furnish amusement to trace the course of such a line on the map; but I have purposely distinguished, by italics, some observations containing principles which have not before been reduced to practical improvement.

${ }^{26}$ It is in the act of removing trees and thinning woods that the landscape gardener must shew his intimate knowledge of pleasing combinations, his genius for painting, and his acute perception of the principles of an art which transfers the imitative though permanent beauties of a picture to the purposes of elegant and comfortable habitation, the ever-varying effects of light and shade, and the inimitable circumstances of a natural landscape.

${ }^{27}$ Examples of this may be seen at Bulstrode, at Michel Grove, at Brentry Hill, etc.

${ }_{28}$ Although I have never seen Valley Field myself, yet it flatters me to learn that under the direction of my two sons, by taking advantage of the deep romantic glen and wooded 
banks of the river which flows through the grounds and falls into the Frith of Forth at a short distance from the house, an approach has been made, which, for variety, interest, and picturesque scenery, may vie with anything of the kind in England; while it remains a specimen of the powers of landscape gardening in that part of Scotland where the art had been introduced only by those imitators of Mr. Brown's manner who had travelled into the north. His own improvements were confined to England.

2.) Earl Harcourt, although possessing great good taste, gives the whole merit of this garden to Mason the poet, as he does of his pleasure-grounds to Brown. Thus, superior to that narrow jealousy which would deny the just tribute of praise to the professor, his lordship is satisfied with having been the liberal friend and patron of merit.

${ }^{30} \mathrm{Mr}$. Knight has endeavoured to ridicule all display of extent of property, which I consider one of the leading principles of the art. I contend that it is impossible to annex the same degree of importance to a modern house, however large, by the side of a highroad, that may be justly given to one surrounded by an extensive park. To this principle of improvement $I$ have given the name of "appropriation."

3: Mr. Price builds a theory of improvement on the study of the best pictures, without considering how little affinity there is betwixt the confined landscape exhibited on canvas and the extensive range which the eye at once comprehends; and argues that the best works of the painter should be models for the improver.

${ }^{32}$ One great error in Mr. Brown's followers has been the unnecessary extent of parks. It is my opinion that, provided the boundary can be properly disguised, the largest parks need not exceed two or three hundred acres, else they are apt to become farms within a pale, or they are forests rather than parks.

33 Since I began these remarks on Attingham, Mr. Price has published a second volume of Essays on the Picturesque, the whole of which is founded on his enthusiasm for pictures; and he very justly observes (page 269), "Enthusiasm always 
leads to the verge of ridicule, and seldom keeps totally within it." Thus, not content with making the works of great painters the standard for laying-out grounds, they are also to furnish plans and elevations for all our buildings, from the palace co the cottage: and since we cannot be quite reconciled to their being in a state of ruin, which would certainly be most picturesque, we must build them in such irregular forms that trees may be introduced in various hollows and recesses, to be left for this purpose. These will, indeed, very soon contribute to produce those weather-stains and harmonious tints which are more grateful to the painter's eye than polished marble, as the green rust on copper coins is more interesting to the antiquarian than the bright surface of gold or silver. Mr. Price confesses that two small difficulties occur in putting these projects fully in practice, viz. that "he sees no examples of chimneys and very few of slanting roofs" where fine pictures can be transferred from the canvas to the real residence of man. How void of taste must that man be who could desire a chimney or roof to his country-house when we are told that Poussin and Paul Veronese built whole cities without a single chimney and with only one or two slanting roofs! This idea of deriving all our instruction from the works of great painters is so ingenious and useful that it ought not to be confined to gardenıng and building. In our markets, for instance, instead of that formal trim custom of displaying poultry, fish, and fruit for sale on different stalls, why should we not rather copy the picturesque jumble of Schnyders and Rubens? Our kitchens may be furnished after the designs of Teniers and Ostade, our stables after Wooverman's, and we may learn to dance from Watteau or Zuccarelli ; in short, there is no individual, from the emperor to the cobbler, who may not find a model for his imitation in the works of painters if he will but consult the whole series from Guido to Teniers.

34 If I were to enumerate all those who have occasionally mentioned gardening as a relative subject of taste, I should hardly omit the name of any author, either ancient or modern. Some of the most ingenious hints, and even some just princi- 
ples in the art, are to be found in the works of Theocritus, Homer, Virgil, Petrarch, Rousseau, Voltaire, Temple, Bacon, Addison, Home, Gilpin, Allison, etc.

35 That this simile may not appear ludicrous, I should observe that the ancient gardens were often made with reference to military dispositions, or trees were somctimes planted in conformity to the order of certain battles; thus, at Blenheim, the square clumps planted before Brown saw the place were in imitation of the famous battle from whence the place was named. And in an old map of a place in Suffilk, which, I believe, was planned by le Nôte, the names of regiments were given to square clumps or platoons of trees, which on paper resembled the positions of an army.

${ }_{36}$ Twelve years ago, when I first delivered these opinions, they were deemed so contrary to modern practice that I was cautious in defending them. I have since more boldly supported my original opinion, and rejoice that the good sense of the country admits their propriety.

37 Elements of Criticism.

$3^{8}$ Like those described by Sir William Chambers, in his Chinese Gardening.

39 By this term I mean to express scenery, less rude and neglected than the forest haunts of wild animals, and less artificial than the farmer's field laid out for gain and not for appearance: or, in the words of a celebrated author, "to create a scenery more pure, more harmonious, and more expressive than any that is to be found in nature itself."

$4^{\circ}$ Lest it should be objected that I am going beyond the precise boundaries of my profession, either as a landscape gardener or as an architect, I shall observe that the professor of taste in those arts must necessarily have a competent knowledge of every art in which taste may be exercised. I have frequently given designs for furniture to the upholsterer, for monuments to the statuary, and to the goldsmith I gave a design for one of the most sumptuous presents of gold plate which was ever executed in this country: it consisted of a basin, in the form of a broad flat vase, and pedestal, round 
which were the figures of Faith, Hope, and Charity; the former spreading her hand over the water, as in the act of benediction, and the two latter supporting the vase, which resembled a baptismal font: the whole was executed in gold, and was the present of a noble duke to his son on the birth of his first child.

$4^{\prime}$ Mr. Brown's fame as an architect seems to have been eclipsed by his celebrity as a landscape gardener, he being the only professor of the one art, while he had many jealous competitors in the other. But when I consider the number of excellent works in architecture designed and executed by him, it becomes an act of justice to his memory to record that, if he was superior to all in what related to his own peculiar profession, he was inferior to none in what related to the comfort, convenience, taste, and propriety of design in the several mansions and other buildings which he planned. Having occasionally visited and admired many of them, I was induced to make some inquiries concerning his works as an architect, and, with the permission of Mr. Holland, to whom, at his decease, he left his drawings, I insert the following list :

For the Earl of Coventry. Croome, house, offices, lodges, church, etc., 1751 .

Earl of Donegal. Fisherwick, house, offices, and bridge.

Earl of Exeter. Burleigh, addition to the house, new offices, etc.

Ralph Allen, Esq., near Bath, additional building, 1765.

Lord Viscount Palmerston. Broadland, considerable additions.

Lord Craven. Benham, a new house.

Robert Drummond, Esq. Cadlands, a new house, offices, etc.

Earl of Bute. Christ Church, a bathing-place.

Paul Methuen, Esq. Corsham, the picture-gallery, etc.

Marquis of Stafford. Trentham Hall, considerable alterations.

Earl of Newbury. House, offices, etc., 1762.

Rowland Holt, Esq. Redgrave, large new house, 1765.

Lord Willoughby de Broke. Compton, a new chapel.

Marquis of Bute. Cardiff Castle, large additions.

Earl Harcourt. Nuneham, alterations, and new offices.

Lord Clive. Clermont, a large new house. 
Earl of Warwick. Warwick Castle, added to the entrance.

Lord Cobham. Stowe, several of the buildings in the garden.

Lord Clifford. Ugbrooke, a new house.

To this list Mr. Holland added: "I cannot be indifferent to the fame and character of so great a genius, and am only afraid lest, in giving the annexed account, I should not do him justice. No man that I ever met with understood so well what was necessary for the habitation of all ranks and degrees of society; no one disposed his offices so) well, set his buildings on such good levels, designed such good rooms, or so well provided for the approach, for the drainage, and for the comfort and conveniences of every part of a place he was concerned in. This he did without ever having had one single difference or dispute with any of his employers. He left them pleased, and they remained so as long as he lived; and when he died, his friend, Lord Coventry, for whom he had done so much, raised a monument at Croome to his memory."

Such is the testimony of one of the most eminent and experienced architects of the present time; and in a letter to me from the Earl of Coventry, written at Spring Hill, his lordship thus mentions Mr. Brown:

"I certainly held him very high as an artist, and esteemed him as a most sincere friend. In spite of detraction, his works will ever speak for him. I write from a house which he built for me, which, without any pretension to architecture, is, perhaps, a model for every internal and domestic convenience. I may be partial to my place at Croome, which was entirely his creation, and, I believe, originally, as hopeless a spot as any in the island."

I will conclude this tribute to the memory of my predecessor, by transcribing the last stanza of his epitaph, written by Mr. Mason, and which records, with more truth than most epitaphs, the private character of this truly great man:

"But know that more than genius slumbers here:

Virtues were his which art's best powers transcend;

Come, ye superior train, who these revere, And weep the Christian, husband, fatber, friend." 
42 The want of comfort, inseparable from a house in an exposed situation, even in the climate of Italy, is well illustrated by Catullus:

"Furi! villula nostra, non ad Austri

Flatus opposita est, nec ad Favoni,

Nec saevi Boreae, aut Apeliotae;

Verum ad millia quindecim et ducentos.

$O$ ventum horribilem ! atque pestilentem!"

Catullus, Ode 26.

My cottage, Furius, is not exposed to the blasts of the South, nor to those of the West, nor to the raging North, nor to the Southeast; but to fifteen thousand two hundred blasts. Oh, that horrible and pestilent wind!

43 [In 1832, the property on which Michel Grove stood was purchased by the Duke of Norfolk, and added to the domain of Arundel Castle. The house was pulled down and the materials sold. - J. C. L.]

${ }_{44}$ C'est par une suite de cet usage de voir et d'entendre par les yeux et les oreilles de l'habitude, sans se rendre raison de rien, que s'est établie cette manière de couper sur le même patron la droite et la gauche d'un bâtiment. On appelle cela de la symétrie; Le Nôtre l'a introduite dans les jardins, et Mansard dans les bâtiments, et ce qu'il y a de curieux, c'est que lorsqu'on démande à quoi bon? aucun expert Juré ne peut le dire; car cette sacrée symétrie ne contribue en rien à la solidité ni à la commodité des bâtiments, et loin qu'elle contribue à leur agrément, il n'y a si habile peintre qui puisse rendre supportable dans un tableau un bâtiment tout plattement symétrique. Or, il est plus que vraisemblable que si la copie est ressemblante et mauvaise, l'original ne vaut guères mieux, d'autant qu'en général tous les desseins de fabriques font plus d'effet en peinture qu'en nature.

C'est donc l'effet pittoresque qu'il faut principalement chercher pour donner aux bâtiments le charme par lequel ils peuvent séduire et fixer les yeux. Pour y parvenir, il faut d'abord choisir le meilleur point de vue pour développer les objets; et tacher, autant qu'il est possible, d'en présenter plusieurs faces. 
C'est à donner de la saillie et du relief à toutes les formes, par l'opposition des renfoncemens et par un beau contraste d'ombre et de lumière; c'est dans un juste rapport des proportions et de la convenance avec tous les objets environnans, qui doivent se presenter sous le méme coup d'exil ; c'est a bien disposer tous les objets sur differens plans, de maniere que l'effet de la perspective semble donner du movement aux différentes parties dont les unes paroissent éclairées, les autres dans l'ombre; dont les unes paroissent venir en avant, tandis que les autres semblent fuir; enfin, c'est à la composer de belles masses dont les ornéments et les détails ne combattent jamais l'effiet principal que doit s'attacher essentiellement l'architecture.

Les anciens l'avoient si bien senti qu'ils ne se sont jamais occupées dans leur constructions, que de la grande masse, de manière que les plus précieux ornements sembloient se confondre dans l'effet général, et ne contrarioient jamais l'objet principal de l'ensemble, qui annonçoit toujours au premier coup d'ail, par son genre et ses proportions, le caractère et la destination de leur édifices.

[It is in consequence of this habit, of seeing and hearing with the eyes and ears of custom and prejudice, without considering the reason of anything, that the practice of designing the right and left of a building to the same pattern has arisen. This is called symmetry; Le Nutre introduced it in gardens and Mansard in buildings; and what is singular is that if any one asks to what purpose is it so? no adept in the art can tell; for this detestable symmetry contributes, in no degree, either to the solidity or convenience of the buildings: and so far is it from contributing to their beauty that there is no painter, however skilful he may be, who can render a building, insipidly srmmetrical, tolerable in a picture. Now, it is more than probable that if the copy, though a good likeness, be bad, the original is no better, - inasmuch as, in general, all drawings of buildings have more effect in a painting than in nature.

It is picturesque effect that must principally be sought for, in order to give to buildings the charm necessary to attract and 
rivet the eye. For this purpose a point of view should be chosen which appears the best for shewing all the objects; and the builuing should be so contrived as to present as many sides as possible at once.

It is in giving prominence and relief to the principal forms, by the opposition afforded by the others, and by a fine contrast of shade and light; it is in an accurate adjustment of the proportions of the buildings to those of the surrounding objects, which will be seen in the same coup $d$ 'ceil; it is in placing the objects on different levels, so that the effect of the perspective may seem almost to give movement to the different parts, of which some will appear in strong light and others in the shade, some will be brought prominently forward and others seem as though retiring; in short, it is in composing beautiful masses, of which the ornaments and details never interfere with the principal effect, that the great art of architecture consists.

The ancients understood this so well that in their buildings the general mass only was taken into consideration, so that the most costly ornaments seemed to be absorbed in the general effect, and were never at variance with the principal object of the whole, which always announced, at first sight, by its style and proportions, the character and destination of their edifices.]

45 This remark concerning our finest prospects being towards the west has been so often confirmed by repeated ob servations that I have endeavoured to discover some natural cause for its general prevalence; and perhaps it may, in some degree, be accounted for from the general position of the strata in all rocky countries, which appear to dip towards the east and rise towards the west; in one direction, the view is along an inclined plane; in the other, it is taken from the edge of a cliff, or some bold promontory overlooking the country towards the west.

$4^{6}$ It has occasionally been objected to Gothic houses that the old form of windows is less comfortable than modern sliding sashes; not considering that the square top to a window is as much a Gothic form as a pointed arch, and that to introduce sash-frames, as at Donnington, we have only to sup- 
pose the mullions may have been taken out without injuring the general effect of the building; while, in some rooms, the ancient form of window with large mullions may be preserved. Those who have noticed the cheerfulness and magnificence of plate-glass in the large Gothic windows of Cashiobury and Cobham will not regret the want of modern sashes in an ancient palace.

\section{THEORY OF COLOURS AND SHADOWS}

By the Rev. Dr. Milner, F.R.S.

dean of Carlisle, and president of queen's college, cambridge

I. Several years ago some curious questions concerning the colours of the shadows of bodies were proposed to me by an ingenious and philosophical friend, who himself can paint very well, and is an excellent judge of colours. He first mentioned the following facts :

2. Supposing a piece of writing-paper to be weakly illumined by white light, and, at the same time, to have a strong red light thrown upon it by any contrivance, the shadow upon the paper, of a body placed in the said red light, will be green.

3. Or, vice versa, if a strong green light be thrown upon the same paper, the shadow of a body placed in the green light will be red.

4. Under similar circumstances, the shadow of a body intercepting orange-coloured light will be blue, purple, or almost violet, according as the orange light contains more or less red; and vice versa.

5. And lastly, the shadow of a body which intercepts yellow light will be purple, and vice versa.

6. The phenomena just mentioned may be exhibited in several ways. The weak white light may always be had in a dark room, either by admitting a small portion of daylight or by means of a small lamp or wax taper, the light of which is sufficiently white for the purpose; and in regard to the strong coloured lights, they are also easily procured, either by using 
transmitted or reflected light of the particular colour wanted. As candles and lamps are always at hand and solar rays not so, I will here briefly describe the method of shewing any one, and, consequently, all, of these beautiful experiments by candlelight.

7. $\mathrm{L}, \mathrm{M}, \mathrm{N}, \mathrm{O}$ [in Fig. 27] is a piece of white paper, illumined as in the figure; $\mathrm{D}$ is a small cylinder of wood, as a black

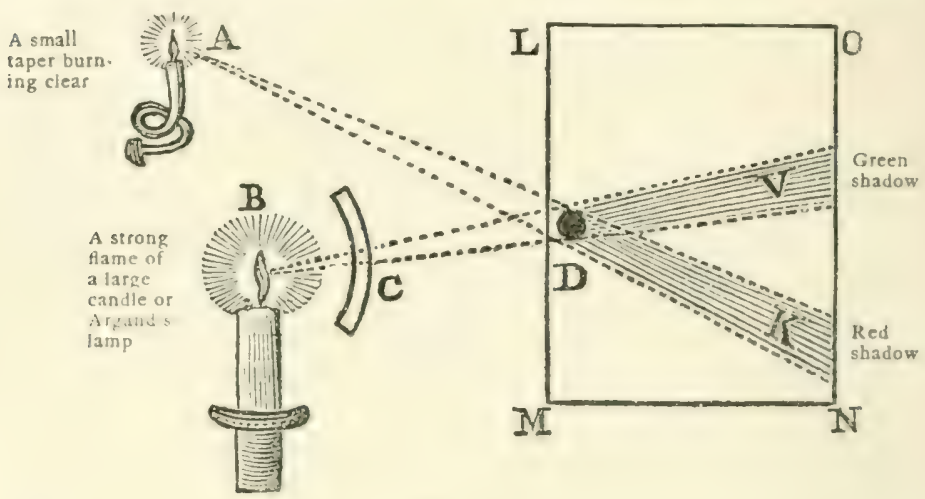

Fig. 27 .

lead pencil, or even one's finger, in such a manner as to produce the respective shadows $\mathrm{DV}$ and $\mathrm{D} \mathrm{K}$; $\mathrm{C}$ being a piece of red glass in this experiment.

8. If, instead of red glass, a piece of green glass be placed at $\mathrm{c}$, then the shadow $\mathrm{D} V$ will no longer be green, but of a reddish cast; and so of the rest as mentioned above, at section 3 .

9. My friend was very desirous that I should endeavour to account for these beautiful and most extraordinary appearances; with this view, I first observe that the burning lights, $A$ and $B$, when the experiments are made without daylight, may be reckoned nearly white, particularly if they are made to burn without smoke, though, in reality, they are yellowish, or even orange-coloured sometimes, as is very plain when they are compared with strong daylight.

IO. Secondly, white light is well known to consist of several other colours, as red, orange, yellow, green, blue, purple, 
and violet; and, further, as violets and purples, with all then varietres, may be imitated by mixing blue and red in different proportions, and as green also may be compounded in a simllar way by mixing blue and yellow, and orange by mixing red and yellow, we need not attend to more than the three primary colours, red, yellow, and blue; for, in fact, it is found that by mixing these three colours in certain proportions, a sort of white, or any colour may be formed; and there is reason to believe that if we had colours equal in brilliancy to the prismatic colours, the white so formed would be perfect.

II. This last observation shews us that white may be considered as made up even of two colours only, and we shall find it very convenient, in the explanation of the phenomena in question, to consider white as so made up, namely, of red and green, of yellow and purple, or of blue and orange. These colours are called contrasts to each other respectively: their apparent brilliancy, when they are placed contiguous to each other, is promoted in a remarkable manner, but they cannot be mixed together without mutual destruction to their natural properties, and an approach to a white or a grey colour.

12. To understand the cxperiment above represented on the paper, we are first to consider the nature of the shadow $\mathrm{D} \mathrm{V}$ green, as it is in appearance; that is, we are to consider what kind of light or lights can possibly come to this portion of the paper which we call the shadow D V; and here it is plain that this space DV is illumined only by the white light ${ }^{\mathrm{x}}$ (I will call it) which comes from the small taper $\mathrm{A}$, directly, and also by a small quantity of white light from $\mathrm{B}$, not directly, but by reflection from the sides of the room or from other objects. The direct red light coming from $\mathrm{B}$, through the red glass $\mathrm{c}$, is intercepted by D; and the small quantity of this red light which can arrive at the space $\mathrm{D} \mathrm{v}$ by reflection is not worth mentioning; the green shadow $\mathrm{D} v$, therefore, is illumined by

I I call it white light because it is nearly so, and because it answers all the purposes of perfectly white light in such an experiment, supposed to be made in a room without daylight. When actually compared with daylight, it is found to be yellowish, or even orange-coloured. 
a smal! quantity of white light, and our business is to explain why it should appear green to the eye.

13. Keep in mind that the idea of a perfect shadow excludes all light, and that the space $\mathrm{D} v$ is an imperfect shadow, illumined, as we have seen, with a small portion of white light. Let this small portion of white light be considered as made up of red light and green light, according to what has been stated above, in section 12 , and the reason of the phenomenon will be readily understood. For we must now attend to the strong red light which passes through the glass $\mathrm{c}$, and covers the paper everywhere, except in the space D v, where it is intercepted: the effect of this strong light coming up to the very boundaries of the shadow D V is such as to incapacitate the eye from seeing at the same time the weaker red light contained in the shadow D $v$, which we have proved to be really of a weak dull white colour, but which, because its red light cannot be seen, appears green to the eye.

14. This effect of rendering the organs of perception insensible to weaker excitations, by strongly exciting those organs, is analogous to the constitution of the human frame in many instances. Accustom the eye either to much light or to intense colours, and, for a time, it will hardly discern anything by a dull light or by feeble colours, provided the feeble colours be of the same kind with the previous strong ones. Thus, after it has been excited by an intense red, for example, it will, for a time, be insensible to weak red colours, yet it will still easily perceive a weak green or blue, etc., as in the instance before us respecting the shadow D v, where the green part of the compound still affects the eye, after the red has ceased to produce any effect, owing to the previous excitation of a stronger red.'

" This distinction should always be kept in mind, for, unless the eye has been absolutely injured or weakened by excessive excitation, there is reason to believe that strong excitations of it, whether immediately preceding weaker ones, or contemporaneous with them, much improve its sensibility in regard to those weaker ones, provided only that they be of a different class. If the eye has been excited by a lively red colour, it will scarcely perceive a weak red, but it will perceive a weak green much better, on account of the previous excitation by the strong red ; and the reason may be that, in looking at a red colour, the eye wastes none of that nervous sensibility which is necessary for its 
15. Nor is this the case only with the eye: it is the same with every other sense; precine instances of this kind in regard to the taste, the smell, the touch, etc., will occur plentifully to every one.

I6. I consider this solution of the appearances of the colours as perfectly satisfactory. Here it is applied only to one instance, but it is equally applicable to all the rest; and it appears to me to account for all the difficulties which seem to have embarrassed Count Rumford, in his very ingenious and entertaining paper (Phil. Trans. I794, p. 107). Also in Dr. Priestley's History of Optics, p. 436 , there is a curious chapter, containing the observations of philusophers on blue and green shadows; the true cause of these shadows is not, I think, there mentioned; and it may be entertaining to read that chapter with these principles in the mind.

I 7. When the sun has been near setting on a summer evening, I have often observed most beautiful blue shadows upon a white marble chimney-piece. In this case, the weak white light of the evening, which illumines the shaded part of the marble, is to be considered as compounded of two colours, orange and blue. The direct orange rays of the sun at this time render the orange part invisible, and leave the blue in perfection.

I 8. And in the same way is to be explained that beautiful and easy experiment mentioned by Count Rumford (p. I03, Phil. Trans. 1794,) where a burning candle in the daytime produces two shadows, and one of them of a most beautiful blue colour. The experiment is the more valuable, as it may be made at any time of the day with a burning candle. Almost darken a room, and then by means of a lighted candle and a little daylight produce two shadows of any small object, as of

seeing a green colour; and the same reasoning holds in all other cases where the colours are contrasts to each other. For such colours seem incapable of mixing with each other, in the proper sense of the word, as when red and yellow are mixed together, and produce a compound evidently partaking of the obvious properties of the two ingredients. When contrasts are mixed together, as red and green, these colours seem destructive of each other, and effect a compound approaching to whiteness. Similar observations may be made on the other senses. 
a pencil, etc., one from the candle, and another from the daylight received at a small opening of one of the window-shutters; the light of the candle will appear orange-coloured in the daytime, and so will that shadow of the body which belongs to or is made by the daylight; but the shadow of the body made by the candle will surprise any person, by being of a fine blue.

19. More than once I have been agreeably struck with this appearance, produced unintentionally when I have been writmg by candle-light on a winter's morning ; upon the daylight being let in, the shadow of my pen and fingers in the orange-light of the candle, were beautifully blue.

20. I suppose there is such a thing as the harmony of colours, of which painters speak so much; according to the explanation here given, our key to the solution of every case of harmony and of contrast is to consider what is the other colour, simple or compound, which, joined to a given one, simple or compound, will constitute white. Thus red requires green; yellow, purple; blue, orange; and vice versa, the mixtures in proper proportions will be white.

21. Sir Isaac Newton (prop. 6, part 2, of book i, Optics) has given a method for judging of the colour of the compound in any known mixture of primary colours, but it is not easy, even for mathematicians, to put his rules in practice. The gentleman who consulted me on this subject of shadows has been accustomed, for a long time, to assist his memory, when he is painting, by the use of the simple diagram [Fig. 28]. Let $\mathrm{R}, \mathrm{Y}, \mathrm{B}$ represent the three uncompounded colours, red, yellow, blue; and let o, G, P represent the compounds orange, green, and purple; it is evident that, to make a deeper orange, we must add more red; and to make a bluer green, we must add more blue; and to make the purple redder, we must add more red, and vice versa: but besides this, the diagram puts us in mind that $\mathrm{G}$ is the contrast to $\mathrm{R}$, and that, therefore, those two colours cannot be mixed without approaching to a dull whiteness or greyness; and the same may be said of $\mathrm{Y}$ and $\mathrm{P}$ and of $\mathrm{B}$ and $\mathrm{O}$. These colours are also contrasts to each other; 
by mixture they destroy each other, and produce a whiteness, or greyness, according as they are more or less perfect; but when kept distinct, they are found to make each other look more brilliant by being brought close together: and all this is agreeable to what is said in section II, and in the note to section 14.

22. Sir Isaac Newton observes that he had never been able to produce a perfect white by the mixture of only two primary

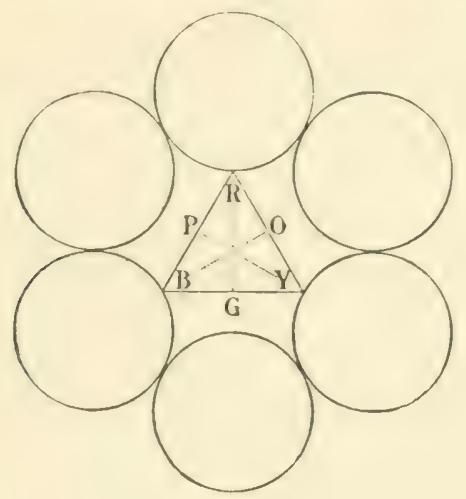

Fig. 28.

colours, and seems to doubt whether such a white can be compounded even of three. He tells us that one part of red lead and five parts of verdigris composed a dun colour, like that of a mouse; but there is nothing in all this which militates aganst the explanation here given of the cause of the coloured shadows of bodies; for even supposing that there did not exist in nature any two bodies of such colours as to form perfect whiteness by their mixture, or, to go still further, supposing that no two prismatic colours of the sun could form a compound perfectly white, still the facts and reasonings here stated respecting the mixtures of such colours as are called contrasts are so near the truth that they furnish a satisfactory account of the appearances of the colours of the shadows which we have been considering. The terms by which we are accustomed to denominate colours have not a veryaccurate or precise 
meaning, and particularly those terms which denote colours that are known to be mixtures of others, as green, purple, and orange. Neither the prismatic green nor the colour of any known green body may, perhaps, combine with red so as to make actually an accurate white, and yet the existence or composition of such a green may not be impossible. The philosophical reader will clearly perceive that no argument of any weight can be drawn from considerations of this sort against this theory of coloured shadows.

23. Every one knows that red colours and yellow colours mixed together, in different proportions, produce orange colours of various kinds: also that reds and blues produce purples and violets; and, lastly, that blues and yellows produce greens in great variety; but it is not so generally known that green, purple, and orange colours are, as it were, almost annihilated by mixture, and much improved by contiguity with red, ye!low, and blue colours respectively.

The little diagram [Fig. 28] suggests all these things to the memory, and a great many more of the same kind; and, therefore, must be extremely useful to the artist who is endeavouring to produce certain effects by contrast, harmony, etc., but it should always be carefully remembered that it contributes nothing to the proof of any of the truths here advanced; the proof rests upon the reasons given for each of them respectively. 

(Tbe tiuersion press

CAMBRIDGE - MASSACHUSETTS

$\mathbf{U} \cdot \mathbf{S} \cdot \mathbf{A}$ 






\section{BINDING SECT. MAY 201976}

PLEASE DO NOT REMOVE

CARDS OR SLIPS FROM THIS POCKET

UNIYERSITY OF TORONTO LIBRARY

SB

471

R46

1907

cop. 2

Biological

\& Medical 
